\title{
Chapter 5 \\ Development of the core melt accident
}

\subsection{Development of the accident in the reactor vessel}

\subsubsection{Progression of the core melt in the reactor vessel}

\subsubsection{Introduction}

If the reactor core remains dry for a considerable length of time, the temperature of the fuel rods rises and may locally reach levels that cause significant and irreversible core degradation. The mechanisms of this degradation are both chemical and mechanical. Depending on the local temperature levels, degradation may result in more or less severe hydrogen production, fission product (FP) release, and molten corium formation and propagation towards the lower head. These phenomena have been studied in many national and international research programmes $[1,2,11,12,15,22]$. The main degradation mechanisms that appear as the core temperature rises, as well as their consequences, are described in Section 5.1.1.2. This description is followed by a presentation of the main experimental programmes that have increased the state of knowledge of the degradation mechanisms, as well as a description of the modelling and computer codes that capitalise on that knowledge. The main mechanisms involved in the evolution of the fuel rod and core degradation are schematically shown in Figures 4.1, 4.2 and 4.3 of the previous chapter. 


\subsubsection{Physical phenomena}

\subsection{Cladding oxidation and hydrogen formation}

At temperatures above approximately $1300 \mathrm{~K}$, the zircaloy in the cladding is exothermically oxidised by the steam. This reaction plays a major role in aggravating the core degradation, as the thermal power that it releases can become significantly higher than the residual power. The equation of this oxidation reaction is as follows:

$$
\mathrm{Zr}+2 \mathrm{H}_{2} \mathrm{O} \rightarrow \mathrm{ZrO}_{2}+2 \mathrm{H}_{2}
$$

with an enthalpy reaction $\Delta \mathrm{H}$ between -600 and $-700 \mathrm{~kJ} /$ mole of zirconium and $0.0442 \mathrm{~kg}$ of hydrogen produced per $\mathrm{kg}$ of oxidised zirconium.

This oxidation produces a zirconia $\left(\mathrm{ZrO}_{2}\right)$ layer on the external surface of the cladding. The mass of oxygen absorbed by the cladding and the thickness of the oxide formed are governed by a parabolic time law. The square of the increase in the mass of oxygen fixed by the zirconium $\Delta M_{0}$ is proportional to the time interval $\Delta t$, that is to say:

$$
\left(\Delta M_{0}\right)^{2}=K_{0}(T) \Delta t
$$

The reaction rate $K_{0}(T)$ varies as an exponential function of the inverse of temperature (Arrhenius law) and, at temperatures above 1600-1700 K, the energy supplied to the cladding by the reaction cannot be evacuated by convection with the steam; the reaction rate then increases rapidly, resulting in the cladding temperature exceeding the zirconium melting temperature $(2100 \mathrm{~K})$. Numerous experimental and theoretical studies have focused on this phenomenon, which is now well understood. The hydrogen produced can escape from the RCS (through a break, if there is one) into the containment building atmosphere; this results in an explosion risk regarding which the strength of the containment must be assessed. Knowing how to predict hydrogen production is therefore an important aspect of the safety studies, as we have already discussed in Section 4.3.

In the case of the $1300 \mathrm{MWe}$ PWRs, the control rods are partly composed of boron carbide $\mathrm{B}_{4} \mathrm{C}$ (Section 2.3.2.1). This can also oxidise at temperatures above $1600 \mathrm{~K}$, producing hydrogen. Little hydrogen is produced through this reaction, however, in comparison with the volume of hydrogen produced by the zirconium oxidation reaction. In the case of $900 \mathrm{MWe}$ PWRs, the Ag-In-Cd alloy in the control rods does not oxidise.

\subsection{Meltdown of materials and interactions with the intact rods}

The control rods melt at lower temperatures than the fuel rods, either through meltdown (the Ag-In-Cd alloy melts at temperatures above $1100 \mathrm{~K}$ ) or, in the case of the $1300 \mathrm{MWe}$ reactors, through a chemical reaction resulting in their liquefaction (with steel, the $\mathrm{B}_{4} \mathrm{C}$ forms a liquid eutectic mixture at temperatures above $1500 \mathrm{~K}$ ). The $\mathrm{B}_{4} \mathrm{C}$ may also oxidise once the steel cladding and the zircaloy guide tube have disappeared. $\mathrm{B}_{4} \mathrm{C}$ oxidation is an exothermic process, effectively accelerating control rod degradation. It also produces hydrogen (always through steam decomposition, as for Zr oxidation), and part of the boron is in gaseous form $\left(\mathrm{HBO}_{2}\right)$. 
After they melt, the control rod materials (including some steel) flow into the core and come into contact with the fuel rods, thereby weakening the cladding of those that are still intact through chemical interactions (forming eutectic liquids). It should be noted that the spacer grids made in Inconel may also react with the zirconium cladding. The major dissolution reactions include the Ag-Zr and Fe-Zr interactions, both of which form a eutectic liquid whose melting point is considerably lower than that of zircaloy. Experimental studies have been conducted on these interactions; the existing knowledge of these interactions and their modelling is satisfactory. Some uncertainties still remain regarding the influence of $\mathrm{B}_{4} \mathrm{C}$, however, as it seems to cause the cladding of the fuel rods to degrade at a lower temperature than that indicated by the models developed using the current state of knowledge.

\subsection{Cladding failure}

The increased fuel temperature and the formation of fission gas within the pellets increase fuel rod internal pressure. The zircaloy cladding begins to distort when the temperatures exceed $1000 \mathrm{~K}$, due to the degradation of their mechanical properties. In some cases, the pressure inside the fuel rods can exceed the pressure inside the reactor vessel. This overpressure within the fuel rod causes the cladding to swell as a result of creep. This phenomenon, which is called "ballooning", can cause a mechanical failure in the cladding before they are oxidised. Some major distortion, referred to as "flowering", has also been observed. This is the result of the fuel pellets growing in volume, causing additional stresses in the cladding. There are sufficient experimental data on these phenomena, and their modelling is satisfactory.

During a core melt accident, not all of the fuel rod cladding suffers from mechanical failures before they oxidise. The oxidised cladding that has not failed mechanically may lose its integrity as a result of other mechanisms occurring at higher temperatures. These other mechanisms are much less well-known, however. The current hypotheses used to take them into account are based on experimental findings; consequently, it is accepted that the zirconia layer breaks above a certain temperature (typically around 2300 to $2500 \mathrm{~K}$ ). Another mode of failure may occur when the thickness of the zirconia layer is less than a certain value (approximately $300 \mathrm{~mm}$ ). The rupture mechanism involved is still poorly known, and it is modelled using a correlation deduced from the results of integral experimental programmes such as Phebus and CORA (Section 5.1.1.3.1), which use a rupture temperature that varies according to the thickness of the zirconia layer. In order to improve our understanding of the mechanism involved, it would be necessary to perform experiments that are both difficult and costly. Such experiments are not planned, as most users of the computer codes consider that the modelling described above is adequate for representing this mechanism in the computer codes used to simulate core melt accidents. It should nevertheless be remembered that the zirconia layer rupture criterion is a key parameter in these codes, as it defines the threshold for liquid zircaloy relocation towards the lower parts of the core. 


\subsection{Zircaloy melting and fuel dissolution}

When the zircaloy melting point is reached, the $\mathrm{UO}_{2}$ fuel is partially dissolved by the liquid metal (which does not flow out of the cladding as long as the zirconia layer remains intact). This may result in the mechanical integrity of the fuel rods being lost and the fragments produced in certain areas of the core accumulating long before the $\mathrm{UO}_{2}$ melting point is reached (approximately $3100 \mathrm{~K}$ ). The resulting fusion-dissolution, mechanical degradation and relocation of core materials within the reactor vessel (melts of molten materials and local accumulations of fragments) determine how the distribution of the degraded materials in the reactor core evolves during the course of the accident, and these must be taken into account in the modelling in order to realistically predict the degraded condition of the core. This can then be used to predict which areas are likely to be cooled if water is injected (reflooding) and which areas cannot be cooled because molten materials have accumulated, thereby preventing water from reaching them. Many experimental studies have been conducted in order to study changes in the distribution of the degraded materials in the core during the course of a core melt accident and considerable knowledge has been gained as a result, but the modelling is not yet satisfactory, undoubtedly due to the complexity of the phenomena involved. Despite the progress made (the development of mechanistic models based on detailed analyses of tests conducted on fuel rod clusters), some experimental results are still difficult to explain or interpret using the existing models, particularly the finding that fuel pellet dissolution exceeds the possible values based on the phase diagrams. It also remains difficult to model the simultaneous phenomena of fuel pellet dissolution and cladding oxidation. An ISTC (International Science and Technology Centre, a European Commission body) project named THOMAS, led by IBRAE (the Nuclear Safety Institute of the Russian Academy of Sciences in Moscow) resulted in the development of a model capable of computing the oxidation of a large corium pool (with natural convection processed in 2D or 3D) and the formation and dissolution of solid crusts at the edge of the pool.

\subsection{Corium flow}

The flow of the molten materials through the degraded core and their solidification in its colder areas may result in considerable localised reductions in coolant flow crosssections (Figure 5.1 clearly shows this phenomenon), which directly affects coolant flow and the cooling of the degraded core. This flow depends on various factors including the viscosity of the molten mixture, which is a function of its oxidation degree. In the 2100-2900 K temperature range, the viscosity of a U-Zr-O mixture is an increasing function of the oxygen content. Knowing how to calculate the oxidation of such mixtures is thus particularly critical in determining the corium flow. The current understanding of this phenomenon is incomplete, notably because, in most of the experiments conducted (Phebus, CORA and PBF, described in Section 5.1.1.3.1), the corium globally flows in a single direction (a one-dimensional flow). It is likely, however, that corium radial flow would be just as important if not predominant in the case of an accident affecting a reactor core. Various corium flow models provide partially satisfactory results, i.e. they

1. This is illustrated by the example of the Three Mile Island core melt accident, although this accident scenario is a special case (Section 7.1). 

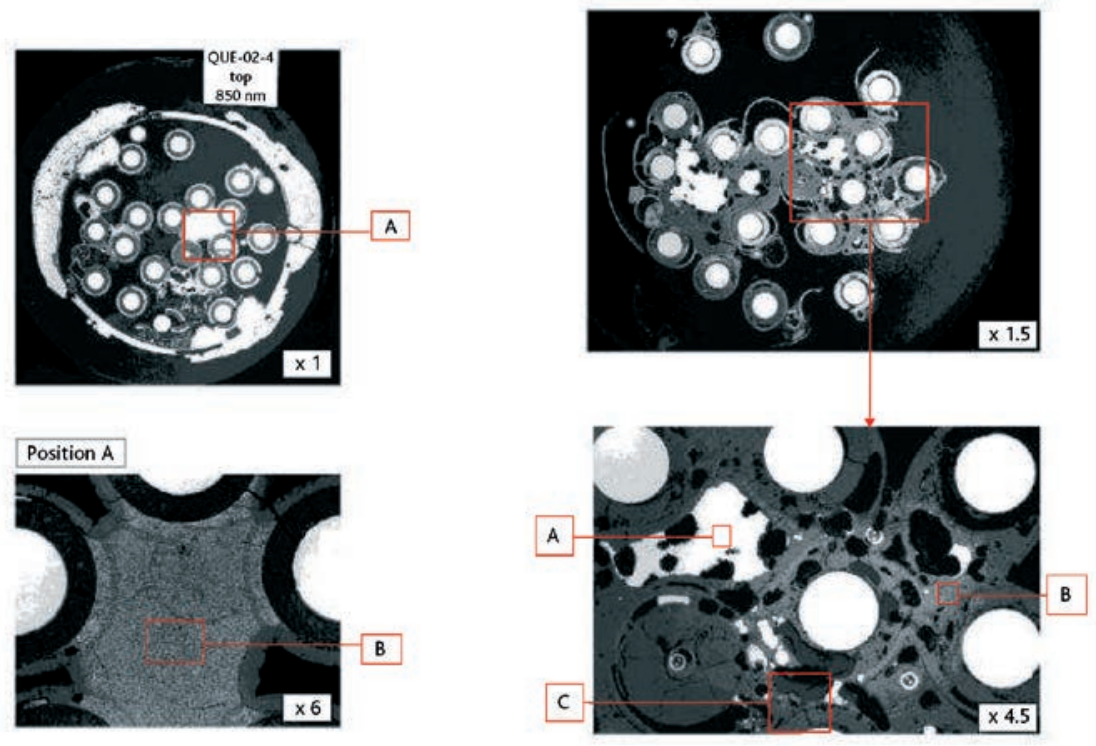

Figure 5.1. Photographs of two cross-sections of the fuel assembly after the QUENCH-02 test. These show the distribution of the solidified molten materials (melts) between the rods and the impact of these melts upon their degradation. The solidified melts are visible between the rods. They either totally block the spaces between the rods (position A, lower left) or partially block the spaces, leaving porosities (photograph, lower right).

generally predict the place in which the molten materials accumulate, but they are not capable of accurately predicting the resulting porosity (experimentally, it is found that the molten materials still do not occupy all of the available space). For the moment, however, it is not possible to improve them on the basis of existing experimental data. In the experiments conducted with corium melts, the corium flow is closely linked both with the localised temperatures reached in the tested fuel assemblies and with the degree of oxidation in the corium. These data cannot be determined sufficiently accurately from the experimental results or computed from the models, due to the complexity of the phenomena involved. Furthermore, in most of these experiments, corium progression is one-dimensional. The flow models have not been validated using sufficiently large-scale two- or three-dimensional test data. Uncertainties also remain regarding the physical properties of corium, notably its solidus and liquidus temperatures, as well as regarding the apparent viscosity (the viscosity of the liquid-solid mixture) where the solid and liquid phases are present simultaneously. These properties directly influence the corium flow. 


\subsection{Oxidation of the molten mixtures}

When the corium flows through the core, it contains zircaloy that has not been completely oxidised. On contact with the steam, the zircaloy continues to oxidise. No experimental measurements of a $\mathrm{U}-\mathrm{Zr}-\mathrm{O}$ liquid mixture oxidation rate are available. However, during integral tests such as QUENCH (reflooding of an assembly of already-oxidised rods), substantial hydrogen production has been observed over a very brief period in the case of scenarios involving reflooding or a local increase in steam flow rate. This observation is particularly important when assessing the hydrogen explosion risk, as reflooding may lead to the instant hydrogen release rate within the containment temporarily exceeding the capacity of the hydrogen recombiners in the containment building concerned.

The QUENCH tests were the first that could be used to understand this effect, but they had two disadvantages. Firstly, the use of $\mathrm{ZrO}_{2}$ pellets instead of $\mathrm{UO}_{2}$ pellets forms a corium that is a $\mathrm{Zr}-\mathrm{O}$ mixture instead of the $\mathrm{U}-\mathrm{Zr}-\mathrm{O}$ mixture that would be formed in a reactor core melt accident. Secondly, it is difficult to distinguish between the oxidation itself and the other phenomena (flow, cooling, etc.) in these integral tests; as a result, it is not possible to determine whether the materials oxidise while they are flowing or afterwards. The most likely explanation regarding the prolonged and intense oxidation of zircaloy is that of a relatively slow melt consisting of the very hot $\mathrm{U}-\mathrm{Zr}$-O liquid mixture (progressing at a speed of up to a few $\mathrm{mm} / \mathrm{s}$ ) along the fuel rods. The oxidation kinetics of such a mixture depend on the ability of steam to access the zircaloy and, therefore, on the porosity of the medium. The more the liquid mixture fills the open spaces, the lower the oxidation kinetics are. From this point of view, the zircaloy oxidation phenomenon is globally understood and most computer codes include models for calculating core melt progression in the reactor vessel. The validation of these models is still often very succinct, however. In particular, more analytical test results are needed; these could be used to determine the oxidation rates for $\mathrm{U}-\mathrm{Zr}-\mathrm{O}$ melt mixtures. The hypothesis of zirconia layer spalling in the event of reflooding (detaching zirconia layers from the rods, bringing the metal zircaloy into contact with the water or steam) does not provide a valid explanation for the intensified oxidation process while the rods are being reflooded. To date, no experimental results support the existence of such spalling in the case of the zircaloy 4 or the M5 alloy (there is very little experimental data for the latter), which are used as cladding materials in the PWRs. It has only been found in the case of alloys that are not used in the French PWRs, such as the E110 ( $\mathrm{Zr}-\mathrm{Nb})$ used in the Russian PWRs (VVER).

\subsection{Formation of a corium pool and corium flow into the lower head}

If the temperature reaches the melting point of $\mathrm{UO}_{2}$, a "molten pool" forms in the reactor core. Due to the formation of the eutectic liquids, the melting temperature may be several hundred degrees below that of the $\mathrm{UO}_{2}$ melting point $(3100 \mathrm{~K})$.

As the eutectic molten mass increases, the pool expands axially and radially in the core until it reaches either the baffle or the core support plate (internal structure; see Section 2.3.2). At this moment, the corium flows into the lower head. Considering its 
low surface/volume ratio, the corium pool formed in this way is very difficult to cool; as a result, it may grow by incorporating the rods located around it, even if it is reflooded. This is what occurred in the Three Mile Island accident (Section 7.1).

It is essential to predict the weight, composition and temperature of the materials reaching the lower head during the course of the accident, as well as the instants when these materials do so, in order to study the subsequent sequence of events of the accident. These phenomena are modelled in most computer codes. Their level of validation and detail are satisfactory, considering the experimental data available. Only partial data is available, however, as they exist either for small-scale, virtually one-directional fuel rod assemblies (around twenty rods, in the case of the Phebus assemblies), or for preformed debris beds, which are also small (RASPLAV, ACRR and Phebus-FPT4; these programmes are described in Section 5.1.1.3.1 and Section 5.1.2.3.1). At present, there are no experimental data allowing detailed characterisation of corium pool formation and flow in the core. More representative data are still to be obtained in order to characterise the evolution of a corium pool through two-dimensional rod assemblies.

The degradation may ultimately result in very different configurations in the core simultaneously, ranging from intact or barely degraded rods to the formation of a corium pool or a bed of debris. These different degraded core conditions are described in greater detail in Section 5.4.1.

\subsubsection{Experimental programmes, modelling and computer codes}

\subsection{Experimental programmes}

This section provides a brief description of the main experimental programmes, ranging from the oldest to those still under way or scheduled in 2015 , to study the degradation of the core materials. The programmes performed have provided data for validating the computer codes. An OECD summary report presents all the tests whose results have been used to validate the core melt accident simulation computer codes [13].

Separate effect tests on the oxidation kinetics of fuel rod materials and the associated chemical interactions: many tests conducted by different teams including Forschungszentrum Karlsruhe (PzK) of Germany, and Atomic Energy of Canada Limited $(A E C L)$ of Canada have determined the oxidation kinetics of zircaloy, $\mathrm{UO}_{2}$ dissolution by the molten zircaloy, $\mathrm{B}_{4} \mathrm{C}$ oxidation ( $\mathrm{FzK}$ and IRSN), zircaloy dissolution by the molten steel, etc.

Separate effect tests on cladding failure mechanisms: these tests (for example, the EDGAR tests conducted by CEA) have helped to determine the cladding creep law based on the cladding temperatures and the oxidation conditions.

LOFT-FP [19]: this test programme, which was completed in 1985, was conducted by the Idaho National Laboratory (INL) of the United States on an assembly consisting of $121 \mathrm{UO}_{2}$ fuel rods with in-pile nuclear heating. It consisted of tests on fuel assembly degradation and FP release, and involved temperatures up to $2400 \mathrm{~K}$ (locally). Steam cooling was used, followed by water reflooding. 
PBF-SFD [20]: this test programme, which was completed in 1985, was conducted by INL on an assembly consisting of $32 \mathrm{UO}_{2}$ fuel rods with in-pile nuclear heating. It also included tests on fuel assembly degradation and FP release, but at temperatures up to $2600-3100 \mathrm{~K}$ (locally). Steam cooling was used, followed by water reflooding (for certain tests).

NRU-FLHT [14]: this test programme, which was completed in 1987, was conducted by $A E C L$ on an assembly consisting of 16 non-irradiated $\mathrm{UO}_{2}$ fuel rods with in-pile nuclear heating. These degradation tests were unusual because they used fuel rods $3.7 \mathrm{~m}$ high (full-scale).

ACRR-MP [8]: this test programme, which was completed in 1992, was conducted by the Sandia National Laboratory (SNL). It consisted of in-pile tests of small debris bed melting $\left(\mathrm{UO}_{2}+\mathrm{ZrO}_{2}\right)$ in an inert atmosphere, at temperatures up to 3000-3200 K. The formation and then flowing of a corium pool were observed.

CORA $[17,18]$ : this test programme, which was completed in 1993, was conducted by KIT (formerly FzK) on an assembly consisting of 25 non-irradiated $\mathrm{UO}_{2}$ fuel rods with electric heating. It consisted of tests in which fuel rod temperature reached $2200 \mathrm{~K}$ (locally). Each test included a steam pre-oxidation phase, followed by reflooding with water or steam at a high flow rate.

QUENCH [21]: this test programme, which was still under way in 2013, was conducted by FzK on an assembly consisting of 25 non-irradiated $\mathrm{ZrO}_{2}$ fuel rods with electric heating. It consisted of degradation tests and involved temperatures up to more than $2000 \mathrm{~K}$ (locally). Steam cooling was used, followed by water reflooding. Recent tests have studied the behaviour of cladding materials other than zircaloy-4, such as E110 or M5 (Zr-Nb alloys).

Phebus FP [5]: this test programme, which was completed in 2004, was conducted by IRSN on an assembly consisting of 21 irradiated $\mathrm{UO}_{2}$ fuel rods with in-pile nuclear heating. It involved degradation and FP release tests with temperatures up to 2600$3100 \mathrm{~K}$ (locally). Steam cooling was used.

ISTC 1648 (QUENCH): this test programme, funded by the International Science and Technology Centre (ISTC), was conducted by NIIAR (Scientific Research Institute of Atomic Reactors) in Russia. It aimed at studying the reflooding of a core that has reached temperatures exceeding $2000 \mathrm{~K}$ (locally), and performed three tasks: conducting degradation and reflooding tests using irradiated VVER fuel components, performing reflooding tests using a new VVER assembly of 31 rods, and developing a reflooding model for the SVECHA code by IBRAE (Nuclear Safety Institute of the Russian Academy of Sciences). The results of this programme have not been publicly published, but some reports are available by contacting ISTC.

PARAMETER: this test programme, funded by ISTC and launched by LUCH (Scientific Manufacturer Centre, Russia), studied the degradation of fuel assemblies consisting of 19 non-irradiated prototype fuel rods for VVER reactors (the tests were similar to those of the QUENCH project, but used $\mathrm{UO}_{2}$ pellets instead). The experimental apparatus was 
used to reflood the system from above or below, at temperatures up to $2300 \mathrm{~K}$ at the moment it was reflooded. Three tests had been conducted by the end of 2009. After the apparatus had been considerably degraded in the first test, care was taken to ensure that the temperature did not exceed $1870 \mathrm{~K}$ at the hottest point during the preliminary oxidation phase in the subsequent tests, in order to preserve the integrity of the fuel assembly holder. A fourth test was conducted in 2010, with a preliminary oxidation phase in air intended to simulate the entry of air into the reactor vessel. This programme's experimental data have not been publicly published either, but some publications discuss the validation of computer codes using some results of these tests.

Few in-pile experimental programmes study the phenomena involved when core melts go so far as to form a debris bed or corium pool in the core and corium flows into the lower head, with the exception of Phebus FP and ACRR. The LOFT and PBF tests attained late-phase fuel degradation but did not involve detailed analysis of rod melt and corium progression.

The Three Mile Island accident remains the only available source of knowledge on the condition of a reactor core following massive melting (Section 7.1). This accident and the condition of the reactor core have been analysed in detail; the results have been published and are publicly available $[4,15,26,27]$. Figure 7.7 shows the condition of the core following the accident. Of particular interest are the large molten pool within the core, the collapse of a large portion of the rods above the pool (forming a debris bed) and partial corium relocation towards the lower head. Two aspects of the accident scenario are worth noting: the high-pressure sequence, and the corium melt in the lower head after the core was, at least partially, reflooded.

\subsection{Core melt modelling and computer codes}

This Section provides a brief description of the main dedicated models and computer codes used to simulate the phenomena of reactor core material degradation occurring in a core melt accident (it does not describe the integral computer codes used to process all of the phenomena involved in a reactor when a core melt accident occurs, as these are presented in Chapter 8).

SCDAP/RELAP (US NRC, United States Nuclear Regulatory Commission) is a mechanistic $^{2}$ computer code developed by INL. It is the result of coupling the RELAP 5 thermal-hydraulic code with the SCDAP core degradation modelling code. Its core modelling is based on parallel, one-dimensional channels and includes several models for simulating various aspects of fuel rod changes during the course of their degradation: heat transfers, residual power, cladding oxidation, fuel dissolution, cladding failures and FP release. This computer code is no longer developed by NRC but a private version known as SCDAPSIM is still developed [3, 6].

2. A "mechanistic" computer code consists of models that, whenever possible, are based on a physical or chemical description of the phenomena involved rather than adopting an empirical approach (based on correlations obtained using experimental results). In reality, mechanistic computer codes always include several empirical models. 
ATHLET-CD (GRS, Gesellschaft für Anlagen - und Reaktorsicherheit, Germany) is a mechanistic computer code that is the result of coupling the ATHLET thermal-hydraulic code with a core degradation computer module. Much like SCDAP/RELAP, its core modelling is based on parallel, one-dimensional channels and includes several models for simulating various aspects of fuel rod changes during the course of their degradation: heat transfers, residual power, cladding oxidation, fuel dissolution, cladding failures and FP release. GRS is continuing to develop this computer code, notably with the addition of the MEWA module relating to the formation of a corium pool in the core $[23,25]$.

ICARE/CATHARE (IRSN) is a mechanistic computer code that simulates PWR core melt accidents. It is the result of coupling the CATHARE thermal-hydraulic code with the ICARE code that simulates core degradation and is similar to SCDAP/RELAP, except that considerable development has been carried out to simulate the phenomena involved when large-scale melting leads to significant degradation of the core (the formation of a debris bed or corium pool, and corium flows). It also allows axisymmetrical 2D modelling of the core and the reactor vessel. Several models simulate changes in the core fuel rods over time, as well as those occurring in the corium in the core and the lower head; they process heat transfers, residual power, cladding oxidation, fuel dissolution, cladding failures, FP release, 2D corium flow modelling, flow oxidation, fuel rod collapse and corium pool development. Development of this computer code is being continued by IRSN and includes a model of degraded core reflooding and complete modelling of corium behaviour in the lower head $[7,9]$.

RATEG/SVECHA (IBRAE, Russia) is a mechanistic computer code that is the result of coupling the RATEG thermal-hydraulic code with the SVECHA core degradation simulation computer module. This computer code includes highly detailed modelling of certain phenomena, notably cladding oxidation, fuel dissolution, cladding failure and FP release. The computer code is designed to describe in detail fuel assembly degradation (or that of a representative fuel rod). Its major limitation lies in its inability to process the radial propagation of degradation; notably, it does not process corium pool formation in the core, but it is able to simulate a molten pool in the lower plenum. IBRAE is continuing to develop this computer code, including the development of a module relating to corium flow oxidation [24].

\subsubsection{Summary and outlook}

The physics relating to the evolution of a PWR core melt accident is now well understood and modelled for the main processes. This notably concerns fuel rod cladding oxidation and failure. The complex phenomena involved in the later phases of the accident can only be modelled with significant uncertainties, however. This is particularly true of fuel rod collapse and corium oxidation. Additional experimental data would be needed in order to refine the modelling, but no related programmes are ongoing or planned in 2015. Given the high cost of the potential tests, which would have to be conducted with real irradiated materials, it seems unlikely that new experimental programmes (national or international) will be initiated in the near future. To reduce the remaining uncertainties, the only alternative is to perform additional analysis on past tests (which were often insufficiently investigated) and develop more detailed models. 


\subsubsection{Corium behaviour in the lower head}

\subsubsection{Introduction}

In most of the expected cases, the lower head is filled with water when the corium coming from the hottest area of the core flows into it. The results of the fuel assembly melt tests in the Phebus, QUENCH and CORA programmes show that the zircaloy in the assemblies at the end of the tests is only partially oxidised. In the assemblies' hottest areas, 20 to $100 \%$ of the zircaloy is oxidised; total oxidation is only seen locally in the areas in which the temperatures and steam concentrations have been high enough to provide intense oxidation over a long period. The corium that flows in the lower head therefore contains a percentage of unoxidised zircaloy that is estimated to be 25 to $80 \%$ of the zircaloy (depending on the scenario, following the general trend that a large break sequence leads to a low percentage of oxidised Zr whereas a small break sequence leads to a high percentage of oxidised $\mathrm{Zr}$ ). This corium is said to be substoechiometric while its composition is not $(\mathrm{U}-\mathrm{Zr}) \mathrm{O}_{2}$, which corresponds to its composition after complete oxidation.

The interaction of corium (above $2500 \mathrm{~K}$ ) with water leads to more or less finegrained fragmentation of the corium into particles, on the one hand, and intense steam production capable of substantially increasing the pressure in the RCS, on the other hand. When the partially fragmented corium has accumulated in the lower head, it forms what is called a debris bed. This bed is either very compact if there is little cooling (part of the corium is not solidified), or composed of porous solid debris. It is unlikely that a large debris bed can be cooled effectively. In all cases, the corium gradually evaporates the water present in the lower head. If there is no additional water supply and the debris configuration is such that it cannot be cooled effectively, the materials' temperature gradually rises until it reaches the melting point of the steel structures (plates, tubes, etc.) located in the lower head. A substantial quantity of molten steel then gradually enters the corium. As the temperature rises, first the zircaloy and then the oxide debris melt and either form a pool or become part of an existing pool. The formation of this corium pool in the lower head is a critical step in a PWR core melt accident: in this situation, there is a considerable heat flux at the interface between the pool and the reactor vessel that can lead to reactor vessel failure. Reactor vessel failure is described in detail in Section 5.1.3.

\subsubsection{Physical phenomena}

When the hot corium pours into the lower head filled with water, steam is produced, leading to a pressure peak or even a steam explosion in the reactor vessel (Section 5.2.3), which creates mechanical stresses likely to damage the RCS. In addition, the reactor vessel is subjected to a heat flux that can locally be very high, resulting in melt erosion of the vessel walls and potentially leading to its failure. Regarding the last point, studies seek to determine the likelihood of in-reactor vessel corium retention or the conditions under which the reactor vessel would fail (timing, location, and characteristics of the corium flowing from the reactor vessel into the containment). It is thus important to be able to predict the changes the corium will undergo, from its relocation towards the lower head to its cooling or flow out of the reactor vessel. The main phenomena governing these changes are briefly described below. 


\subsection{Corium fragmentation and debris formation}

When a corium melt comes into contact with the water present in the lower head, the corium becomes fragmented (Figure 5.2). Corium fragmentation is described in detail in Section 5.2.3 on steam explosions. The fragmentation is very complex to model and includes considerable uncertainties $[34,40]$.

\subsection{Direct impact of a corium melt upon the reactor vessel}

If there is little water in the lower head or there is a substantial mass of relocated corium, the corium melt only partially interacts with the water and part of this very hot melt comes into direct contact with the reactor vessel.

This situation can rapidly lead to reactor vessel failure during its period of contact with the corium melt. Although few experimental studies have been conducted on this phenomenon (a few CORVIS tests with molten materials simulating a corium, notably a molten thermite mixture [a mixture of iron and alumina], arriving on a mock-up of a BWR vessel), this phenomenon is relatively well-known. In such a situation, it would probably form an insulating - and therefore protective - crust between the corium and the reactor vessel, given the very large difference between the temperature of the reactor vessel and the corium solidification temperature. In the TMI-2 accident (Section 7.1), such a crust was probably formed; this would explain why, although a massive corium melt flowed into the lower head, the vessel was not damaged ${ }^{3}$. One of the key parameters is the degree of corium overheating above its melting point; this degree directly influences the thickness and, therefore, the efficiency of the protective crust.

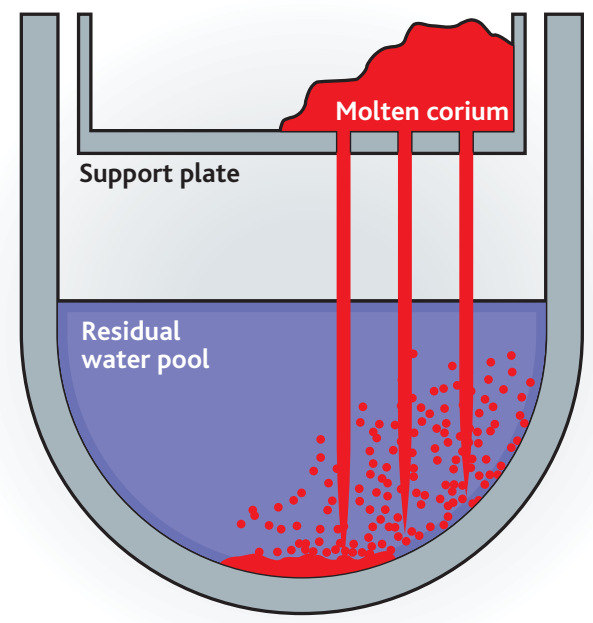

Figure 5.2. Schematic diagram of molten corium arriving in the lower head and fragmenting upon contact with water.

3. In the case of TMI-2, the presence of water in the lower head undoubtedly also contributed to the efficient cooling of the reactor vessel during the corium melt. 


\subsection{Steam explosion}

The interaction between a corium melt and the water can result in a steam explosion (Section 5.2.3). Although the physics of this phenomenon are generally understood, it is not yet possible to predict with certainty under which conditions this phenomenon can occur. Despite the relatively low probability of an explosion occurring that had been observed in the tests conducted in order to study the interaction between very hot corium and water, such an explosion cannot be entirely ruled out and so the phenomenon is studied because of its possible consequences for the containment. It should be noted that in the TMI-2 accident, corium melt arrival did not lead to a steam explosion despite the presence of water in the lower head. This could indicate that there was no fine-grained fragmentation of the corium on contact with the water. It could also be due to the high pressure in the reactor vessel (approximately 100 bar).

\subsection{Debris bed dry-out and possible reflooding}

Corium melt fragmentation produces corium drops that cool and solidify on contact with the water, forming particles that settle in the lower head and create a "debris bed". This debris bed may be very compact if the cooling of the corium drops resulting from the fragmentation is insufficient to solidify them totally. In this case, the formed debris bed cannot be cooled effectively because the water cannot access some regions of the debris bed due to its low permeability. The debris bed then continues to heat up, gradually drying up the lower head and then melting to form a corium pool that is much more difficult to cool. The final risk is that the corium pool builds up and comes into contact with the reactor vessel and causes it to rupture. The possibility of avoiding the lower head drying and cooling down such a debris bed with the water present in the lower head or with an additional injection of water from the RCS is therefore under study (Section 5.4.1).

One of the parameters currently used to estimate the possibilities of cooling a debris bed is the "critical dry-out heat flux" (CHF), which corresponds to the maximum residual power density of the debris bed multiplied by the height of the bed within which it does not lead to a local dry-out. Below the CHF, the water is present everywhere in the debris bed and the temperature of the debris bed remains low. The CHF depends on the characteristic parameters (debris size, bed geometry and porosity, etc.) of the debris bad. Typical values are approximately $0.2 \mathrm{MW} / \mathrm{m}_{2}$ for particles with a diameter of $1 \mathrm{~mm}$ and $1.2 \mathrm{MW} / \mathrm{m}_{2}$ for particles with a diameter of $7 \mathrm{~mm}$.

In a core melt accident, water may re-enter the reactor vessel whereas the debris bed is partly or totally dry. In such a situation, reflooding the debris bed may produce a large quantity of steam in a very short time, which can rapidly build up the pressure in the RCS and cause major oxidation of the unoxidised zircaloy in the hot upper parts of the core to resume. Few studies have been conducted on the phenomenology of debris bed reflooding and research programmes are still studying the subject in 2015 (notably the PEARL test programme conducted by IRSN). 


\subsection{Corium pool formation}

As mentioned above, the dry-out of a large volume of a debris bed is a key step in the evolution of a core melt accident because it determines when corium pool formation begins or, if only a portion of the corium is fragmented into solid particles, when the propagation of the existing pool begins. Thanks to the results of the ACRR-MP, Phebus FPT4 and RASPLAV AW-200 tests $[39,32,28]$, the molten pool formation is now quite well modelled when it occurs under conditions that do not result in significant corium oxidation and the main components of the corium are $\mathrm{UO}_{2}, \mathrm{Zr}$ and $\mathrm{ZrO}_{2}$. The pool may also contain a large quantity of molten steel. Although the interactions between the liquid steel and a ( $\mathrm{U}-\mathrm{Zr}$ )-O corium have been studied for some time, the effect of these interactions upon the evolution of the corium in the lower head (see later in this document) when the corium is in inert atmosphere was only revealed at the beginning of the 2000 s, notably in the OECD's MASCA project [37]. The evolution of a debris bed containing steel under oxidising conditions requires further study. This is because the residual power causes the steam to circulate within the debris, which is likely to oxidise as a result (Figure 5.3). The melting of the debris and the development of a corium pool under oxidising conditions have never been studied experimentally, notably because of the high cost of the tests, which would require the use of real materials. The uncertainties regarding the degree of oxidation of the materials in the formed corium pool are processed in the core melt accident simulation computer codes by means of sensitivity studies.

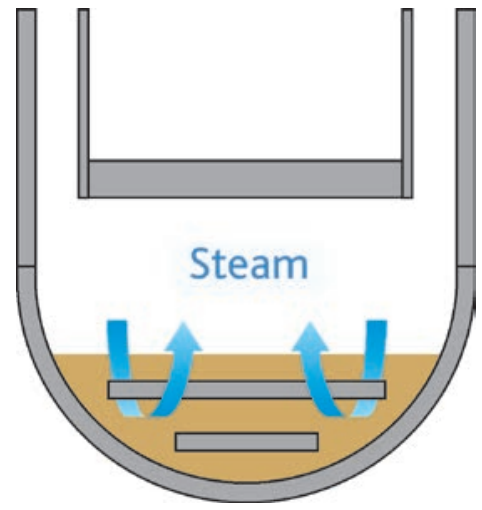

Figure 5.3. Schematic diagram of corium configuration after the lower head has dried out: a debris bed (which is more of less porous, depending on the degree of fragmentation of the corium) around steel structures, with steam circulating through natural convection.

\subsection{Convection movements in the corium pool}

The power released by the corium pool can be evacuated both through its lateral edges (thus via the vessel wall) and through its upper surface (through convective exchange with any water present, or through radiative transfer). These heat transfers cause natural convection movements of the molten materials in the corium pool (Figure 5.4). One of the key parameters when taking into account this phenomenon is the relationship between the upward heat flux and the lateral flux evacuated through 


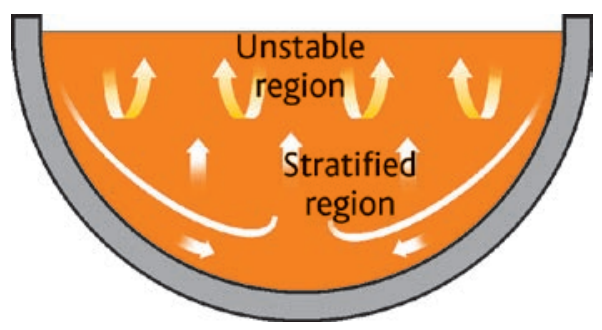

Figure 5.4. Schematic diagram of convection movements in a turbulent corium pool with top-down and lateral cooling. These movements cause the corium to flow downwards along the reactor vessel then rise (slowly) in the centre. The top of the pool is the site of considerable agitation in the form of thermoconvective cells (Rayleigh-Besnard instability).

the vessel wall. The movements in the corium pool are mainly turbulent, except in some highly stratified regions at temperatures in which there is almost no convection (the bottom part, for example). This phenomenon is relatively well understood for simple corium pool configurations, and correlations have been established for heat exchanges at the edges of the pool (see Section 5.4.1.1 and the reference documents $[33,41]$ ).

\subsection{Corium oxidation (in the form of particles or a pool), and hydrogen production}

When the corium is being fragmented, it may be oxidised. This oxidation, if it occurs, produces hydrogen, on the one hand, and determines the later evolution of the corium, on the other hand. The ZREX/ZRSS tests (by Sandia National Laboratory, with a $\mathrm{Zr}+\mathrm{ZrO}$ or Zr-stainless steel mixture) and CCM tests (by Argonne National Laboratory, with a $\mathrm{UO}_{2}+\mathrm{ZrO}_{2}$ corium mixture containing $24 \%$ steel) have provided partial information on corium oxidation. These tests suggest that, in the absence of a steam explosion, the fragmentation is not fine enough to result in significant debris oxidation. Nevertheless, tests with water at saturation have led to the oxidation of up to $30 \%$ of the metallic masses present in the corium. In the event of a steam explosion, oxidation may be complete. Not enough tests have been conducted to allow sufficient quantification of this phenomenon (because of the risks involved).

As to corium pool oxidation, this phenomenon has not been extensively studied and models are inadequate as a result in 2015 . The MASCA-2 programme tests (on the evolution of a stratified pool under oxidising conditions, see reference document [37]) have provided some information on this subject, but not enough to allow the oxidation kinetics to be measured; in addition, it is very difficult to extrapolate their small-scale data to the scale of a power reactor lower head.

\subsection{Metal/oxide stratification in the corium pool}

The MASCA MA and STFM tests [37], which were conducted at high temperatures with a corium containing uranium, zirconium and iron in the form of metals and oxides, have revealed the existence of two immiscible liquid phases at equilibrium, one metallic and the other consisting of oxides. Depending on the initial composition of the mixture, 
the metallic phase, consisting mainly of steel, may contain uranium and zirconium and become denser than the oxide phase. This results in pool stratification with the metallic phase at the bottom of the reactor vessel (Figure 5.5). Phase composition at equilibrium can be predicted using thermochemical databases such as NUCLEA (developed by Thermodata for IRSN and CEA). Pool stratification depending on the evolution of density over time is rarely modelled in the computer codes used to simulate core melt accidents, however. Although stratification of two immiscible liquids is a known phenomenon, the coupled interaction between mass exchange (thermochemistry) and flow dynamics (natural convection and stratification) remains a difficult process to model. In 2015, some computer codes incorporate simplified modelling of the oxide and metallic layers' evolution based on changes in their density.

The challenge lies in being able to predict under what conditions the molten metal layer is lighter than the oxide layer, resulting in the heat flux in the reactor vessel being "concentrated" in the metallic layer (when it is thinner than approximately $50 \mathrm{~cm}$ ); this phenomenon is named the "focusing effect". In the initial studies on corium retention in the reactor vessel, which adopted a "conventional" approach (for the Westinghouse AP600 reactors, for example), the metal was supposed to merely contain steel and so be lighter than the oxide. The heat flux transferred to vessel wall is then higher in the metallic layer, particularly when it is thin: as a first-order approximation, the heat flux transferred to the vessel wall is inversely proportional to the thickness of the molten metal layer thickness. A thin molten metal layer above a corium pool therefore has the effect of "concentrating" the heat delivered to the wall. This phenomenon, which is rather well understood and modelled [44], is one of the main threats to reactor vessel integrity. It is explained in detail in Section 5.4.1.1.

"Conventional representation"

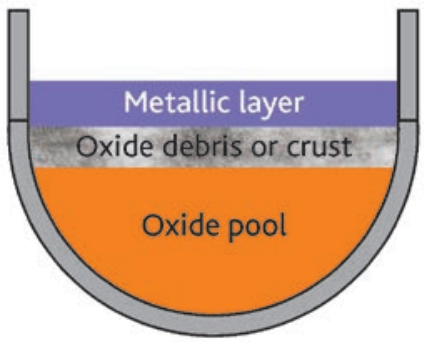

"MASCA observations"

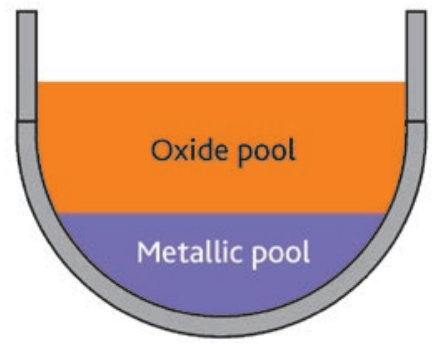

Figure 5.5. Layout of the potential metallic, oxide and debris layers resulting from corium fragmentation, as supposed in the "conventional" approach (left) and as observed in the MASCA tests (right).

\subsection{Dissolution of reactor vessel steel at temperatures below its melting point}

As a result of the formation of eutectic mixtures (Fe- $\mathrm{U}-\mathrm{Zr}$ ), reactor vessel steel may dissolve at temperatures above $1360 \mathrm{~K}$. This can lead to erosion of vessel steel if it is in contact with a corium containing uranium oxide, zirconia and zirconium. The 
METCOR tests (studying the interaction between a high-temperature corium containing uranium, zirconium and oxygen, and a steel sample representing a reactor vessel) have made it possible to estimate the erosion kinetics of reactor vessel steel, but the need remains for a more detailed understanding of the process. However, the rate of creep above $1300 \mathrm{~K}$ is such that the steel no longer has any mechanical strength at such temperatures (Section 5.1.3). This phenomenon can therefore be considered of secondary importance.

\subsubsection{Experimental programmes, modelling and computer codes}

\subsection{Experimental programmes}

This section provides a brief description of the main experimental programmes dedicated to the behaviour of corium in the lower head, ranging from the oldest to those still under way or planned in 2015.

DEBRIS [43]: the purpose of this test programme, conducted by the University of Stuttgart Institute of Research (IKE) in Germany, is to measure pressure losses and cooling (caused by water flow) for two-phase flows in a heated debris bed. The experimental system is one-dimensional and consists of steel balls heated by induction. Initially, a set of measurements taken for an isothermal water-air flow through the bed of balls was used to determine the two-phase pressure losses, as a knowledge of these values is essential in predicting the "critical dry-out heat flux" (CHF). Since 2008, the experimental system has been modified in order to perform debris bed reflooding tests. As the preliminary tests were satisfactory, more quantitative tests have been performed since 2011 to measure debris bed cooling through reflooding.

SILFIDE [29]: the purpose of this test programme conducted by EDF and completed in 2000 was to measure the CHF of a debris bed heated within its volume. The experimental system was two-dimensional and therefore differed from the DEBRIS test programme. The debris bed consisted of steel balls heated by induction. Useful results were obtained despite the challenge of establishing a homogeneous power distribution within the balls. In particular, local fluxes were sometimes observed to be higher than the theoretical critical flux (for $3 \mathrm{~mm}$ particles, the maximum flux measured in the SILFIDE tests was $1.7 \mathrm{MW} / \mathrm{m}^{2}$ instead of the approximately $1 \mathrm{MW} / \mathrm{m}^{2}$ predicted by the Lipinski correlation). Researchers also observed temporary, localised dry-out prior to reflooding.

RASPLAV [28]: this experimental programme, which was completed in 2000, was conducted under the auspices of the OECD by the Kurchatov Institute of Moscow in Russia. IRSN, CEA and EDF also participated in this project. Its purpose was to study the two-dimensional thermal hydraulics of a corium pool composed of "real" materials (the corium was composed of $\mathrm{UO}_{2}, \mathrm{ZrO}_{2}$ and $\mathrm{Zr}$ ). The tests, involving up to $200 \mathrm{~kg}$ of corium, produced heat fluxes in accordance with predictions using the correlations developed from tests with simulants. However, it was revealed that the interactions between the materials could result in a non-homogeneous corium composition, notably due to stratification, but this phenomenon is minor compared with the stratification observed in the presence of iron during the MASCA tests (see below). 
MASCA: this experimental programme, which was completed in 2006, was conducted under the auspices of the OECD by the Kurchatov Institute of Moscow in Russia. IRSN, CEA and EDF also participated in this project. The experimental facilities used for the MASCA programme were found to provide useful results on material interactions and their impact upon heat flux distribution in a corium pool. The MASCA experiments studied how material interactions affected stratification of the corium pool and, consequently, flows and heat exchanges at the edges of the pool. The main tests were used to study the addition of steel, fission products or $\mathrm{B}_{4} \mathrm{C}$ to a corium pool composed of $\mathrm{UO}_{2}, \mathrm{ZrO}_{2}$ and $\mathrm{Zr}$. At the same time, certain thermophysical properties of metallic alloys composed of uranium, zirconium and iron or oxides were measured, such as their density, viscosity, and solidus and liquidus temperatures. The programme's second phase was aimed at studying the evolution of a stratified corium pool in an oxidising atmosphere.

SIMECO [45]: this experimental programme, which was completed in 2009, was conducted by the Royal Institute of Technology (RIT) in Stockholm, Sweden. Its purpose was to study the heat fluxes in a stratified pool in which a thermal power was generated. In tests using simulants (salts or paraffins), three-layer pool configurations were produced, consisting of a heavy "metallic" layer, an "oxide" layer where most of the power was dissipated and a light "metallic" layer. This allowed the heat flux distribution across the corium pool to be measured. In 2015, the results have yet to be interpreted in greater detail, but it already seems that they will help to modify the distribution estimated on the basis of conventional correlations.

METCOR: this experimental programme by the International Science and Technology Centre (ISTC), which was completed in 2009, was conducted by the Alexandrov Scientific Research Technological Institute (NITI) in Saint Petersburg, Russia. Its purpose was to study the erosion of a steel sample representing the reactor vessel by a corium $\left(\mathrm{UO}_{2}+\mathrm{ZrO}_{2}+\mathrm{Zr}\right)$. The sample was externally cooled and subjected to a heat flux representative of conditions in a large corium pool, with a temperature gradient of over $1000 \mathrm{~K}$ across the sample [30]. The results of this programme seem to show that the erosion does not weaken the reactor vessel, as its mechanical strength mainly depends on the profile of temperatures in the wall under core melt accident conditions.

LIVE: this experimental programme, which began in 2004 and still under way in 2015, is conducted by Forschungszentrum Karlsruhe GmbH Technik und Umwelt (FzK) in Germany, with support from the European Commission. Its purpose is to study the behaviour of a corium using simulants in a hemispherical lower head (approximately $1 \mathrm{~m}$ in diameter). The chosen simulant is a mixture of $\mathrm{NaNO}_{3}$ and $\mathrm{KNO}_{3}$. The first test studied the steady-state thermal hydraulics of the pool (distribution of thermal fluxes at the wall). The second studied the corium melt and its spread in the lower head, with the formation of a crust through solidification. Other tests performed between 2011 and 2013 have studied the effect of stratification, the melting of debris and the effect of top cooling. Those tests were partially funded by the European network of excellence SARNET-2, with support from the European Commission. These new tests have completed our knowledge of the temperature at the solid-liquid interface and crust stability. 
INVECOR: this experimental programme supported by the European Commission in the context of the ISTC was conducted between 2006 and 2010 by IAE-NNC-RK (Kazakhstan). Its purpose was to study the interactions between a liquid corium $\left(\mathrm{UO}_{2}+\mathrm{ZrO}_{2}+\mathrm{Zr}\right)$ and a steel hemispherical lower head approximately $80 \mathrm{~cm}$ in diameter by maintaining a constant power density using electrodes inserted into the corium pool. Four tests were carried out. Each test used $60 \mathrm{~kg}$ of corium, which was poured into the reactor vessel mockup then heated, and then cooled using water. The results are quite difficult to interpret because of the presence of the electrodes, which have a considerable influence upon convection in the pool as well as its cooling. The results are primarily qualitative. They reveal that the upper layer of the corium pool is fragmented, encouraging its cooling. It therefore seems that reflooding the lower head, even after a corium melt, are beneficial in retaining the corium in the reactor vessel (in addition to external cooling of the reactor vessel).

\subsection{Models and computer codes}

This section provides a brief description of the main models and dedicated computer codes used to simulate the behaviour of a corium pool and its interactions with the lower head (the integral computer codes used to simulate core melt accidents, which are presented in Chapter 8, are not presented here).

CFD computer codes: these computer codes solve Navier-Stokes equations for compressible or incompressible fluids in any geometry (2D or 3D). These include the FLUENT and CFX codes, which were both developed by ANSYS and are used for many industrial applications involving 3D flows. These computer codes generally use numerical resolution methods that are efficient and fast, and their user interfaces are designed for ease of use. Offering many optional models (turbulence, material transfers and chemistry), they are increasingly used to study pools of molten materials. They are intended for rather generic applications, however, and may prove of limited use for modelling a particular phenomenon (such as solid particle formation and stratification, for example).

MC3D (CEA/IRSN): this mechanistic computer code simulates in detail the interactions between a corium and water (fragmentation and steam explosion). It is described in Section 5.2.1 [31].

CONV 2D/3D (IBRAE): this code solves Navier-Stokes equations for incompressible fluids, regardless of geometry (2D or 3D). It can be used to calculate the evolution of a corium pool and its spread outside the reactor vessel, and is similar to a CFD code. It does not have a turbulence model (essential when simulating large pools) or a model for processing the chemical interactions within the corium (no material transfers or chemical kinetics), however [35]. It was used in the preparation of the RASPLAV and INVECOR tests.

TOLBIAC (CEA): this is a dedicated model for simulating corium pools in the lower head. It takes into account the existence of two immiscible liquids that can stratify in either direction; it also accounts for potential crust formation on the upper surface of the pool or along its edges. It can be used to calculate transient changes in axisymmetrical 2D domains [46]. 
SURCOUF (CEA/IRSN joint development for the ASTEC integral computer code): this module, which was developed for the ASTEC integral computer code (see Chapter 8) is designed to model the evolution of debris in the lower head by integrating the coupled interaction between thermochemistry and thermal hydraulics. The OD approach accounts for the existence of several layers (light metal, heavy metal, oxide and solid debris) and can be used to calculate their respective positions, based on changes in density. This code has been replaced by the PROCOR code which is significantly improved. PROCOR is also used by EDF, with a coupling to MAAP.

ICARE/CATHARE (IRSN): this mechanistic software calculates core degradation under core melt accident conditions. It offers axisymmetrical 2D modelling of the reactor vessel and includes several models designed to simulate the behaviour of corium in the lower head: corium melt fragmentation, debris bed dry-out, debris melting, metal/ oxide stratification, corium oxidation and debris reflooding. The lower plenum mesh is still rather crude, however, and the numerical methods used do not provide as much accuracy as the CFD models $[36,38,42]$. The lack of precision in the mesh is nevertheless acceptable, given the uncertainties regarding the properties of materials or some physical phenomena.

\subsubsection{Summary and outlook}

There are still many uncertainties in the description of corium behaviour in the lower head. Firstly, the effects of the material interactions (stratification, oxidation and dissolution) seem very important and are not all properly modelled yet (notably because the experimental results are very recent); this should be improved by analysing the latest results, obtaining more experimental data and developing more advanced models (that, among other things, address the problem that thermodynamic equilibria are not currently processed at the local (mesh) scale). Secondly, the effects of scale are difficult to estimate, and it is sometimes tricky to transpose reduced-scale test results to a full-sized power reactor. Further analysis and modelling is required to make this transposition possible by reducing these uncertainties, considering the fact that it is hardly feasible to perform full-scale tests.

\subsubsection{Reactor vessel failure}

\subsubsection{Introduction}

When a core melt accident occurs in a PWR, the integrity of the reactor vessel may be threatened by three main phenomena. The corium flowing into the lower head may erode the reactor vessel immediately upon direct contact, or the reactor vessel may be damaged by a potential steam explosion immediately the corium comes into contact with the liquid water present; if the reactor vessel withstands this transient phase, its integrity may then be threatened by the effect of a corium pool forming in the lower head.

The reactor vessel is more intensely eroded if the volume of the corium melt is large, or if the water present in the lower head is shallow. In theory, this can result 
in the reactor vessel very rapidly failing on contact with the melt. Some experiments have shown that a crust forms between the melts and the molten metal, substantially slowing the rate of erosion [47]. If the temperature of the corium in the melts is higher than $2500 \mathrm{~K}$, however, this insulating crust may not form (Section 5.1.2). Other factors probably reduce the degree of erosion, such as the point of contact of the melt rapidly changing over time, resulting in a very short contact time for a given point in the reactor vessel and the presence of water in the lower head.

When a corium melt and water come into contact, this can also very rapidly produce a large quantity of steam, resulting in a very high pressure peak and possibly a steam explosion capable of damaging the reactor vessel (see Section 5.2.3 and references $[48,49])$.

Should molten corium form a pool in the lower head, heat exchange between the pool and the reactor vessel may provoke localised, partial melting of the reactor vessel, possibly resulting in reactor vessel rupture. This heat exchange is even greater for high-mass corium pools. Nevertheless, reactor vessel failure does not occur in all cases, as the Three Mile Island-2 accident showed in 1979 (see Section 7.1 and references $[50,51])$. When this accident occurred, the reactor vessel remained intact even though a corium pool formed in the lower head. Subsequent analysis concluded that 1) the corium debris was porous, allowing some cooling, and 2) a gap existed between the pool and the inner surface of the reactor vessel. The gap is believed to have allowed water or steam to circulate. It should also be noted that high pressure in the primary coolant system may have a favourable impact on corium cooling when the corium melts (increased critical flux and reactor vessel deformation from creep or plasticity, potentially enlarging the gap).

It should lastly be noted that the reactor vessels of operational PWRs are equipped with a number of guide thimble passageways (also called "penetrations") for insertion of instruments to measure the neutron flux in the reactor core. Reactor vessel rupture may be initiated in the zones around these passageways, due to the presence of singularities and welds. If guide thimble passageways fail in the reactor vessel (by melting, for example), water, steam, fission products and corium may leave the reactor vessel via the interior of these guide thimbles.

\subsubsection{Physical phenomena}

This document only describes the physical phenomena involved in the case of a corium pool in the lower head resulting in the reactor vessel failing. Three parameters must be determined that are important in the later sequence of accident events outside the reactor vessel: the moment when the reactor vessel fails, the location of the break in the lower head, and the size of the break.

The moment when the reactor vessel fails mainly depends on the pressure of the reactor coolant system (RCS) and reactor vessel temperature (linked with the mass and configuration of the corium pool). RCS pressure is generally uniform throughout the reactor vessel, but it may rapidly increase if water is injected into the reactor vessel. 
Reactor vessel temperature is closely linked with the heat flux evacuated through its thick walls.

The location of the break mainly depends on the temperature distribution within the reactor vessel. The area that has been subjected to the greatest heat is the most likely to fail first, excluding singularities and welds; the other sensitive areas are those in which the thickness of the reactor vessel may have been eroded by corium melts, as well as those with singularities due to the presence of the guide thimble passageways and their welds.

Reactor vessel failure may be triggered either by plastic instability or by creep. Plastic instability occurs when the membrane stress acting on the thickness of the reactor vessel exceeds the ultimate tensile strength of the steel, which decreases considerably at higher temperatures. Creep, however, generally occurs at temperatures above $800 \mathrm{~K}$. When the temperature rises throughout the thickness of the reactor vessel, creep may occur even if pressure levels remain low.

Once the reactor vessel begins to crack, the cracking spreads; the final size of the break greatly depends on the method of propagation, and this is directly related to the metallurgical characteristics of the reactor vessels' steels (see later in this document). Differences in chemical composition (even regarding trace elements) can change reactor vessel behaviour at high temperatures; the failure may be either brittle or ductile. Tests conducted on reactor vessel mock-ups $[52,53]$ have shown that if two materials behave differently at high temperatures (hot shortness vs. ductility), the final break sizes will also differ considerably.

\subsubsection{Experimental programmes, modelling and computer code}

In the context of experimental research on lower head behaviour, CEA conducted the RUPTHER programme [60] from 1995 to 1999 in collaboration with EDF and FRAMATOME. Its objective was to determine the tensile and creep properties (between $300 \mathrm{~K}$ and $1600 \mathrm{~K}$ ) of 16 MND5 grade steel (the steel used for French PWR reactor vessels) and model the mechanical behaviour of a PWR reactor vessel subjected to accident loads. The specimens used for the validation tests consisted of cylindrical tubes that were subjected to internal pressure and heated to very high temperatures (between $1000 \mathrm{~K}$ and $1600 \mathrm{~K}$ ). The programme revealed certain deficiencies (both in the modelling and in the mechanical characterisation of 16MND5 grade steel). There were also other difficulties, mainly related to the metallurgical complexity of the steel (the effect of elements present in the steel, even at low levels, notably sulphur). The results have also shown that the metallurgical properties of the steel greatly affect its rupture behaviour. Additional programmes were subsequently carried out.

These included two experimental programmes entitled "Lower Head Failure" (LHF, 1994-1999) and "OECD Lower Head Failure" (OLHF, 1999-2002), which were carried out by the US Sandia National Laboratories (SNL) to study the strength of reactor vessels produced in US steel (SA533B1) subjected to complex thermomechanical loads representative of those resulting from the presence of a corium pool in the lower head [52, 53]. 
The second of these programmes, which was an extension of the first, was led by OECD. The LHF programme involved eight tests, and the OLHF programme involved four. Although the same type of 1/5th scale mock-up was used for both programmes, the wall thickness was doubled for the OLHF programme in order to study the impact of the temperature gradient across the reactor vessel wall. Several methods were used to heat the mock-up in the LHF tests, namely a superheated azimuthal band (representing a corium pool in the lower head with maximum heat flux at the free surface of the pool), superheating a localised zone (representing a lower head hotspot) and finally, uniform heating throughout the lower head area. The experimental protocol called for increasing the temperature at a constant rate until the mock-up failed. The LHF tests were carried out under constant pressure (seven tests at 100 bar and one test at 50 bar). Two of them studied the behaviour of the guide thimble passageways. In the case of the OLHF tests, only uniform heating was applied (Figure 5.6) and two pressures were applied: 50 and 100 bar. One OLHF programme test studied the influence of a rapid pressure increase from 50 to 100 bar upon reactor vessel failure mode. Another test studied the behaviour of the guide thimble passageways (at a pressure of 50 bar). During tests with guide thimble passageways, weld leaks generally occurred, resulting in the experiments being terminated before the lower head actually failed.

The FOREVER tests [58, 59] were carried out between 1999 and 2002 by RIT (Royal Institute of Technology in Stockholm, Sweden). These tests used $1 / 10^{\text {th }}$ scale mock-ups of a PWR reactor vessel in 16MND5 steel. The experimental protocol consisted in pouring a mixed oxide melt ( $30 \%$ by weight of $\mathrm{CaO} ; 70 \%$ by weight of $\mathrm{B}_{2} \mathrm{O}_{3}$ ) into the reactor vessel simulating the corium at a temperature of approximately $1500 \mathrm{~K}$. This melt was then maintained at approximately this temperature, and the reactor vessel was then subjected to a pressure of 25 bar until it failed.

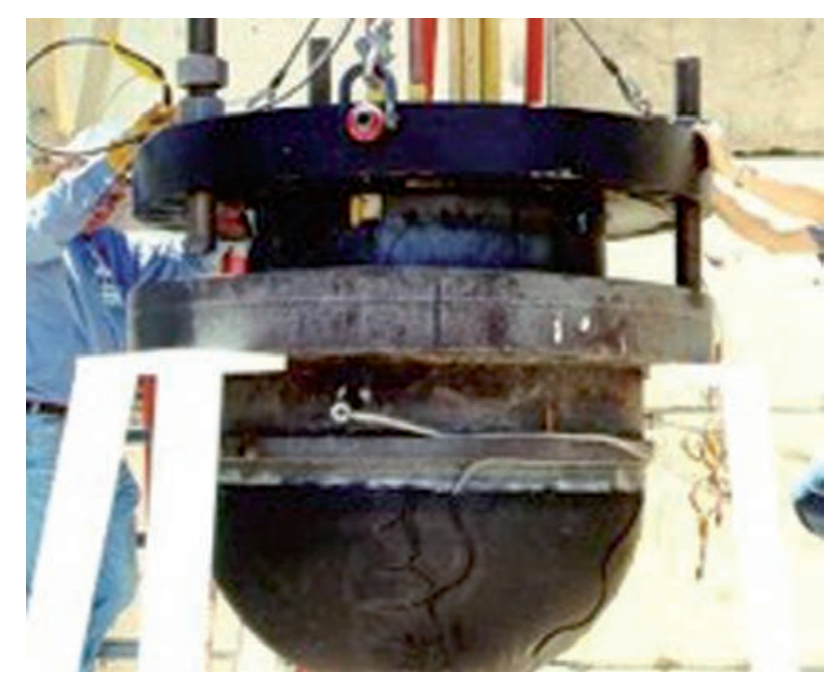

Figure 5.6. Lower head mock-up for carrying out the $1 / 5^{\text {th }}$ scale OLHF tests, and setting up of its internal induction heating system. 
In these three series of tests, particular attention was paid to the instant of reactor vessel failure and its mode, as well as the size of the resulting breaks. These tests were used to develop and validate numerical models for the thermomechanical behaviour of a PWR lower head under pressure prior to its failure. The models developed in this way are briefly described below:

- IRSN developed two simplified models, one one-dimensional (1D) and one twodimensional (2D): the 2D simplified model has been introduced into the ICARECATHARE and ASTEC [54] computer codes;

- models with 2D finite elements have been developed by the Association Vinçotte Nucléaire (AVN: the Samcef code), the French Alternative Energies and Atomic Energy Commission (CEA: the Cast3M code), Electricité de France (EDF: the Aster code), the German laboratories Forschungszentrum Dresden Rossendorf (FZD: the Ansys code) and Gesellschaft für Anlagen- und Reaktorsicherheit (GRS: the Adina code), the US Sandia National Laboratories (SNL: the Abaqus code), the Czech Republic's UJV (the Systus code), and the Finnish VTT technical research centre's Pasula code;

- 3D finite-element models have been developed by AVN, CEA and SNL.

Two successive comparison exercises were carried out in order to compare the results of the 1D and 2D models with the experimental results of the OLHF1 test. The first exercise was carried out as part of the OLHF project, and the second was carried out by the European SARNET (Severe Accident Research NETwork of excellence) $[55,56]$. These have established that the instant and location of the failure were generally accurately predicted by the models. Figure 5.7 shows that the elongation in lower head steel estimated by the different numerical models for the OLHF1 test is also consistent with the experimental results.

The 3D models also determined an initial failure time and initiating breaking zone that are compatible with the experimental results [56]. Additional work by CEA on the Cast $3 \mathrm{~m}$ code for the OLHF1 test produced a crack propagation simulation and an

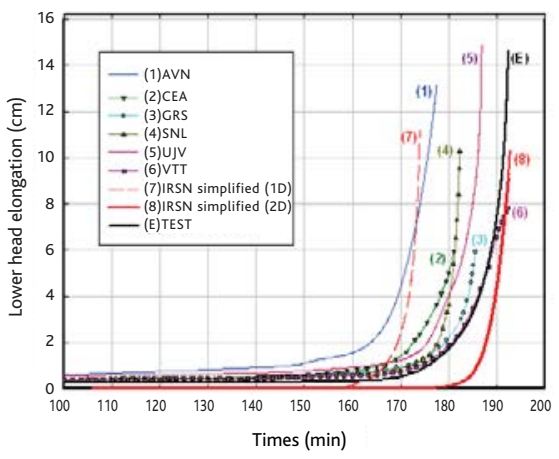

OECD comparison exercise

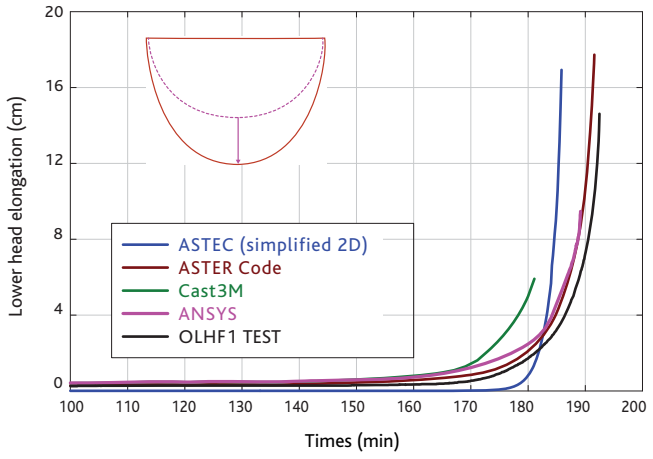

SARNET comparison exercise

Figure 5.7. Comparison between the final elongation in the lower head steel estimated by different numerical models and the experimental results of the OLHF1 test. 
estimate of the final break size that were both totally in keeping with the experimental results. The 3D models, on the other hand, did not give satisfactory results for the LHF tests, and this has been attributed to the variability of the steels used in the tests (ductile steels were used for the OLHF tests, whereas steels that were brittle at around $1300 \mathrm{~K}$ were used for the LHF tests).

The following conclusions were drawn from the analysis and interpretation of the test results [57]:

- the LHF and OLHF tests revealed variations in the behaviour of reactor vessel steels (brittle or ductile) at around $1300 \mathrm{~K}$, influencing the final break size and difficulty in integrating the results into existing numerical models. This variability seems to be strongly linked to the presence of certain elements in the steels (sulphur, aluminium nitride, etc.);

- the experimental results could not be used to develop a method of estimating the size of the break in function of the mechanical loads applied to the reactor vessel. In order to develop a method applicable to the power reactors, it seems necessary to use a 3D finite-element calculation with a failure criterion that takes into account the variability of the behaviour of the studied steels, notably in the LHF and OLHF tests.

In order to clarify the variability in reactor vessel steel behaviour, IRSN launched a research programme in collaboration with CEA and INSA Lyon in 2003 [61]. This programme focused on the steels used in French reactor vessels and had a twofold objective: to complete the characterisation database for these steels, and to apply the study results to French reactors.

The programme began with an inventory of the metallurgical properties and compositions of the steels used to manufacture French reactor vessels (carried out by AREVA NP) and then turned to the selection of five study materials with sufficiently different metallurgical and mechanical properties to cover the range of steels used.

Samples of the five materials were then heated to a temperature of around $1300 \mathrm{~K}$ in order to identify their behaviour (brittle or ductile); these tests confirmed the brittleness of certain steels (ductility trough). Identification of the metallurgical factors responsible for this brittleness under heating also revealed aluminium nitrate precipitates and manganese sulphide precipitates at the grain boundaries and provided an insight into their role. Concurrently, high-temperature characterisation tests (at between 1200 and $1300 \mathrm{~K}$ ) were carried out on CT (compact tension) specimens to determine the reactor vessel steels' metallurgical and mechanical properties that define the crack propagation kinetics. The results of these tests were used to develop a crack propagation model [62]. Lastly, INSA Lyon conducted tests on the steel tubes at high temperatures to measure the dependence of crack propagation kinetics on the properties of the tested steel. The reference documents present the state of knowledge in this R\&D programme $[63,67]$.

Several theoretical studies and the CORVIS tests [65], which were conducted by the Institut Paul Scherrer (IPS) in Switzerland, have focused on guide thimble and 
guide thimble passageway behaviour under core melt accident conditions with corium in the lower head. These investigations targeted the corium penetration into the guide thimbles and studied various possibilities of guide thimble passageway failure (see the summary [64]). It has been found that even if corium penetrates quite far into the guide thimbles, the resulting heat flux is usually not sufficient to melt the thimble walls and the RCS pressure and temperature conditions should not cause any plastic instability resulting in their rupture. Tube ejection following the failure of the welds between the lower head and the guide thimble sleeve or the melting of the retaining flange is also unlikely.

It should be noted that two finite-element models for studying guide thimble passageway behaviour have been developed by the Finnish VTT institute as part of the OLHF programme [66]. The results from these models are consistent with the experimental findings.

\subsubsection{Summary and outlook}

In order to better appreciate the thermomechanical behaviour of a PWR lower head in the event of a core melt accident and determine the consequences of the potential failure in particular upon the subsequent sequence of events in the accident, the essential parameters consist of the time of failure, the failure mode and the break zone and size.

The numerical models (2D simplified or finite-element models) developed in the context of the RUPTHER, LHF, OLHF and FOREVER programmes have shown their ability to predict the time before lower head failure and the location of the break. The results obtained agree with the experimental data.

Only the 3D finite-element models can be used to provide a more accurate model of the crack and its propagation until a break is created. However, no 3D finite-element model is currently able to correctly assess the size of the break, as this depends on reactor vessel failure mode at high temperature. The failure criterion used in the models must take into account the behavioural variability of the steels used to form the reactor vessels (ductility or hot shortness).

In order to improve the failure criterion and better assess the size of the break in the different cases of core melt accidents, IRSN undertook a collaborative research programme with CEA and INSA Lyon in 2003 on cracking in French reactor vessel steels. Although this programme provided very accurate high-temperature steel cracking kinetic measurements, a crack propagation model is very complex to develop.

The programme has been redirected towards carrying out studies to identify, among the plausible core melt accident scenarios, those for which the propagation of the crack could play an important role in the development of the accident. In the case of accident scenarios with a low pressure in the RCS when the reactor vessel fails (a pressure of less than 20 bar) and with no external cooling of the reactor vessel, these studies show that the reactor vessel failure occurs rather as a result of vessel wall melting. At pressures above 40 bar, on the other hand, cracking of the reactor vessel wall may play an 
important role in reactor vessel failure. With the aim of completing the results of these studies, other accident scenarios, notably those with external cooling of the reactor vessel, are currently under study.

\subsubsection{High-pressure core melt}

\subsubsection{Introduction - accident definition and possible consequences}

A PWR core melt accident can occur at a high pressure mainly as a result of the following:

- an equipment failure or human error resulting in the RCS valves not being opened;

- a rapid pressure increase in the RCS when it is partly or completely depressurised; such a pressure increase can, for example, be caused when a degraded core is reflooded, due to a very fast interaction between the reflooding water and the core's materials at very high temperatures, or even melt.

These accidents are known as "high-pressure melt" accidents.

At high pressures, the different components of the RCS (hot legs, steam generators, etc.) are simultaneously subjected to the following:

- high temperatures;

- high stresses (mainly due to pressure forces).

The combination of both these factors can result in one of these components failing, i.e. creating a break in it. Such a break is qualified as an "induced break" in the terminology used for PWR core melt accidents.

An induced break can be either of the following:

- a break induced by creep in a hot leg, the steam generator's tubes or even in another RCS component; this mechanical failure occurs under the effect of heating coupled with a high pressure;

- a reactor vessel rupture at high pressures (if no other RCS rupture has occurred previously). In this case, the corium present in the lower head can be ejected into the reactor pit and then into the containment and cause it to heat up directly in a process named "Direct Containment Heating" (DCH), which can result in its failure (see Section 5.2.1).

The creation of an "induced break" reduces the pressure in the RCS, thereby reducing the possibility of DCH occurring. If an induced break in the RCS occurs in the steam generator tubes, however, radioactive substances may be directly discharged into the environment.

It is therefore important to study the behaviour of the RCS in the event of a melt under pressure in order to fully appreciate the associated risks. This chapter solely concerns the induced breaks, as DCH is discussed in Section 5.2.1. 


\subsubsection{Physical phenomena}

As we have seen in the preceding sections, when a core melt accident occurs in a power reactor, the reduction in the water inventory in the RCS exposes the fuel rods, resulting in the temperature rising and the reactor core's component elements progressively melting. Part of the power released in the core's unflooded zones is then removed from the core through natural convection, i.e. the hot gases (mainly the steam/water vapour that gradually replaces the liquid water as it evaporates) transport a certain quantity of heat from the core into the coldest regions of the RCS. The hot gases are themselves replaced in the core by the cooler gases. As a result, loops form in which the gases flow from the hot areas of the RCS to its cooler ones and the gases that have been cooled in the cooler areas then flow back into the core's hot ones; these are referred to as "convection loops". These movements are "driven" by buoyancy forces according to Archimedes' Principle, i.e. the forces resulting from the difference in density between the hot (and, therefore, lighter) gases and the cold (and, therefore, heavier) gases.

Theoretically, there are two possible modes of gas circulation in the RCS, as shown in Figure 5.8:

- in the first (shown in the left part of Figure 5.8), the gases leaving the core pass through the hot legs of the RCS, the steam generators, the intermediate legs and cold legs before being reinjected into the core's lower part;

- in the second (shown in the right part of Figure 5.8), a water slug remains present in the so-called "intermediate" legs, located, in the case of each RCS loop, between the steam generator outlet and the RCS pump; due to their shape, the intermediate legs (which are called " $U$ " legs) in the loops of the RCS create a siphon (Figure 5.8) in which water can stagnate, forming a slug. The superheated steam leaving the core passes through some of the steam generator tubes (referred to as the "direct tubes") where they cool down, and then return to the reactor vessel through some of the other tubes (referred to as the "indirect tubes") and through the hot leg (which is therefore the seat of a countercurrent flow: the hot gases flow from the reactor vessel to the steam generator through the upper part of the hot legs and the cold gases flow from the steam generators to the reactor vessel through the lower part of the same hot legs, as shown in Figure 5.8). This flow pattern has been experimentally demonstrated in a scale mock-up and seems to be the most probable (IRSN's computer models predict high water slug stability; if the slug disappears in a loop, the steam follows the path described in the previous paragraph).

These convective phenomena are not specific to high-pressure melt scenarios, however, a high pressure has the following consequences:

- convective exchanges are much greater at high pressures than at low pressures;

- the pressure present in the RCS generates stresses that are sufficiently great to cause a significant risk of a creep rupture in some of the pipes (the hot leg, SG tube, etc.). 


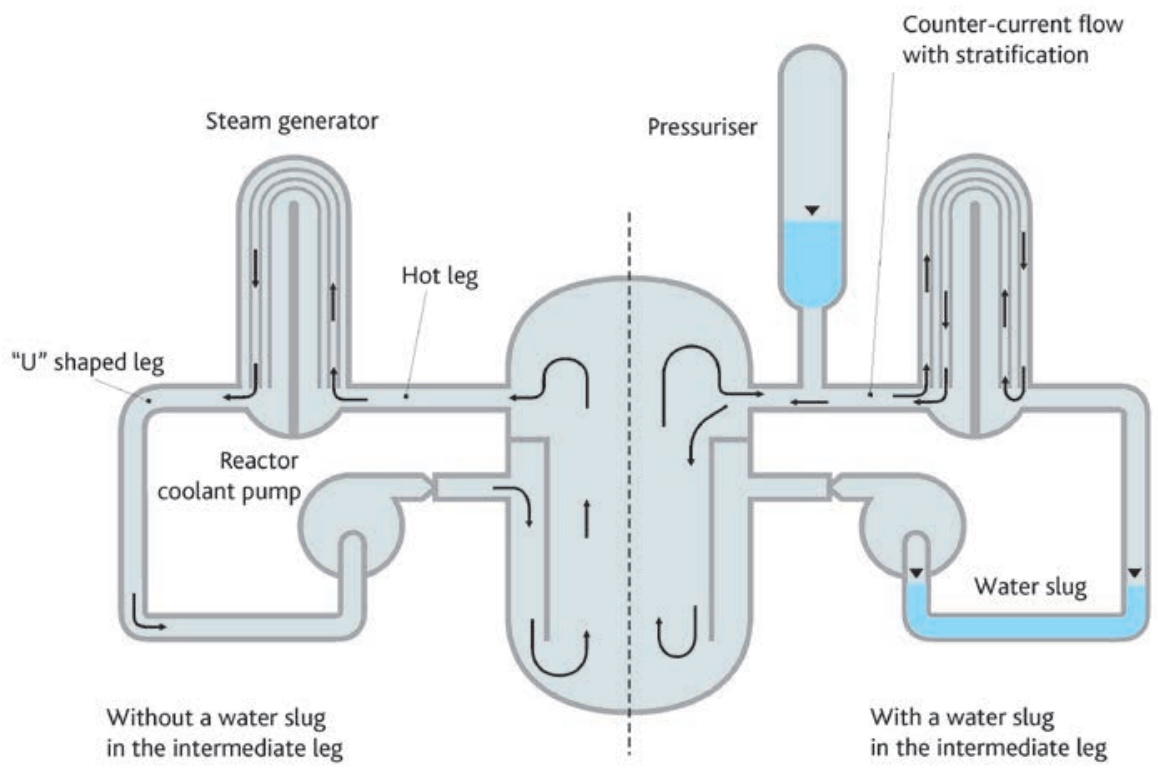

Steam path

Figure 5.8. Modes of steam circulation in the RCS.

In order to determine the location of the break in the RCS, the time sequence of possible RCS failures must be assessed, thereby identifying the earliest. This means that the mechanical and thermal conditions (thermal and mechanical loads) acting on the components of the RCS (SG tubes, RCS piping, etc.) must be known, as well as the behaviour of the corresponding materials at high temperatures.

The mechanical loads are due to the pressure and the thermal expansion of the structures involved (the structures cannot freely expand under the action of heat; they are constrained to do so in a specific way, notably because they are connected to other equipment).

The thermal loads mainly depend on three factors:

- the power released in the core (residual power and power released by the exothermic oxidation reaction of the $\mathrm{Zr}$ );

- the transport of heat from the core and into the RCS by means of superheated steam;

- the residual power released by the fission products when they are transported in the RCS (see Section 5.5 for further details of how the fission products are transported in the RCS).

In order to determine the thermal loads, therefore, it is important to be able to model the different convection loops and the release, transport and deposition phenomena of 
the fission products in the RCS. Other elements must also be modelled in order to assess correctly the thermal loads: whether or not water continues to be injected at the RCS pump seals (a seal failure can result in an RCS rupture), the behaviour of the pressuriser steam bleed SEBIM valves (if a valve jams open, the RCS would be depressurised after a certain number of cycles), and the potential formation of hydrogen "slugs" in the upper part of the SG tubes (hydrogen is mainly produced as a result of oxidation of the zirconium in the cladding by the steam) resulting in the gas flow being blocked.

Studies of high-pressure core melt accidents therefore consist of two parts:

- a thermal-hydraulic part to determine the temperatures (and, also the pressures) in the different parts of the RCS;

- a mechanical part, based on the results of the thermal-hydraulic studies and the properties of the materials involved, to assess when and where the RCS fails.

\subsubsection{Experimental programmes, modelling and computer code}

All of the research programmes on core degradation, the release of fission products, corium melt and lower head mechanical strength more or less directly provide data for the high-pressure core meltdown studies. Experimental and modelling programmes specific to this type of situation have also been performed, however.

The first programmes to specifically address high-pressure meltdown were carried out in the United States at the beginning of the 1980s. These notably revealed, in mockups, the gas flow patterns. Different existing computer codes were modified in order to model this flow circulation using a simplified geometry; these enabled the thermal loads of the structures to be better assessed. Finite-element mechanical studies were then conducted using these thermal load models. These studies provided more precise models of structural response to the different thermal and mechanical loads. At the beginning of the years 2000 , mechanical tests confirmed the validity of this approach and provided data for the modelling of RCS welds.

The improved performance of the computational models can be used to perform Computational Fluid Dynamics (CFD) simulations, which solve 3D fluid mechanics equations, in order to calculate the velocity and temperature fields in the hot legs and the steam generators at a given moment. These methods can partially compensate for the lack of experimental data and help to develop simplified models (for assessing the number of direct tubes and the number of indirect tubes in the steam generators, for example).

\subsection{Experimental programmes}

Westinghouse tests: a test programme conducted by Westinghouse at the beginning of the 1980s, funded by the Electric Power Research Institute (EPRI) in the United States, concerning gas flows and thermal exchanges in the event of a PWR core melt accident. These tests were conducted in a $1 / 7^{\text {th }}$ scale mock-up reproducing one side of a four-loop Westinghouse PWR (the mock-up reproduced the reactor vessel, two hot 
legs and two steam generators) and were carried out with sulphur hexafluoride $\left(\mathrm{SF}_{6}\right)$ in place of superheated steam (this gas behaves like superheated steam under pressure and temperature conditions similar to atmospheric conditions, which greatly simplifies the tests). In particular, these tests revealed circulation flows in the hot legs and SG tubes, the mixing of hot and cooler gases in the SG inlet plenums, and gas stratification in the hot legs. The tests also estimated certain flow data: the mixing ratio in the SG inlet plenums as well as the ratio between the number of "direct" SG tubes (i.e. in which the gases flow from the inlet plenum to the outlet plenum) and the number of "indirect" SG tubes (i.e. in which the gases flow in the opposite direction). These tests are described in several publications, but only partially $[68,69]$, and were used to qualify computational tools $[70,71]$. The ROSA tests, which are mentioned below, aim to provide additional information.

MECI programme: conducted by CEA between 2000 and 2004 and financed by IRSN, this programme:

- included a part to determine the mechanical properties of RCS component materials;

- conducted tube burst tests representing the hot legs (half-scale mock-up);

- conducted tube burst tests representing the hot legs (full-scale mock-up).

The material characterisations of the $\mathrm{MECl}$ tests added to the existing data on the various grades of steel of the RCS hot legs. They also made it possible to assess uncertainties under creep conditions, determine the properties of the materials used in the burst tests and compare their properties with those available in the literature (including the inventory of RCS material properties compiled by AREVA).

The high-pressure tube burst tests then validated the methods of assessing the failure times for the various structures. They were conducted on the SG tubes and on the tubular test specimens representative of hot leg geometry (half-scale straight tubes) and materials. At constant pressure, the test specimens were subjected to a "temperature ramp" thermal load (heating to provide a constant rate of temperature increase) until they burst.

The tests conducted on the specimens representing the hot legs were mainly intended to determine the behaviour of various grades of materials present in the RCSs. The programme included mock-up tests carried out upon a single material (in other words, entirely consisting of 16MND5 steel, the grade of steel used to construct the French reactor vessels, or $316 \mathrm{~L}$ steel, the grade of steel used to manufacture the hot leg components) as well as tests conducted upon welded mock-ups representative of the actual welded joints (between the hot legs and the reactor vessel, and between a hot leg's different components, including the joints with the SGs). As a result, two types of welds were studied: "homogeneous" joints $(\mathrm{HJ})$, represented by a welded assembly consisting of two 316L steel tubes (a half-scale study of the links between a hot leg's components), and bimetallic joints (BMJ), represented by the welded joint between two half-mock-ups in 16MND5 and 316L grade steels (to study the links between the hot legs and the reactor vessel). 
The test grid is shown in Table 5.1. The first column indicates the component material, the second states the tube's thickness, the third the membrane stress ( $\sigma$ in MPa; the stress as defined here is a pressure that "measures" the effect of the forces applied to the structure) and the fourth the temperature heat-up rate (in degrees per second).

In the case of the SG tube tests, two pressure loads were studied: that of a highpressure secondary coolant system, and that of a depressurised secondary coolant system. These tests were reproduced for various temperature ramp rates, with intact tubes or with tubes containing a notch or recess defect (see Table 5.2). It should be noted, however, that such defects are obtained by machining the parts and so are not completely representative of the defects found in the PWRs.

Table 5.1. "Hot leg" mock-up burst test grid.

\begin{tabular}{|c|c|c|c|}
\hline Material & $\begin{array}{c}\text { Thickness } \\
(\mathbf{m m})\end{array}$ & $\sigma(\mathrm{MPa})$ & $\begin{array}{c}\Delta \mathrm{T} / \Delta \mathrm{t} \\
\left({ }^{\circ} \mathrm{C} / \mathrm{s}\right)\end{array}$ \\
\hline 316L & 10.5 & 107 & 0.2 \\
\hline 316L & 10.5 & 107 & 0.05 \\
\hline 316L & 15 & 75 & 0.2 \\
\hline 316L & 15 & 75 & 0.05 \\
\hline 16MND5 & 10.5 & 107 & 0.2 \\
\hline 16MND5 & 10.5 & 107 & 0.05 \\
\hline 16MND5 & 15 & 75 & 0.2 \\
\hline 16MND5 & 15 & 75 & 0.05 \\
\hline BMJ (16MND5L/316L) & 15 & 75 & 0.2 \\
\hline BMJ (16MND5L/316L) & 15 & 75 & 0.2 \\
\hline BMJ (16MND5L/316L) & 15 & 75 & 0.05 \\
\hline BMJ (16MND5L/316L) & 15 & 75 & 0.2 \\
\hline HJ (316L/316L) & 15 & 75 & 0.2 \\
\hline HJ (316L/316L) & 15 & 75 & 0.05 \\
\hline HJ (316L/316L) & 15 & 75 & 0.05 \\
\hline HJ (316L/316L) & 15 & 75 & \\
\hline
\end{tabular}

Table 5.2. SG tube burst test grid.

\begin{tabular}{|c|c|c|c|c|c|c|c|}
\hline \multirow{2}{*}{$\begin{array}{c}\text { Sample } \\
\text { reference }\end{array}$} & \multicolumn{2}{|c|}{$\begin{array}{c}\text { Internal pressure } \\
\text { (bar) }\end{array}$} & $\begin{array}{c}\text { Rate of temperature } \\
\text { increase } \\
\left({ }^{\circ} \mathrm{C} / \mathrm{s}\right)\end{array}$ & \multicolumn{4}{c|}{ Defect geometry } \\
\cline { 2 - 9 } & 80 & 150 & 0.05 & 0.1 & None & Notch & Recess \\
\hline 0 & $\bullet$ & & & $\bullet$ & $\bullet$ & & \\
\hline 1 & $\bullet$ & & & $\bullet$ & $\bullet$ & & \\
\hline 2 & & $\bullet$ & & $\bullet$ & $\bullet$ & & \\
\hline 3 & & $\bullet$ & $\bullet$ & & $\bullet$ & & \\
\hline
\end{tabular}




\begin{tabular}{|c|c|c|c|c|c|c|c|}
\hline \multirow{2}{*}{$\begin{array}{c}\text { Sample } \\
\text { reference }\end{array}$} & \multicolumn{2}{|c|}{$\begin{array}{c}\text { Internal pressure } \\
\text { (bar) }\end{array}$} & $\begin{array}{c}\text { Rate of temperature } \\
\text { increase } \\
\left({ }^{\circ} \mathrm{C} / \mathrm{s}\right)\end{array}$ & \multicolumn{4}{c|}{ Defect geometry } \\
\cline { 2 - 9 } & 80 & 150 & 0.05 & 0.1 & None & Notch & Recess \\
\hline 4 & $\bullet$ & & $\bullet$ & & $\bullet$ & & \\
\hline 5 & & $\bullet$ & & $\bullet$ & & $\bullet$ & \\
\hline 6 & & $\bullet$ & & $\bullet$ & & $\bullet$ & \\
\hline 7 & $\bullet$ & & & $\bullet$ & & $\bullet$ & \\
\hline 8 & $\bullet$ & & $\bullet$ & & & $\bullet$ & \\
\hline 9 & & $\bullet$ & $\bullet$ & & & $\bullet$ & \\
\hline 10 & & $\bullet$ & $\bullet$ & & & & $\bullet$ \\
\hline 11 & $\bullet$ & & $\bullet$ & & & & $\bullet$ \\
\hline 12 & $\bullet$ & & $\bullet$ & & & & $\bullet$ \\
\hline
\end{tabular}

Figure 5.9 shows the experimental system and the condition of a "hot leg" mock-up after the test.

ROSA-V programme: the ROSA experimental programme began in 1970 in Japan and mainly studied the thermal-hydraulic phenomena occurring in PWRs during accident scenarios. The fifth segment of this programme, ROSA-V, was conducted between 2005 and 2009 in the ROSA/LSTF facility of the Japan Atomic Energy Agency (JAEA) and involved many partners including EDF, AREVA, CEA and IRSN in a four-party agreement. The purpose of these tests was to contribute to the development and validation of the thermal-hydraulic models utilised in the computer codes used to compute accident transients that can occur in PWRs by providing "benchmark tests", notably for studying high-pressure core melt accidents. These tests were used to perform comparative exercises between the computer codes used to simulate the thermal hydraulics of the RCS and assess their ability to compute thermal-hydraulics during accident transients. The ROSA/LSTF loop consists of a $1 / 48^{\text {th }}$ scale mock-up (regarding the volumes; the vertical dimensions are respected) and two loops of a four-loop 1100 MWe PWR. The last tests conducted simulated the natural convection phenomena when superheated steam was present in the loops.

ARTIST programme: the ARTIST-1 (AeRosol Trapping In a Steam-generaTor) experimental programme, in which IRSN participated, was launched by the Paul Scherrer Institute (PSI, Switzerland) in 2001. It is intended to reproduce the circulation and retention, for the secondary (cold) side of a steam generator, of the fission products (FPs) present in the form of aerosols in the event of a SG tube rupture; its objective is to obtain an experimental database that can be used for safety studies or for the development of models to analyse the retention of FPs, notably in the case of high-pressure melt accidents resulting in an induced break in SG tubes.

The transport and retention of FPs in the RCSs and Secondary Coolant Systems (SCSs) are described in detail in Section 5.5.3.1 of this document. 


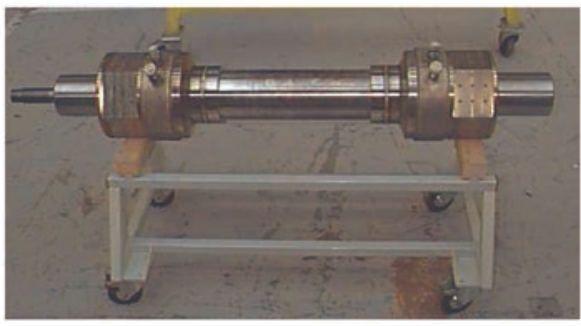

$\Delta$ Tube 2 before being set up on the test bench

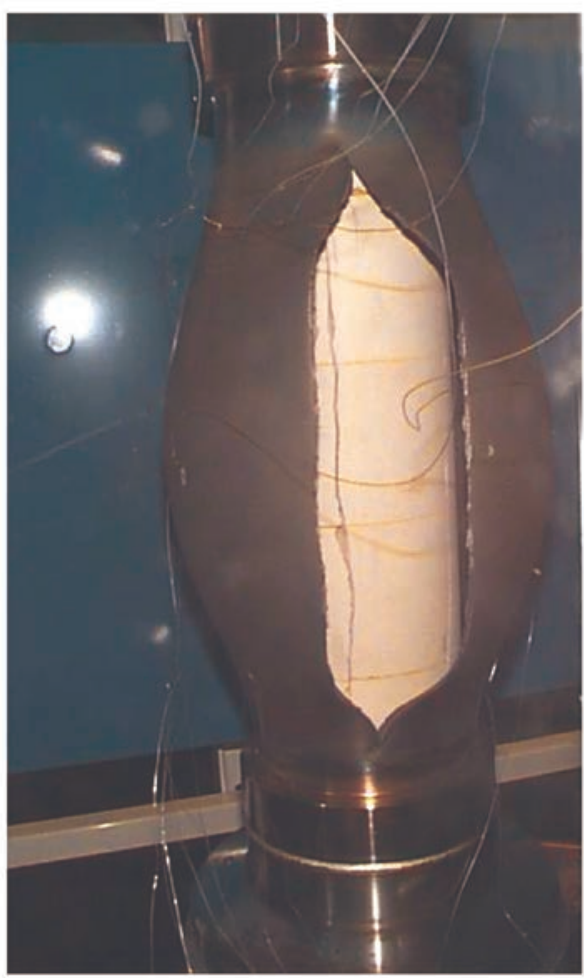

Close-up of one end of the crack

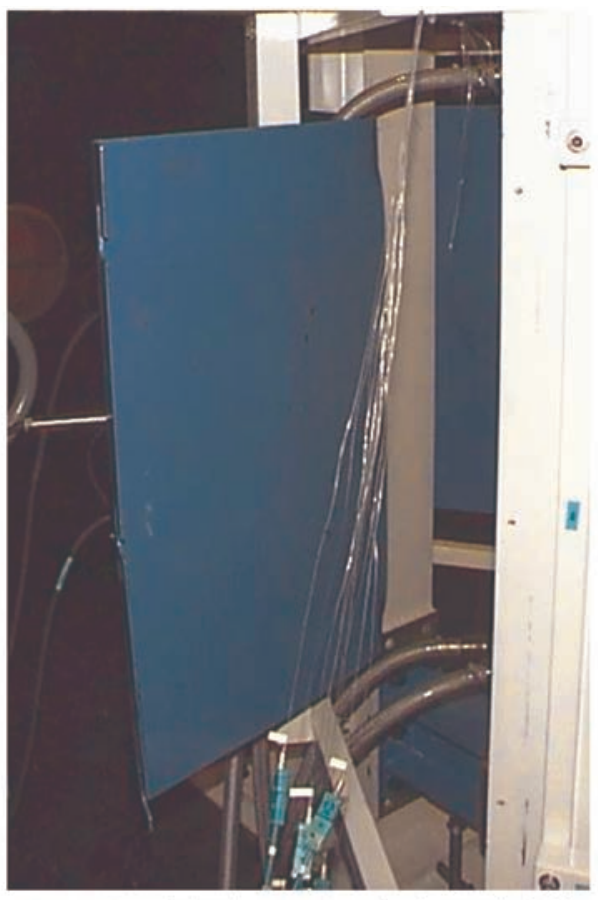

$\Delta$ Overview of the damage; view of a damaged shield

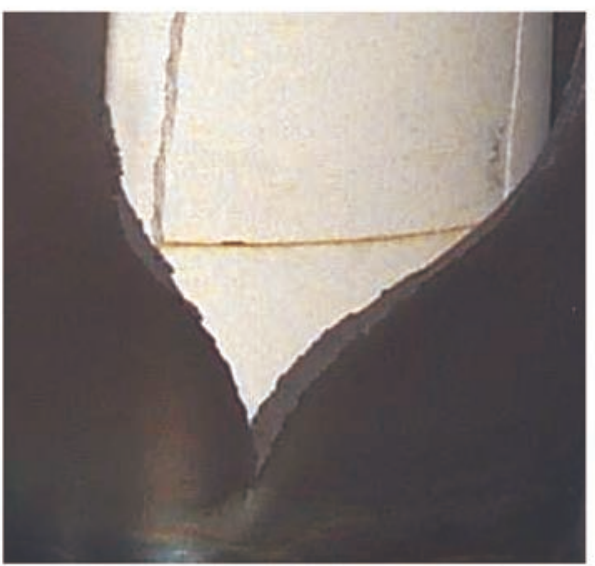

Figure 5.9. Overview of the burst in tube no. 2 in $316 \mathrm{~L}$ steel with a temperature ramp of $0.05^{\circ} \mathrm{C} / \mathrm{s}$ and a membrane stress of $107 \mathrm{MPa}$.

\subsection{Models}

In order to assess the strength of the RCS (resistance to failure), so-called "integral" computer codes are used to simulate a complete accident sequence (these integral computer codes are described in Chapter 8) and, therefore, notably to assess the temperature changes of the different components of the RCS over time (thermal loads). 
Given the current possibilities of computation, these complex computer codes generally use highly simplified models of one-dimensional coolant systems to compute the temperature fields. The thermal loads computed with these codes are therefore subject to significant uncertainties.

Complementing the integral computer codes, specialist computer codes are used to perform much more detailed local simulations, notably those of the temperature fields and gas circulation flows, and to assess the thermal loads more precisely. The initial detailed models of convective heat transfers in the RCS in the event of accident transients date back to the 1980s [68]. Subsequent progress in computation has resulted in CFD codes that can be used to conduct thermal-hydraulic studies or to perform finiteelement calculations in thermomechanical studies to model convection more precisely without the need for large-scale experimental tests that are difficult to implement.

\section{Modelling of high-pressure core melt in integral computer codes}

The integral computer codes presented in Chapter 8 can be used to simulate all of the phenomena that may be involved in a core melt accident, and notably the core degradation and fluid circulation flows in the RCSs and SCSs. They generally use a onedimensional representation of these systems. To enable the circulation flows and the mixing of hot and cold gases in the SG inlet plenums to be simulated, they are represented in this type of computer code by several volumes, and the gas transfers are performed between the volumes.

The computations performed using the ICARE-CATHARE code can be used to assess the mechanical strength of all of the components of the RCS when a high-pressure core melt accident occurs, depending on the computed thermal loads; some calculations compute the risk of a break occurring in the RCS pump seals. It should be noted, however, that the case of a pressuriser valve jamming in the open position has not been specifically examined (but its modelling would not create any problems). The calculations performed with the code have shown that, if there is a water slug in the intermediate leg of the RCS (see Figure 5.8), it remains in place throughout the period of the accident transient. They have also revealed that the risk of a hydrogen slug forming in the upper part of SG tubes could be avoided.

These computational results must be used with care, however, because of the uncertainties in the thermal load computations. These uncertainties are due to the simplified models used for the coolant systems, on the one hand, and to certain simplified aspects inherent in the ICARE-CATHARE computer code, on the other hand: the code does not model the transport and possible deposition of the FPs released when the core is degraded; furthermore, the core is represented in a highly simplified way, as the code's user must predefine the heat transfers outside the core (two-dimensional [axisymmetrical] modelling of the core can compensate for this simplification, but these models are very costly in terms of computation time). 


\section{Modelling of RCS thermal-hydraulics}

The approach described in the previous paragraph results in a model of the hot legs or SG inlet plenums consisting of several volume elements (a few dozen at most). By its nature, therefore, it is highly simplified. On the other hand, it can be used to simulate an accident transient lasting several hours.

The CFD approach can be used to model these zones by means of thousands of unit cells and so can numerically simulate the circulation flows of the gases in a RCS loop more realistically than with an "integral" computer code. It requires a long computation time, however, thereby making the calculation of the complete sequence of events in an accident impossible. We must limit ourselves to studying the gas circulation flows at a given moment. The CFD approach has been adopted by the United States Nuclear Regulatory Commission (NRC) in the FLUENT computer code [71] and by IRSN in its CFX and TRIO computer codes (in the latter case, as part of a collaboration with CEA) [72]. The current means of computation restricts the number of unit cells in a model. A steam generator tube bundle (which consists of several thousand tubes) is modelled by a smaller bundle (consisting of approximately ten times fewer tubes), composed of equivalent tubes whose characteristics are determined so that, for example, the total flow cross-section of the tubes of the equivalent bundle is equal to the total flow cross-section of the actual bundle's tubes. The modelling is restricted to the RCS: the exchanges with the SCSs are defined in the form of limit conditions (in other words, only the temperature, which is assumed to be uniform, of the steam in the SCS and a thermal exchange coefficient used to calculate the thermal fluxes between the PCSs and the SCSs are defined). The computations of this type provide a detailed view of the flows in the SG tubes at a given moment and can be used to assess some of their characteristics (mixing ratio in an SG plenum, and the number of "direct" SG tubes and "indirect" SG tubes).

This type of computation provides more precise thermal load results that can then be used to improve the thermal modelling in the integral computer codes as well as to improve the assessment of the mechanical strength of RCS components. Computations performed using the TRIO computer code have, for example, revealed that besides the SG direct and indirect tubes, there were also many tubes with no significant gas circulation flows. They also revealed the possibility of triple stratification occurring in the hot legs, with a "warm" layer between the hot and cold layers.

In addition, they provide 3D profiles of the gas temperatures in the RCS loops. Figure 5.10 shows an example of a thermal profile in a hot loop and a steam generator, calculated using the TRIO-U code. The colours represent the gas temperature ranges (in degrees Kelvin). The superheated steam leaving the reactor vessel passes through the upper part of the hot leg and then cools down when it enters the SG plenum and mixes with the "cooler" steam found there. "Relatively" cold steam flows back towards the reactor vessel through the lower part of the hot leg. A prior computation performed using an integral computer code provides this simulation's "limit conditions" (flow rate and temperature of the hot gases as they enter the hot leg, and SCS temperature). 


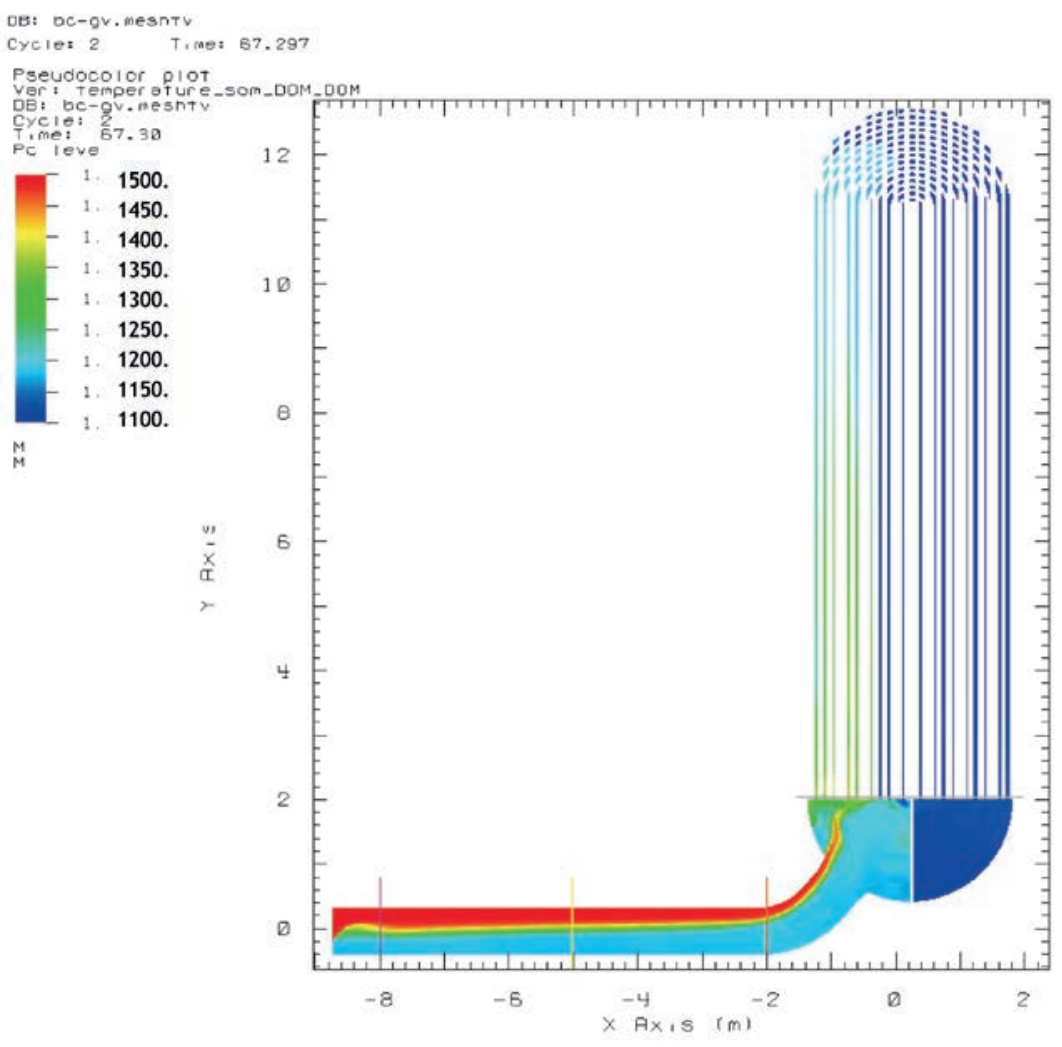

user : bieder

Tue Jon 20 10:42:03 2004

Figure 5.10. Example of a thermal field in a hot leg and the associated steam generator, determined using a TRIO-U calculation. The temperature scale is in degrees Kelvin.

The US NRC has conducted similar studies [72]. In particular, it focused on studying the thermal-hydraulic consequences of SG tube leaks existing prior to the accident and showed that such leaks very considerably increased the risk of SG tube failures.

\section{Modelling of RCS component mechanics}

In order to simulate the mechanical phenomena, CEA performed finite-element calculations for the assembly comprising a hot leg and the lower head of a steam generator with the CAST3M code at IRSN's request. The mechanical phenomena have been used to study the effects of hot leg expansion upon the mechanical stresses and, consequently, upon the times and places at which it failed. The developed model used takes into account a "realistic" spatial distribution, provided by CFD computations, of the hot and cold layers in a hot leg (in other words, it takes into account the fact that a hot leg is not divided into a cold lower half and a hot upper half and uses the geometrical profile 
of the separation zone obtained through the CFD computations). To a certain degree, special use of the computational results can be used to take into account the uncertainties regarding material properties as well as those regarding welds.

Figure 5.11 shows a cross-section view of damage to the hot leg at the moment of the failure for a specific thermal load (obtained for a simulation of a total loss of electrical power). One side of the hot leg is welded to the reactor vessel via a sleeve (visible at the right side of the figure), and the other side is welded to the lower head of the steam generator via an elbow and a conical trunk tube (visible at the left side of the figure). The start of the pressuriser's expansion line that connects the hot leg to the pressuriser can be seen in the figure.

In the computation performed with the CAST3M code, the reactor vessel and the steam generator have been simulated by means of special limit conditions.

The colours represent the level of damage suffered. The damage is a coefficient whose value is between 0 and 1 and is calculated at all points of the unit cell mesh and at every computation step by means of different models specific to the material. A value of 1 represents a failure, whereas a value of 0 represents an intact structure. In this case, the break begins at the beginning of the inner wall of the elbow before the steam generator.

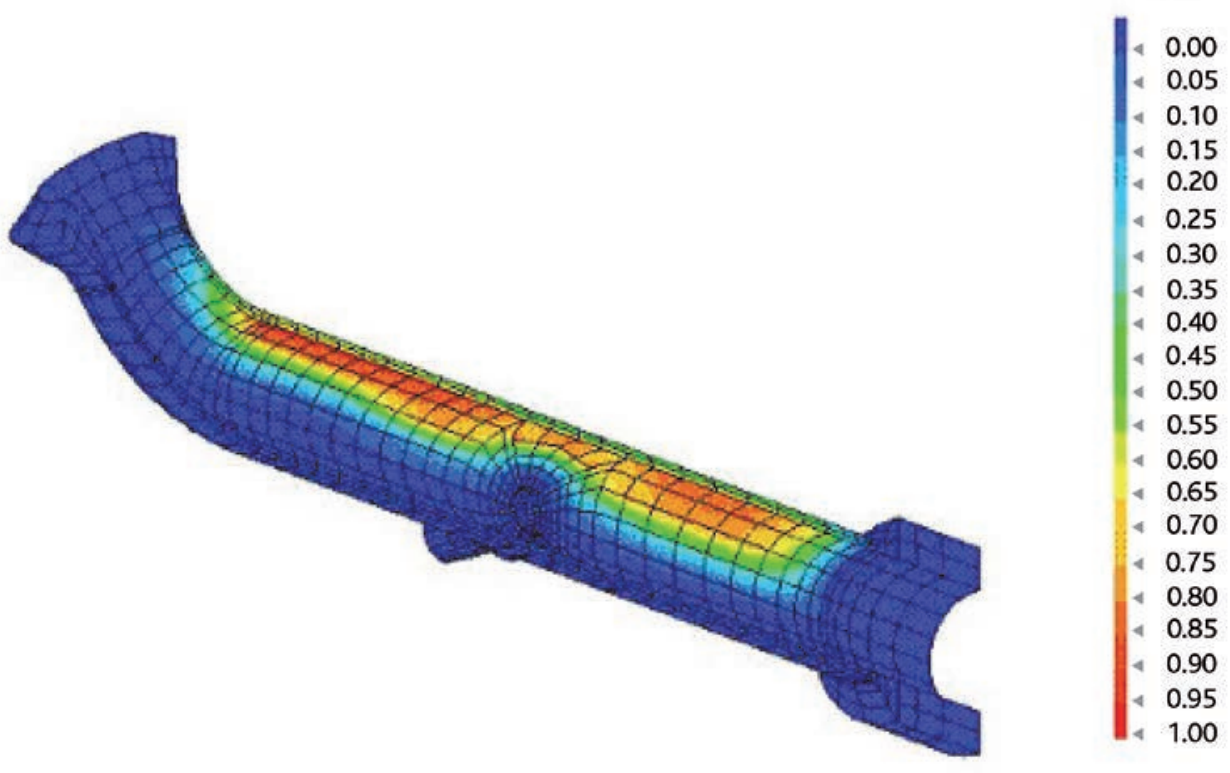

Figure 5.11. CAST3M mechanical computation of the strength of the hot leg - damage level at the moment of the "break" (see text for further details). 


\subsubsection{Summary and outlook}

Research has helped to improve our understanding of high-pressure core melt accidents by increasing our knowledge of the thermal and mechanical loads to which the different components of the RCS are subjected as well as our knowledge of the mechanical behaviour of these components in such situations. Given the complexity of the phenomena involved, notably the RCS gas circulation flows that govern the temperatures of the RCS components, however, it is still difficult to predict with certainty where the first failure in the RCS will occur. The studies performed by IRSN are based on the results of this research; they tend to show that, when a high-pressure core melt accident occurs, the first failure would occur in a SG tube when the SGs are depressurised on the secondary side, or in the hot legs if not.

In the case of the modelling tools, progress could be made in validating the existing tools (notably on the basis of the ROSA test results) or improving the 3D modelling of RCS thermal-hydraulics. This is because only a 3D approach can take into account the complex natural convection phenomena that govern RCS temperature. As things are, it is sufficient to model the mechanics of RCS components, given the uncertainties associated with the thermal load computations.

From the point of view of PWR safety, measures have been taken in France to avoid a high-pressure core melt accident occurring (as in other countries), given the potential consequences of this type of accident, notably in the event of direct containment heating. These provisions include deliberate depressurisation of the RCS if possible before the core melts. This can be achieved by opening the pressuriser steam relief valves. The action of depressurising the RCS is included in the emergency operating procedures and must be performed immediately by the operators as soon as the Severe Accident Operating Guidelines (GIAG) is in use (see Section 4.3.3.4 of the Severe Accident Operating Guidelines).

It should be noted that it has been decided to modify the opening control of the pressuriser steam bleed valves in third ten-yearly outage programme of $900 \mathrm{MWe}$ reactors, in order to make their operation more reliable and thereby make it possible to depressurise the RCS during a core melt accident.

In the case of the EPR, design provisions have been made aiming to "practically eliminate" high-pressure core melt accidents. These are described in Section 4.3.4.2.

\section{Reference documents}

[1] B. Adroguer et al., Core Loss During a Severe Accident (COLOSS project), Proceedings of the FISA-01 meeting, Luxembourg, Nov. 2001.

[2] B. Adroguer et al., Corium Interactions and Thermochemistry, CIT project, FISA-99 Symposium, Luxembourg, EUR 19532 EN, Nov. 1999. 
[3] C.M. Allison, J.L. Rempe, S.A. Chavez, Final design report on SCDAP/RELAP5 model improvements - debris bed and molten pool behavior, INEL-96/0487, December 1996.

[4] J. Broughton, P. Kuan, D. Petti, E. Tolman, A Scenario of the Three Mile Island Unit 2 Accident, Nuclear Technology 87, 34-53, 1989.

[5] B. Clément, N. Hanniet-Girault, G. Repetto, D. Jacquemain, A.V. Jones, M.P. Kissane, M.P. von der Hardt, LWR severe accident simulation: synthesis of the results and interpretation of the first Phebus FP experiment FPTO, Nuclear Engineering and Design 226 (1), 5-82, 2003.

[6] E.W. Coryell, Summary of Important Results and SCDAP/RELAP5 Analysis for OECD LOFT Experiment LP-FP-2, NUREG/CR-6160, NEA/CNSI/R(94)3, EGG2721, April 1994.

[7] F. Fichot, O. Marchand, P. Drai, P. Chatelard, M. Zabiégo, J. Fleurot, Multi-dimensional approaches in severe accident modelling and analyses, Nuclear Engineering and Technology 38 (8), 733-752, 2006.

[8] R.D. Gasser, R.O. Gauntt, S.C. Boursier et al., Late-phase melt progression experiment: MP-2. Results and analysis, Report NUREG/CR--6167; SAND--93-3931, 1997.

[9] V. Guillard, F. Fichot, P. Boudier, M. Parent, R. Roser, ICARE/CATHARE coupling: three-dimensional thermal-hydraulics of severe LWR accident, Proceedings of ICONE-9, Nice, France, 2001.

[10] S. Hagen, P. Hofmann, V. Noack, L. Sepold, G. Schanz, G. Schumacher, Comparison of the quench experiments CORA-12, CORA-13, CORA-17, Report FZKA 5679, 1996.

[11] T. Haste et al., Degraded Core Quench: A Status report, OCDE/GD(97)5, NEA/ CSNI/R(96)14, August 1996.

[12] T. Haste, K. Trambauer, Degraded Core Quench: Summary of Progress 1996-1999, NEA/CSNI/R(99)23, February 2000.

[13] T. Haste, B. Adroguer, Z. Hozer, D. Magalon, K. Trambauer, A. Zurita, In-Vessel Core Degradation Code Validation Matrix, Update 1996-1999, OECD/GD(94)14, NEA/CSNI/R(95)21, 1996.

[14] G.M. Hesson, N.J. Lombardo, J.P. Pilger, W.N. Rausch, L.L. King, D.E. Hurley, L.J. Parchen, F.E. Panisko, Full-length high-temperature severe fuel damage test No. 2. Final safety analysis, Report PNL-5547, 1993.

[15] R. Hobbins, M. Russel, C. Olsen, R. Mc Cardell, Molten Material Behaviour in the Three Mile Island Unit 2 Accident, Nuclear Technology 87, 1005-1012, 1989.

[16] R. Hobbins, D. Petti, D. Osetek, D. Hagrman, Review of experimental results on light water reactor core melt progression, Nuclear Technology 95, 287-307, 1991. 
[17] P. Hofmann et al., Chemical-Physical Behaviour of Light water reactor core components tested under severe reactor accident conditions in the CORA facility, Nuclear Technology 118, 200-224, 1997.

[18] P. Hofmann, S. Hagen, G. Schanz, A. Skokan, Reactor Core Materials Interactions at Very High Temperatures, Nuclear Technology 87, August 1989.

[19] S.M. Jensen, D.W. Akers, Post-irradiation examination results from the LP-FP-2 center fuel module, Report EGG-M-90152; CONF-9005179—2, 1990.

[20] D.A. Petti, Z.R. Martinson, R.R. Hobbins, C.M. Allison, E.R. Carlson, D.L. Hagrman, T.C. Cheng, J.K. Hartwell, K. Vinjamuri, L.J. Seifken, Power Burst Facility (PBF) severe fuel damage test 1-4 test results report, Report NUREG/CR-5163; EGG2542, 1989.

[21] L. Sepold, P. Hofmann, W. Leiling, A. Miassoedov, D. Piel, L. Schmidt, M. Steinbrück, Reflooding experiments with LWR-type fuel rod simulators in the QUENCH facility, Nuclear Engineering and Design 204 (1-3), 205-220, 2001.

[22] I. Shepherd et al., Investigation of Core Degradation, COBE project, FISA-99 Symposium, Luxembourg, EUR 19532 EN, Nov. 1999.

[23] K. Trambauer, Coupling methods of thermal-hydraulic models with core degradation models in ATHLET-CD, ICONE-6, (c) ASME 1998.

[24] M.S. Veshchunov, K. Mueller, A.V. Berdyshev, Molten corium oxidation model, Nuclear Engineering and Design 235 (22), 2431-2450, 2005.

[25] A.B. Wahba, International activities for the analysis of the TMI-2 accident with special consideration of ATHLET calculations, Nuclear Engineering and Design 118, 43-53, 1990.

[26] R. Wright, Current understanding of in-vessel core melt progression, Proceedings of the Dubrovnick meeting, IAEA-SM-296/95, 1995.

[27] Progress Made in the Last Fifteen Years through Analyses of TMI-2 Accident Performed in Member Countries, Rapport NEA/CSNI/R(2005)1, 2005.

[28] V. Asmolov et al., RASPLAV Application Report, OECD RASPLAV Seminar, Munich (Germany), 2000.

[29] K. Atkhen, G. Berthoud, Experimental and numerical investigations on debris bed coolability in a multidimensional and homogeneous configuration with volumetric heat source, Nuclear Technology 142 (3), 2003.

[30] S.V. Bechta, B. Khabensky, V.S. Granovsky, E.V. Krushinov, S.A. Vitol, V.V. Gusarov, V.I. Almiashev, D.B. Lopukh, W. Tromm, D. Bottomley, M. Fisher, P. Piluso, A. Miassoedov, E. Alstadt, H.G. Willschutz, F. Fichot, Experimental Study of Interactions Between Suboxidized Corium and Reactor Vessel Steel, Proceedings of ICAPP'06, Reno, NV USA, June 4-8, 2006. 
[31] G. Berthoud, M. Valette, Description des lois constitutives de la version 3.2 du logiciel de prémélange MC3D, NT SMTH/LM2/99-39, 1999.

[32] P. Chapelot, A.C. Grégoire, G. Grégoire, Final FPT4 Report, IRSN/DPAM-DIR 20040135, PH-PF IP-04-553, 2004.

[33] T.C. Chawla, C.H. Chan, Heat Transfer from Vertical/Inclined Boundaries of Heat Generating Boiling Pools, Journal of Heat Transfer 104, 465-473, 1982.

[34] D.H. Cho, D.R. Armstrong, W.H. Gunther, S. Basu, Experiments on interactions between Zirconium-containing melt and water (ZREX): Hydrogen generation and chemical augmentation of energetics, Proceedings of JAERI Conference, 97-011, Japan, 1997.

[35] V.V. Chudanov, A.E. Aksenova, V.A. Pervichko, Development of 3D unified computational tools to thermalhydraulic problems, Proc. 10-th International Topical Meeting on Nuclear Reactor Thermal Hydraulics (NURETH-10), Seoul, Korea, October 5-9, 2003.

[36] F. Fichot, V. Kobzar, Y. Zvonarev, P. Bousquet Mélou, The Use of RASPLAV Results in IPSN Severe Accident Research Program, in OECD-NEA, editor, Proceedings of RASPLAV Seminar, Munich, 2000.

[37] F. Fichot, J.-M. Seiler, V. Strizhov, Applications of the OECD MASCA Project Results to Reactor Safety Analysis, MASCA Application Report, OECD-NEA, 2003.

[38] F. Fichot, F. Duval, N. Trégourès, M. Quintard, The impact of thermal non-equilibrium and large-scale 2D/3D effects on debris bed reflooding and coolability, Proceedings of NURETH-11 Conference, Avignon, France, 2005.

[39] B.D. Gasser, R.O. Gaunt, S. Bourcier, Late Phase Melt Progression Experiment MP-1. Results and Analyses, NUREG/CR-5874, SAND92-0804, 1992.

[40] D. Magallon, The FARO programme recent results and synthesis, Proceedings of CSARP Meeting, Bethesda, USA, 1997.

[41] F. Mayinger et al., Examination of thermo-hydraulic processes and heat transfer in core melt, Final Report BMFT RS 48/1. Technical University, Hanover, Germany, 1975.

[42] M. Salay, F. Fichot, Modelling of metal-oxide corium stratification in the lower plenum of a reactor vessel, Proceedings of NURETH11 Conference, Avignon, France, 2005.

[43] P. Schäfer, M. Groll, W. Schmidt, W. Widmann, M. Bürger, Coolability of Particle Beds: Examination and Influence of Friction Laws, International Congress on Advances in Nuclear Power Plants (ICAPP'04), Pittsburgh, PA, USA, June 13-17, 2004.

[44] J.M. Seiler, K. Froment, Material effects on multiphase phenomena in late phases of severe accidents of nuclear reactors, Multiphase Science and Technology 12, $117-257,2000$. 
[45] A.V. Stepanyan, A.K. Nayak, B.R. Sehgal, Experimental Investigations of Natural Convection in a Three-layer Stratified Pool with Internal Heat Generation, Proceedings of NURETH11 Conference, Avignon, France, 2005.

[46] S. Vandroux-Koenig et al., TOLBIAC version 2.2 code description, NT SMTH/ LM2/99-36, 1999.

[47] M. Saito et al., Melting attack of solid plates by a high-temperature liquid jet effect of crust formation, Nuclear Engineering and Design 121 (1), 11-23, 1990.

[48] T. G. Theofanous et al., Lower head integrity under steam explosion loads, Nuclear Engineering and Design 189 (1-3), 7-57, 1999.

[49] B. R. Sehgal et al., Assessment of reactor vessel integrity (ARVI), Nuclear Engineering and Design 235 (2-4), 213-232, 2005.

[50] J. R. Wolf et al., OECD-NEA-TMI-2 Vessel Investigation Project. Report TMI V(93) EG10, 1993.

[51] L. A. Stickler et al., OECD-NEA-TMI-2 Vessel Investigation Project. Calculations to estimate the margin-to-failure in the TMI-2 vessel, Report TMI V(93)EG01, 1993.

[52] T. Y. Chu et al., Lower Head Failure Experiments and Analyses, NUREG/CR-5582, SAND98-2047.

[53] L. L. Humphries et al., OECD Lower Head Failure Project Final Report, OECD/NEA/ CSNI/R(2002)27.

[54] V. Koundy, N. H. Hoang, Modelling of PWR lower head failure under severe accident loading using improved shells of revolution theory, Nuclear Engineering and Design 238, 2400-2410, 2008.

[55] V. Koundy et al., Progress on PWR lower head failure predictive models, Nuclear Engineering and Design 238, 2420-2429, 2008.

[56] L. Nicolas et al., Results of benchmark calculations based on OLHF-1 test, Nuclear Engineering and Design 223, 263-277, 2003.

[57] OLHF Seminar 2002 - Nuclear Safety - NEA/CSNI/R(2003)1.

[58] Sehgal et al., Assessment of reactor vessel integrity (ARVI), Nuclear Engineering and Design 221 (1-3), 23-53, 2003.

[59] Sehgal et al., Assessment of reactor vessel integrity (ARVI), Nuclear Engineering and Design 235 (2-4), 213-232, 2005.

[60] J. Devos et al., CEA programme to model the failure of the lower head in severe accidents, Nuclear Engineering and Design 191, 3-15, 1999.

[61] V. Koundy et al., Study of tearing behaviour of a PWR reactor pressure vessel lower head under severe accident loadings, Nuclear Engineering and Design 238, 2411-2419, 2008. 
[62] P. Matheron, S. Chapuliot, L. Nicolas, V. Koundy, C. Caroli, Characterization of PWR vessel steel tearing under severe accident condition temperatures, Nuclear Engineering and Design 242, 124-133, 2012.

[63] V. Koundy, Défaillance du fond d'une cuve REP en situation accidentelle grave et programme de recherche sur la déchirure des matériaux de cuve française, Rapport scientifique et technique (RST), IRSN, 2008.

[64] B. Autrusson, G. Cénérino, Synthèse des études concernant le comportement mécanique du fond de cuve, Note technique DPEA/SEAC/97-069 - Référence non publique.

[65] S. Brosi et al., CORVIS. Investigation of light water reactor lower head failure modes, Nuclear Engineering and Design 168, 77-104, 1997.

[66] K. Ikonen, R. Sairanen, FEM Analysis of OLHF tests with and without penetration, OLHF Seminar 2002, Madrid, June 26-27, 2002 - (Paper from VTT, Nuclear Energy, Finland).

[67] N. Tardif, Étude du comportement à haute température d'une fissuration instable dans l'acier 16MND5 et application au calcul de la rupture d'un fond de cuve en cas d'accident grave, thèse de doctorat, $\mathrm{n}^{\circ}$ d'ordre 2009-ISAL-0105, LaMCoS UMR CNRS 5259 - INSA de Lyon.

[68] W. A. Stewart et al., Experiments on natural circulation flows in steam generators during severe accidents, Proceedings of the international ANS/ENS topical meeting on thermal reactor safety, San Diego, California, USA, 1986.

[69] W. A. Stewart et al., Experiments on natural circulation flow in a scale model PWR reactor system during postulated degraded core accidents, Proceedings of the 3rd international topical meeting on reactor thermal hydraulics, Newport, Rhode Island, USA, October 1985.

[70] B. R. Seghal, W. A. Stewart and W.T. Sha, Experiments on natural circulation during PWR severe accidents and their analysis, International ENS/ANS Meeting on Reactor Safety, Avignon, France, 1988.

[71] C. F. Boyd and K. Hardesty, CFD predictions of severe accident steam generator flows in a $1 / 7^{\text {th }}$ scale pressurized water reactor, Proceedings of the 10th International Conference on Nuclear Engineering (ICONE10), Arlington, Virginia, USA, April 14-18, 2002.

[72] C. F. Boyd, D. M. Helton and K. Hardesty, CFD analysis of full-scale steam generator inlet plenum mixing during a PWR severe accident, NUREG-1788, 2004.

[73] H. Mutelle and U. Bieder, Study of severe accident natural gas circulation with the CFD code TRIO-U, Technical meeting on use of CFD codes for safety analysis of reactor systems, including containment, Pisa, Italy, November 11-14, 2002. 
[74] D.L. Knudson and C. A. Dobbe, Assessment of the potential for high-pressure melt ejection resulting from a Surry station blackout transient, NUREG/CR-5949, 1993.

[75] http://www.nea.fr/html/jointproj/rosa.html

[76] T. Takeda et al., Analysis of the OECD/NEA ROSA project experiment simulating a PWR small break LOCA with high-power natural circulation, Annals of nuclear energy 36 (3), 386-392, 2009.

[77] Güntay S. et al., ARTIST: introduction and first results, Nuclear engineering and design 231 (1), 109-120, 2004. 


\subsection{Phenomena liable to result in early containment failure}

\subsubsection{Direct containment heating}

\subsubsection{Introduction}

The phenomenon of direct containment heating $\left(\mathrm{DCH}^{4}\right)$ is diagrammatically represented in Figure 5.12. In the event of a PWR core melt accident, a corium melt composed of uranium and zirconium oxides as well as non-oxidised metals (zirconium and steel) and various fission products may form in the lower head. If the lower head ruptures in this situation, the corium is ejected, along with steam and, in some cases, hydrogen from the RCS and liquid water still present in the reactor vessel head when it fails. Depending on the internal pressure of the reactor vessel when it ruptures, this causes more or less finelygrained corium fragmentation and more or less widespread dispersion of the fragments outside the reactor pit. Corium dispersion leads to very efficient heat exchange between the corium and the gases present, as well as oxidation of metallic components of corium, producing hydrogen as a result. The oxidation is mainly due to the steam present in the RCS but also to the steam contained in the containment. The temperatures reached by the gases in the containment and the presence of very hot corium particles then triggers the combustion of the hydrogen created through oxidation of the dispersed corium. This combustion could cause the hydrogen already present in the containment to ignite at the time the reactor vessel ruptures if the concentration is high enough. These phenomena cause the containment atmosphere to heat up and its pressure to rapidly build up (in a few seconds), resulting in the containment being damaged or its integrity failing. In addition, the loads directly applied to the reactor vessel (thrust due to the gases and liquids leaving the reactor vessel, and pressure in the reactor pit) may result in a more or less significant movement of the reactor vessel itself, possibly causing a shock to the structures, the RCS and the SCS and the possible bypass of the containment if breaks are induced in the exterior of the containment, in a system connected to the RCS and not isolated from it.

The risk of the containment rupturing as a result of the gases inside the containment being directly heated is assessed from a technical point of view, assuming that there is no water in the reactor pit when the reactor vessel ruptures. Tests have shown that the risk of combustion is greater when there is no water in the reactor pit. If there is a large quantity of water in the reactor pit, the main phenomenon that can threaten containment integrity is the steam explosion that could occur when the reactor vessel ruptures as a result of the very hot corium coming into contact with the water in the reactor pit; the subject of steam explosions is discussed in Section 5.2.3. In the case of the reactors in operation in France, if there is no water in the reactor pit when the reactor vessel ruptures, this is because the Containment Spray System (CSS) was not operating before the reactor vessel ruptured. For the PWRs, the objective of "practical elimination" of the steam explosion risk in the reactor pit requires the reactor pit to be kept dry before the reactor vessel ruptures.

4. The acronym DCH (Direct Containment Heating) is generally used. 


\subsubsection{Physical phenomena}

Although the phenomena involved in $\mathrm{DCH}$ are well understood at the qualitative level, many uncertainties remain regarding the corresponding detailed physical phenomena and their importance in the pressure build-up within the containment $[1,7]$. The extent and consequences of $\mathrm{DCH}$ greatly depend upon reactor geometry and an experimental approach has been preferred for some time, coupled with the development of simplified models for interpreting the test results and extrapolating them to the case of a power reactor. The particularly violent nature of the phenomenon and the highly specific conditions under which nuclear reactor core melt accidents occur demand the use of simplified geometries and materials and modest instrumentation in the tests, however. Most of the information obtained in experiments is global (corium dispersion rate and pressure peak), includes significant uncertainties (corium oxidation rate and hydrogen combustion) and is often result of analyses performed after the tests are conducted (dispersion and grain size distribution, for example). With the recent development of simulation tools and computational capabilities, certain phenomena can now be assessed in greater detail. All of these phenomena, including dispersion, metal oxidation, hydrogen combustion and the presence of water, have not yet been combined in CFD modelling, however, and it seems difficult to envisage doing so in the short term.

Figure 5.12 shows a diagram of the phenomena and the associated risks. When the reactor vessel ruptures, it contains, apart from the structural elements still in place,

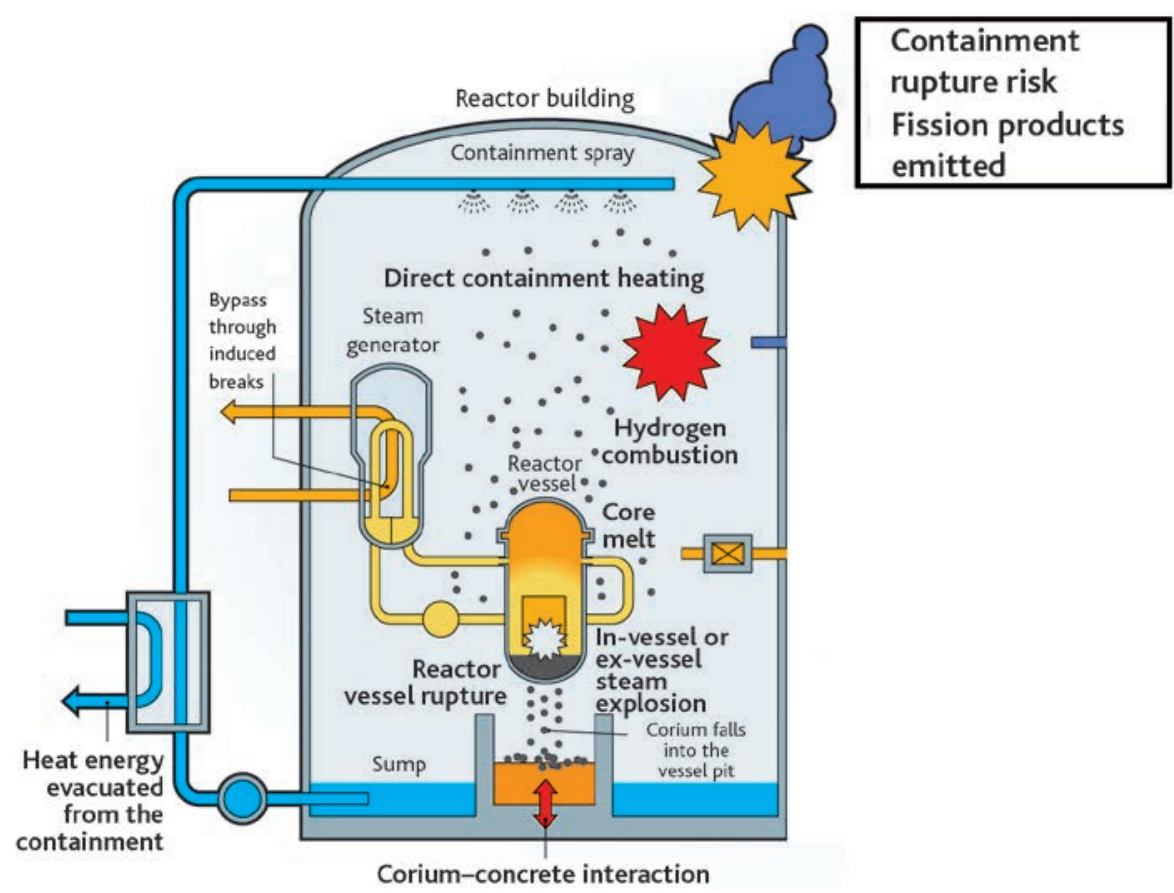

Figure 5.12. Schematic diagram of the physical phenomena occurring during direct heating of the gases in the containment. 
a mixture of steam and hydrogen, some corium in the lower head and possibly some water, all of which is subjected to a pressure ranging from the operating pressure of the RCS (approximately 160 bar) to a pressure close to that of the containment (a few bar) if the RCS is completely depressurised. The corium and the steam, and possibly some hydrogen, are ejected under pressure into the reactor pit in different phases (singlephase liquid corium jet, followed by a two-phase corium and gas jet and a gaseous jet). The characteristics of their ejection, of course, depend on the size, shape and location of the break in the reactor vessel wall. The characteristics of the break are currently difficult to predict and so are uncertain (Section 5.1.3).

When the corium is ejected under pressure, it is fragmented into liquid droplets that rapidly oxidise, producing hydrogen. A flow of steam, hydrogen and corium then forms in the reactor pit. This highly complex flow is greatly influenced by the geometry of the reactor pit. It is also central to the following phenomena: the projection of corium onto the reactor pit walls, the formation of a liquid film along these walls and the entrainment and fragmentation of the film by the gases. All these phenomena increase the pressure of the gases in the reactor pit relative to that of the containment. As a result, part of the corium is entrained by the steam into the areas adjoining the reactor pit and towards the containment dome, while another part remains trapped in the pit. During this phase, the gases and the corium droplets interact both thermally and chemically. The gases' temperature and pressure in the reactor pit therefore increase considerably. Hydrogen combustion is not possible in the reactor pit, however, because its atmosphere contains little oxygen (it was driven out by the gases leaving the reactor vessel). When hot gases and corium particles enter the containment, they contribute to the superheating and rapid pressurisation of its atmosphere. The greater the mass of corium dispersed and the finer its fragmentation, the greater the containment pressure build-up. The distribution of corium in the different areas of the containment and the duration of the flow also play an important role in defining the pressure build-up. Furthermore, when the very hot gases and corium particles enter the containment they provoke hydrogen combustion. This combustion is highly complex because it combines turbulent diffusion flames (in the containment area into which the jet leaving the reactor pit spreads) with premixed flames (in the containment areas outside the jet). In most situations, hydrogen combustion does most to heat up and pressurise the containment gases.

It should be noted that the above description of DCH and its current modelling has been simplified compared with reality for various reasons including the following:

- the presence of water, both in the reactor vessel and in the reactor pit, affects the phenomenon in various ways by creating the opposite effects. The water present in the reactor vessel, which is strongly depressurised when it ruptures, very rapidly vaporises (referred to as "flash vaporisation"). This causes the reactor vessel to depressurise more slowly, on the one hand (increasing the corium dispersion time), and causes a greater thrust upon the reactor vessel, on the other hand. This water does not entirely vaporise, however, and the water present in the reactor pit also disperses and so, firstly, acts as a heat sink and, secondly, disrupts or even inhibits combustion. As a result, it is difficult to know whether the presence of water has a generally beneficial effect or not; 
- as a result of the pressure in the reactor pit, the water can move and so modify the geometric configuration and close flow routes or open others.

Technically, therefore, the problem is very difficult to model precisely.

\subsubsection{Experimental programmes}

The existing knowledge of phenomena involved in DCH has mainly been gained through test programmes conducted on mock-ups, which provide small-scale reproductions of the main geometrical characteristics of reactors. The different geometries studied are presented in the following paragraphs, after which the results of the tests are discussed, based on the temperature and materials used to simulate the corium and the presence of water in the reactor pit.

In the late 1980s and early 1990s, many tests were conducted on more or less detailed mock-ups of American reactors at scales varying from 1/40 to 1/25 [1-4]. The most widely studied and documented geometry is that of the ZION reactor. The link between the reactor pit and the containment dome (through which the gases and corium pass via the annular passage around the reactor vessel) was not represented in the purpose-built mock-up of the Zion reactor in the Sandia National Laboratory's Surtsey facility in the United States (Figure 5.13). An instrumentation tunnel represented the connections between the reactor pit and the intermediate compartments of the containment. In addition, the system simulating the reactor vessel was positioned outside the containment. The integral tests were conducted at high pressures (around 60 bar).

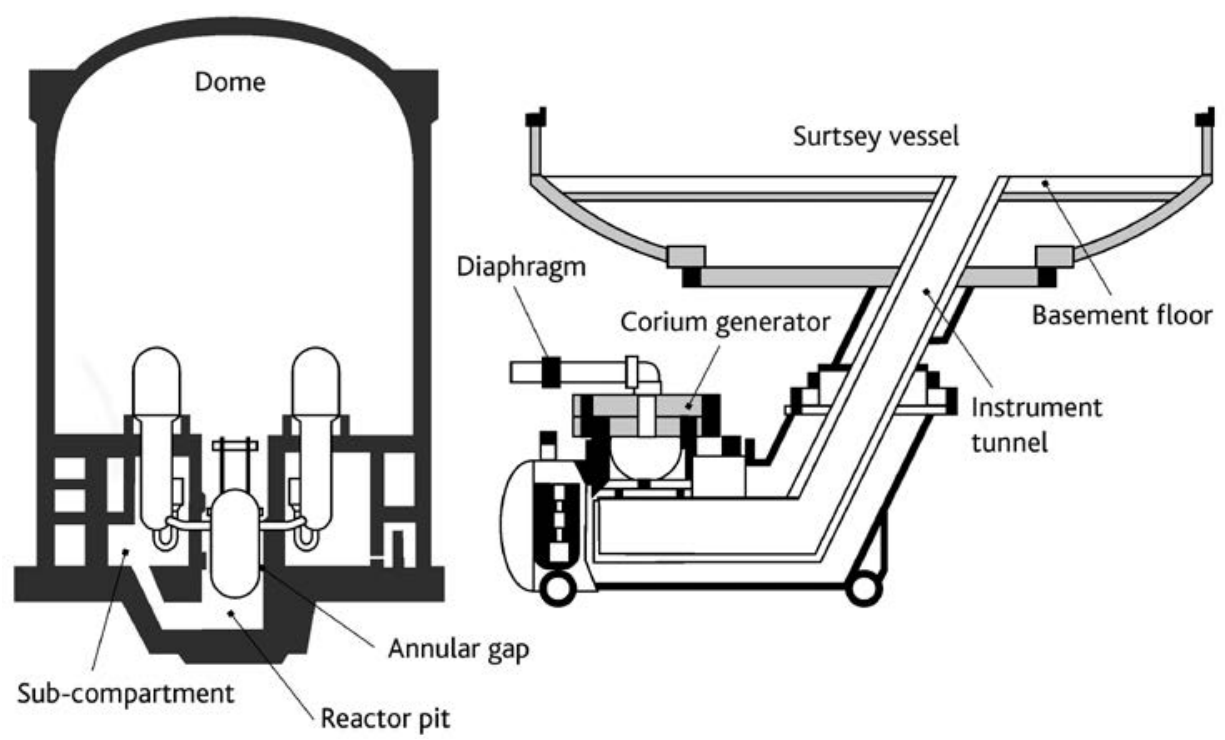

Figure 5.13. Diagram of the Zion reactor (left) and its representation in the experiments conducted in the Sandia National Laboratory's Surtsey facility (right) [1]. 
The second geometry studied was that of the Surry reactor. Some of the corresponding tests took into consideration the annular passage around the reactor vessel, directly linking the reactor pit with the containment dome, and the presence of thermal insulation around the reactor vessel. A limited number of experiments have been conducted with this geometry. Lastly, a third geometry, that of the Calvert Cliffs reactor, was studied; in this geometry, there is a larger annular passage around the reactor vessel, whose configuration is more like that of the French reactors.

In 1997, KAERI (South Korea) conducted a test campaign for IRSN (IPSN at that time). These tests were the first to study the $\mathrm{DCH}$ phenomenon, albeit solely in cold tests, in a geometry similar to that of a French $900 \mathrm{MWe}$ reactor at a 1/20 scale.

More recently, tests were conducted in the DISCO facilities of Forschungszentrum Karlsruhe (FzK), now called Karlsruhe Institut für Technologie (KIT), in Germany [5, 7]. The initial test facilities, referred to as DISCO-C, were used to conduct cold tests, whereas another, referred to as DISCO-H, was used to conduct integral tests simulating all of the thermal and chemical phenomena. The DISCO facilities, which were initially constructed for studies on the PWR reactor (1:18 scale), were then modified so that the geometry of the 1300 MWe P' 4 reactors could be studied (in collaboration with IPSN, Figure 5.14), for that of the KONVOI reactors (German reactors whose geometry is similar to that of the PWRs) and for that of the VVER-1000 reactors (a single test in DISCO-H). The PWR and KONVOI geometries are unusual as their reactor pit is very small, encouraging corium dispersion outside the reactor pit, particularly as there is no access corridor; in the case of the $900 \mathrm{MWe}$ and $1300 \mathrm{MWe}$ French reactors (Figure 5.14), the reactor pit is much deeper and there are three possible exit routes from the reactor pit: to the upper part of the containment (dome), to the compartments at the bottom of the containment and to the reactor pit access corridor. The DISCO tests were limited to reactor vessel internal pressures below 25 bar.

\section{Low-temperature simulant tests (dynamic aspects)}

These tests aim to establish correlations relating to the entrainment of the simulant to the compartments adjacent to the reactor pit and to the containment based on experimental parameters, which generally consist of the size of the break in the lower head, the internal pressure of the reactor vessel when it ruptures, and the physical properties of the corium simulant and of the carrier gas leaving the reactor vessel. Various simulants have been used for the tests of this type: water (Figure 5.14), oils, Wood metal (a eutectic alloy composed of bismuth, lead, tin and cadmium) and gallium. The latter two simulants offer the advantage of possessing properties (density, viscosity and surface tension) that are similar to those of corium, whereas water is a poor simulant (its physical properties are very different from those of corium, and its phase changes evaporation or freezing - are unrepresentative of it).

The KAERI tests, whose geometry is representative of that of the $900 \mathrm{MWe}$ French reactors, have shown that when the internal pressure of the reactor vessel is high enough, up to $80 \%$ of the simulant can be entrained into the annular space around the reactor vessel and into the passage towards the containment dome, and then released 


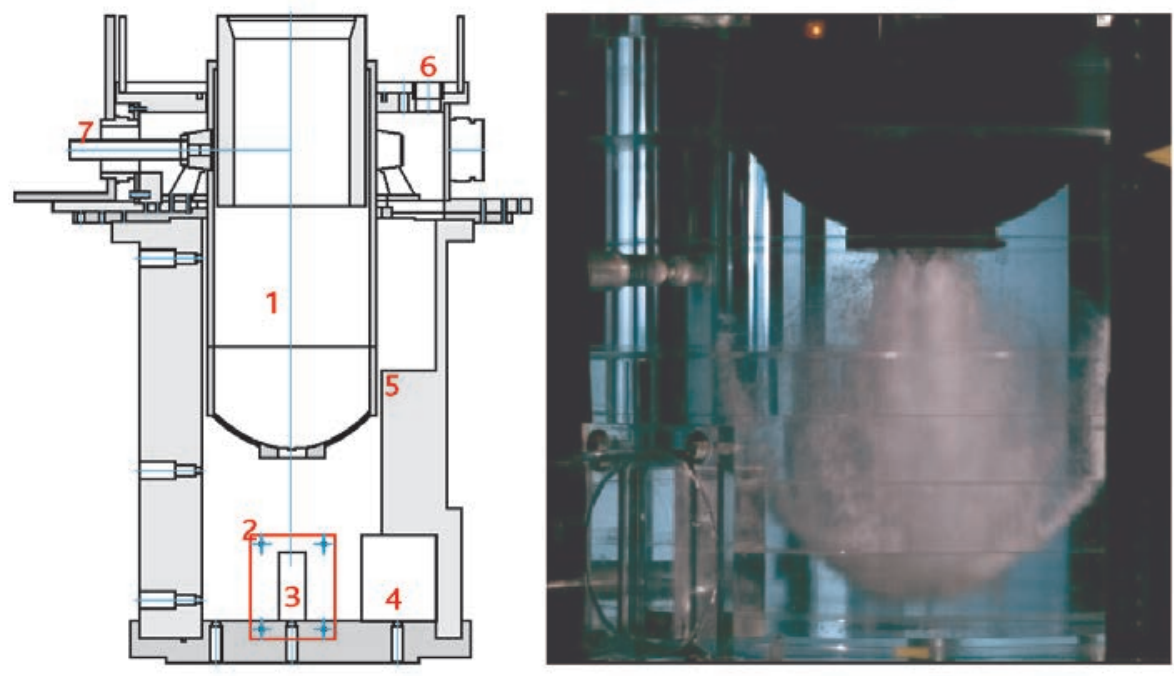

Figure 5.14. Representation of the reactor pit geometry of a P'4 reactor for the DISCO-C tests: 1-reactor vessel, 2-reactor pit, 3-reactor pit access corridor, 4-niche, 5-annular passage, 6-exit to the containment dome, 7 -exit to the intermediate compartments of the containment. Right: photograph of a high-pressure water ejection.

into the containment. In this geometry, the passage to the intermediate compartments of the containment is in fact very small and most of the fuel is ejected into the containment. In the case of the 1300 MWe reactors, a smaller fraction of the fuel is dispersed into the annulus $(60 \%)$, as a substantial proportion of the fuel $(-30 \%)$ is trapped in the reactor pit access corridor. Of the $60 \%$, approximately $20 \%$ is directly entrained towards the containment dome and the rest is entrained into the intermediate compartments of the containment.

The geometry of the EPR reactor pit is very different. Due to the very small volume of the reactor pit, almost all of the corium may be drawn into the containment even if the internal pressure of the reactor vessel is very low (a few bar). The geometry of the EPR reactor pit has changed since the DISCO tests were conducted on EPRs and no longer includes a direct passage between the reactor pit and the containment; most of the ejected corium would then be entrained towards the intermediate compartments of the containment housing the equipment (SGs and pressuriser). The effect of various lower head rupture modes (break in the centre of the lower head, lateral break or partial de-capping of the lower head) upon simulant ejection dynamics has also been studied in tests on EPR geometries [6]; these tests have shown that greater masses are dispersed in the case of central breaks.

\section{- High-temperature integral tests}

In addition to the dynamic aspects, these tests provide an insight into heat exchange phenomena and chemical interactions. Table 5.3 lists all integral tests conducted until 2010. The most frequently-used simulant in tests of this type consists of an iron and alumina 
mixture $\left(\mathrm{Al}_{2} \mathrm{O}_{3}\right)$ resulting from a thermitic reaction ${ }^{5}$, with small quantities of chrome and zirconium sometimes added. Some tests have also been conducted using a composition more similar to that of an actual corium (containing a $\mathrm{UO}_{2}+\mathrm{ZrO}_{2}$ mixture). The main differences between thermite $\left(\mathrm{Fe}-\mathrm{Al}_{2} \mathrm{O}_{3}\right)$ and corium are their density (approximately $4000 \mathrm{~kg} / \mathrm{m}^{3}$, compared with $8000 \mathrm{~kg} / \mathrm{m}^{3}$ ) and their oxidisable metal composition (Fe, compared with $\mathrm{Zr}+\mathrm{Fe}+\mathrm{Cr}$ ). Consequently, the results of the tests conducted using thermite cannot be directly extrapolated to the case of a DCH incident. Many tests have been conducted in the United States, mainly by the Sandia laboratories (SNL) and Argonne laboratories (ANL), for three types of geometry (principally that of the Zion reactor, the Surry reactor and the Calvert Cliffs reactor) and different experimental conditions [1]. These tests were conducted using high reactor vessel pressures between 60 and 120 bar: as a result, dispersion of the simulant and the pressure build-up within the containment were both high.

In the case of Zion reactor geometry, the different tests (conducted using the Surtsey mock-up with no direct connection between the reactor pit and the containment dome ${ }^{6}$ ) showed that the intermediate compartments of the containment retained $90 \%$ of the simulant and that there was a limited containment pressure build-up of approximately 2.5 bar (Figure 5.15). On the basis of these results, the US NRC has estimated that, in the case of this reactor, the risk of the containment rupturing as a result of $\mathrm{DCH}$ was zero [8].

Table 5.3. Main experimental programmes studying DCH.

\begin{tabular}{|c|c|c|c|c|c|c|c|c|}
\hline Series & $\begin{array}{l}\text { Number } \\
\text { of tests }\end{array}$ & Scale & Geometry & $\Delta \mathrm{P}$ (bar) & Material & $\begin{array}{c}\mathrm{D}_{\text {break }}{ }^{(4)} \\
(\mathrm{m})\end{array}$ & $\begin{array}{c}\text { Direct } \\
\text { connection } \\
\text { with dome }\end{array}$ & Water \\
\hline $\mathrm{DCH} / \mathrm{WC}^{(1)}$ & 7 & $1 / 10$ & Zion & $26-67$ & $\mathrm{Fe}-\mathrm{Al}_{2} \mathrm{O}_{3}$ & $0.4-1$ & No & Pit \\
\hline TDS/LFP ${ }^{(1)}$ & 13 & $1 / 10$ & Surry & $25-40$ & $\mathrm{Fe}-\mathrm{Al}_{2} \mathrm{O}_{3}-\mathrm{Cr}$ & $0.4-0.9$ & No & No \\
\hline IET-Zion ${ }^{(1)}$ & 9 & $1 / 10$ & Zion & $60-70$ & $\mathrm{Fe}-\mathrm{Al}_{2} \mathrm{O}_{3}-\mathrm{Cr}$ & 0.4 & No & Pit \\
\hline IET-Surry ${ }^{(1)}$ & 3 & $1 / 6$ & Surry & 120 & $\mathrm{Fe}-\mathrm{Al}_{2} \mathrm{O}_{3}-\mathrm{Cr}$ & $0.7-1$ & $\begin{array}{l}\text { Depending } \\
\text { on the test }\end{array}$ & Pit \\
\hline ANL-IET ${ }^{(2)}$ & 6 & $1 / 40$ & Zion & $57-67$ & $\mathrm{Fe}-\mathrm{Al}_{2} \mathrm{O}_{3}-\mathrm{Cr}$ & 0.4 & No & Pit \\
\hline $\mathrm{U}^{(2)}$ & 3 & $1 / 40$ & Zion & $30-60$ & $\begin{array}{c}\mathrm{UO}_{2}+\mathrm{ZrO}_{2} \\
+\mathrm{Z}_{\mathrm{r}} \text {-stainless } \\
\text { steel }\end{array}$ & 0.4 & No & No \\
\hline $\mathrm{CE}-\mathrm{CES} \mathrm{S}^{(1)}$ & 7 & $1 / 10$ & Calvert Cliffs & $40-80$ & $\mathrm{Fe}-\mathrm{Al}_{2} \mathrm{O}_{3}$ & $0.4-0.5$ & Yes & $\begin{array}{c}\text { Reactor } \\
\text { vessel }\end{array}$ \\
\hline DISCO-H & 6 & $1 / 18$ & EPR & $8-22$ & $\mathrm{Fe}-\mathrm{Al}_{2} \mathrm{O}_{3}$ & $0.5-1$ & $\begin{array}{l}\text { Depending } \\
\text { on the test }\end{array}$ & No \\
\hline DISCO-FH ${ }^{(3)}$ & 5 & $1 / 16$ & $P^{\prime} 4$ & $15-25$ & $\mathrm{Fe}-\mathrm{Al}_{2} \mathrm{O}_{3}$ & $0.5-1$ & Yes & No \\
\hline DISCO-KH ${ }^{(3)}$ & 2 & $1 / 18$ & Konvoi & $20-25$ & $\mathrm{Fe}-\mathrm{Al}_{2} \mathrm{O}_{3}$ & 1 & No & No \\
\hline
\end{tabular}

${ }^{(1)}$ Sandia NL, ${ }^{(2)}$ Argonne NL, ${ }^{(3)} \mathrm{FzK}$, ${ }^{(4)}$ reactor vessel break diameter relative to the scale of the reactor vessels concerned, ${ }^{(5)}$ study of the effect of the thermal insulation, depending on whether it remains in place or not.

5. When an iron oxide and aluminium are brought into contact, a highly exothermic chemical reaction occurs in which the aluminium reduces the iron oxide to produce what is called "thermite", an iron and alumina mixture $\left(\mathrm{Al}_{2} \mathrm{O}_{3}\right)$; the reaction raises the temperature of the mixture, resulting in it melting.

6. In reality, there is a connection between the reactor pit and the dome in the reactor, but this has been ignored. 
The various subsequent tests, including those conducted in the DISCO facility, suggest that when no combustion occurs (due to the inert atmosphere in the containment), the compartmentalisation of the containment plays an important role in $\mathrm{DCH}$ and only the simulant fraction dispersed into the containment dome effectively heats its atmosphere. This is because the thermal equilibrium is reached more rapidly in a small volume, as the ratio between the volume of corium and the volume of gas is greater and so the gases are heated more rapidly.

The chemical phenomena of oxidation and combustion play a key role in DCH. The first tests to study the effect of these phenomena are the IET tests conducted for the Zion and Surry reactors' geometries (in most cases, with no direct connection between the reactor pit and the containment dome). In these tests, there was initially a moderate hydrogen concentration of approximately $2-3 \%$ in the containment. The metals were always very intensely oxidised. Hydrogen combustion rate was around $70 \%$, resulting in the pressure doubling or tripling within the containment (Figure 5.15, left).

The DISCO-H tests confirmed these experimental findings [7]. They also showed that the oxidation not only occurs with the steam initially present in the reactor vessel, but also with the steam present in the containment (this could not be observed in the IET tests conducted with no direct connection between the reactor pit and the containment dome). Hydrogen combustion rate is very high in these tests - around $80 \%$ for initial hydrogen levels of $4.5-6 \%$. Above all, they showed that there is a linear relationship between the pressure build-up in the containment and the estimated quantity of hydrogen contributing to combustion (Figure 5.15, right). If there is considerable hydrogen combustion, therefore, the heat transfers between the corium and the gas play a smaller
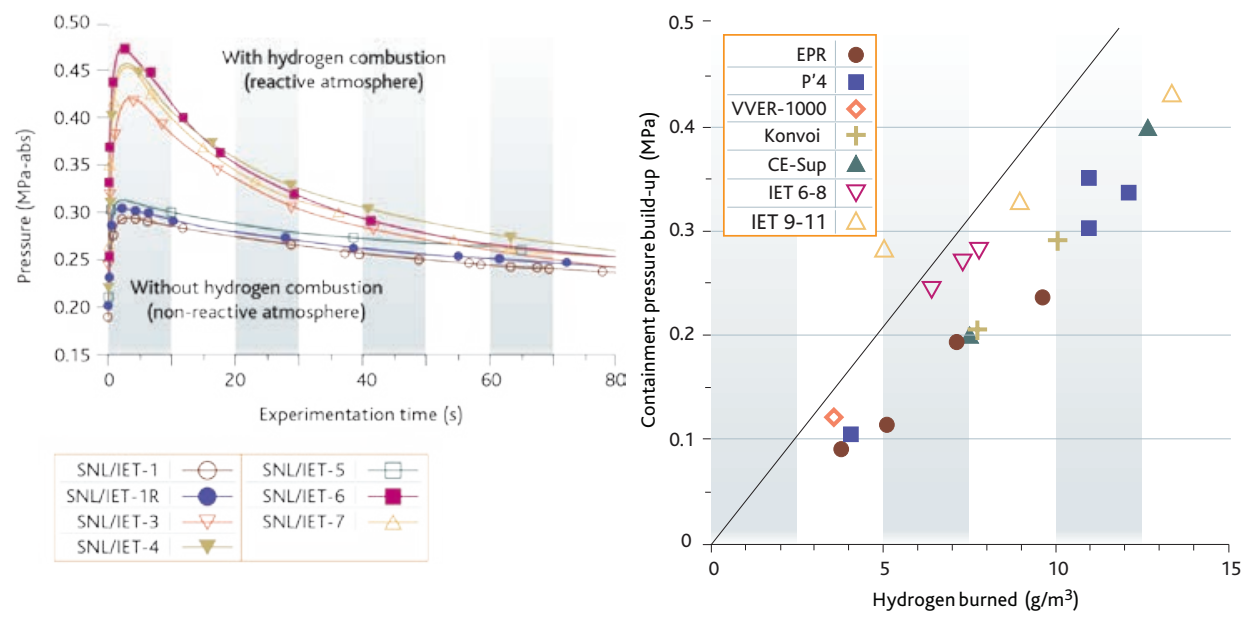

Figure 5.15. Influence of combustion upon the pressure build-up in the containment. Left: comparison of the pressure build-up observed for an atmosphere with and without hydrogen combustion in the IET-Zion tests (Sandia NL) [1]. Right: relationship between the pressure build-up and the estimated quantity of burnt hydrogen (per unit of volume) for a selection of DISCO (FzK), CE and IET tests (Sandia, IET6-8: Zion geometry, IET9-11: Surry geometry) [7]. The line represents the theoretical envelope values of the pressure build-up linked with hydrogen combustion. 
role in $\mathrm{DCH}$. This can be explained by the fact that the gas heating up due to combustion limits the thermal transfers between the corium droplets and the gas.

In addition, the DISCO tests conducted using the geometries of the PWR and $1300 \mathrm{MWe}$ reactors show that the effect of compartmentalising the containment is less marked if combustion occurs. The combustion itself is less sensitive to compartmentalisation with high hydrogen concentrations (5-6\%). When the initial hydrogen concentration is low (less than $3 \%$ ), however, combustion has difficulty in propagating to the regions that the corium has not entered.

\section{Tests with real materials}

Following the IET tests using thermite, three similar tests were conducted using a mixture of $\mathrm{UO}_{2}, \mathrm{Zr}, \mathrm{ZrO}_{2}, \mathrm{Fe}$ and $\mathrm{Cr}$ in the COREXIT facility (1/40 scale mock-up of the Zion reactor) in order to demonstrate the effect of using real materials in place of thermite [2]. Very little data is therefore available on tests using real materials, and only very partial conclusions can be drawn from these tests.

Two tests were conducted using an almost inert containment atmosphere, eliminating all hydrogen combustion as a result; corium oxidation was possible, however, as the reactor vessel had a high steam content. For these two tests without combustion, which were conducted using a material whose specific energy is lower than that of thermite (approximately $1.2 \mathrm{MJ} / \mathrm{kg}$, in the case of actual corium, instead of $2.7 \mathrm{MJ} / \mathrm{kg}$ for thermite), the pressure build-up in the containment dome was lower than in the tests conducted under similar conditions using thermite. The production of hydrogen due to oxidation of the materials by steam was much greater for corium, with corium oxidation of around $70 \%$, compared with only $30-40 \%$ for thermite. This strong oxidation is mainly due to oxidation of the metals of which the corium is composed. Uranium dioxide $\left(\mathrm{UO}_{2}\right)$ can also be "superoxidised" by steam if enough is present; this "superoxidation" is probably limited, however, and produces little hydrogen.

In these two tests, it is also probable that corium oxidation was limited by the quantity of steam contained in the reactor vessel, which was insufficient to oxidise all of the oxidisable component materials of the corium. These tests therefore show that very high corium oxidation can occur for coriums whose compositions are representative of those that would form in a PWR core melt accident. For power reactors, a conservative approach to processing DCH consists in supposing that all the metals in the corium are completely oxidised when they are dispersed and ignoring uranium dioxide oxidation.

\section{- Effects of the presence of water}

The effect of water being present when the reactor vessel ruptures, either in the reactor vessel or in the reactor pit, has also been studied in the United States. The small number of tests conducted, coupled with the lack of even simplified models, only allows qualitative interpretations to be made, however. In the CE-CES tests (Calvert Cliffs reactor geometry, [4]), the corium simulant was initially in the bottom of the reactor pit, and water or steam that had previously been pressurised to between 40 
and 80 bar was ejected from the reactor vessel through a break $4 \mathrm{~cm}$ in diameter (corresponding to a $40 \mathrm{~cm}$ diameter when scaled up to the real size of the reactor vessel). When the water was initially saturated (and so flash-vaporised on leaving the reactor vessel), this was not seen to have a significant influence upon the pressure build-up in the containment; the pressure build-up due to the water vaporising was therefore offset by a reduction in the effects of combustion and oxidation (approximately $30 \%$ ). When the water temperature was close to the ambient temperature (meaning that the water did not vaporise on depressurisation), a significant drop (of around 30\%) in the pressure loads was seen. In the CE-CES tests in which water was present in the reactor vessel, approximately $60 \%$ of the simulant was entrained towards the containment dome through the annular space.

Several tests were conducted by adding a small quantity of water in the reactor pit (the WC and IET tests). Some IET-Zion tests were also conducted using various quantities of water in the reactor pit. In these tests, the pressure build-ups were similar to those observed in tests with no water in the reactor pit; the presence of water therefore does not seem to have any overall effect upon the pressure build-up. The temperature measurements established that $50 \%$ less hydrogen was burned up than when there was no water in the reactor pit; in this case, therefore, the pressure build-up is largely due to water vaporisation. As a result, the presence of water has a very considerable effect upon the phenomena occurring in $\mathrm{DCH}$ and so could affect the pressure build-up under conditions different from those of the test. The current studies are based on the experimental results, however, and, as no adequate modelling is available, ignore the effect of the presence of water.

The presence of water in the reactor vessel or reactor pit seems fairly beneficial to $\mathrm{DCH}$ by limiting hydrogen combustion, although this must be confirmed by more detailed studies. When water is present, however, a steam explosion resulting from the interaction between the fragmented corium and the water may occur. Considering the measures taken to limit the possibility of high-pressure corium ejection in the event of a power reactor core melt accident (consisting of intentionally depressurising the RCS, see Section 4.3.3.3) and, therefore, the possibility of DCH occurring, conducting steam explosion studies is considered a priority in terms of risk mitigation.

The Sandia laboratories in the United States have conducted experiments in which molten corium was ejected at high pressure in a 1:10 scale mock-up of a flooded reactor pit (SPIT/HIPS experiments) [15]. In every case, a steam explosion destroyed the reactor pit in the tests. Details of the research results regarding the steam explosion are provided in Section 5.2.3.

\subsubsection{Modelling}

The complexity of DCH prevents it from being modelled in detail by coupling all of the important phenomena (corium ejection and fragmentation, heat transfers, oxidation of the component materials of the corium, hydrogen combustion and the presence of water). 
Until the middle of the 2000s, the only existing models were constructed from simplified models mainly based on experimental correlations that were themselves implemented in "integral" computer codes used to calculate more or less complete accident sequences (MELCOR, MAAP, CONTAIN, ASTEC, etc.; see Chapter 8). These simplified models are mainly parametric, and their purpose is not to study and precisely understand the phenomena occurring in a $\mathrm{DCH}$ incident. They reflect the state of knowledge of these phenomena and can be coupled to provide a complete, albeit approximate, means of studying the progression of an accident.

For some years, FzK then IRSN have been conducting studies using multiphase, multidimensional simulation codes (the AFDM and MC3D codes, respectively). Unlike the parametric models discussed above, these computer codes represent certain important aspects of $\mathrm{DCH}$ more precisely, notably corium geometry and behaviour at different scales, but they do not represent the coupling of all phenomena. Furthermore, they process the complex chemistry occurring during $\mathrm{DCH}$ in a very simplified form. The AFDM and MC3D computer codes firstly aim to provide the parametric models with more appropriate correlations.

The modellers are now mainly focusing their attention on questions regarding corium dispersion. The experiments conducted show that both the oxidation of corium component materials and the hydrogen combustion are very closely linked with corium dispersion, and the simplified approaches producing envelope estimates of their effects upon the oxidation and combustion pressure do not excessively overestimate the pressures reached.

\subsection{Parametric models}

The DCH module of the US CONTAIN computer code [9] is the most advanced 0-D code available, and offers many computational options. Thus it also highlights the difficulties involved in modelling corium dispersion in $\mathrm{DCH}$, as more than a dozen models or correlations may be used to describe how the corium debris is transported and the flows take place between the compartments of a containment, as well as describing how the structures trap debris.

The DCH module of the CONTAIN code contains relatively mechanistic models for describing how the corium is fragmented and the corium debris is entrained. It assesses the convection and radiant heat transfers between the debris and the atmosphere by means of conventional heat exchange laws. The code processes the chemical reactions involved in corium oxidation as well as in the combustion of hydrogen (both that produced through $\mathrm{DCH}$ and that already existing in the containment). Hydrogen combustion is evaluated by means of a simplified approach. Although the DCH module of the CONTAIN code provides a solid basis for qualification [10], its use is limited to US Zion or Surry reactors (GRS found it difficult to use when interpreting the results of the DISCO tests, which consisted of PWR and P'4 geometries) [11, 12]; this may be due to software complexity (notably its large choice of options) and, therefore, the need for its users to be highly experienced.

The other integral codes used to analyse core melt accidents adopt simpler approaches. The DCH module of the MAAP code, for example, uses correlations (based on the 
geometry) to evaluate the total fraction of the dispersed corium [12]. The corium droplets are assumed to be in dynamic and thermal equilibrium with the gases. The distribution of droplets in the different outlets of the reactor pit then depends on the gas flow rates that the code computes for each outlet. Although this type of modelling can hardly be used to process precisely the geometry (notably that of the outlets) and the flows in the outlets (which depend on their geometry), it nevertheless offers the advantage of being simple.

The ASTEC computer code evaluates the pressure loads due to $\mathrm{DCH}$ by means of the RUPUICUV, CORIUM and CPA modules (see Chapter 8). The reactor pit phenomena are addressed by means of the RUPUICUV module. The CPA thermal-hydraulics module, which is used to compute the gas flows within the containment, cannot directly handle the special DCH phenomena associated with the presence of corium particles (heat transfers from the corium particles to containment gases, and corium oxidation), and an intermediate module - the CORIUM module - serves as an interface and processes corium energy contributions for use by the CPA module itself. The total dispersed fraction of the corium is determined using correlations. IRSN plans to revise the DCH modelling while still maintaining a simplified approach. Notably, it will introduce new correlations deduced from the results of the DISCO tests and the modelling conducted using the MC3D computer code.

\subsection{Simulation software}

IRSN and KIT have chosen to use multiphase thermal-hydraulics simulation codes to improve the state of knowledge of flows during $\mathrm{DCH}$ and simplify the development of simple models [13].

KIT uses the AFDM computer code, which was initially developed for conducting safety studies on fast neutron reactors (FNRs). This is a forerunner of the SIMMER III computer code, to which physical models relating to $\mathrm{DCH}$ have been added in order to simulate the chemical reactions between the metals and the steam or oxygen, for example, or else hydrogen combustion in the containment (parametric simplified model). The code processes gas flow configurations and thermal transfers between the gases and the corium in a comparatively comprehensive way, including the formation of corium films and crusts on the reactor pit cavity walls. Its use is limited to axisymmetrical 2D geometries, however. Promising results have been obtained for interpreting the DISCO tests conducted using the geometries of the EPR and Konvoi reactors; in particular, it has enabled IRSN to perform comparative analyses with the MC3D computer code.

The MC3D code is developed by IRSN and CEA; it is mainly used to evaluate the pressure loads caused by a steam explosion (Section 5.2.3). It can, however, also process many multiphase phenomena including - partially - DCH. This code is distinctive in that it describes the corium in detail: the "droplet field" (dispersed corium) is handled separately from the "jet field" (continuous corium) (see Figure 5.33 in Section 5.2.3, which illustrates this point). A detailed model of corium fragmentation and droplet coalescence allows users to move from one field to another. It includes a corium oxidation model. The MC3D code does not handle combustion, however. As combustion is the main contributor to the pressure build-up in the containment, the studies conducted 
using the MC3D code only address corium dispersion and aim to develop simplified dispersion models for the ASTEC computer code and the probabilistic safety assessments (PSAs). The MC3D code can also be used to perform 3D computations that handle the French reactors' special geometries more precisely. As an example, Figure 5.16 shows a reactor geometry processed using the MC3D computer code (simplified $\mathrm{P}^{\prime} 4$ ) as well as the computed results for corium dispersion in the annulus, as a function of the internal pressure of the reactor vessel.

As well as providing a direct comparison of the computational results at several experimental points, this type of code can be used to study, by means of many computations and fairly coarse meshes, the sensitivity of corium dispersion to parameters such as the internal pressure of the reactor vessel, the gas temperature and the break size. A correlation for processing corium dispersion has therefore been developed on the basis of the DISCO test results. This correlation predicts, for example, that when water is used as the simulant, the threshold pressure (minimum) resulting in dispersion is around 5 bar (see also Figure 5.16). In the case of $\mathrm{P}^{\prime} 4$ reactors, the studies show that, for a reactor vessel break approximately one metre in diameter, the corium dispersion threshold pressure (minimum) is around 20 bar and the pressure above which maximum corium dispersion occurs is around 40 bar. Figure 5.17 shows these results, based on the internal pressure of the reactor vessel for three break diameters (the size of the break is not known precisely; it can vary from a few centimetres to a metre, as described in Section 5.1.3).

It has also been observed, again for the P'4 reactors, that the cross-section of the reactor pit access corridor only affects the maximum quantity of corium dispersed in the containment; the other characteristics such as the dispersion threshold pressure are barely affected. This has been confirmed by additional DISCO experiments.
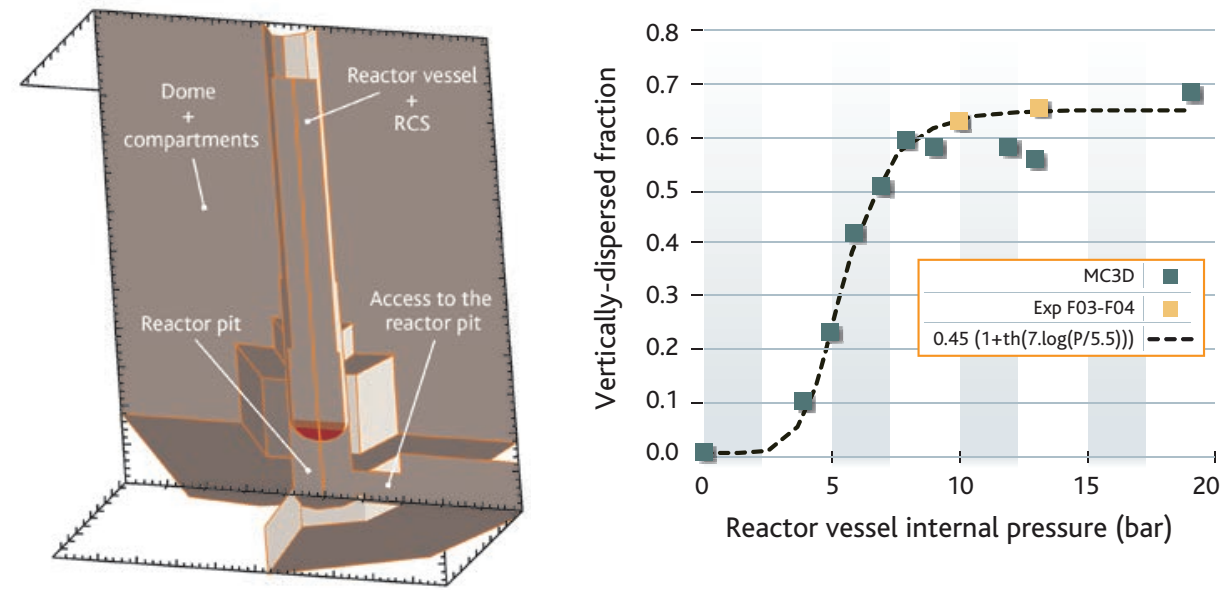

Figure 5.16. Left: 3D geometry used when interpreting the DISCO tests conducted using the geometry of the P'4 reactors (simplified geometry) processed by the MC3D code. Right: MC3D code evaluation of the fuel fraction dispersed towards the top of the reactor pit compared with the results of the tests conducted using water as the simulant and a reactor vessel break diameter of $60 \mathrm{~mm}$. 


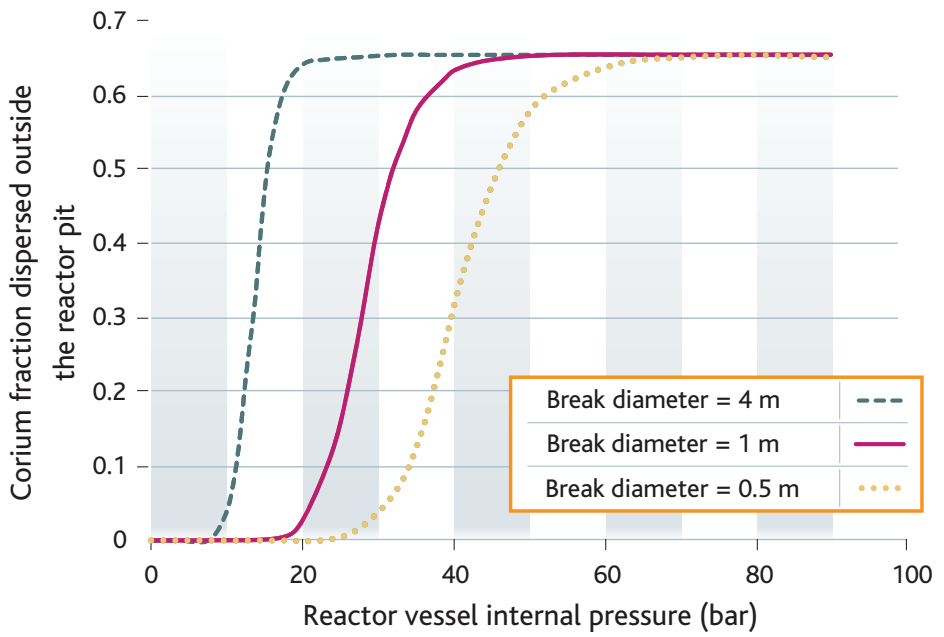

Figure 5.17. IRSN evaluation of corium dispersion outside the reactor pit depending on the internal pressure of the reactor vessel for different break diameters, in the case of $\mathrm{P}^{\prime} 4$ reactors. The $4 \mathrm{~m}$ diameter corresponds to the lower head being torn off.

The great weakness in the existing models concerns hydrogen combustion. The combustion computer codes cannot compute corium dispersion and oxidation; conversely, the MC3D and AFDM codes do not include an adequate combustion model. It appears necessary to model combustion if these computer codes' predictive abilities are to be improved. Work on this point began in 2009 in the European SARNET system, under the supervision of KIT, with the aim of determining the most appropriate models and the way of introducing them into the multiphase simulation codes.

\subsubsection{Summary and outlook}

It is not easy to study the DCH risk. The risk is different for each type of reactor and, for a given geometry, depends on factors including the following:

- the internal pressure of the RCS at the moment the reactor vessel ruptures;

- the size of the break in the reactor vessel;

- the quantity of unrecombined hydrogen still present in the containment and in the RCS when the reactor vessel ruptures;

- the quantity of unoxidised metal in the corium.

The surest way of avoiding or limiting the effect of $\mathrm{DCH}$ upon the containment is to intentionally depressurise the RCS. This is incorporated into the design of PWR and AP1000 reactors. Depressurising the RCS is generally considered to be a key action in PWR safety during operation, notably in the Severe Accident Management Guidelines. Figure 5.17 shows the benefits of depressurising the RCS for the $\mathrm{P}^{\prime} 4$ reactors and undoubtedly more generally, taking into account the uncertainties listed above, for all of the reactors in operation in France. DCH at a reactor vessel internal pressure of less 
than 10 bar seems impossible for these reactors. Depending on the hydrogen concentration present in the containment, the corium melt outside the reactor vessel may result in hydrogen combustion without $\mathrm{DCH}$ in such a situation. The pressure loads on the containment would then only be due to hydrogen combustion.

The experimental data also show that the consequences of $\mathrm{DCH}$ are essentially related to reactor pit geometry and to the routes between it and the other areas of the containment. In particular, it is accepted that the consequences of DCH are reduced in reactors with no direct route for the corium and gases between the reactor pit and the containment dome; this solution has notably been chosen for the PWR reactors.

The combustion of the hydrogen created through oxidation of the corium dispersed by steam and of any initially present in the reactor vessel as well as in the containment atmosphere appears to be the main phenomenon responsible for building up the pressure in the containment. A detailed knowledge of the constituent metals of the corium as well as of the hydrogen quantities present in the containment and in the reactor vessel is needed to be able to evaluate precisely this pressure build-up. In situations in which there is considerable corium dispersion (dispersion of 30-50 tonnes of liquid corium; depending on the envisaged core melt accident scenarios, 100 tonnes or corium or even more may be dispersed), the studies conducted by IRSN show that containment mechanical strength limits may be reached during the resulting hydrogen combustion.

DCH is difficult to model. This is because the complexity and diversity of the phenomena involved in $\mathrm{DCH}$, coupled with their dependence upon reactor building geometry, do not lend themselves to simple modelling. Parametric studies have been developed and used to conduct studies to estimate the pressure build-up in the containment during $\mathrm{DCH}$, but their usefulness is highly doubtful outside their precise fields of validation (notably concerning the geometry of the reactor pit and the adjoining compartments). Multi-phase simulation codes have been used to obtain important results, notably concerning corium dispersion depending on the internal pressure of the reactor vessel. These are also difficult to use, however, and they cannot precisely determine all consequences of DCH in 2015, notably because of the difficulties of modelling corium oxidation and particularly, hydrogen combustion. In addition, the meshes used to process the complex real geometries are quite crude, and some geometric details cannot be modelled without simplification, resulting in inaccuracies in the flow computation.

The impact of water present in the reactor vessel or in the reactor pit during $\mathrm{DCH}$ has not really been characterised either. A better knowledge of this effect is necessary, but this can only be achieved by developing models coupled in a simulation code such as MC3D.

It appears necessary to use more precise simulation codes to compensate for the lack of experimental results (notably using real materials) and the limitations of the correlations developed on the basis of the existing results as well as to allow the results to be extrapolated to the case of a power reactor; this is why IRSN began development to improve DCH modelling for the French nuclear reactors in the middle of the 2000 s. 


\subsubsection{Hydrogen risks and means of mitigating their consequences}

\subsubsection{Introduction}

In the context of core melt accident studies on pressurised water reactors (PWRs), "hydrogen risk" is defined as the possibility of containment integrity being lost in a reactor or its safety systems as a result of hydrogen combustion. The hydrogen is principally produced through oxidation of the metals present in the reactor core (mainly the zirconium contained in the cladding of the fuel elements) during the core degradation phase (Section 5.1.1), and oxidation of the metals present in the corium pool or in the basemat during the molten corium-concrete interaction phase (Section 5.3). The hydrogen produced in this way is released into the containment. The hydrogen distribution in the containment is more or less homogeneous depending on the degree to which the atmosphere is mixed (this is mainly linked with the convection loops resulting from steam condensation within the containment). If it is heterogeneous, there may be local hydrogen concentrations that exceed the flammability limit of the gaseous mixture; if it ignites, this may result in pressure loads that can threaten containment or safety component integrity. The distribution and concentration of hydrogen within the containment may also be modified by the use of safety systems, such as the Containment Spray System (CSS), which homogenise the containment atmosphere and lead to an increase in hydrogen concentration due to steam condensation on water droplets. Moreover, systems such as recombiners and igniters already installed inside the reactor containments may affect hydrogen distribution by avoiding hydrogen building up in part or all of the structure (the PWRs in operation in France are only equipped with recombiners).

\subsubsection{Physical phenomena}

When a PWR core melt accident occurs, the hydrogen released from the RCS enters the containment atmosphere, which initially mainly consists of air and steam. In this atmosphere, convection movements are caused by the presence of steam and its condensation on cold surfaces. The hydrogen then plays a role in increasing the natural convection movements due to its low density and in reducing steam condensation on the walls by hindering steam diffusion. Convection within the containment may therefore be altered, and it is important to know whether the entire contained volume is set into movement as a result. If it is, the hydrogen and the air mix rapidly enough for it to be assumed that, outside the regions in which the gases are released and near to the walls, the atmosphere is homogeneous. Otherwise, only part of the contained volume - probably the upper part of the containment - is mixed, and the homogeneity of that part of the containment atmosphere is initially concerned; if its volume is small, that part can contain a gas mixture that is relatively rich in hydrogen. The hydrogen will then migrate more slowly (over the course of several hours, given the containment geometry and compartmentalisation) to the "dead" regions, which are probably in its lower part. In these regions, the hydrogen will be incorporated into the gas mixture, but the hydrogen level of the mixture will never exceed that found in the homogeneous region. 
The flammability of the gas mixture in the containment depends on the temperature, pressure and composition of the mixture, as well as its ignition mode. In practice, however, the position of the point representing the composition of the mixture (hydrogen, air and steam) in the Shapiro diagram (see Figure 5.18) can be used to determine whether the mixture is flammable. In this diagram, the ignition and detonation regions are bounded by curves: the flammability limit curve bounds the flammability region, and the detonation limit curve bounds the detonation region. The detonation region, which is smaller, is within the flammability region. The flammability and detonation limits depend on the temperature and pressure; furthermore, the detonation limit is not an intrinsic characteristic of the gas mixture; it is only valid for the geometry in which it is obtained.

In a mixture flammable, combustion may be triggered by an energy source of a few millijoules. Consequently, in the presence of electrical power sources or hot points, it seems probable that ignition would occur rapidly once the gas mixture enters the flammability domain. In contrast, more energy (at least 100 kilojoules) is required to trigger a stable detonation. This explains why direct detonation can be ruled out for practical purposes; the only mechanism considered likely to provoke detonation is flame acceleration and the deflagration-to-detonation transition. In fact, due to hydrodynamic instabilities and turbulence (primarily caused by obstacles in the path of the flame), an initially laminar deflagration (with a flame velocity of around $1 \mathrm{~m} / \mathrm{s}$ ) may accelerate. Rapid combustion conditions may also develop, involving rapid deflagration (a few hundred $\mathrm{m} / \mathrm{s}$ ), deflagration-to-detonation transition (DDT) and detonation (over $1000 \mathrm{~m} / \mathrm{s}$ ). These explosive phenomena pose the biggest threat to the mechanical integrity of the containment walls, as they can produce very large, localised dynamic loads. The higher the combustion speed, the higher the pressure peak, albeit with a shorter peak application time.

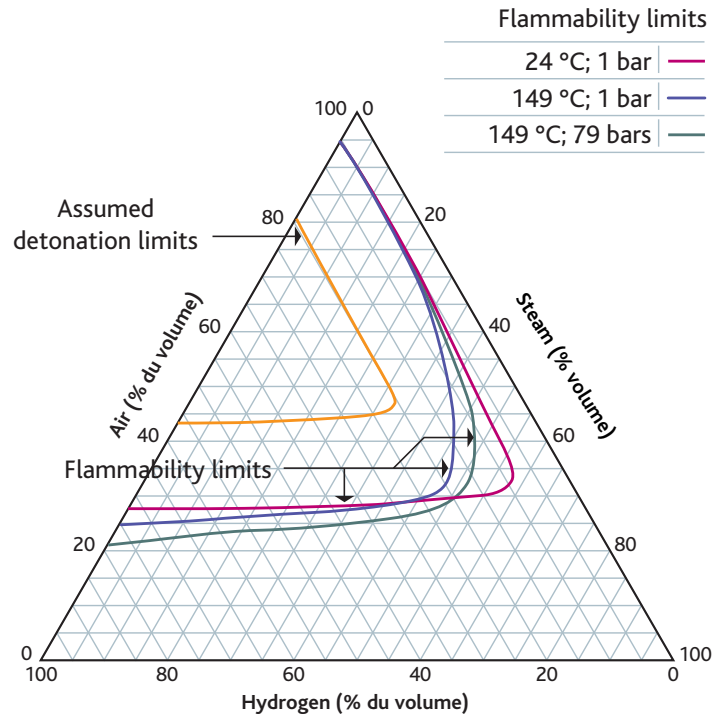

Figure 5.18. Shapiro diagram for the hydrogen, air and steam mixtures. 
Due to the large volume and geometric complexity (mainly due to its compartmentalisation) of the containment, it is currently not possible to perform predictive computations concerning flame acceleration. Based on their understanding of the mechanisms involved, researchers have nevertheless developed prerequisite criteria, i.e. conditions required for the various combustion modes. Two types of criteria have been defined in this way:

- the criterion " $\sigma$ " concerns the flame acceleration; the value $\sigma$ is the expansion factor of the mixture, the relationship between the cold gas and burnt gas densities at a constant pressure, and so is an intrinsic property of the mixture in question; the critical value $\sigma^{*}$ above which flame acceleration is possible depends on the initial temperature of the gases and the stability of the flame and has been determined using the results of many experiments at different scales and in different geometries;

- similarly, the necessary conditions have been established for assessing the possibility of a deflagration-to-detonation transition (DDT); these are based on comparing a length typical of the geometry of the studied chamber with the size of the detonation cells (marked $\lambda$ ) characterising the sensitivity of the mixture.

These criteria were initially established for homogeneous gas mixtures and then extended to cover mixtures in which there are hydrogen concentration variations, on the basis of ENACCEF programme results (Section 5.2.2.3.2). These criteria are used to determine the situations presenting a rupture risk to the containment for which it appears necessary to compute the loads resulting from possible combustion, by studying the hydrogen distribution in the containment (taking into account its geometry). It should be noted that before these criteria can be applied, the codes used to compute the hydrogen distribution in the containment must be validated based on situations representative of core melt accident conditions; this has been the aim of experimental programmes on hydrogen distribution in recent years.

\subsubsection{Experimental programmes}

\subsection{Hydrogen distribution}

Hydrogen distribution in the containment is controlled by various coupled complex physical phenomena, such as:

- the flows in the release region and the transporting of gases in the containment, notably hydrogen and steam;

- natural convection induced by temperature differences between the atmosphere and the walls and by density differences between the various gases present;

- steam condensation on the containment walls and internal structures;

- heat and mass stratification of the gases;

- diffusion in flows and turbulence;

- the effect of spray droplets on flows or of steam condensation on spray droplets. 
Many analytical experiments have studied these phenomena separately. Regarding condensation, for example, the Dehbi experiments [31] on natural convection, together with those of Tagami, Uchida and Huhtiniemi [32] on forced convection, have enabled global models for steam condensation to be developed. The resulting correlations are more or less dependent on the test conditions and geometry, however. As the various phenomena governing hydrogen distribution are strongly coupled, large-scale global experiments have been conducted in addition to the analytical tests. A state-of-theart report sponsored by EOCD on containment thermal-hydraulics and hydrogen distribution was completed in 1999 by a group of international experts (including IRSN experts) [16]. It provides a description of all of the experiments (HEDL, HDR, BMC and NUPEC) conducted since the beginning of the 1980s. In most cases, they consist of largescale global experiments using limited instrumentation and an imprecise knowledge of the boundary conditions, meaning that they can only be used to validate OD computer codes and are unsuitable for validating multidimensional codes.

To overcome the lack of data, well-equipped new facilities were constructed at the beginning of the 2000 s to validate the multidimensional, multi-compartment computational tools. These include the PANDA, THAI, TOSQAN and MISTRA facilities (Figures 5.18, 5.19, 5.20 and 5.21).

\section{PANDA facility programme}

The PANDA facility at the Paul Scherrer Institute in Switzerland was initially designed for studying containment thermal-hydraulics in boiling-water reactors (BWRs). It consists of four interconnected compartments with a total volume of $460 \mathrm{~m}^{3}$ [28].

As part of the OECD SETH (SESAR Thermal-Hydraulics) project between 2004 and 2006 , tests were conducted (mostly without condensation) on a test facility mainly

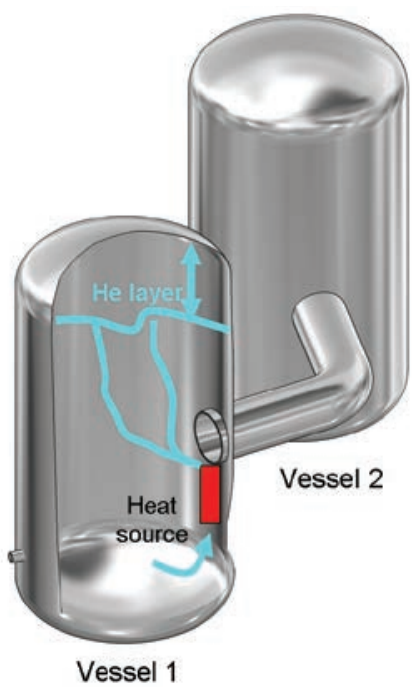

Figure 5.19. Diagram of the PANDA facility. 
consisting of two compartments with a total volume of $180 \mathrm{~m}^{3}$, using instrumentation specially designed to accurately measure the flows in order to validate the multidimensional codes. The test grid for this project concerned flows resulting from a lateral or central injection of steam or helium, gas jet interaction with the containment wall within the injection region, and the impact upon gas distribution of an opening between the two compartments in the upper part of the containment and those in its lower part. The PANDA facility offers the possibility of studying complex flows; the lack of control over the temperature of the facility walls prevents the condensation phenomenon from being precisely characterised, however.

More recently, a new experimental programme, OECD/SETHII [35], was conducted in the PANDA and MISTRA facilities to obtain additional data on transient flows under conditions that could result in the homogenisation of an initially-stratified environment. Various configurations covering the effect of hydrogen recombiner use and the spraying or injection of steam at different flow rates upon the elimination of previous hydrogen stratification were studied as a result.

\section{THAI programme}

Becker Technology's THAl facility in Germany is dedicated to analysing phenomena associated with the "hydrogen risk", iodine chemistry, and the transport and deposition of aerosols in PWR containments.

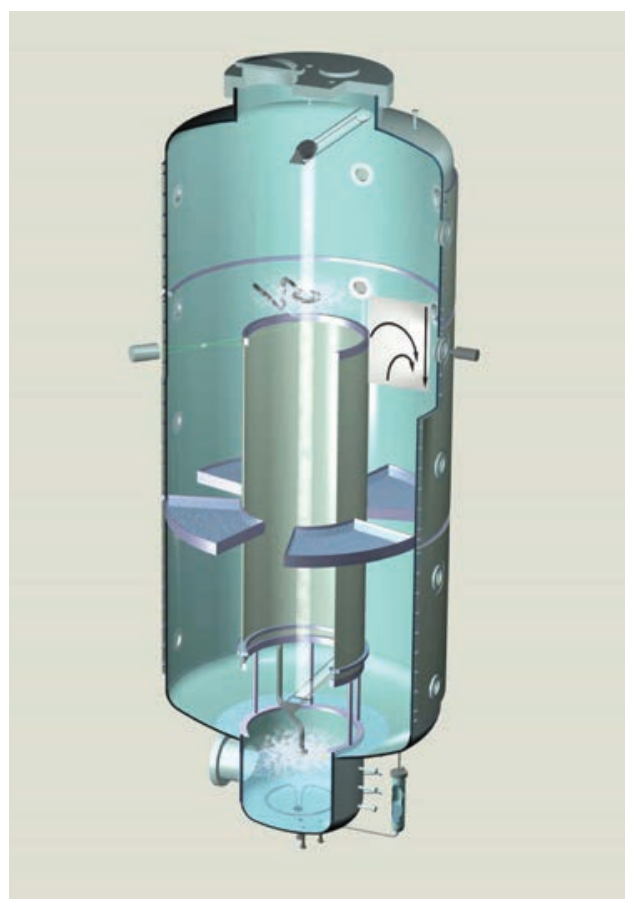

Figure 5.20. Diagram of the THAI facility [36]. 
The $60 \mathrm{~m}^{3}$ containment has a multi-compartmented internal structure with thermally-insulated external walls. With regard to the hydrogen risk, the THAl facility is designed for the study of hydrogen distribution and combustion, and the characterisation of catalytic recombiner operation. Between 1999 and 2002, the THAI facility was used to conduct thermal-hydraulics tests, one of which served as the basis of the OECD International Standard Problem (ISP) no. 47, which was completed in 2007 [18]. In this test, stratification of the gas mixture used (air, helium and steam) was created by injecting the helium and steam into the upper part of the containment (vertical injection); a lateral, low-flow-rate steam injection into its lower part could not cause movement throughout the compartmentalised containment atmosphere and so could not homogenise the gas mixture. This unexpected finding has shown the failings of the existing computer codes, which computed containment atmosphere homogenisation, and revealed the need to model flows in the injection regions in greater detail.

As a result, the study of phenomena governing the creation or destabilisation of stratification was continued as part of the OECD/THAI study [36] in order to improve the modelling of hydrogen distribution in a containment in the event of a core melt accident. As we will see later, the purpose of this project was also to study hydrogen combustion, recombiner behaviour and iodine chemistry. The tests conducted in this project also confirmed that the helium spread in the same way as hydrogen in the containment, meaning that it can be used in tests to study hydrogen distribution.

\section{TOSQAN programme}

The TOSQAN facility, which IRSN has set up and operates at its Saclay site, consists of a cylindrical steel vessel with an internal volume of $7 \mathrm{~m}^{3}$ (excluding the sump, the lower part of the containment containing water). The wall temperature of this containment is adjusted, allowing the cold area in which condensation occurs to be delimited. Instrumentation for the gas volume includes equipment for measuring its pressure, temperature, concentration of gas species (by mass spectrometry and spontaneous Raman scattering) and velocity (by laser velocimetry). The water droplets dispersed by the spray system are measured in terms of their size (using imaging), velocity (using laser velocimetry) and temperature (using refractometry). The test programme studies the phenomena of steam condensation, containment spray, condensation and evaporation at the interface between the sump and the containment atmosphere as well as the spraydown of aerosols by aspersion [26].

The condensation tests, one of which served as the basis of ISP47, have been completed; they studied the stabilised conditions (constant steam injection condensation flow rates) with and without helium. In the test on which ISP47 was based, the helium added to the steam injection began to spread homogeneously in the upper part of the facility (above the injection point). This is where the main convection loop is situated. Instability then develops as a result of the fluid heated by the walls in the containment lower areas, curtailing the slow helium enrichment phase there and causing movement throughout the atmosphere, homogenising the mixture as a result. Under steady-state conditions, the atmosphere is homogeneous. 


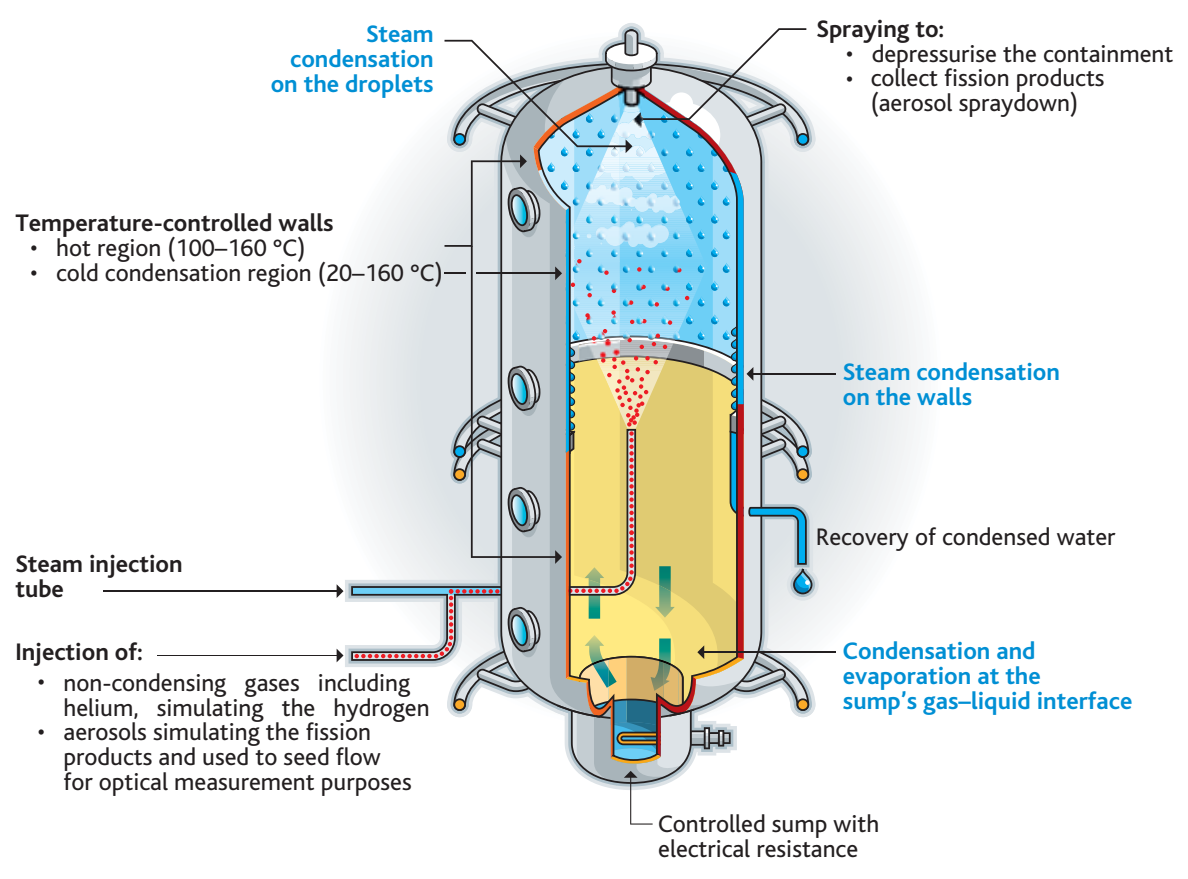

Figure 5.21. Diagram of the TOSQAN facility.

Spraying tests with centred and off-centre spray nozzles have been conducted. In addition, an international comparative study has been organised on the basis of the tests conducted in the European SARNET network. Test campaigns have been also conducted to study the interactions between the containment atmosphere and the sump as well as aerosol spraydown, and their results have been analysed.

\section{MISTRA programme}

The main objective of the CEA MISTRA programme is to study condensation on the walls and on water droplets (from spraying) in a containment that is larger than that of TOSQAN and may contain compartments [27]. To be exact, the MISTRA facility consists of a $100 \mathrm{~m}^{3}$ stainless-steel containment (diameter $4.25 \mathrm{~m}$; height $7 \mathrm{~m}$ ) that is thermally-insulated and has three temperature-controlled internal condensing surfaces. The instrumentation used includes equipment for measuring pressure, temperature, gas concentration and flow velocities (using laser Doppler anemometry). It can be used to qualify multi-compartment and multidimensional computer codes and their coupling.

The condensation tests conducted in the MISTRA facility, one of which served as the basis of ISP47, were carried out under stabilised conditions to reach a balance between the steam injection and condensation rates when steam is injected into the uncompartmentalised or compartmentalised containment from centred and off-centre nozzles. In the test used for ISP47, in which helium was added to the steam injection flux, the helium distribution results were similar to those obtained in the TOSQAN test used for 


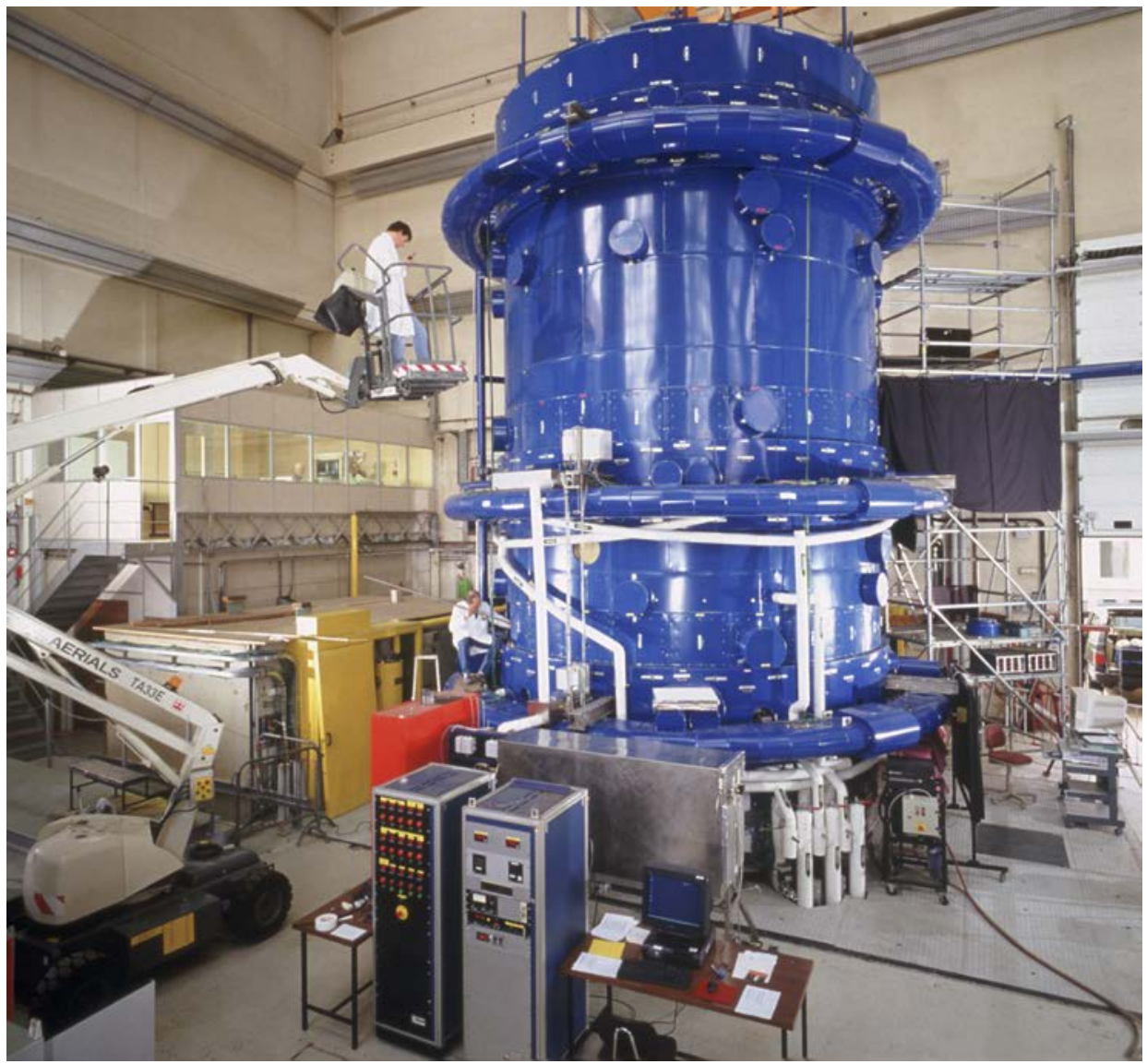

Figure 5.22. Picture of the MISTRA facility (building 452) [reference document PAR-20050629-003, credit: A. Gonin/CEA].

the same ISP. A homogeneous atmosphere was firstly created in the uniform part of the containment under the effect of convection currents; below the helium injection level, the helium concentration slowly increased until the containment atmosphere was completely homogenised in approximately three hours. The overall movement observed in the TOSQAN test described above did not occur because the lower part of the containment was colder than its other parts (in a stable configuration). The TOSQAN and MISTRA test programmes on spraying showed that it was effective in homogenising an initially-stratified gaseous atmosphere. The MISTRA containment is also used in the OECD/SETHII project to study the effect of low-velocity steam injection upon an initially-stratified atmosphere.

IRSN and CEA conducted a study of the effect of scale between the TOSQAN and MISTRA facilities in order to assess the possibility of using the existing computer codes for a PWR building. This study was based on tests for which the initial conditions and the limit conditions were similar, resulting in homogeneous mixtures. This work on 
the heterogeneous gas mixtures is being continued in the European ERCOSAM project (2011-2015). In this project, the study involves tests defined using the results of severe accident scenario computations and conducted in the TOSQAN, MISTRA and PANDA facilities in Switzerland (see above) and SPOT and HYMIX facilities in Russia on volumes ranging between 7 and $1920 \mathrm{~m}^{3}$; it will be used to assess the ability of the models developed and validated on the basis of small-scale tests to predict hydrogen distribution within a power reactor containment [33].

\subsection{Hydrogen combustion}

As for hydrogen distribution in the containment, many experimental programmes have been conducted on flame propagation in a premixed atmosphere containing hydrogen. These tests have two objectives: 1) to characterise the transition between slow and fast conditions and between deflagration and detonation; and 2) to produce a database for validating computer codes. There are two types of tests:

- analytical tests to determine the laminar flames' characteristics and to construct a database for qualifying the different flame conditions;

- dedicated tests for studying turbulent flames with the aim of validating computer codes and establishing criteria for characterising the possible flame conditions.

As was the case for hydrogen distribution in the containment, a state-of-the-art report on flame acceleration and the deflagration-to-detonation transition was produced in 2000 by a group of international experts (including IRSN experts) within the framework of OECD [21]. This report provides a description of the major experiments conducted in the facilities of BMC, NUPEC, VIEW, HTCF, FLAME, RUT, etc. on flame acceleration and the deflagration-to-detonation transition. Criteria for the transition between the different combustion conditions were developed on the basis of the results obtained from the tests conducted in these facilities; these criteria were then refined as part of the European HYCOM programme and the ENACCEF programme (both these programmes are presented later in this document). It also reports on the state of the art in combustion models.

\section{- RUT experimental programme}

The RUT facility, which is operated by the Kurchatov Institute in Russia, has studied the turbulent combustion of hydrogen in a large-scale facility. IRSN and FzK (Germany) have helped to define and finance a set of tests in this facility. The facility, with a total volume of $480 \mathrm{~m}^{3}$ and total length of $62 \mathrm{~m}$, consists of three parts: one channel that is completely rectilinear, a second - shorter - channel that is curved at one end and a "canyon" or cavity in the intermediate area. All three regions have a rectangular crosssection and may possibly be blocked by obstacles.

These geometric characteristics can be used to study both the mono-directional acceleration of a flame produced as a result of hydrogen combustion in the channels and more complex 3D effects or interactions in the "canyon". It is the only facility of its size used to study turbulent hydrogen combustion and thus the only one subjected to 


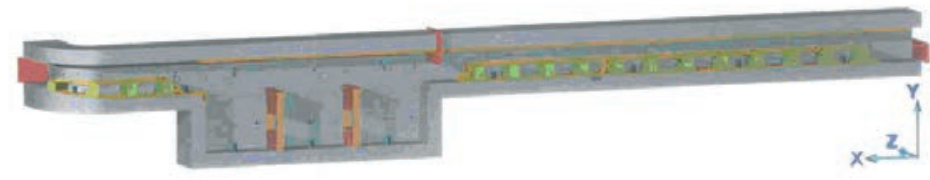

Figure 5.23. Diagram of the RUT facility.

pressure loads that can be transposed to reactor scenarios. The gas mixtures used in the tests, which contained hydrogen, air and possibly steam, are supposed to be representative of the mixtures present in a containment when a core melt accident occurs. The instrumentation is highly suitable for validating CFD computer codes [22].

The various test campaigns have investigated the following combustion conditions:

- slow deflagration, in which flame velocities are below the speed of sound in the case of cool gases and the pressure levels are below the adiabatic isochoric complete combustion (AICC) pressure;

- fast deflagration, in which flame velocities are around the speed of sound in the case of burnt gases and the pressure levels are above the AICC pressure;

- "critical" conditions, in which a deflagration-to-detonation transition (DDT) occurs but the resulting detonation does not spread or is not directly transmitted to the entire mixture;

- stable detonation, in which the detonation forms after a DDT in one region of the facility and in which the velocities and pressure peaks are close to the ChapmanJouguet values $(\mathrm{CJ})$ and propagate to the rest of the fuel mixture.

The objectives of the different programmes conducted in the RUT facility have included the establishment and validation of the criteria $\sigma$ and $\lambda$ (defined in Section 5.2.2.2).

\section{HYCOM European programme}

The European HYCOM programme has been designed to build upon the first tests conducted in the Kurchatov Institute RUT facility in the context of a collaboration between FzK, the US NRC, IRSN and the Kurchatov Institute; its objective is to study flame acceleration in hydrogen-air mixtures and especially to validate the $\sigma$ criterion [25]. The effect of burnt gas expansion (the "piston" effect) and the impact of compartmentalisation were studied using the RUT facility; the impact of venting was studied using the DRIVER and TORPEDO facilities operated by FzK, consisting of cylindrical tubes that are $174 \mathrm{~mm}$ in diameter and $12.2 \mathrm{~m}$ long and $520 \mathrm{~mm}$ in diameter and $12.4 \mathrm{~m}$ long, respectively.

This programme, in which IRSN and EDF participated, also added to the available data on flame acceleration and validated the criteria for special situations in which there are gas mixture richness and containment geometry differences. 


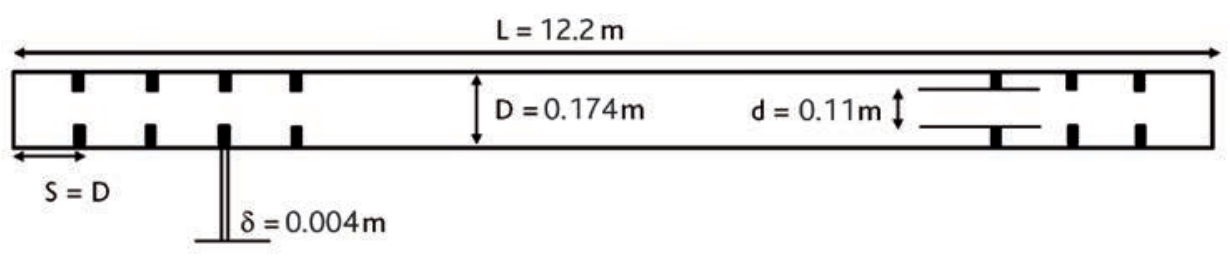

Figure 5.24. Diagram of the DRIVER facility.

\section{ENACCEF programme}

The ENACCEF (flame acceleration containment) programme on flame acceleration was conducted for IRSN by CNRS and, during its initial years, EDF. Its primary goal was to validate the criterion $\sigma$ using tests conducted on a vertical structure representing an SG bunker opening up into the dome [17]. The ENACCEF facility contains an acceleration tube forming the lower part of the containment and an adjustable dome forming the upper part of the containment. The acceleration tube, which was $168.3 \mathrm{~mm}$ in diameter and $3.2 \mathrm{~m}$ high, can be fitted with obstacles of various shapes, resulting in different blockage rates and notably an obstacle simulating an 11.12-litre SG. The adjustable dome volume may be 780.9 litres or 957.8 litres.

The instrumentation used includes photomultiplier and pressure sensors for measuring the progression of the flame front and the pressure generated as a result of hydrogen combustion. In addition, gas sampling points are positioned along the facility's acceleration tube to measure the composition of the gas mixture within the facility. Lastly, laser Doppler velocimetry (LDV) and particle image velocimetry (PIV) are used to determine the velocity field of the gas flow before the combustion flame reaches it. The ENACCEF facility is therefore well equipped with instrumentation and particularly well suited to validating CFD computer codes. It can also be used to study the flames' upward and

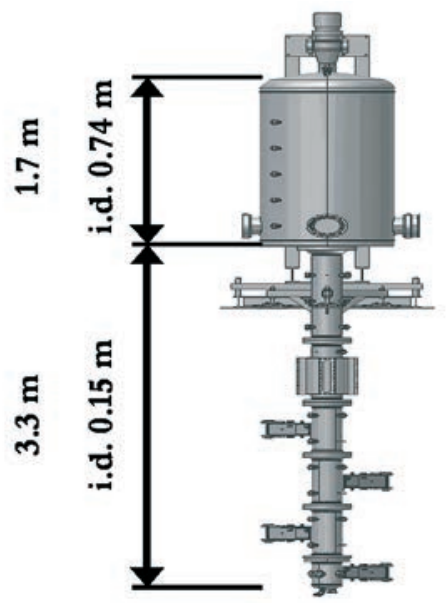

Figure 5.25. Diagram of the ENACCEF facility [17]. 
downward propagation, taking into account the ignition points at the bottom and top of the facility. The effects of dilution by steam simulant gases and of the volume and heterogeneity of the mixture have been studied in addition to those of the ignition position; this has confirmed and improved the criterion $\sigma$ developed in the RUT and HYCOM programmes as well as obtaining data for the validation of CFD computer codes. The ENACCEF facility has also studied the effect upon flame propagation of the presence of water droplets due to spraying. These results showed that under certain conditions, the flames progressed more rapidly when the spray system was activated. This statement had been confirmed by the experiments results performed in framework of the OECD/ THAI II project (2011-2014).

Some tests were also conducted in the ENACCEF facility and serve(d) as the basis for the international comparative exercises organised within the European SARNET network and the OECD International Standard Problem no. 49 [34].

\subsection{Means of reducing the hydrogen risk}

Catalytic hydrogen recombiners (see Figure 5.26) have been set up in the French PWRs' containments to reduce their hydrogen content in the event of a core melt accident. They are usually constructed from a catalytic material (platinum or palladium on an alumina mounting) and housed in a metallic casing whose purpose is to enable the gases to circulate inside the catalyser (consisting of a bed of beads or a row of vertical plates). On contact with the catalytic recombiner plates, the hydrogen and oxygen present in the containment atmosphere react to produce steam.

Many test programmes, most of which were conducted by the recombiners' manufacturers (SIEMENS, AECL, etc.) [20], have studied the behaviour of the recombiners in the event of a core melt accident in order to evaluate their recombinatory capacity.

The H2PAR programme, conducted by IRSN at its Cadarache facilities with financial support from EDF, was mainly intended to investigate the behaviour of the catalytic hydrogen recombiners [19] in an atmosphere representative of that found in the

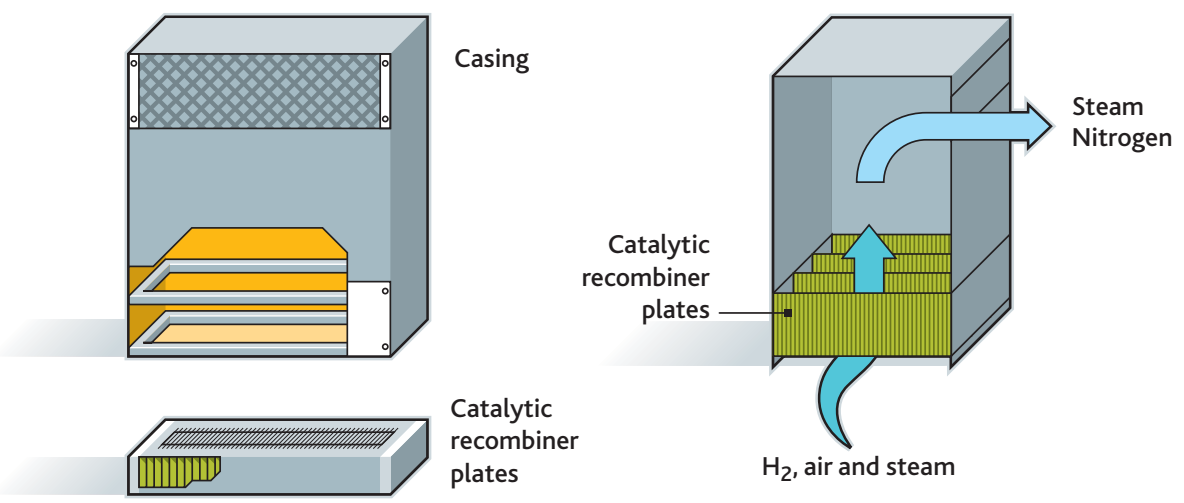

Figure 5.26. Block diagram of a passive catalytic hydrogen recombiner. 


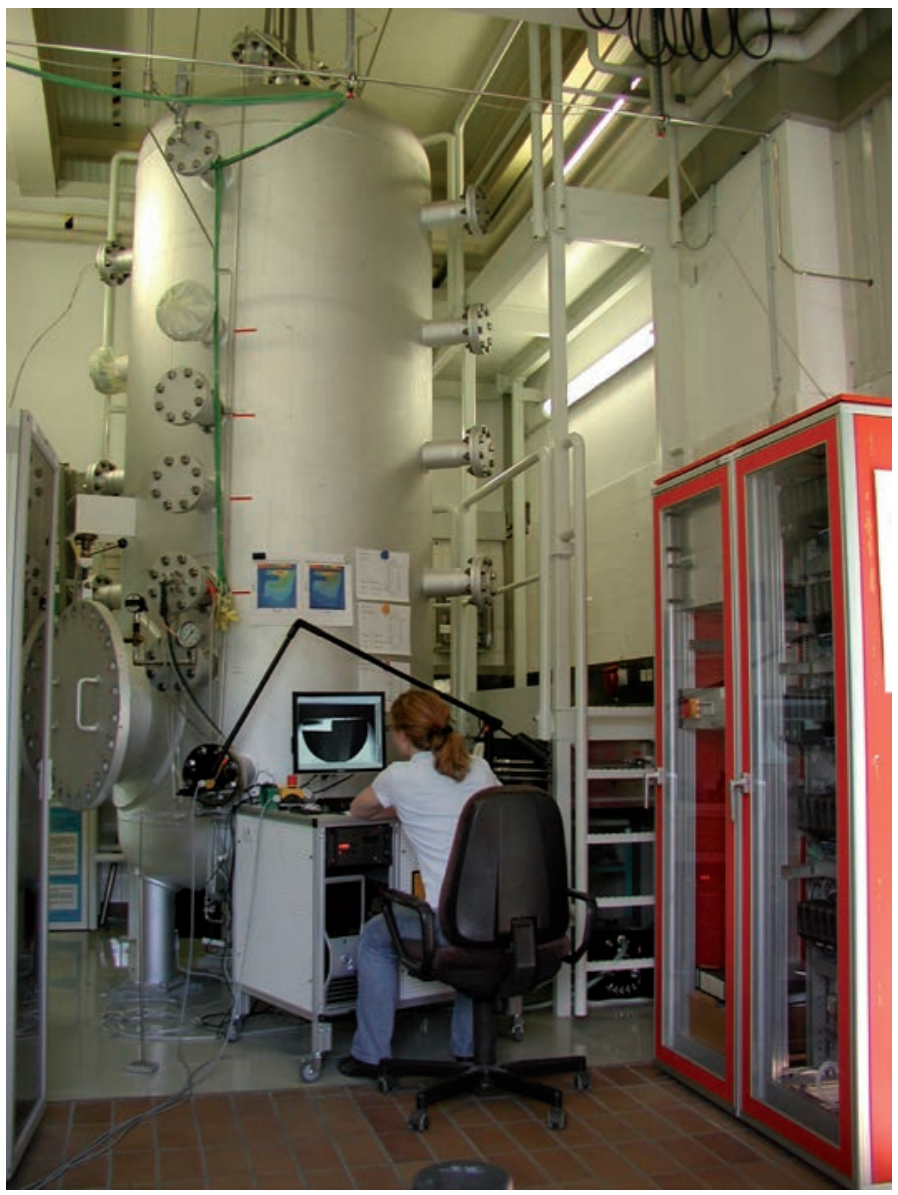

Figure 5.27. Picture of the REKO 4 facility (credit: Jülich Institute).

containment in the event of severe accident within chemical compounds in aerosol form (creating a risk of catalyser poisoning). It also studied the risk of the mixture present in the containment igniting as a result of the recombiner (which heats up in the recombination reactions) and determined the limits above which such ignition would occur for a given recombination model. In addition, it analysed recombination sensitivity to different geometric parameters (number of catalytic recombiner plates and height of the passage between the plates (called the "stack"), physical parameters (molar fraction of hydrogen) and chemical parameters (replacing several catalytic plates by chemically neutral plates) [29]. These tests notably demonstrated the aerosols' limited impact upon recombination efficiency.

The aims of the KALIH2 test programme, conducted by CEA with financial support from EDF, were complementary to those of the H2PAR programme and concerned the behaviour of the recombiners in special situations (when not poisoned by the fission products). It evaluated the effects of the following upon recombiner 
performance: humidity, exposure to smoke from cable fires, and the presence of carbon monoxide $[23,24]$. Unlike H2PAR, KALIH2 studied the impact of spray system use and overpressure upon recombiner efficiency. The tests revealed that spray system use has little effect recombiner efficiency but overpressure has a major effect upon it.

More recently, the OECD/THAI project confirmed and supplemented the H2PAR and $\mathrm{KALIH} 2$ programmes' results concerning the limits of ignition by the hydrogen recombiners and their performance under conditions in which there is little oxygen.

The effect of the hot plumes emitted from the recombiners upon hydrogen distribution in the containment, which the H2PAR and KALIH2 programmes did not address, was also studied in the OECD/SETHII programme tests as well as in additional tests as part of the European ERCOSAM project, in which recombiner models were used in the PANDA, MISTRA and KMS facilities. It is also being studied in the European SARNET project by conducting tests with recombiners in the REKO 4 facility operated by the Jülich Institute.

\subsubsection{Modelling and simulation codes}

The computer codes used to predict hydrogen distribution in the containment are based on a multi-compartmental approach. These include the CONTAIN, MAAP, GOTHIC, MELCOR and COCOSYS codes, the ASTEC code CPA module and the TONUS code multi-compartment computation module. These codes have demonstrated their ability to compute hydrogen distribution in small- and large-scale experiments, with or without the use of a spray system. The models used by these codes are too simple to precisely describe the complex gas flows likely to be produced locally at the power reactor scale, notably in the volumes in which concentration differences can appear (stratification, jets, etc.).

The codes that use a multidimensional approach, such as the TONUS code multidimensional module or the GASFLOW code developed by KIT, can model complex flows much more precisely and so can be used to complete the studies conducted using the codes listed above in the case of complex flows. They may be of limited use in some cases, however, due to the geometric complexity of the internal structures of the containment as well as to the costs involved, which may be considerable.

The comparative computational exercises (ECORA and ISP47) based on the experimental results of the four programmes named above have led to the following conclusions.

The ECORA exercise, which involved a gas injection transient with no steam condensation, used CFD tools and showed that the main limitation in the use of this type of computer code lay in the computation of large-scale slow transients. The existing means of computation are not powerful enough to allow computation convergence or mesh sensitivity over time to be studied. The models used have accurately predicted steam transport between the compartments of the PANDA facility, however, which was one of the key points of this exercise. 
In the ISP47 exercise, multi-compartment and multidimensional computer codes were used. Furthermore, as several research bodies have used the same tool, it has been possible to assess the user effect more accurately. The following points were emphasised in the final conclusions of the exercise:

- the CFD tools have not shown any significant advantages over the multi-compartment tools, possibly due to the relatively simple flow structures in the case of the TOSQAN and MISTRA tests;

- the results obtained using multi-compartment tools varied greatly depending on the user. They have therefore highlighted the need to draw up and implement best practices (this recommendation is also true of the CFD codes that use the correlations);

- the "blind" exercises, which are important in assessing the codes' predictive aspect, produced a wide range of results;

- supplementary studies are needed in order to model the condensation of steam on the walls, notably concerning the effect of the presence of helium;

- the processing of the effects of scale in computer codes has not been fully resolved: this is the objective of the European ERCOSAM project.

Additionally, the pressure loads resulting from hydrogen combustion and applied to the containment can be computed using codes adopting multi-compartment or multidimensional approaches. The multi-compartment codes are generally used to compute slow flames whose pressure loads can be considered as being static. Multidimensional CFD codes must usually be used to compute the dynamic pressure loads, however. For example, the HYCOM project has produced very complete results with regard to hydrogen combustion in reactor containments and the modelling of this phenomenon. In particular, this project has revealed the following:

- global values such as the maximum pressure are relatively well-computed by the CFD and multi-compartment codes. CFD codes give better results for fast flames, however, whereas multi-compartment codes are better suited to slow flames;

- differences exist between the results obtained using the various codes for "dynamic" values, such as the flame velocity or pressure build-up;

- the computer codes do not accurately compute some experimentally-observed phenomena such as smothering;

- modelling the energy dissipation of the flame during its progression is an important point and must be improved.

Above all, however, the HYCOM project has highlighted the difficulties of modelling hydrogen combustion when the mixtures are not homogeneous, particularly when this is accompanied by a change in the combustion conditions. These situations - which are nevertheless similar to actual conditions - are not modelled satisfactorily and require additional experimental data, notably concerning the turbulence level, to allow the computer codes to be validated. This was also the finding of the comparative exercises 
applying the codes to the OECD International Standard Problem (ISP49) and in the SARNET project.

\subsubsection{Summary and outlook}

Research and development on the hydrogen risk have produced a number of results reinforcing the decision to install passive hydrogen recombiners in all French nuclear power plants. Studies of core melt accident scenarios in the case of the existing reactors and the EPR have shown that despite the installation of recombiners, it is difficult to prevent, at all times and locations, the formation of a combustible mixture potentially resulting in local flame acceleration.

Furthermore, the events that occurred at the Fukushima Daiichi nuclear power plant in Japan have shown that the R\&D studies must be continued in order to advance the state of knowledge of hydrogen risk phenomena.

Additional research is being conducted to improve the tools needed to evaluate the hydrogen risk. This concerns the following:

- in the case of hydrogen distribution, studies of transient flows with stratification. This aspect was studied in the SETHII project and is now being studied in the test programmes of the European ERCOSAM project, notably in the TOSQAN, PANDA and MISTRA facilities;

- in the case of combustion, studies of the effect of the presence of water droplets upon hydrogen flame acceleration. This subject is covered in the ENACCEF programme and is part of the current OECD/THAI II project;

- in the case of recombiners, studies of how the recombiners' location affects the recombination rate as well as flame ignition by the recombiners. Both these subjects are covered in the European SARNET network and are being studied in a programme based on the tests conducted in the REKO3 and REKO4 facilities. The effects of the recombiners' location upon the surrounding atmosphere are also discussed in the OECD/SETHII project;

- in the case of hydrogen distribution, the development of models representing steam condensation in the presence of incondensable gases and stratification, as well as "destratification" mechanisms. Furthermore, the comparative exercise organised by IRSN regarding spraying have shown the limits of the computer codes in describing the effect of spraying upon atmospheric mixture kinetics;

- in the case of hydrogen combustion, additional work to improve and validate the models is needed in order to better simulate flame propagation in a heterogeneous environment, notably when there are differences in the hydrogen concentrations enabling the flame propagation condition to change.

In conclusion, the R\&D conducted to date has significantly increased our knowledge of the phenomena governing the distribution of gas mixtures and their combustion in the containment when a core melt accident occurs. In particular, by enabling us 
to establish criteria that have been validated using experimental data, it has enabled us to more accurately determine which situations involve hydrogen combustion risks. Although the computer codes have now achieved a significant level of maturity, their predictive capabilities must be further improved by defining best practice guidelines to mitigate the "user" effect, by improving the models (notably regarding combustion), or else by improving the numerical performance of the CFD multidimensional tools and increasing the computing power of the computers permitting their widespread use.

\subsubsection{Steam explosions}

\subsubsection{Introduction}

The phenomenon of steam explosions is relatively well understood since the 1970s. When two fluids come into contact, with one (the molten fuel, or corium, resulting from core meltdown) being at a temperature higher than the boiling point of the other (the coolant), an explosive interaction may be caused. This phenomenon is the result of the chained interaction of several mechanisms shown below:

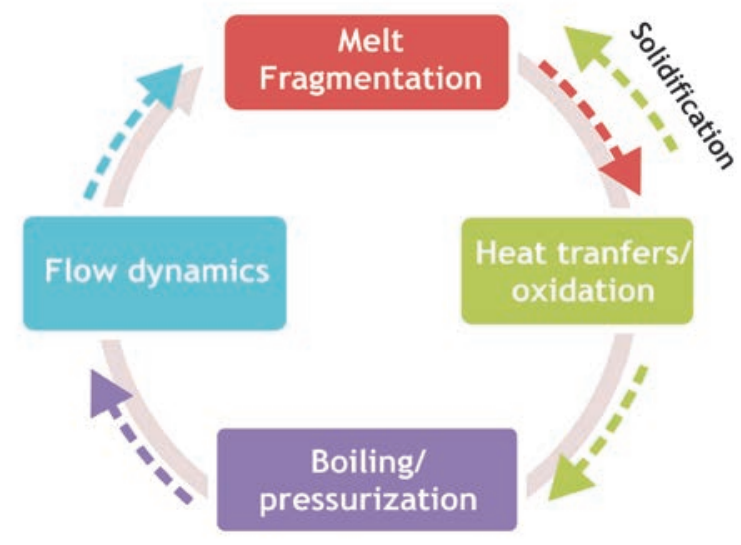

Corium fragmentation into ultra-fine fragments below a hundred microns in diameter causes the transfer of energy from the corium fragments into the coolant. The associated phase change (or simply density changes) may induce a pressure build-up faster than the pressure release. The pressure build-up causes relative motion in the fluids (the water moves faster than the fuel because their densities are different). This leads to substantial overpressure, followed by a more or less slow expansion that may damage surrounding structures (overpressures of up to 1000 bar have been measured in the KROTOS tests conducted in the Joint Research Centre (JRC) at Ispra in Italy, using alumina as a simulant of corium. Two additional phenomena have significant impacts. The heat transfer induces a cooling of the melt and thus its solidification, which, to a degree to be specified, will prevent the fragmentation. Experiments have also shown that oxidation may be very intense. Through the associated energy and through the 
production of hydrogen, a non-condensable gas, oxidation has strong impacts which may either limit or enhance the explosion strength.

The prerequisite condition for triggering a steam explosion is the contact between the two fluids, but the situations generating most energy are those in which the two fluids are mixed before they are finely fragmented (hence the terms "pre-mix" or "premixing"). In the case of PWR or BWR core melt accidents, such mixtures may form after core meltdown and while the corium is flowing in the lower head if any water remains ("in-vessel" explosion), and then possibly in the flooded reactor pit when the vessel is penetrated ("ex-vessel" explosion).

This condition is not sufficient in itself, however: an explosion does not necessarily occur when the fluids are in contact or mixed. The corium then remains at the coarse fragmentation stage (with fragments millimetres or centimetres in diameter) and its energy is transferred to the coolant relatively slowly (approximately a second for one droplet), resulting in the pressure slowly building up (this is what occurred in the Three Mile Island-2 accident, described in Section 7.1). In order for an explosion to occur, there must be an "internal" triggering event (producing what is referred to as a spontaneous explosion) or an "external" event (shock wave), causing fine fragmentation somewhere in the pre-mix and then propagating throughout the rest of the pre-mix. Such spontaneous or artificially-triggered explosions have been experimentally produced with the molten materials of which a PWR corium is composed (a mainly $\mathrm{U}-\mathrm{O}-\mathrm{Zr}-\mathrm{Fe}$ mixture).

In its most extreme form, a steam explosion is similar to a detonation due to a chemical reaction, with a shock wave propagating at the speed of sound and heat transfers between the fragmented corium and the water playing an equivalent role to the release of energy in chemical reactions. The analogy is somewhat limited, however, and quite unrealistic approximations are needed in order to construct analytical models (based on detonation models), which have very little potential for practical application. This is why complex multiphase and multidimensional models are needed in order to compute steam explosions. The most frequently-used computer code in France is the MC3D code developed by IRSN in collaboration with CEA (Section 5.2.3.3.3).

The OECD SERENA (Steam Explosion REsolution for Nuclear Applications) programme brought together the leading steam explosion specialists. In its initial phase between 2001 and 2005, they evaluated the current state of knowledge of the phenomenon and assessed the computational capabilities of the main dedicated software solutions [44]. The second phase of the programme, which took place between 2008 and 2012, consisted of an experimental programme devoted to studying steam explosions with various corium compositions likely to be found in a power reactor core melt accident, with the aim of improving the existing models (Section 5.2.3.3.2).

\subsubsection{Physical phenomena}

While the corium melt is in the water present in the lower head or, after the vessel ruptures, in the reactor pit, the explosive interaction appears as a two-stage dispersion and fragmentation phenomenon shown diagrammatically in Figure 5.28. The first 


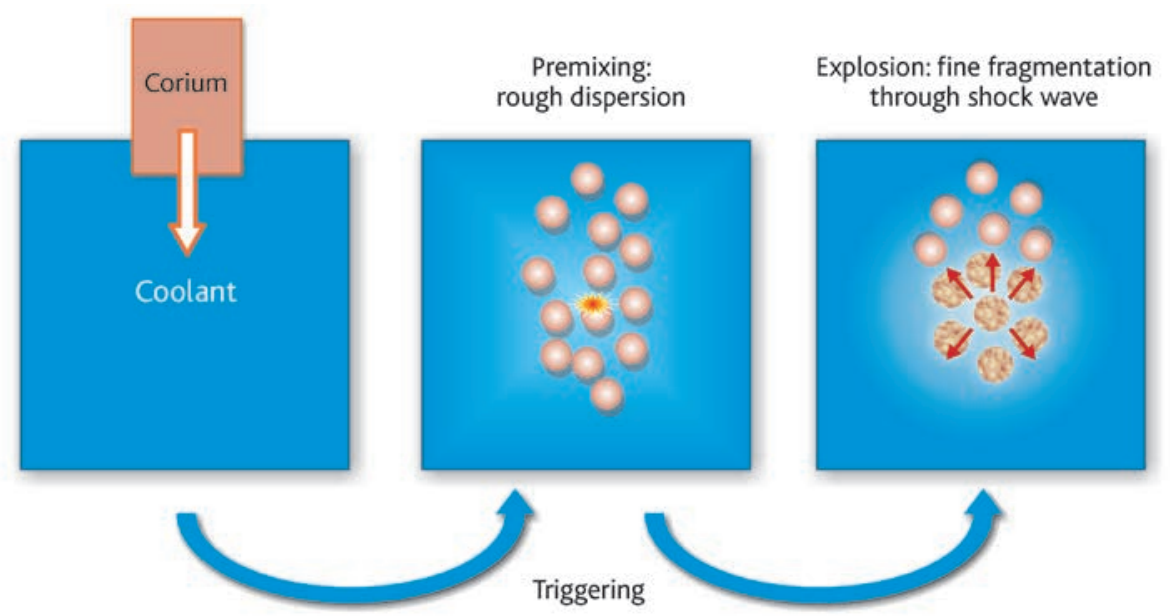

Figure 5.28. Schematic diagram of the phases in a steam explosion.

stage - the pre-mixing phase - may, depending on how it occurs, result in the explosion itself (the second stage) due to the fundamental, self-sustaining mechanisms described in the introduction: fine corium fragmentation, energy transfer between the fragmented corium and the water, and the associated pressure build-up and differentiated motion in the fluids. As the pre-mixing and explosion phases' timescales are very different (seconds compared with milliseconds), the explosion takes place within a virtually static pre-mix that determines the initial conditions of the explosion.

As a result, the explosion greatly depends on the pre-mix characteristics at that time; these consist of the composition and distribution of the various phases present (corium, water and steam) and the corium interface, including its temperature and its possible state of solidification. It is thus essential to accurately describe this first phase in order to obtain the initial conditions of the explosion. Accurate prediction of the explosion phase is therefore achievable only if pre-mixing is accurately described. This first phase was neglected for some time but has been the subject of most R\&D efforts for the last ten years.

The explosion therefore begins with a "trigger" phase and is followed by a phase referred to as the "escalation" phase, during which the intensity of the explosion increases until a stationary state is reached. There is no phenomenological difference between these two steps of the explosion and they are modelled in the same way in the current computer tools. On the following pages, we will use the more general term "explosion phase" to describe them both. The pre-mixing, the triggering of the explosion and the explosion itself are described in detail in the following sections.

\subsection{Pre-mixing}

The importance of pre-mixing has been clearly demonstrated, particularly in the KROTOS experiments, in which the very different pre-mixes observed with the alumina and the corium (Figure 5.29) resulted in very different explosion intensities (alumina 

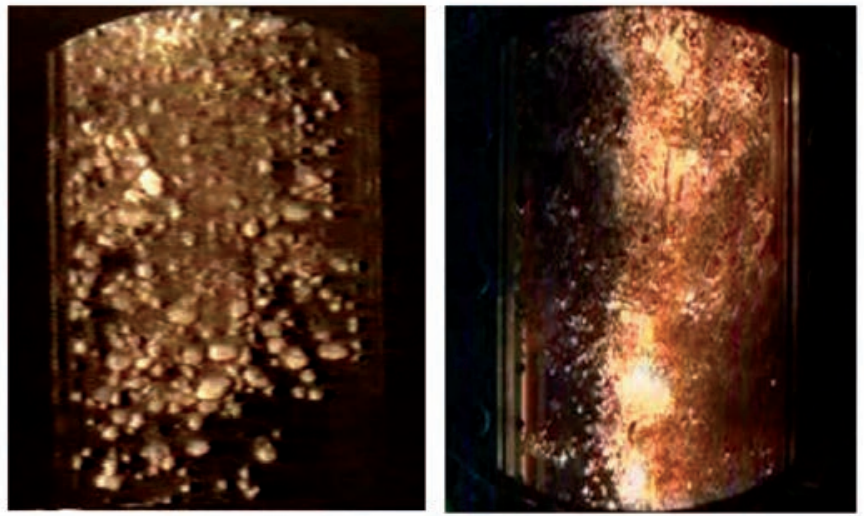

Figure 5.29. View of an alumina and water pre-mix (left: KROTOS-57 experiment) and a corium and water pre-mix (right: KROTOS-58 experiment). 10 × $20 \mathrm{~cm}$ window [37].

releases ten times more energy than corium) [37]. In all the tests, mostly qualitative information was obtained on the pre-mixing of materials with high melting points $\left(>2000^{\circ} \mathrm{C}\right.$ ). This information is not sufficient to explain the observed differences in behaviour. The second phase of the OECD/SERENA programme sought more detailed information on the pre-mixing, notably concerning the fragmentation and boiling processes (Section 5.2.3.3.2).

With regard to modelling, pre-mixing is evaluated using multidimensional, multiphase thermal-hydraulic computer codes (Section 5.2.3.3.3), as the many dynamic, thermal and chemical interactions prevent pre-mixing from being modelled simply.

The three essential points upon which R\&D concentrates, namely corium fragmentation, determining of the void fraction (the fraction of the volume occupied by the steam) and fuel solidification, are presented below. For the sake of completeness, the effects of oxidation of the corium materials - which could greatly modify each of these points should also be studied.

\section{Corium fragmentation}

During the pre-mixing phase, fragmentation occurs in two stages: primary fragmentation, from the continuous phase (typically a corium jet), produces a first generation of droplets that may then undergo secondary fragmentation. In reality, jet fragmentation is a highly complex phenomenon and involves several instability and then fragmentation processes, as Figure 5.30 shows.

Secondary fragmentation continues until the droplets formed cannot become any smaller (the droplets consist of fragments wrenched from larger droplets by the gas flow; this fragmentation is only possible if the droplet is unstable under hydrodynamic flow conditions). 


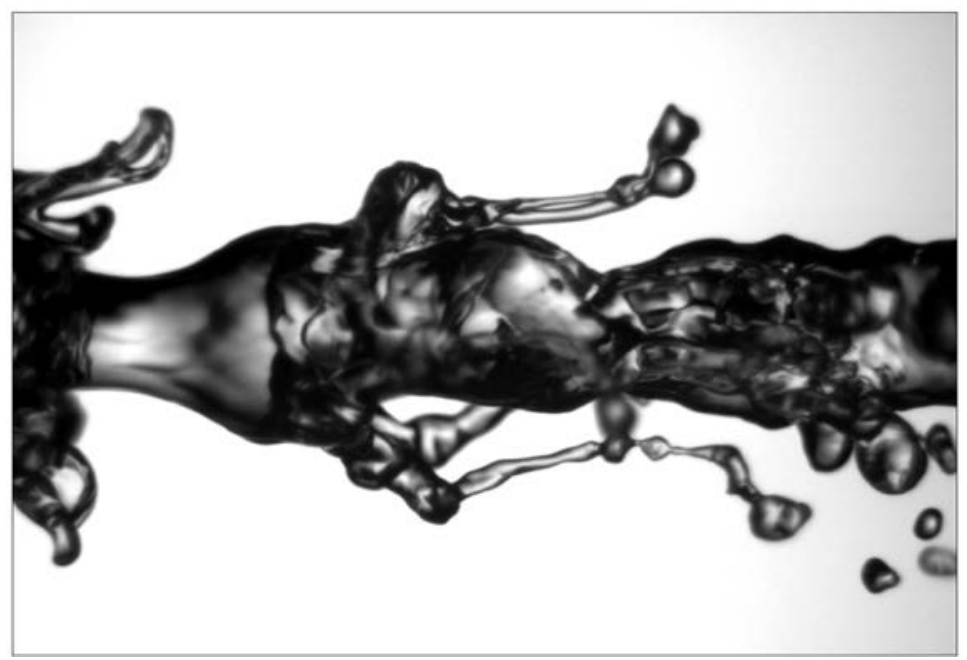

Figure 5.30. Illustration of fragmentation process complexity in the case of a liquid jet in a coaxial air flux [63].

Considerable research has been conducted on the primary fragmentation of corium jets (in particular, see the results of the doctoral theses presented in references [42, 43]). The models developed in these theses are mainly devoted to direct fine fragmentation (atomisation) ${ }^{7}$ of the corium jet. It was, however, seen that the corium jet can be fragmented by other mechanisms involving "large-scale" hydrodynamic instabilities causing larger fragments to be formed and greater spatial dispersion of the corium fragments (Figure 5.31). These mechanisms are believed to cause the behaviour observed during tests with alumina in the KROTOS facility [37], where the fragments filled the entire cross-section of the experimental tube (see Figure 5.29).

Secondary fragmentation was the subject of substantial work until the 1980s. This work revealed trends and fundamental characteristics numbers (Weber number: $W e=\frac{\rho_{\text {amb }} V^{2} D}{\sigma} ;$ characteristic fragmentation time: $\left.\frac{D}{V} \sqrt{\frac{\rho_{\text {comb }}}{\rho_{\text {amb }}}}\right)$. The knowledge acquired as a result only provides a qualitative description of the pre-mixing, however.

Apart from the fact that the theoretical knowledge must be improved, the modelling of fragmentation in the computer codes faces two difficulties. The first concerns the local aspect of the phenomena, resulting in the need for fine spatial resolution, whereas the second lies in the models' extreme sensitivity to the local flow conditions, which are quite unstable and can trigger the explosion themselves. Parametric modelling of flow dynamics is therefore often preferred to more-detailed modelling; this approach, which is based on simplified models of the gravitational fall of corium fragments, is of limited use, however, as these simplified models have not been sufficiently validated to compute corium-water pre-mixes when a core melt accident occurs in a power reactor.

7. This must not be confused with the "fine fragmentation" process during the explosion, in which the fragments are much smaller. 

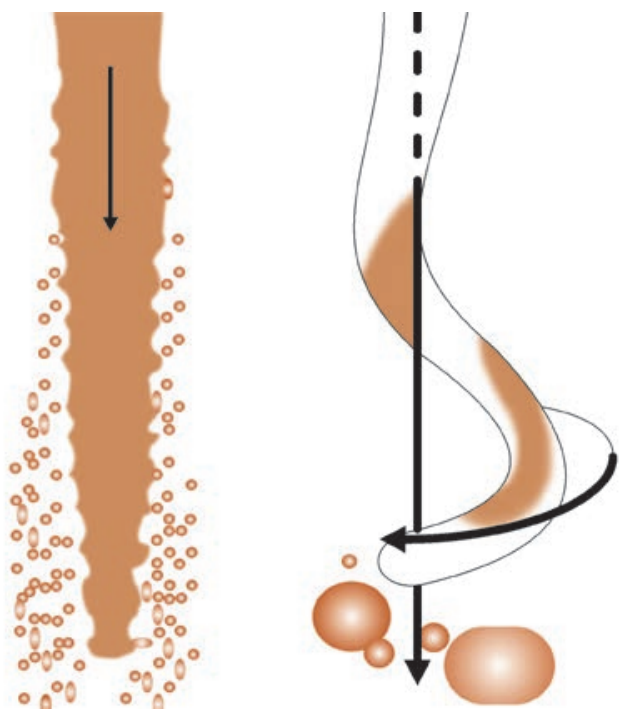

Figure 5.31. Schematic diagram of the primary fragmentation of a corium jet upon contact with water: liquid jet fragmentation due to atomisation (left) and fragmentation due to large-scale hydrodynamic instabilities (right); these instabilities result in corium jet deformation (torsion around the flow's vertical axis) and, therefore, greater spatial dispersion of the fragments.

\section{Void production}

The volumetric fraction of the gases in the corium-water mixture is called the "void fraction". There are still many uncertainties regarding the effect of the void fraction upon steam explosion, however. The greater the void fraction is, the more the average compressibility of the mixture increases and the more explosion becomes difficult. Predicting the void fraction in the pre-mix (the initial state of the explosion) is a complex task, mainly because of the corium's very high temperatures (it should be remembered that at $3000 \mathrm{~K}$, the steam is already greatly dissociated). The steam production processes of film boiling are poorly understood. Similarly, the steam condensation processes are very difficult to model. The flow configurations used in modelling are based on studies of isothermal two-phase flows in piping. Their suitability for describing pre-mixing is therefore uncertain. The presence of non-condensing gases produced through oxidation of corium metallic phases modifies the boiling and condensation processes, making the void fraction even more complex to model.

This results in a certain degree of disparity between the existing models, and this disparity is largely the cause of the uneven computational results obtained during phase 1 of the SERENA programme. Due to the lack of detailed experimental results, particularly concerning the local void fractions and the corium's configuration, the validity of the various models cannot be established with sufficient certainty. Correctly evaluating the void fractions and their distribution was thus a major objective of phase 2 of the SERENA programme, as described in Section 5.2.3.3.2. 


\section{Corium solidification}

An additional phenomenon must be taken into account when the models are applied to power reactors. This concerns corium solidification during the pre-mixing phase, which inhibits the fine fragmentation process and, therefore, the explosion. This phenomenon is particularly difficult to study because of the complex mixtures of component materials in corium and the complex pre-mixing conditions (gas and corium flows, corium fragmentation, high temperatures, etc.). As a result, considerable uncertainties remain regarding the solidification processes themselves. The codes computing these processes (including MC3D) assume that solidification occurs under thermodynamically balanced conditions, and that there is a solid surface crust and a well-defined solidification front.

\subsection{Triggering of the explosion}

The steam explosion triggering phase is undoubtedly the most difficult phase to process when evaluating the steam explosion risk. There are no reliable models for predicting when and where an explosion will be triggered. The physical parameters that determine the triggering of the explosion are not precisely known. The existing knowledge is mainly based on experimental results. In the case of corium, it has been experimentally observed that spontaneous explosions occur when the corium makes contact with the test system lower head containing the corium-water mixture. However, nothing says that an explosion could not occur before or after this contact.

From a theoretical point of view, it is known that a hot corium droplet may explode under the influence of a low-pressure disturbance of a few bar (Figure 5.32). The phenomenon includes isotropic fragmentation, unlike the fragmentation linked with dynamic effects (the fragments are found in the flow's wake). Despite many research studies, this "thermal fragmentation" phenomenon is still poorly understood. However, a doctoral thesis study conducted from 2005 to 2008 at IRSN [45] added to our understanding of this phenomenon and validated the most widely-posited hypothesis whereby the phenomenon is due to the steam film surrounding the corium droplet becoming destabilised. This destabilisation causes localised contact between the corium and the coolant, thereby creating local build-ups in pressure that, in their turn, destabilise the corium droplet. The corium's "thermal fragmentation" phenomenon only appears possible under fairly specific conditions of ambient pressure (approximately 2-15 bar) and water under-cooling (above $70^{\circ} \mathrm{C}$ according to the experimental results obtained by the Sandia National Laboratories [64], and above $40^{\circ} \mathrm{C}$ according to the model in this doctoral thesis). It is thought to contribute to the triggering and escalation of the explosion, but its actual importance has not yet been determined. A spontaneous explosion was therefore observed at a pressure of 50 bar in a programme at the British Winfrith nuclear centre under apparently unfavourable conditions for thermal fragmentation [38].

An explosion may also be triggered by the corium enveloping some coolant when it lands on the floor (the bottom of the testing cross-section), which would explain the spontaneous explosions occurring when the corium comes into contact with the floor. Furthermore, the small scales of the tests do not encourage spontaneous explosions. 


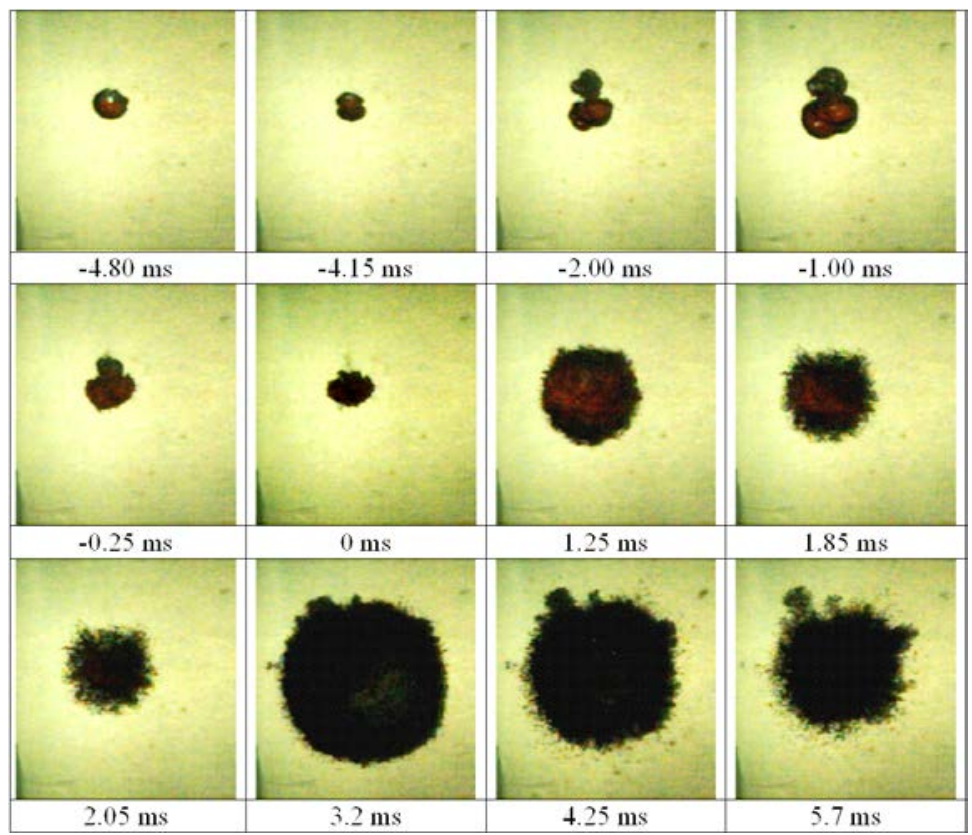

Figure 5.32. View of a $\mathrm{WO}_{3}-\mathrm{CaO}$ droplet $\left(1500^{\circ} \mathrm{C}\right)$ exploding in water at $25^{\circ} \mathrm{C}$ due to thermal fragmentation [65].

Spontaneous explosions therefore occur more frequently in the experiments conducted with wide testing cross-sections (the FITS [32-34] or TROI [62] programmes) than in geometries with narrow cross-sections (KROTOS [37]).

In the probabilistic safety assessments, a triggering probability is sometimes used. No probabilistic quantification is currently based on precise physical arguments, however. Uncertainties regarding the triggering of the explosion therefore lead us to consider that steam explosion risk cannot be eliminated and to study the consequences of such an explosion. It should be noted, however, that the triggering caused by a pressure disturbance does not necessarily result in an interaction likely to endanger the structures if the temperature and pressure conditions are not combined. In the computations as well as in some experiments, therefore, certain situations that notably have a high void fraction or high solidification do not result in an explosion that threatens the structures (or any explosion whatsoever).

\subsection{Explosion}

The explosion is caused by very intense heat transfers between the corium and the coolant and the resulting coolant vaporisation ${ }^{8}$. In the case of the violent explosions such as those obtained in the KROTOS facility's mono-dimensional geometry using

8. It may seem surprising to speak of vaporisation when the pressure exceeds the critical pressure. In this case, we are misusing the term to describe the fact that, even under supercritical conditions, the hot fluids are still less dense than the cold fluids, a phenomenon similar to evaporation. 
alumina (with pressure peaks of 500-1000 bar), the explosion may be approximately described as follows:

- propagation of a detonation-type shock wave with intense isochoric thermal transfers;

- expansion of the mixing region behind the passing shock wave.

Because of the obvious instrumentation limitations, experimental studies on the detailed mechanisms of the explosion are extremely complicated. As a result, very little data - which have often been obtained under questionably representative conditions - are available. The analytical models, concerning complex phenomena that are frequently unbalanced, reach their limits comparatively rapidly. It is, however, interesting to note that with the increase in computing power, it is becoming feasible to study these highly localised phenomena using numerical simulation tools (such as the MC3D code itself, described later in this document).

Paradoxically, however, the explosion is comparatively "simpler" to model than the pre-mixing phase, subject to the use of suitable approximations for the corium's fine fragmentation as well as heat and mass transfers between the corium and the coolant, as these processes produce the pressure peak. For one thing, these two processes are clearly predominant mechanisms; for another, many aspects can be simplified or even ignored because of the timescale of the explosion (a few milliseconds). The studies therefore concentrate on understanding the two predominant phenomena, consisting of the fine fragmentation of the corium and the boiling of the coolant, both of which are briefly described below.

\section{- Fine fragmentation}

The fragmentation mechanisms are astonishingly complex (see, for example, reference [66]). The fine fragmentation of a corium droplet in water when subjected to a shock wave is illustrated in Figure 5.33, from reference [46]. Traditionally, the fragmentation phenomena are characterised by means of the Weber number $\left(W e=\left(\rho V^{2} D / \sigma\right)\right.$, which expresses the ratio between the destabilising dynamic forces $\left(\rho V^{2}\right)$ and the stabilising force due to surface tension $(\sigma / D)$.) When the Weber number is not too large, the droplet surface layers are firstly detached due to water friction. The fragmentation occurs later behind the film drained by the friction. With high Weber numbers, instability occurs earlier and directly results in droplet fragmentation.

When the corium is finely fragmented, the size of the droplets is reduced by one or two orders of size in approximately one millisecond. Opinions differ regarding the way in which the phenomenon develops. The studies conducted by IRSN using the MC3D computer code suggest that the corium's fine fragmentation is the result of Kelvin-Helmholtz shearing instabilities (because the flow speeds of the corium and coolant droplets are different). These studies have led to the development of a model describing the changes in the fragments' size; this model is integrated into the MC3D code. 


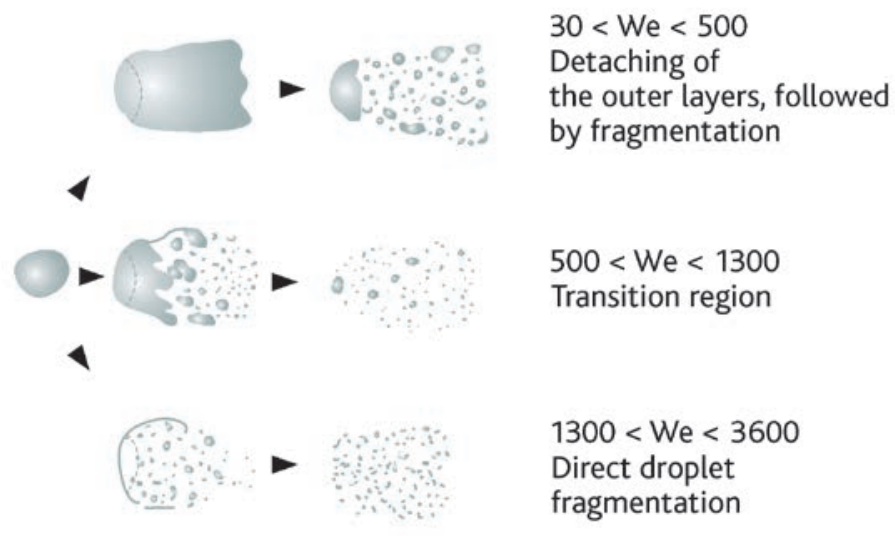

Figure 5.33. Fine fragmentation mechanisms observed by Bürger et al. [46] depending on the Weber number $\left(\rho V^{2} D / \sigma\right)$.

Corium solidification tends of course to modify or even inhibit the phenomenon, potentially explaining the (relative) weakness of the explosions observed with corium oxide $\left(\mathrm{UO}_{2}+\mathrm{ZrO}_{2}\right)$. It is difficult to model the solidification phenomenon during the premixing phase, however. This is because its effect upon fine fragmentation is difficult to quantify. In some models, the crust has an effect similar to an elastic shell. The models remain highly parametric, however, due to the many approximations and uncertainties concerning, for example, the mechanical properties of the solid corium layers.

\section{Pressurisation mechanisms}

The initial steam explosion models [47] assumed that there was an instantaneous balance between the resulting corium fragments and the coolant; in these models, the coolant temperature increase due to direct contact with the hot corium fragments directly results in the pressure build-up, either through boiling or simply through thermal expansion. This approach has been refined by Theofanous [48] with the so-called "microinteraction" approach, which considers that only a fraction of the water is heated. The term "micro-interaction" comes the hypothesis that the interaction between the fragment and the water is highly local and that only a part of the water is involved (except in transmitting the pressure build-up). Experimental observations show that in reality, at least up to the critical pressure, the hot corium fragments are surrounded by a thin film of steam, affecting the heat transfers between the corium fragments and the coolant as well as coolant vaporisation. The model representing the interaction between the corium fragments and the water integrated into the MC3D code assumes that the pressure build-up is the result of the direct vaporisation accompanying the heat transfers through the steam film between the hot corium fragments and the coolant (the so-called "imbalance" model); this model, which is more mechanistic a priori, assumes that the mass 
transfers associated with the heat transfers between corium fragments (whose average size is $100 \mu \mathrm{m}$ in the KROTOS experiments) and the coolant are known. It is important to remember that these transfers occur during a pressure transient of a few hundred bar lasting a few milliseconds, which are difficult conditions to achieve in experiments.

\subsubsection{Experimental programmes, modelling and computer code}

\subsection{Mechanical efficiency concept}

Before we present the main experimental programmes, it is important to discuss the mechanical efficiency concept, as it is often used to characterise the intensity of an explosion in the experiments (as well as in the initial thermodynamic models). This concept is intended to represent the efficiency of the transfer of the heat energy contained in the fuel, the source of the explosion's energy (excluding chemical phenomena), into mechanical energy. In reality, this concept is rather vague, as the mechanical energy concerned can be defined in several ways. In the initial estimates, the energy in question was that linked with the system's overall pressure build-up - in other words, the gaseous atmosphere in the test section (the compression is assumed to be adiabatic). In reality, this definition created considerable difficulties and expression used for the energy was revised several times. It was then judged preferable to use the kinetic energy of the mixture. To avoid confusion, we will talk of kinetic efficiency in the rest of this document. This kinetic energy is also impossible to measure accurately, and it is generally obtained by evaluating load impulsion (the pressure build-up integral, $I=S \int \Delta \mathrm{P} d t$, where $S$ is the bottom surface area of the test cross-section to which the pressure load $\Delta \mathrm{P}$ is applied). Although the mixture is assumed to be non-deformable (like a slug) and expelled by the explosion, the approximate value of its kinetic energy is provided by the expression $I^{2} / 2 M$, where $M$ is the mass of the mixture. This approximation leads to a minimisation of the actual energy but provides acceptable orders of magnitude.

The efficiency concept must therefore be used with caution, and any comparisons between different experiments must be purely qualitative.

\subsection{Experimental programmes}

Table 5.4 shows the main programmes that have studied the pre-mixing phase or the steam explosion using corium or simulant jets and whose results have been used as the basis for developing and qualifying computational models. The FITS programme, which was the "pioneer" in the domain, was conducted by the Sandia laboratories in the United States and included many experiments in the different configurations and on different materials described in references [38-41]. Notably, spontaneous violent explosions were obtained using a corium consisting of a $\mathrm{UO}_{2}+\mathrm{ZrO}_{2}$-steel mixture (little information is provided on the corresponding tests, unfortunately) [49]. The programme ended with the loop being unexpectedly destroyed in the RC2 test. These experiments are not used to qualify the codes, however, as little is known of the experimental conditions under which the fluids come into contact, and so the conditions are often poorly known and difficult to reproduce in the computations. 
Table 5.4. Experimental programmes studying steam explosions resulting from an interaction between a corium jet or a simulant jet and the coolant (water).

\begin{tabular}{|c|c|c|c|c|}
\hline Programme & Laboratory & Type of test & Materials & Conditions and key facts \\
\hline $\begin{array}{l}\text { FITS } \\
{\left[5.2 \_38\right] \text { at }} \\
{\left[5.2 \_41\right]}\end{array}$ & $\begin{array}{l}\text { Sandia } \\
\text { (USA) }\end{array}$ & Explosion & $\begin{array}{l}\mathrm{Al}_{2} \mathrm{O}_{3} \text {-Fe thermite } \\
\text { or } \\
\text { corium } \\
\mathrm{A} \mathrm{few} \mathrm{kg}\end{array}$ & $\begin{array}{l}\text { - First major programme } \\
\text { - Many tests } \\
\text { - Series of extended conditions } \\
\text { materials (MDC) tests with } \\
\text { corium: spontaneous explo- } \\
\text { sions (approx. } 2 \% \text { efficiency) } \\
\text { - Series of extended efficiency } \\
\text { (RC) with thermite: RC2 } \\
\text { experiment with the highest } \\
\text { observed efficiency (8-15\%, } \\
\text { gas compression work) }\end{array}$ \\
\hline $\begin{array}{l}\text { CCM } \\
{\left[5.2 \_53\right]}\end{array}$ & $\begin{array}{l}\text { ANL } \\
\text { (USA) }\end{array}$ & Pre-mixing & $\begin{array}{l}\mathrm{UO}_{2}+\mathrm{ZrO}_{2}^{-} \\
\text {steel mixtures } \\
\text { at } 2800{ }^{\circ} \mathrm{C} \\
\text { A few } \mathrm{kg}\end{array}$ & $\begin{array}{l}\text { - Well-controlled conditions } \\
\text { - } 6 \text { tests under different condi- } \\
\text { tions (including geometry, } \\
\text { jet diameters and water } \\
\text { temperature) } \\
\text { - No spontaneous explosions }\end{array}$ \\
\hline $\begin{array}{l}\text { FARO } \\
{\left[5.2 \_54\right]} \\
{\left[5.2 \_55\right]}\end{array}$ & $\begin{array}{l}\text { CCR Ispra } \\
\text { (European } \\
\text { Commission) }\end{array}$ & $\begin{array}{l}\text { Pre-mixing } \\
\text { Explosion }\end{array}$ & $\begin{array}{l}\mathrm{UO}_{2}+\mathrm{ZrO}_{2} \text { at } \\
2800^{\circ} \mathrm{C} \\
100-200 \mathrm{~kg}\end{array}$ & $\begin{array}{l}\text { - Very large programme } \\
\text { - } \text { Reference for pre-mixing } \\
\text { phase model qualification } \\
\text { - Large masses } \\
\text { - } \\
\text { - Ex spontaneous explosions } \\
\text { (low efficiency) }\end{array}$ \\
\hline $\begin{array}{l}\text { KROTOS } \\
{\left[5.2 \_37\right]}\end{array}$ & $\begin{array}{l}\text { CCR Ispra } \\
\text { (European } \\
\text { Commission) }\end{array}$ & Explosion & $\begin{array}{l}\mathrm{Sn} \text { at } 1000^{\circ} \mathrm{C} \\
\mathrm{Al}_{2} \mathrm{O}_{3} \text { at } 2300- \\
2800^{\circ} \mathrm{C} \\
\mathrm{UO}_{2+} \mathrm{ZrO}_{2} \\
\text { at } 2800^{\circ} \mathrm{C} \\
1 \text { litre }\end{array}$ & $\begin{array}{l}\text { - Reference programme for } \\
\text { explosion code validation } \\
\text { - One-dimensional (narrow test } \\
\text { cross-section) } \\
\text { - Influence of the composi- } \\
\text { tion (alumina or corium } \\
\mathrm{UO}_{2}+\mathrm{ZrO}_{2} \text { ) } \\
\text { - } \mathrm{No} \mathrm{spontaneous} \mathrm{explosions} \text { with corium }\end{array}$ \\
\hline ZrEX-ZrSS & $\begin{array}{l}\text { Sandia } \\
\text { (USA) }\end{array}$ & Explosion & $\begin{array}{l}\mathrm{Zr}+\mathrm{ZrO}_{2} \text { mixtures } \\
\mathrm{Zr} \text {-steel } \\
\mathrm{A} \text { few } \mathrm{kg}\end{array}$ & $\begin{array}{l}\text { - } \text { Triggered explosions } \\
\text { - Very great impact of Zr rate } \\
\text { upon efficiency }\end{array}$ \\
\hline $\begin{array}{l}\text { TROI } \\
{\left[5.2 \_56\right]}\end{array}$ & $\begin{array}{l}\text { KAERI } \\
\text { (South Korea) }\end{array}$ & $\begin{array}{l}\text { Explosion } \\
+ \\
\text { Pre-mixing }\end{array}$ & $\begin{array}{l}\mathrm{UO}_{2}+\mathrm{ZrO}_{2} \text { corium } \\
\text { Around } 10 \mathrm{~kg}\end{array}$ & $\begin{array}{l}\text { - Poorly defined conditions } \\
\text { - Spontaneous explosions } \\
\text { - Low efficiency } \\
\text { - Only } 2 \mathrm{~kg} \text { in the mixture at } \\
\text { the time of explosion } \\
\text { - Influence of corium } \\
\text { composition }\end{array}$ \\
\hline
\end{tabular}

The reference results regarding the pre-mixing phase are based on the FARO experiments (conducted by the European Commission Joint Research Centre (JRC) at Ispra in Italy) [54], which used $100-200 \mathrm{~kg}$ of corium oxide $\left(\mathrm{UO}_{2}+\mathrm{ZrO}_{2}\right)$. The KROTOS 
programme (which was also conducted at the JRC in Ispra) [37] was similar to the FARO programme in studying the explosion, albeit at a smaller scale (fuel volume was approximately one litre); this programme demonstrated a lower tendency towards explosion as well as lower pressure loads for a corium oxide $\left(\mathrm{UO}_{2}+\mathrm{ZrO}_{2}\right)$ in comparison with alumina $\left(\mathrm{Al}_{2} \mathrm{O}_{3}\right)$. This result was the subject of considerable speculation regarding the "material effect". The difference in density between the corium oxide and the alumina may explain this result; the lower density of the alumina has two effects: firstly, jet fragmentation into larger particles, resulting in less vaporisation and solidification, and secondly, an increase in the volume of fuel in the mixture because the speed of deposition on the bottom of the test cross-section is lower. The kinetic efficiencies (Section 5.2.3.3.1) of the strongest explosions were evaluated at approximately $2 \%$, which is similar to those of the explosions in the FITS programme.

We should also mention the programmes whose results are little used, either because of a specific complication in the results or because of limitations in the dissemination of the results. The former category notably includes the ZREX tests by the Argonne National Laboratory in the United States [50], which revealed that explosion intensity was very greatly increased due to oxidation of the zirconium contained in the $\mathrm{Zr}+\mathrm{ZrO}_{2}$ and $\mathrm{Zr}$-steel mixtures.

The TROI programme, which was conducted by the Korea Atomic Energy Research Institute (KAERI) in South Korea, confirmed that spontaneous explosions were possible with corium [56].

To support modelling, experimental programmes investigating separate effects (thermal transfers, fragmentation, etc.) have been conducted, generally in a national context. Notably, the TREPAM tests (CEA/IRSN) have made it possible to specify the heat transfers associated with the corium fragments under fairly representative conditions (pressures of up to 240 bar, speed differences between fragments and water of up to $46 \mathrm{~m} / \mathrm{s}$ and temperatures of approximately $2200^{\circ} \mathrm{C}$ ). In the case of fine fragmentation, the DROPS programmes (conducted at the Institut für Kernenergetik und Energiesysteme (IKE) in Stuttgart, Germany, and then at CEA) [60] and MISTEE (conducted at the Royal Institute of Technology (KTH) in Stockholm, Sweden) [61] were devoted to studying the fragmentation of the corium droplets in the water by using simulants (generally liquid metals) at relatively low temperatures.

In order to validate the codes, various programmes also tried to represent the corium jets by jets of solid beads, thereby eliminating the fragmentation-related difficulties in order to concentrate on the heat transfer and friction aspects. In particular, the QUEOS programme conducted by Forschungszentrum Karlsruhe in Germany [51] studied the pre-mixing phase of solid sphere packets for temperatures of up to $2200^{\circ} \mathrm{C}$.

At the end of the programmes described above, many uncertainties remained at the beginning of the '00s regarding the steam explosions potentially resulting from interactions between a hot corium and the coolant. This conclusion explained the launch of the international SERENA programme described below, in line with the conclusions of OECD's "Technical opinion paper on fuel coolant interaction" and with the summary 
report published by OECD in 2001 concerning the nuclear safety research conducted in the OECD countries, which show the usefulness of continuing R\&D on the corium-water interaction [52].

The OECD international SERENA programme took place between 2001 and 2005, to provide a state of the art on steam explosions resulting from the interaction between hot corium and the coolant in a core melt accident and evaluating the existing codes' ability to describe this interaction. It showed that there were many differences of opinion between the experts, mainly due to the few experimental results available, highlighting the need for a new experimental programme.

This programme was implemented as part of a second phase of the programme, called SERENA-II, which took place between 2008 and 2012; its main objective was to study the effect of the corium's composition upon the explosion in integral tests and obtaining results to improve the state of understanding of certain points and qualify the computer tools.

The studies conducted in the first phase of SERENA made it possible to confirm that there was little risk of the containment rupturing as the result of a steam explosion in the reactor vessel ("Alpha" mode) and that the studies conducted in the second phase of the programme should give priority to studying the steam explosions that might occur in the reactor pit after the reactor vessel fails. From the point of view of the phenomena involved, there are no fundamental differences between in-vessel and ex-vessel interactions (in the reactor pit). The difference lies in the conditions under which the fluids come into contact. In particular, the mode of corium transfer into the water differs: in the ex-vessel case, it depends on the conditions under which the reactor vessel is ruptured and generally occurs in the form of a wide, non-central jet that may possibly be ejected under pressure. The nature of the corium may also differ, notably with a high probability of separation of its metallic (oxidisable) and oxidised phases (in the corium in the lower head). Containment internal pressure is of course generally lower than in the reactor vessel, and the water is assumed to be colder. The studies conducted in this context have also led to the deduction that the main uncertainties regarding steam explosions were due to a lack of detailed results on the pre-mix region and on the behavioural differences between the corium and the simulants such as alumina (the material effect) when they interact with the coolant. A small number of the experiments showed that the interaction between the corium and the water generated less energy than that between the alumina and the water. This finding has to be confirmed and explained.

CEA (supported by IRSN and EDF) and KAERI, an institute in South Korea (supported by KINS, the Korea Institute of Nuclear Safety) proposed the second phase of the SERENA programme with the aim of obtaining further information on pre-mix flow configuration, as well as on the effects of the materials and geometry. Fourteen organisations participated in this phase: CEA, IRSN and EDF in France, the KAERI and KINS institutes in South Korea, IKE-Stuttgart (Institut für Kernenergetik und Energiesysteme) and GRS (Gesellschaft für Anlagen und Reaktorsicherheit) in Germany, JNES (Japan Nuclear Energy Safety) in Japan, AECL (Atomic Energy of Canada Limited) 
in Canada, the US NRC (US Nuclear Regulatory Commission) and the University of Washington in the United States, JSI (Jozef Stefan Institute) in Slovenia, SKI (Swedish Nuclear Power Inspectorate) and KTH in Sweden, PSI (Paul Scherrer Institute) in Switzerland, VTT (Technical Research Centre) in Finland and SUEZ/TRACTEBEL in Belgium. This phase includes experiments in the CEA KROTOS facility (the facility was transferred from the JRC in Ispra to the CEA research centre in Cadarache and then improved) and the KAERI TROI facility [62]:

- the KROTOS facility consists of a small test cross-section $(20 \mathrm{~cm}$ diameter and $1 \mathrm{~m}$ height of water), which uses $3-5 \mathrm{~kg}$ of corium or simulant. The facility was transferred from JRC ISPRA to Cadarache and improved. Notably, it is now equipped with a radioscopy system that is used to obtain more detailed information on the pre-mix and on the initial state of the explosion. The KROTOS facility is still mainly devoted to studying the explosion, however, as the corium's low mass can, in principle, hardly be used to validate the models developed for the pre-mixing (some aspects of the pre-mixing, such as corium jet fragmentation, are sensitive to scale effects);

- the TROI facility has been improved in response to the programme's needs and can inject up to $30 \mathrm{~kg}$ of corium or simulant into a tank larger than that of the KROTOS facility; in particular, it can be used to study explosion development in three-dimensional geometry.

The outcomes of SERENA-2 are not all favourable from a FCI risk assessment perspective but significant improvements in knowledge and modelling were obtained. A

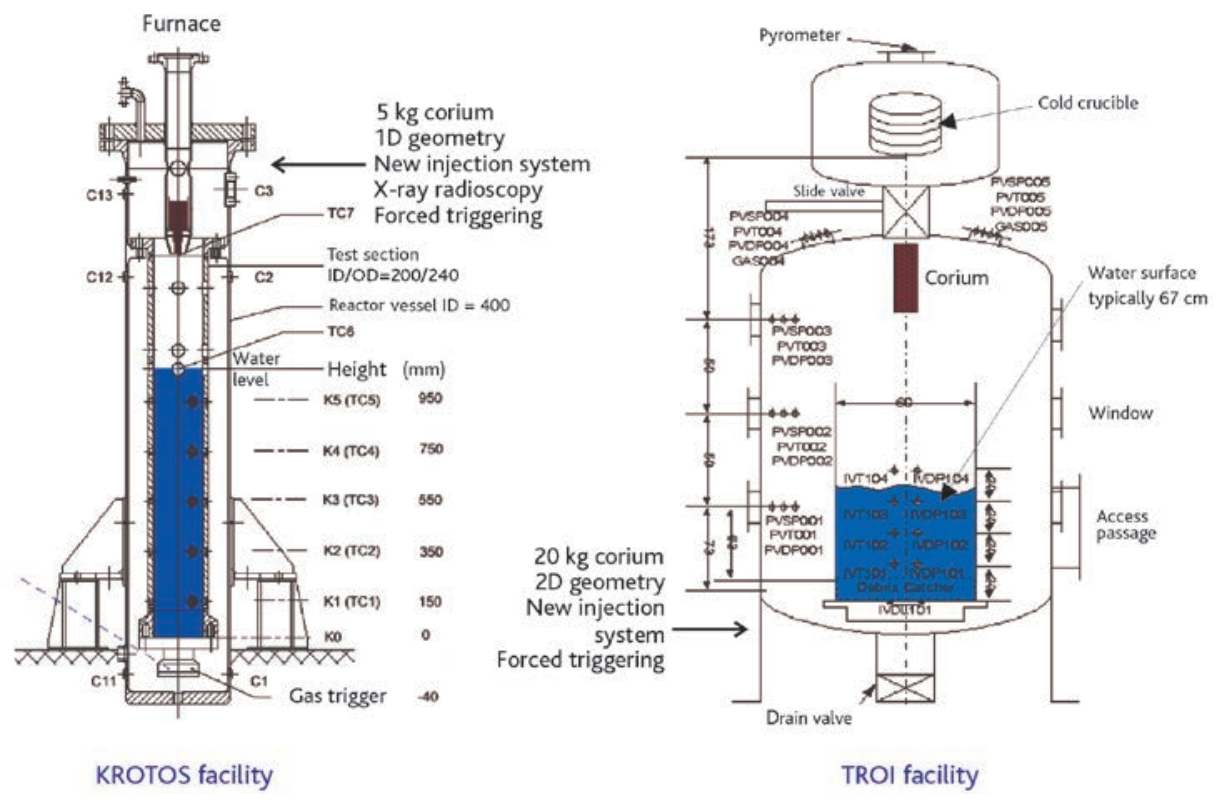

Figure 5.34. KROTOS (CEA, France) [37] and TROI (KAERI, South Korea) experimental facilities [62] Main characteristics and instrumentation. 
negative outcome is the fact that the explosion strengths (peak pressures, impulses) were higher than in previous experiments (with the same melt composition). This is attributed to larger melt masses in the test sections at the moment of triggering the explosion. The analyses of the TROI results indicated also an important "venting effect", i.e. decrease of the pressure waves while travelling from the interaction zone to the walls. The pressure inside the interaction zone can be far higher that the resulting pressure at the wall. Due to this effect, in the hypothetical case of a central vessel break, the loads on the containment structures might be admissible or at least might not lead to immediate failure of the containment integrity (at least for the studied PWR geometry). Another positive outcome, from the point of view of the research efforts, was also the observation that the difference in explosion strengths owing to the exact composition of $\mathrm{UO}_{2} / \mathrm{ZrO}_{2}$ compositions was of second order.

\subsection{Software}

The MC3D computer code is developed and used in France to perform numerical simulations, notably of the pre-mixing and explosion phases [58, 59]. Its development by CEA to simulate steam explosions has mainly been financed by IRSN and partly by EDF. EDF ceased to support this code's development in 2002 and then resumed its support in 2009 when it decided to participate in phase 2 of the SERENA programme. Since 2003, IRSN has been managing and developing the code in collaboration with CEA. Since 2006, the Slovenian JSI institute and the University of Stuttgart Institute of Research (IKE) in Germany have also helped to develop or qualify the code. The MC3D code is now considered as being one of the most advanced steam explosion simulation tools (mainly with JEMI/IDEMO [Germany, GRS/IKE], PM-ALPHA/ESPROSE [United States, UCSB] and JASMINE [Japan]) [59]. MC3D offers many functionalities described later in this document. It is distributed to various international bodies for studying the fuel-coolant interaction (as well as Direct Containment Heating (DCH)) in nuclear reactors.

A steam explosion computer code must process the many interactions between the different phases of the corium and coolant. This involves highly complex modelling with detailed numerical schemes, particularly in order to ensure its robustness. Furthermore, some codes such as MC3D are designed with the dual aims of obtaining results that can be used to assess safety in nuclear installations and improving our understanding of the phenomena involved. This dual purpose (studies and research) involves constraints that are often difficult to reconcile (robustness vs. accuracy).

In the MC3D code PREMIX application, the corium can be modelled in three different ways depending on whether it is in the form of a jet or in the form of droplets:

- the corium jet is modelled by a continuous field by means of a method of monitoring the volume (VOF-PLIC, see Figure 5.35); this numerical methodology is difficult to manage but its handling is a characteristic of the MC3D code, providing a wider scope of investigation than that of the other computer codes;

- the corium droplets are modelled by a field of drops by means of a Eulerian approach; the drops are created through fragmentation of the continuous field. 


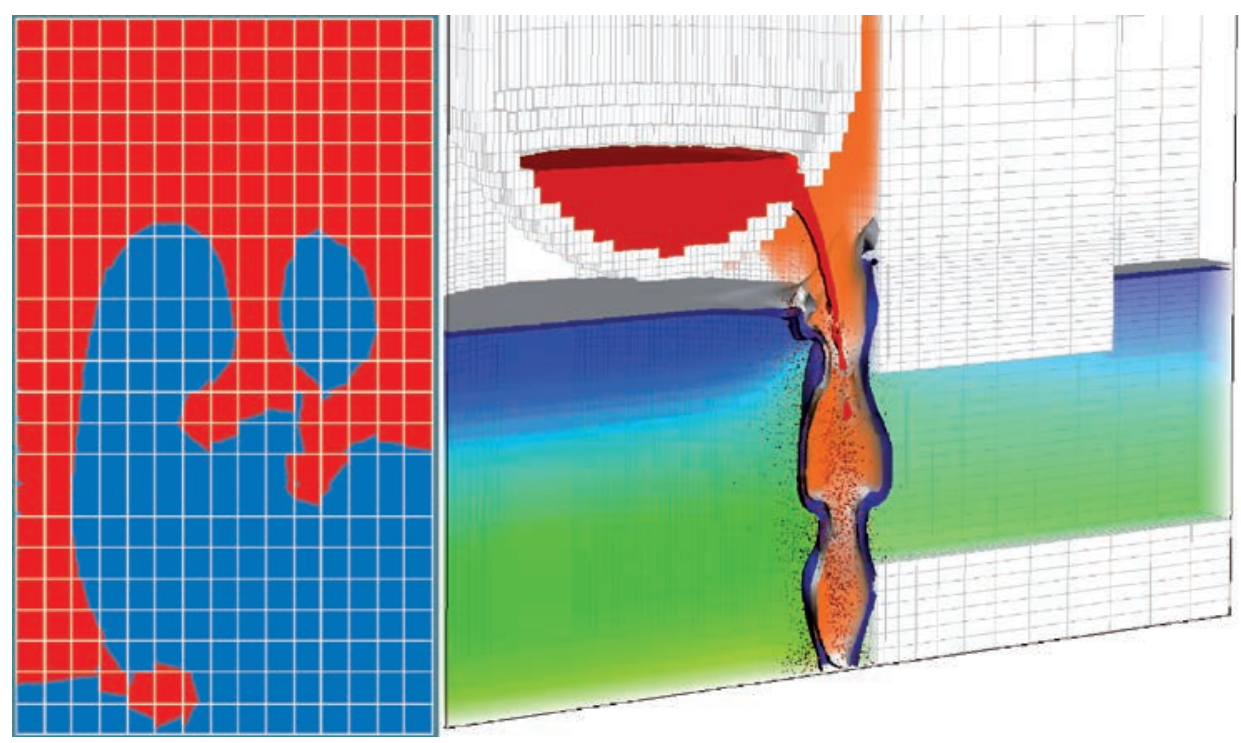

Figure 5.35. Illustrations of the MC3D code VOF-PLIC volume monitoring method for a continuous corium jet (continuous field in red (right) or brown (left); the droplet field is represented by dots). Left to right: Rayleigh-Taylor instabilities, high-pressure corium ejection from a reactor vessel (passage to a two-phase flow at the breach), 3D computation of an ex-vessel interaction, displaying fuel ex-vessel ejection [58] and interaction with the water (displayed in blue) in the reactor pit.

The MC3D code is also special in that it can take into consideration many noncondensing gases and corium oxidation by means of a parametric model. It should be remembered that the oxidation occurring during the explosion may result in a considerable increase in explosion energy. Unfortunately, the oxidation occurring under steam explosion conditions is poorly characterised (or even poorly understood) and the model is currently not sufficiently predictive.

There are fewer functional differences between the codes regarding the explosion phase modelling, and most of them use two fields for the fuel, namely a droplet field and a fragment field recording droplet fragmentation [59].

Some codes, such as PM-ALPHA and IDEMO, use what is known as the "microinteraction" approach, in which the heating of a fraction of the water results in the pressure build-up. The MC3D and JASMINE codes' models assume that, as in the premixing phase, the pressure build-up is due to film vaporisation around the fragments generated by the explosion. IRSN and IKE (using the IDEMO model) are jointly analysing the difference between the two approaches in order to better understand the implications of the various approximations and assumptions.

Although these tools' predictive capabilities are still somewhat limited at this time (they include major uncertainties), they have significantly enhanced overall understanding of the phenomena and the multiple interactions. The MC3D code, despite the constant efforts made to improve the user interface, is still difficult to use because of its complexity, which is itself due to the complexity of the phenomena involved. 
During the SERENA-2 programme, a remarkable evolution of the capabilities of the MC3D code but also of the JEMI/IDEMO codes was obtained. This concerned mainly the physical mechanisms of melt fragmentation and solidification. More recently, JASMINE (JNES) and TEXAS (UW) also received substantial improvements related to solidification and the melt drop description. One important outcome of the analyses conducted during SERENA-2 is the recognition that, in the reactor applications undertaken, mainly due to the large scale, a large fraction of drops are solidified and a large void develops around the melt jet. Both effects, together with the venting effect discussed before, lead to a strong reduction in the potential loads resulting from $\mathrm{FCl}$ on the reactor pit walls. It was also demonstrated that 3D calculations are practically feasible. This is important as it is believed that 2D approximations with a central jet are not fully representative. The real impact of asymmetry of both the flow and the reactor geometry is unclear but it can be investigated only with 3D models.

Following the SERENA-2 conclusions and the Fukushima nuclear accident, a fiveyear programme was launched in 2014. Called ICE, the programme involves the major actors involved in nuclear safety research in France, namely IRSN, CEA, EDF and AREVA. The University of Lorraine is also participating and the programme is partly funded by the French government. The project combines integral experiments in the KROTOS facility, measurements of corium melt properties, dedicated analytical experiments on fragmentation and oxidation and model development for the MC3D code. A significant step forward in knowledge and understanding is expected from the development and use of methods for directly modelling complicated phenomena such as fragmentation, film boiling or oxidation ("quasi" direct simulation). Such methods are expected to give insights that cannot be obtained from experiments due to the very specific conditions (high temperature, high pressures). Some of these developments are done directly in the MC3D code, through specialised new applications.

\subsubsection{Summary and outlook}

The results of the research on steam explosions may appear modest in light of the problems left to solve. This is due to the complexity of the phenomena involved in the interactions between the hot corium and the coolant, on the one hand, and to the difficulty of obtaining experimental data on these interactions for simulants whose composition is typical of a corium formed when a power reactor core melt accident occurs.

The complexity and costliness of the interaction tests using coriums containing uranium have led to the experiments being jointly conducted at the international level, notably resulting in the OECD SERENA programme. This programme aims to provide the missing experimental data for coriums representative of those found in a power reactor accident.

The computer codes include increasingly accurate modelling of the pre-mixing phase and the explosion phase. In this domain too, the work must be shared; this is done by means of partnerships or exchanges, notably in the context of the European SARNET network of excellence (Section 1.3.2). The most difficult key points to describe are jet fragmentation during the pre-mixing phase, corium solidification and its impact upon 
the explosion. A better description of the pressure build-up process during the explosion is also required. These key points form the core of the French ICE project, started in 2014, for five years, which is expected to yield a further step in understanding, modelling and simulation capabilities.

From the power reactor safety point of view, it is generally agreed that there is little risk of a containment rupturing as a direct result of a steam explosion in the reactor vessel (at least in the case of reactors with a large containment, such as the French PWRs). As the flooding of the reactor pit is one of the measures taken or envisaged to limit the consequences of a core melt accident in the operational reactors (with the aim of cooling the corium in the reactor pit and slowing the interaction between the corium and pit concrete, as described in Section 5.3), however, the risk of the containment rupturing as a result of a steam explosion in the reactor pit must be evaluated. Questions also remain concerning the strength of the containment concrete structures, due to the pressure loads caused by a steam explosion.

It should be noted that, in the case of an EPR, the risk of a steam explosion in the reactor pit must be "practically eliminated" by setting up measures guaranteeing that the pit does not contain any water at the time of the corium melt.

\section{Reference documents}

[1] Nuclear Engineering and Design. Special issue on DCH, Vol. 164, 1996.

[2] J.L. Binder, L.M. McUmber, B.W. Spencer, Direct Containment Heating Integral Effects Tests at 1/40 Scale in Zion Nuclear Power Plant Geometry, NUREG/ CR-6168, ANL-94/18, 1994.

[3] T.K. Blanchat, M.D. Allen, M.M. Pilch, R.T. Nichols, Experiments to Investigate Direct Containment Heating Phenomena with Scaled Models of the Surry Nuclear Power Plant, NUREG/CR-6152, SAND93-2519, 1994.

[4] T.K. Blanchat, M.M. Pilch, M.D. Allen, Experiments to Investigate Direct Containment Heating Phenomena with Scaled Models of the Calvert Cliffs Nuclear Power Plant, NUREG/CR-6469, SAND96-2289, 1997.

[5] L. Meyer, G. Albrecht, M. Kirstahler, M. Schwall, E. Wachter, G. Wörner, Melt Dispersion and Direct Containment Heating (DCH) Experiments in the DISCO-H Test Facility, FZKA 6988, 2004.

[6] L. Meyer, M. Gargallo, M. Kirstahler, M. Schwall, E. Wachter, G. Wörner, Low Pressure Corium Dispersion Experiments in the DISCO Test Facility with Cold Simulant Fluids, FZKA 6591, 2002.

[7] L. Meyer, G. Albrecht, C. Caroli, I. Ivanov, Direct containment heating integral effects tests in geometries of European nuclear power plants, Nuclear Engineering and Design 239 (10), 2070-2084, 2009.

[8] M.M. Pilch, M.D. Allen, Closure of the direct containment heating issue for Zion, Nuclear Engineering and Design 164, 37-60, 1996. 
[9] K.K. Murata, D.C. Williams, J. Tills, R.O. Griffith, R.G. Gido, L.G. Tagios, F.J. Davis, G.M. Martinez, K.E. Washington, Code Manual for CONTAIN 2.0: A Computer Code for Nuclear Reactor Containment Analysis, NUREG/CR-6533, SAND97-1735, 1997.

[10] D.C. Williams, R.O. Griffith, Assessment of cavity dispersal correlations for possible implementation in the CONTAIN code, SAND94-0015, 1996.

[11] R. Meignen, S. Mikasser, C. Spengler, A. Bretault, Synthesis of analytical activities on Direct Containment Heating, ERMSAR-2007, FzK GmbH, Germany, 12-14 June 2007, session-3, 2007.

[12] R. Meignen, S. Mikasser, C. Spengler, A. Bretault, D. Plassart, L. Meyer, Direct Containment Heating: Comparison and Analysis of ASTEC, CONTAIN and MAAP, Calculations of the LACOMERA L-1 Test, SARNET-CONT-P09, 2004.

[13] R. Meignen, D. Plassart, C. Caroli, L. Meyer, D. Wilhelm, Direct Containment Heating at Low Primary Pressure: Experimental Investigation and Multi-dimensional Modeling, NURETH-11, Avignon, France, 2005.

[14] S. Mikasser, R. Meignen, Computation and analysis of the Direct Containment Heating dispersion process with the multiphase flow software MC3D, Proceedings of ICAPP 2007, Nice, France, May 13-18, 2007.

[15] W. W. Tarbell, M. Pilch, Pressurized melt ejection into water pools, Sandia National Laboratories, NUREG/CR-3916, 1991.

[16] D. Karwat et al., State-of-the-Art Report on containment thermal hydraulics and hydrogen distribution, NEA/CSNI/R(1999)16.

[17] H. Cheikhravat, Étude expérimentale de la combustion de l'hydrogène dans une atmosphère inflammable en présence de gouttes d'eau, University of Orléans doctoral thesis, September 2009.

[18] H. J. Allelein, K. Fischer, J. Vendel, J. Malet, E. Studer, S. Schwarz, M. Houkema, H. Paillère, A. Bentaib, International Standard Problem ISP-47 on containment thermalhydraulics, Final Report, NEA/CSNI/R(2007)10.

[19] (a) D. Leteinturier et al., Essais H2PAR: période mi-98 à fin 2000 synthèse des essais conclusions du programme, IRSN/DPEA/DIR/02/01 - Not publicly available;

(b) E. Studer, M. Durin, M. Petit, P. Rongier, J. Vendel, D. Leteinturier, S. Dorofeev, Eurosafe Forum, http://www.eurosafe-forum.org/files/b4.pdf

[20] J. Loesel-Sitar et al., Environmental Qualification of Hydrogen Recombiners, Test Report, AECL 00-68460-TR-001 - Not publicly available.

[21] W. Breitung et al., OECD State-of-the-Art Report on Flame Acceleration and Deflagration-to-Detonation Transition In Nuclear Safety, NEA/CSNI/R(2000)7.

[22] S. Dorofeev et al., Large scale experiments for validation of hydrogen combustion models and criteria, article presented to the Jahrestatung Kerntechnick, Stuttgart, May 2002. 
[23] E. Bachellerie et al., Generic approach for designing and implementing a passive autocatalytic recombiner PAR-system in nuclear power plant containments, Nuclear Engineering and Design 221 (1-3), 151-165, 2003.

[24] E. Bachellerie et al., EC PARSOAR project - State-of-the-art report on passive autocatalytic recombiners - Handbook guide for implementing catalytic recombiners, 2002, EUR report, June 2002.

[25] W. Breitung et al., Integral large scale experiments on hydrogen combustion for severe accident code validation HYCOM, Nuclear Engineering and Design 235 (2-4), 253-270, 2005.

[26] J. Malet et al., OECD International Standard Problem ISP-47 on containment thermal-hydraulics - Conclusions of the TOSQAN part, Nuclear Engineering and Design 240 (10), 3209-3220, 2010.

[27] E. Studer, J.-P. Magnaud, F. Dabbene, I. Tkatchenko, International Standard Problem on containment thermal-hydraulics ISP47, step 1-Results from the MISTRA exercise, Nuclear Engineering and Design 237 (5), 536-551, 2007.

[28] D. Paladino, J. Dreier, PANDA: a multipurpose integral test facility for LWR safety investigations, Science and Technology of Nuclear Installations, vol. 2012, Article ID 239319, 9 pages.

[29] P. Rongier, T. Bonhomme, C. Perez, $1^{\text {re }}$ Synthèse H2PAR - Résultats expérimentaux: Fiches d'expériences, expériences E1 à E19 et PHEB 02 - IPSN/DPRE/SERE n 98/014 (I) - Not publicly available.

[30] P. Rongier, T. Bonhomme, C. Perez, $2^{e}$ Synthèse expérimentale H2PAR - Détermination des conditions d'inflammation d'un mélange Air/ $\mathrm{H} 2 / \mathrm{H} 2 \mathrm{O}$ par les recombineurs Siemens et A.E.C.L - Fiches d'expériences - IPSN/DPRE/SERLAB n 99/004 (I) - Not publicly available.

[31] A.A. Dehbi, The effects of noncondensable gases on steam condensation under turbulent natural convection conditions, Ph.D. Thesis, MIT, USA, 1991.

[32] W. Ambrosini, N. Forgione, A. Manfredini, F. Oriolo, On various forms of the heat and mass transfer analogy: discussion and application to condensation experiments, Nuclear Engineering and Design 236, 1013-102, 2006.

[33] ERCOSAM: containment thermal-hydraulics of current and future LWRs for severe accident management, SP5-Euratom, collaborative project, small or medium-scale focused research project, FP7-Fission-2009, Grant agreement N²49691, 2010.

[34] ISP-49 on hydrogen combustion, NEA/CSNI/R(2011)9.

[35] OECD/NEA SETH-2 project PANDA and MISTRA experiments, final summary report, NEA/CSNI/R(2012)5. 
[36] OECD/NEA THAI project final report - Hydrogen and fission product issues relevant for containment safety assessment under severe accident conditions, NEA/CSNI/R(2010)3.

[37] I. Huhtiniemi, D. Magallon, H. Hohmann, Insight into steam explosions with corium melts in KROTOS, Nuclear Engineering and Design 204, 391-400, 2001.

[38] G. Berthoud, L'interaction corium-eau, synthèse et analyse des résultats expérimentaux, STT/LPML/87/28/C, 1987. Not publicly available.

[39] D. E. Mitchell, M. L. Corradini, W. W. Tarbell, Intermediate Scale Steam Explosion Phenomena: Experiments and Analysis, NUREG/CR-2145, SAND81-0124, 1981.

[40] D. E. Mitchell, N. A. Evans, Steam Explosion Experiments on Intermediate Scale: FITSB Series, NUREG/CR-3983, SAND83-1057, 1986.

[41] B. W. Marshall Jr., Recent Fuel-Coolant Interaction Experiments Conducted In The FITS Vessel, SAND87-2467C, 1988.

[42] R. Meignen, G. Berthoud, Fragmentation of molten fuel jets, Proceedings of the International Seminar of Vapor Explosions and Explosive Eruptions, pp. 83-89, 1997.

[43] J. Namiech, G. Berthoud and N. Coutris, Fragmentation of a molten corium jet falling into water, Nuclear Engineering and Design 229 (2-3), 265-287, 2004.

[44] SERENA - Steam Explosion Resolution for Nuclear applications, final report, December 2006. NEA/CSNI/R(2007)11.

[45] J. Lamome, R. Meignen, On the explosivity of a molten drop submitted to a small pressure perturbation, Nuclear Engineering and Design 238 (12), 3445-3456, 2008.

[46] M. Bürger, S.H. Cho, E.V. Berg, A. Schatz, Modelling of drop fragmentation in thermal detonation waves and experimental verification, Specialists Meeting on $\mathrm{FCl}$, Santa Barbara, California, USA, Jan 5-8, 1993.

[47] S.J. Board, R.W. Hall and R.S. Hall, Detonation of fuel coolant explosions. Nature 254 (3), 319-321, 1975.

[48] W. W. Yuen and T. G. Theofanous, On the existence of multiphase thermal detonations, International Journal of Multiphase Flow 25 (6-7), 1505-1519, 1999.

[49] M. Berman, Light water reactor safety research program, quarterly report, JanuaryMarch 1981, NUREG CR-2163/lof4, SAND81-1216/lof4, 1981.

[50] D.H. Cho, D.R. Armstrong and W.H. Gunther, Experiments on Interactions Between Zirconium-Containing Melt and Water, NUREG/CR-5372, 1998.

[51] L. Meyer, QUEOS, An Experimental Investigation of Pre-mixing Phase with hot spheres, Proc. OECD/CSNI Specialist Meeting on FCI, Tokai-Mura, Japan, 19-21 May 1997, pp. 155-166.

[52] (a) Technical opinion paper on fuel coolant interaction. NEA/CSNI/R(99)24. 
(b) Nuclear Safety Research in OECD Countries, Major Facilities and Programmes at Risk. NEA \# 03145, ISBN: 92-64-18468-6, 2001.

[53] S.K. Wang, C.A. Blomquist, B.W. Spencer, L.M. Mc Umber and J.P. Schneider, Experimental Study of the Fragmentation and Quench Behaviour of Corium Melts in Water, Proc. 5th Nuclear Thermal Hydraulics, San Francisco, 1989, pp. 120-135.

[54] D. Magallon, H. Hohmann and I. Huhtiniemi, Lessons Learnt from FARO/TERMOS Corium Melt Quenching experiments, Nuclear Engineering and Design 189, 223238, 1999.

[55] D. Magallon and I. Huhtiniemi, Energetic event in fuel-coolant interaction test FARO L-33, ICONE-9 Conference, Nice, France, 8-12 April 2001.

[56] J.H. Song, J. H. Kim, S. W. Hong, B. T. Min, H. D. Kim, The effect of corium composition and interaction vessel geometry on the prototypic steam explosion", Annals of Nuclear Energy 33 (17-18), 1437-1451, 2006.

[57] Characterization of Molten-Fuel Coolant Interaction Processes, EUR 19567 EN, 4th EC Framework Program, 1999.

[58] R. Meignen, Status of the Qualification Program of the Multiphase Flow Code MC3D, Proceedings of ICAPP '05, Seoul, KOREA, 15-19 May 2005, paper 5081.

[59] R. Meignen et al., Comparative Review of FCI Computer Models Used in the OECDSERENA Program, Proceedings of ICAPP '05, Seoul, KOREA, 15-19 May 2005, paper 5087.

[60] M. Bürger, Comparison and Theoretical Interpretation of Experiments on Hydrodynamic Drop Fragmentation. IKE 2-FB-16, (CEC-RCAMFCI Project, Report INVMFC(98)-D014), Universität Stuttgart, July 1998 - Not publicly available.

[61] H.S. Park, R.C. Hansson, B.R. Sehgal, Fine fragmentation of molten droplet in highly subcooled water due to vapor explosion observed by X-ray radiography, Experimental Thermal and Fluid Science 29 (3), 351-361, 2005.

[62] J. H. Song, I. K. Park, Y. S. Shin, J. H. Kim, S. W. Hong, B. T. Min and H. D. Kim, Fuel coolant interaction experiments in TROI using a $\mathrm{UO}_{2}-\mathrm{ZrO}_{2}$ mixture, Nuclear Engineering and Design 222 (1), 1-15, 2003.

[63] P. Marmottant, E. Villermaux On spray formation, Journal of Fluids Mechanics 498, 73-111, January 2004.

[64] L. S. Nelson, P. M. Duda, Steam explosion experiments with single drops of iron oxide melted with a $\mathrm{CO}_{2}$ laser, NUREG/CR-2295, SAND81-1346, 1981.

[65] R.C. Hanson, An experimental study on the dynamics of a single droplet vapor explosion, Doctoral thesis, School of Engineering Science, KTH, Sweden, 2010.

[66] E. Villermaux, Fragmentation, Annu. Rev. Fluid. Mech., 419-446, 2007. 


\subsection{Phenomena that could lead to delayed containment failure: Molten Core-Concrete Interaction (MCCI)}

\subsubsection{Introduction}

In the event of reactor-vessel failure during a core melt accident, the corium resulting from this core melt and the melting of internal structures will pour onto the reactor pit basemat. Contact between corium and concrete leads to what is called Molten Core-Concrete Interaction. This interaction involves gradual erosion of the concrete basemat (see Figure 5.36) and the walls of the reactor pit, which could lead to basemat penetration, and consequent release of radioactive substances outside the containment building into the ground. Furthermore, contact between the corium and any water present in the reactor pit and adjacent rooms could contribute an increase in the pressure inside the containment building via vaporisation of this water, or could even lead to a steam explosion (see Section 5.2.3). Gases resulting from reactions between corium and concrete also contribute to increasing the pressure inside the containment building. Taking uncertainties into account, the penetration time for the concrete basemat will be from one to several days, depending on the quantity of corium, its possible cooling and the type of concrete (siliceous or calcareous). It should be noted finally that the aerosol production that accompanies $\mathrm{MCCl}$ also affects how the behaviour of radioactive aerosols inside the containment changes and therefore affects any resulting releases.

\subsubsection{Physical phenomena involved}

The residual heat released by fission products within the corium spread on the basemat of the reactor building (20 to $30 \mathrm{MW}$ at the start of the accident for a $900 \mathrm{MWe}$ PWR) cannot be removed by conduction via the basemat due to its thickness and the very low thermal conductivity of concrete; it is only partially dissipated by radiative heat transfer from the surface of the corium. The corium, whose liquidity depends on its composition (which depends on the development of core damage during the accident), therefore heats up to the melting point of the oxide materials $\left(\mathrm{UO}_{2}, \mathrm{ZrO}_{2}\right)$ and the metals from the vessel (i.e. to a temperature of approximately $2200^{\circ} \mathrm{C}$ ), leading to the formation of a corium pool with a temperature exceeding the decomposition temperature of concrete. The heat released by the fission products is transferred by convection to the edges of the corium pool and provokes the destruction of the concrete walls of the reactor pit and their loss of integrity by decomposition of concrete (this process is generally called erosion or ablation). Siliceous or silico-calcareous concrete erodes from $1330^{\circ} \mathrm{C}$ and calcareous concrete from a temperature several hundred degrees higher than that. After an initial corium heating phase, $\mathrm{MCCl}$ therefore leads to a phase of continuous erosion of the concrete walls. During this phase, the residual heat is largely dissipated at the corium-concrete interfaces via erosion of the concrete, and to a lesser extent by radiative heat transfer from the surface of the corium pool (see Figure 5.36). 


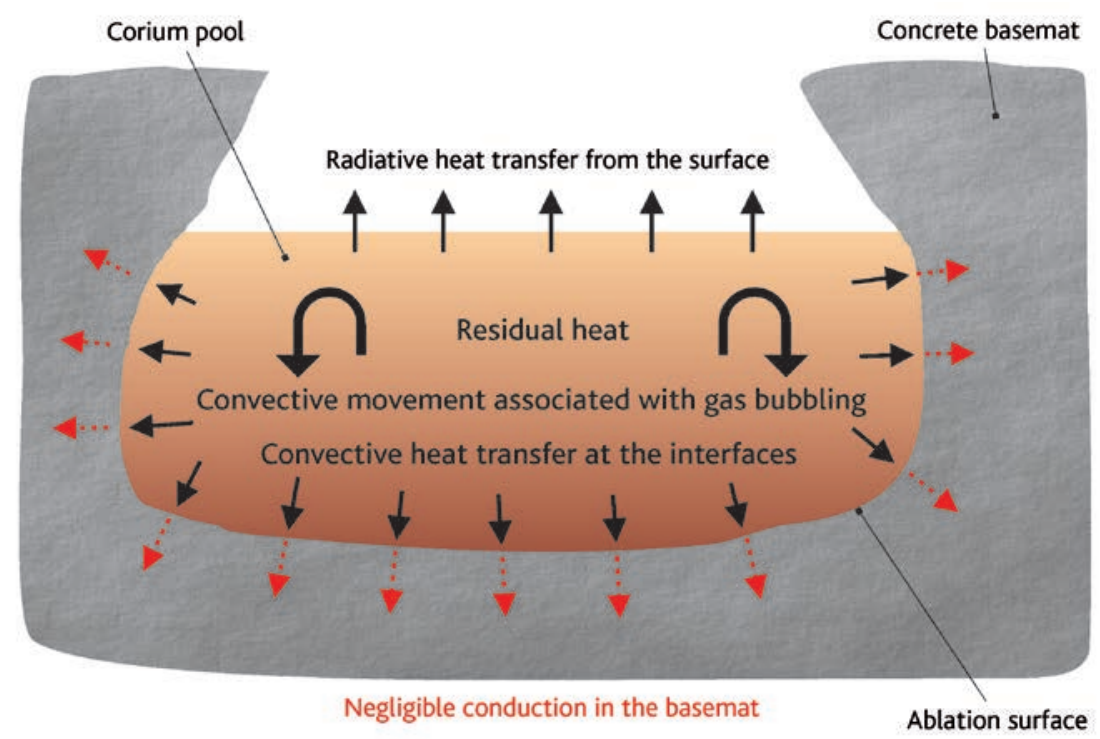

Figure 5.36. Formation of a cavity by erosion of the reactor-pit basemat.

As the concrete is made up mainly of $\mathrm{SiO}_{2}, \mathrm{CaCO}_{3}$ and $\mathrm{H}_{2} \mathrm{O}$, its decomposition leads to the release of condensed $\left(\mathrm{SiO}_{2}\right.$ and $\left.\mathrm{CaO}\right)$ and gaseous $\left(\mathrm{H}_{2} \mathrm{O}\right.$ and $\left.\mathrm{CO}_{2}\right)$ phases into the pool. The corium pool therefore contains heavy oxides from the reactor core $\left(\mathrm{UO}_{2}\right.$ and $\mathrm{ZrO}_{2}$ ), light oxides from the concrete (mainly $\mathrm{SiO}_{2}$ and $\mathrm{CaO}$ ) and metals ( $\mathrm{Fe}, \mathrm{Cr}, \mathrm{Ni}$ and $\mathrm{Zr}$ ), all subject to the mixing induced by the concrete decomposition gases. The mixing of metals with oxides in condensed or gaseous form can lead to exothermic oxidation reactions that produce gases such as $\mathrm{H}_{2}, \mathrm{CO}$ and $\mathrm{SiO}(\mathrm{g})$. Finally, contact between hot corium and colder concrete can lead to local formation of a crust by solidification, and fragments of this crust can become suspended in the liquid corium. The corium pool therefore has several constituents and several phases (liquid, solid and gas) whose composition and physical properties constantly change during $\mathrm{MCCl}$, due to decomposition of the concrete and to chemical reactions.

As the rate of erosion of the horizontal and vertical walls is directly correlated to the relationship between the heat flux received by the walls and the energy density required for their erosion, determination of the rate of erosion of these walls requires calculation of the heat flux distribution at the edges of the corium pool. Even if there are multiple immiscible phases, the liquid pool produced by $\mathrm{MCCl}$ is uniform due to the mixing induced by the gases; however, steep temperature and concentration gradients may exist at the interfaces (see Figure 5.37). The heat flux at the pool interfaces may therefore be calculated using a convective heat transfer coefficient $\left(h_{\text {conv }}\right)$, the pool temperature $\left(T_{b}\right)$ and the temperature of the interface $\left(T_{i}\right)$ between the corium pool and an interface layer separating the concrete from the corium (the composition and temperature of this interface layer are intermediate between those of the corium pool and those of the concrete; the layer may be liquid or solid depending on the conditions); the interface temperature 


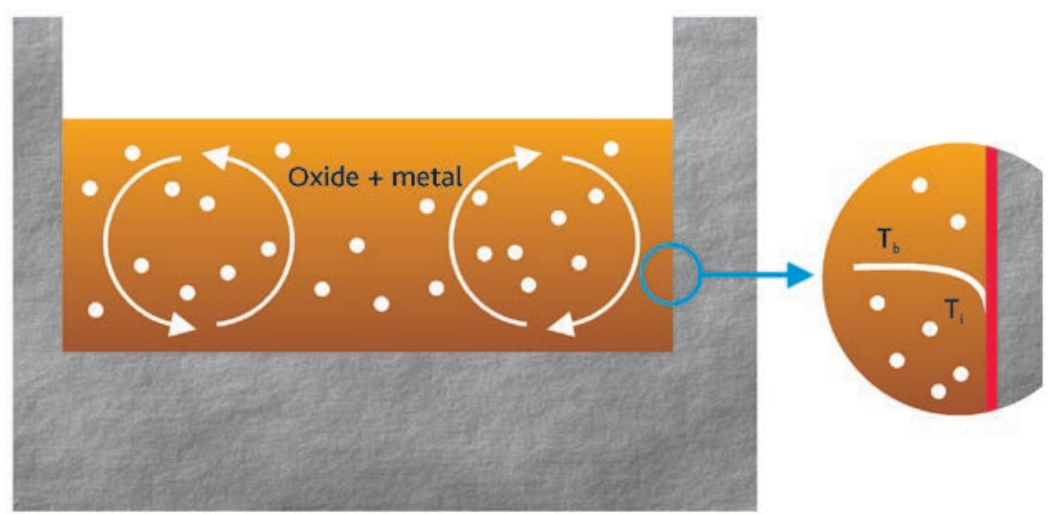

Figure 5.37. Perfectly mixed oxide-metal pool produced by an MCCl. Right: Detail of the pool-concrete interface.

depends on the type of interface between the corium and the concrete (i.e. whether a stable crust forms or not). The configuration of the pool produced by $\mathrm{MCCl}$ may be single layer (oxide and metal mixed) or two layer (oxide and metal stratified based on their respective densities), depending on the gas flowrate released by the concrete and the densities of the oxide and metal phases (which are only partially miscible). In the latter case (see Figure 5.38), determination of temperature at the interface, and of heat transfer coefficient is therefore necessary not only for the interfaces between the layers and the concrete, but also for the interface between the "oxide" liquid and the "metal" liquid.

To facilitate reading of the rest of this section, three phases of $\mathrm{MCCl}$ are distinguished: short term, medium term and long term. As will be seen below, the behaviour of the pool produced during $\mathrm{MCCl}$ depends on:

- its physical transport properties (density, thermal conductivity, specific heat capacity, viscosity and, to a lesser extent, liquid-gas surface tension) and its

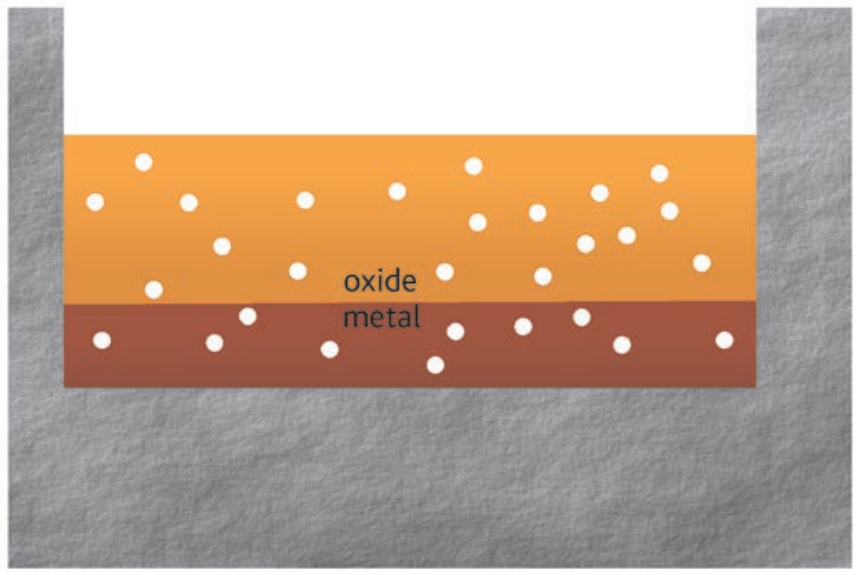

Figure 5.38. $\mathrm{MCCl}$ pool in a stratified configuration. 
thermochemical properties, which are themselves a function of the composition of the pool, in particular the concentration of compounds from concrete erosion;

- the heat flux at the pool interfaces, which is a function of pool volume, and therefore of the quantity of matter from concrete erosion;

- the superficial gas velocity (volume flowrate of gases per unit surface area) along the interface between pool and concrete, proportional to the heat flux.

It therefore seems appropriate to distinguish various phases of $\mathrm{MCCl}$, depending on the concentration of "concrete oxides" in the pool:

- the short-term phase corresponds to a mass fraction of "concrete oxides" in the pool below $25 \%$ (in practice, for a power reactor this corresponds to the initial hours of $\mathrm{MCCl}$ ), with physical and thermochemical properties little different from those of the materials coming from the core, and vigorous gas bubbling;

- the medium-term phase corresponds to a higher mass fraction of "concrete oxides" in the pool (up to around 50\%), i.e. in practice, for a power reactor, to the period between 5 and 15 hours from the start of $\mathrm{MCCl}$, where the physical and thermochemical properties have significantly changed from those of the materials coming from the core but where heat flux at the pool interfaces and gas bubbling remain strong;

- finally, the long-term phase corresponds to a mass fraction of "concrete oxides" in the pool over more than $50 \%$, i.e. in practice, for a power reactor, to the period beyond 15 hours from the start of $\mathrm{MCCl}$, where heat flux at the interfaces and gas bubbling are significantly lower.

\subsubsection{Experimental programmes}

Study of $\mathrm{MCCl}$ includes experiments and computer models. The purpose of the experiments is to identify and understand the corresponding phenomena (heat transfers, solidification, mixing etc.); they are supplemented by studies using simulation software that include models that have been qualified on the basis of experimental data.

Tests devoted to the study of molten core-concrete interactions can be classified into two categories:

- analytical tests, which study one or more specific phenomena using simulant materials at a reduced scale; these tests can determine certain physical values concerning the phenomena studied (interface temperatures, heat transfer coefficients etc.);

- integral tests during which concrete erosion rates are measured, and in certain cases, pool temperatures during $\mathrm{MCCl}$ for coriums made up of simulant materials (containing alumina or thermite) and for coriums more representative of the composition expected during a core melt accident on a power reactor (generally containing a $\mathrm{UO}_{2}+\mathrm{ZrO}_{2}$ mixture). 


\subsubsection{Analytical tests}

\section{Heat transfer coefficients}

Numerous analytical tests were performed between 1980 and 2010, see [1], [2] and [3], aiming to determine the heat transfer coefficients between a liquid pool and a bubbling porous wall. Examination of the results of these various tests, see [5], shows that the physical properties of the liquids used have often been close to those of water and that the data available mainly involves horizontal walls. For water, measurements performed during the various experimental programmes give similar results for the same superficial gas velocity. Data regarding viscous liquids (as for corium "enriched" with concrete erosion compounds) and vertical walls are quite rare, see [4]. However, test results in water show that the heat transfer coefficients between a fluid and a vertical wall are similar to those obtained for a horizontal wall. The CLARA experiments [6], which are described below, were launched in 2007, with a view to filling in gaps in knowledge regarding distribution of heat transfer coefficients along pool interfaces, which influence the distribution of heat fluxes and radial and vertical erosion of concrete during an $\mathrm{MCCl}$.

Results pertaining to heat transfer coefficients between two immiscible liquids with gas bubbling (stratified pool configuration, see Figure 5.38) are less common, see [7] and [8]. In particular, examination of these results shows a significant dispersion of results (by around a factor of 5). Furthermore, the tests are not representative of situations where there is solidification at the interface between the pool and the concrete. However, the $A B I$ tests, see [9], performed until 2008, show that the order of magnitude of the heat transfer coefficient between two stratified oxide and metal layers is comparable to that determined using the correlation deduced from the Werle tests, see [8], and that this heat transfer coefficient is probably large compared with the heat transfer coefficient between a liquid pool and a porous wall mentioned above. These results mean that, in a stratified configuration, heat transfer from the oxide layer into the metal layer could accelerate erosion of the concrete wall in contact with the metal layer (in the lower part, see Figure 5.38). This also highlights the interest of a reliable prediction of pool stratification (mixing and separation phenomena).

\section{Interface temperatures at the edges of a corium pool}

The ARTEMIS programme (see [10]), performed by CEA from 2003 to 2008, is the only one that aimed to determine temperatures at the edges of a corium pool. It studied the coupling between physico-chemistry and thermal-hydraulics through tests conducted with simulant materials ( $\mathrm{LiCl}$ and $\mathrm{BaCl}_{2}$ salt mixtures), whose phase diagram has a similar form to that of the compounds present during an $\mathrm{MCCl}$ for a power reactor, as shown in Figure 5.39.

Tests performed in one-dimensional configurations (horizontal corium-concrete interface) confirmed that, under test conditions representative of the long-term phase of $\mathrm{MCCl}$ for a power reactor in terms of concrete erosion rate and gas bubbling, 
the interface temperatures at pool edges were close to the liquidus temperature of the pool and that the pool temperature decreased with liquidus temperature due to enrichment of the pool with compounds from concrete erosion. However, the interface structure seems to be more complex than expected, with the formation near the interface of a solid porous zone out of thermal equilibrium (i.e. with liquid-solid interface temperature and composition that deviate from those imposed by thermal equilibrium between the liquid and solid phases). Examination of the results of ARTEMIS 1D experiments, see [11] and [12], also shows that, under conditions comparable to those of the short-term and medium-term phases of an $\mathrm{MCCl}$ for a power reactor, the results are not compatible with an assumption of thermodynamic equilibrium: the temperature of the pool-crust interface deviates from the liquidus temperature, the pool becomes mushy in the event of significant gas bubbling, and crusts form at the corium-concrete interface with a composition less refractory than that deduced from the phase diagrams.

Following an initial stage of the ARTEMIS programme dedicated to tests with purely axial erosion, the second stage (ARTEMIS 2D) was dedicated to the study of configurations with two-dimensional concrete erosion (i.e. in both axial and radial directions) during $\mathrm{MCCl}$ tests with differing compositions between pool and concrete and "concrete-concrete" tests with no difference in composition between pool and concrete. The results show significant concrete erosion on the upper part of the concrete side walls for all tests, very little erosion on the lower interface between pool and concrete during concrete-concrete tests and the formation, during $\mathrm{MCCl}$ tests, of a very thick

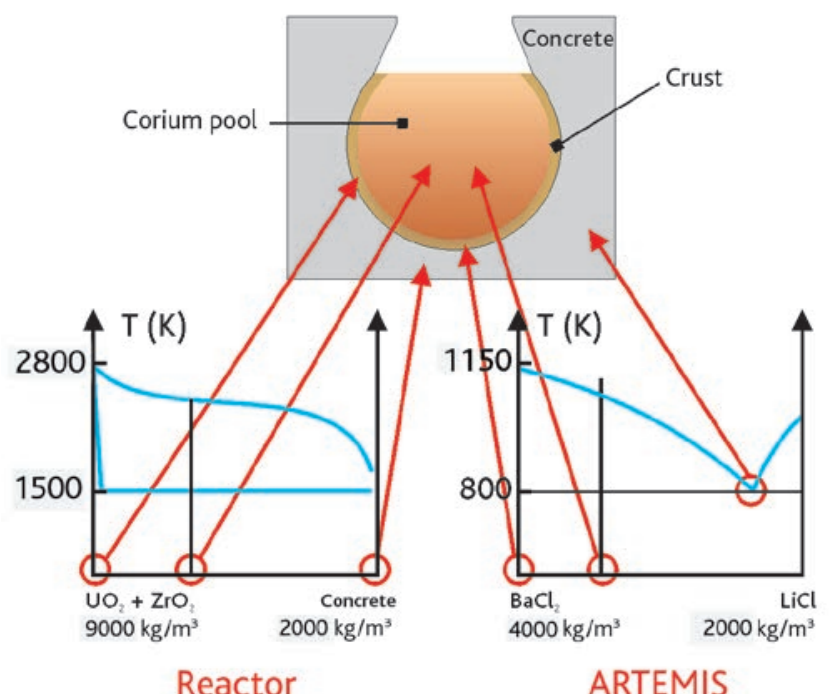

Figure 5.39. Comparison between the phase diagrams of simulant materials from ARTEMIS tests and those of corium materials which would form during a core melt accident on a power reactor (the $\mathrm{BaCl}_{2}$ salt simulates the refractory behavior of corium and the $\mathrm{LiCl}-\mathrm{BaCl}_{2}$ eutectic simulates the behavior of concrete), see [10]. 
mushy crust of corium at the lower interface between the pool and the concrete (covering around a third of the pool); during the tests, this crust remained hot and embedded itself into the concrete. These unexpected results in terms of concrete erosion (in all cases, more concrete erosion was expected in the lower part of the pool) are probably explained by pool bypass by the gases injected into the lower part, due to the formation of stable, leaktight crusts at the lower pool-concrete interface; these crusts meant that gases could not pass during most of the tests. At the scale of a power reactor, it is unlikely that a large non-cracked crust would form at the lower pool-concrete interface. The results of the ARTEMIS 2D tests are therefore not directly applicable to a power reactor; however, they have brought to light the strong dependence of the $2 \mathrm{D}$ erosion profile on gas flow conditions in the pool.

\section{- Mixing and separation of immiscible liquids with gas bubbling}

The mixing and separation of immiscible liquids with gas bubbling has been studied with the aim of predicting the corium pool configuration during $\mathrm{MCCl}$ (i.e. whether the pool is mixed or stratified). The main experimental work on this subject was performed using simulant materials at the Argonne National Laboratory (ANL, [13]) and the University of Wisconsin (see [14]) in the United States, and more recently at CEA Grenoble (BALISE tests), see [15]; all experiments were purely hydrodynamic (with no study of phase change effects). They aimed to determine limit values in terms of superficial gas velocity (or void fraction) leading to a mixed or stratified pool depending on the density difference between the liquids. The results summary given in [15] shows a - sometimes wide - dispersion of results, partially due to differences in the physical properties of the liquids used. Nevertheless, these experiments clearly demonstrate that stratification of a corium pool can only take place for low superficial gas velocities, which are only possible during the long-term phase of $\mathrm{MCCl}$ for a power reactor.

\section{Physical properties of the materials}

Analytical tests with prototypic corium compositions, like those which would form during core melt accident on a power reactor, have also been performed to validate and supplement knowledge regarding the thermophysical properties (in particular viscosity, see [21]) and thermochemical properties of corium, which are needed for the computer models of heat transfer and solidification phenomena for the corium pool outside the reactor vessel. These tests meant that improved estimates could be made of the viscosity of a corium formed from a mix of oxides (as a function of silica concentration), and of the solidus and liquidus temperatures of the corium-concrete mixes.

\subsubsection{Integral tests}

Integral tests provide an overview of $\mathrm{MCCl}$, with all phenomena involved operating in a coupled manner. These tests are difficult to perform given the associated technological difficulties (very high temperatures and materials used etc.). All integral $\mathrm{MCCl}$ tests performed up to 2012 are summarised in Table 5.5 below. 
Table 5.5. Summary of integral $\mathrm{MCCl}$ tests.

\begin{tabular}{|c|c|c|c|c|}
\hline Programme & Characteristics & $\begin{array}{c}\text { Mass } \\
\text { of corium }\end{array}$ & Geometry & Parameters \\
\hline SURC (1D) & $\begin{array}{l}\text { Prototypic corium } \\
\text { compositions } \\
+ \text { fission products }\end{array}$ & $200 \mathrm{~kg}$ & $\begin{array}{l}\text { 0.4-m-diameter } \\
\text { cylinder }\end{array}$ & $\begin{array}{l}\text { Concrete } \\
\text { composition, } \\
\text { power }\end{array}$ \\
\hline ACE (1D) & $\begin{array}{l}\text { Prototypic corium } \\
\text { compositions } \\
+ \text { fission products }\end{array}$ & $\begin{array}{l}250 \text { to } \\
450 \mathrm{~kg}\end{array}$ & $\begin{array}{l}\text { Rectangular box } \\
0.5 \mathrm{~m} \times 0.5 \mathrm{~m} \times 0.4 \mathrm{~m}\end{array}$ & $\begin{array}{l}\text { Concrete } \\
\text { composition, } \\
\text { power }\end{array}$ \\
\hline MACE (1D) & $\begin{array}{l}\text { Prototypic corium } \\
\text { compositions } \\
\text { water injection }\end{array}$ & $\begin{array}{l}100 \text { to } \\
1800 \mathrm{~kg}\end{array}$ & $\begin{array}{l}\text { Rectangular box }(0.5 \text { to } \\
1.2 \mathrm{~m}) \times(0.5 \text { to } 1.2 \mathrm{~m}) \\
\times 0.4 \mathrm{~m}\end{array}$ & $\begin{array}{l}\text { Concrete compo- } \\
\text { sition, power, } \\
\text { water flowrate }\end{array}$ \\
\hline BETA (2D) & $\begin{array}{l}\text { Thermite-alumina + iron } \\
\text { oxide-metal stratified pool }\end{array}$ & $450 \mathrm{~kg}$ & $\begin{array}{l}0.4 \text {-m-diameter } \\
\text { conical frustum }\end{array}$ & $\begin{array}{l}\text { Concrete } \\
\text { composition, } \\
\text { power }\end{array}$ \\
\hline $\begin{array}{l}\text { COMET-L } \\
\text { (2D) }\end{array}$ & $\begin{array}{l}\text { Thermite-alumina }+ \text { iron } \\
\text { oxide-metal stratified pool }\end{array}$ & $920 \mathrm{~kg}$ & $\begin{array}{l}\text { 0.6-m-diameter } \\
\text { cylinder }\end{array}$ & $\begin{array}{l}\text { Concrete } \\
\text { composition, } \\
\text { power }\end{array}$ \\
\hline $\begin{array}{l}\text { OECD-MCCI } \\
(2 \mathrm{D})\end{array}$ & $\begin{array}{l}\text { Prototypic corium } \\
\text { compositions }\end{array}$ & $\begin{array}{l}350 \text { to } \\
550 \mathrm{~kg}\end{array}$ & $\begin{array}{l}\text { Rectangular box } \\
0.5 \mathrm{~m} \times(0.5 \mathrm{~m} \text { or } \\
0.7 \mathrm{~m}) \times 0.6 \mathrm{~m}\end{array}$ & $\begin{array}{l}\text { Concrete } \\
\text { composition, } \\
\text { power, pool } \\
\text { geometry }\end{array}$ \\
\hline ARTEMIS 2D & Simulants (salts) & 110 kg & $\begin{array}{l}\text { 0.3-m-diameter, } \\
\text { 0.6-m-high cylinder }\end{array}$ & $\begin{array}{l}\text { Power, } \\
\text { gas flowrate }\end{array}$ \\
\hline $\begin{array}{l}\text { VULCANO- } \\
\text { ICB (2D) }\end{array}$ & $\begin{array}{l}\text { Prototypic corium } \\
\text { compositions }\end{array}$ & $40 \mathrm{~kg}$ & $\begin{array}{l}\text { 0.3-m-diameter, } \\
0.3 \text {-m-high } \\
\text { half-cylinder }\end{array}$ & $\begin{array}{l}\text { Concrete } \\
\text { composition, } \\
\text { power }\end{array}$ \\
\hline
\end{tabular}

Interpretation of these integral tests is complex due to the limited number of measurements and the lack of precision associated with some of them, the difficulty of estimating heat losses and sometimes the difficulty in quantifying the influence of certain phenomena associated with the test set-up which may affect heat transfers above the pool: effects of the heating method and scale effects which could affect pool formation, ejection of matter (which changes the inventory of corium participating in $\mathrm{MCCl}$ ), and crust adhesion on the walls. Despite these difficulties, the tests performed have brought to light phenomena which had not been previously identified and which could be significant: the strong influence of the type of concrete on the progress of axial and radial erosion and on the ejection of corium during an $\mathrm{MCCl}$ under water during the MACE tests; $\mathrm{MCCl}$ under water is presented in more detail in Section 5.4.2.

From a chronological standpoint, 1D tests with oxides (ACE, MACE and SURC) date from twenty years ago or more. Their analysis has provided an improved understanding of $\mathrm{MCCl}$, supported certain assumptions regarding the corium behaviour models (decrease in pool temperature close to the liquidus temperature) and partially validated simulation software. 
2D tests performed between 2003 and 2012 with oxides representative of a corium which would form during a core melt accident on a power reactor, have provided information on the 2D heat flux distribution during $\mathrm{MCCl}$ (see [16] and [17]). The results of these tests tend to show that, at least at the beginning of $\mathrm{MCCl}$ (the first four hours), concrete erosion is preferentially in the radial direction for siliceous concrete and similar in both radial and axial directions for silico-calcareous concrete (see [18]), as shown in Figure 5.40 .

Tests using siliceous concrete show a possible scale effect on the anisotropy of erosion during the initial phase of $\mathrm{MCCl}$. Analysis and interpretation of these results helped better understand the effect of the type of concrete on 2D erosion and to produce a model to better appreciate the erosion kinetics for the case of a power reactor.

Very few results exist for tests performed with materials representative of a corium which would form during a core melt accident on a power reactor and with pool heating representative of the residual heat of a corium for oxide-metal stratified configurations. The BETA and COMET tests were performed with simulant materials and their (induction-based) heating method meant that the heat was injected into the metal phase, whereas it would come from the oxide phase for a power reactor. The BETA tests showed preferential concrete erosion in the axial direction; however, this behaviour cannot be extrapolated to a power reactor for the reasons mentioned above and because the mass of metal is overestimated with respect to that of a power reactor, see [19]. Only the VULCANO tests, performed with a more representative heating method and composition of pool oxides and metals (see [20]), could provide answers to the question of possible existence of pool stratified during $\mathrm{MCCl}$, which would lead to a high axial erosion rate, as illustrated by the applications to a power reactor presented in Section 5.3.5.
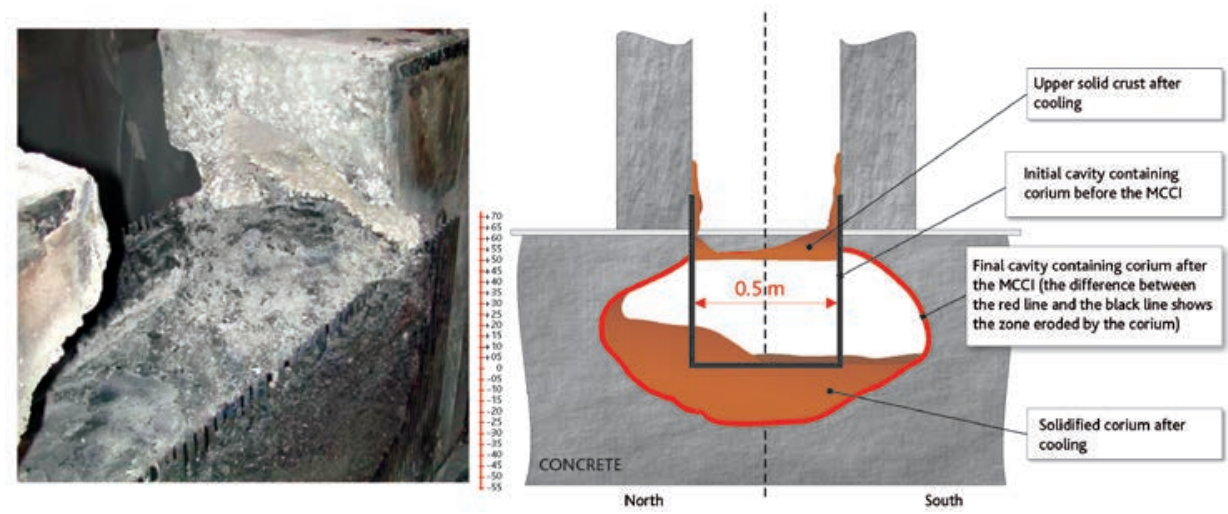

Figure 5.40. Final cavity obtained during the OECD-MCCI CCl-2 experiment, performed with a silicocalcareous concrete; the photo on the left shows the cavity formed in the concrete; this is represented in red on the diagram on the right (cross-section on the vertical axis). 


\subsubsection{Computer modelling and simulation software}

\subsubsection{Models}

\section{Pool behaviour and pool-concrete interface temperatures}

The oldest approach to determining the behaviour of the corium pool and pool-concrete interface temperatures during an $\mathrm{MCCl}$ assumed that, if the mean temperature of the corium pool is between the liquidus temperature and the solidus temperature, the pool is in a "mushy" state, intermediate between a solid phase and a liquid phase. The crust that forms at the interfaces has the same composition as the corium pool and the same solid fraction as the corium at the pool-crust interface. The interface between the pool (with or without crust) and the concrete is made up of a thin layer of decomposed concrete, called the "slag layer". The solid-liquid equilibrium temperature is therefore the solidus temperature and the entire mushy zone is assumed to participate in convective flow near the solid interface. However, use of this assumption does not reproduce the temperature variations measured during certain ACE and OECD-MCCI tests.

In 2000, CEA produced a model called the "phase-segregation model" to describe the behaviour of the corium pool during an MCCI. This model is deduced from the model that couples thermal-hydraulics and physico-chemistry, used to describe the behaviour of the corium in the reactor vessel, see [21]. It is assumed that the pool is liquid and that crusts made up of refractory compounds $\left(\mathrm{UO}_{2}\right.$ and $\left.\mathrm{ZrO}_{2}\right)$ form at the interface between the corium pool and the concrete. These crusts may be unstable. Mechanisms of crust formation at the interfaces and mechanisms that could affect their stability are little understood, in particular those that could explain the instabilities of the crusts formed at the interfaces with the vertical concrete walls, the presence of crusts during initial corium-concrete contact, and then the longer-term disappearance of crusts even at the bottom of the pool, as shown by certain inspections performed after VULCANO tests with an oxide pool. For applications to power reactors, the permanent existence of crusts at the interfaces is considered plausible given the duration of $\mathrm{MCCl}$ and the large pool volume. At the pool-crust interfaces, thermodynamic equilibrium is assumed to exist between the two physical phases present (the pool liquid and the crust solid), with the interface temperature being the liquidus temperature of the pool. If a departure from equilibrium occurs, liquid-solid segregation is partial or absent in the pool, which becomes mushy and the pool-crust transition may therefore correspond to a solid fraction threshold above which conduction dominates convection. The pool-crust interface temperature would then be lower than the liquidus temperature of the pool. This type of approach is adopted in the model used in the MEDICIS code developed at IRSN [27], described in detail in Section 5.3.4.2.

The phase segregation model has been partially validated using the results of ARTEMIS 1D tests, with regard to interactions with a horizontal wall and for low erosion and bubbling rates, which correspond to the long-term phase of $\mathrm{MCCl}$ for a power reactor. However, this "ideal" model, which assumes thermodynamic equilibrium at the pool-concrete interface, does not satisfactorily explain the results of the ARTEMIS 1D tests, with rapid erosion and significant bubbling, which corresponds to the initial 
highly-transitory phase of the interaction; furthermore, this model is not relevant for the long-term phase for a power reactor, despite the good agreement with the ARTEMIS 1D test results corresponding to these conditions, due to the high concentration of silica in the pool in the long-term phase, which reduces the diffusion of chemical species in the pool and delays attainment of equilibrium at the interface, see [22].

\section{Distribution of heat fluxes at the corium-concrete interface}

Numerous correlations of heat transfer between a pool and a bubbling horizontal wall are cited in the literature, see [1] to [4] and [7]. They have been produced on the basis of the experimental data mentioned above, or from more theoretical approaches. They are expressed as correlations which give the Nusselt number $\mathrm{Nu}$ as a function of the Reynolds number Re and the Prandtl number Pr under the assumption that heat transfer is associated with a forced convection produced by the concrete decomposition gases, or $\mathrm{Nu}$ as a function of the Rayleigh number $\mathrm{Ra}$ and $\operatorname{Pr}$ under the assumption that heat transfer is associated with natural convection; the Prandtl number Pronly depends on the fluid properties; the Reynolds number Re depends on the transport properties of the pool and the superficial gas velocity; the Rayleigh number Ra depends on the transport properties of the pool and the void fraction, and therefore indirectly on the superficial gas velocity. The ranges of variation of the physical properties of fluids used for the tests with simulant materials (see Section 5.3.3.1) are narrow and do not always cover those of a corium pool representative of an $\mathrm{MCCl}$, see [23]. Although the correlations give identical results for the experimental conditions of tests performed with simulant materials, a wide dispersion of results is observed when these correlations are used with parameters representative of a power reactor. This dispersion probably shows that the dimensionless numbers used in the correlations do not correctly reflect all physical phenomena involved or the respective weightings of the various physical parameters, due to the narrow range of experimental data used to establish these correlations. For this reason, a model based on a more phenomenological approach was proposed in 2005, see [24]; it provides satisfactory results for the conditions of available experimental data (horizontal wall and vertical wall, see [5]) but would need additional validation for viscous liquids. Finally, it is important to note that, rather than the local value of the heat transfer coefficient between pool and the crusts, it is the distribution of the value of the heat transfer coefficient at the surface of the pool that is crucial to determining the distribution of local heat fluxes and erosion rates during the pseudo-steady state which exists during the longest part of $\mathrm{MCCl}$.

For this reason, the CLARA analytical test programme was launched by CEA and IRSN to improve understanding of the distribution of heat transfer coefficients along the pool interfaces and their variations as a function of superficial gas velocity and pool viscosity.

With regard to heat transfers between the oxide and metal layers which form during pool stratification, several models are found in the bibliography, deduced from analytical tests, see [7], [8] and [25]. Due to the lack of experimental results and the dispersion of the available results, these models were reviewed in 2010 , see [1] taking into account the most recent results obtained for measurement of the convective heat 
transfer coefficient in the context of the $A B I$ experimental programme performed at CEA Grenoble, see [9]. The main conclusion of this work, see [1], is that convective heat transfer between the layers is greater than radial heat transfer, which leads to a rate of axial concrete erosion that is higher than that of radial erosion; however, possible formation a permeable crust at the interface between the two liquids, which would reduce this heat transfer, is difficult to model, precisely because of the probable instability of this crust.

\section{Mixture and separation of immiscible liquids with gas bubbling}

Test results produced with simulant materials are the basis of the development of experimental correlations, see [15], used to estimate the superficial gas velocity thresholds that lead to mixture or stratification of the pool; the values obtained present a non-negligible dispersion (several tens of\%). These correlations have not been validated on test results with real materials, and their use for a power reactor would lead to highly varied configurations: a largely mixed configuration or a stratified configuration or a partially stratified configuration over a longer or shorter period of $\mathrm{MCCl}$. In particular, uncertainties concern the dependence of the correlations on the physical properties of the liquids, the respective volumes of the metal and oxide layers and the size of bubbles.

\subsubsection{Simulation software}

Various software packages developed for $\mathrm{MCCl}$ studies, see [26], [27] and [30], are based on identical basic assumptions:

- the corium pool is made up of various layers (of oxides or metals) each of uniform temperature and chemical composition;

- the corium pool can be in a mixed (uniform) or stratified configuration;

- the structure of the interface is described by a thermal resistance model that takes into account the possible formation of a solid crust or a zone of concrete decomposition products (a thin layer of decomposed concrete called the "slag layer"). The concrete erosion rate is estimated using Stefan's law, which determines the quantity of heat coming from the corium pool that is not removed by conduction in the concrete and which serves to erode the concrete.

These software packages are mainly distinguished by their corium behaviour models and by the sub-models (or correlations) that they use (such as correlations to calculate void fraction, heat transfers etc.).

The TOLBIAC-ICB code (see [26]), developed by CEA, is based on the phase segregation model described above, which assumes the pool of liquid corium and the formation of crust of refractory material at the interface: the interface temperature is the liquidus temperature of the pool (over $2200 \mathrm{~K}$ for a large part of $\mathrm{MCCl}$ ). It is calculated from the pool composition using a coupling with the GEMINI2 thermodynamic code. 
In contrast, the CORCON code (see [30]), developed by Sandia National Laboratories in the United States, considers that the pool is a mix of liquid and solid debris in suspension and assumes the existence of a mushy zone, if the pool temperature is between the liquidus and solidus temperatures. The thin layer of decomposed concrete ("slag layer") model is used describe the corium-concrete interfaces. In this approach, the pool-crust interface temperature is close to the concrete decomposition temperature.

The MEDICIS code (see [27]), developed by IRSN, uses a more flexible model to describe the behaviour of the pool interfaces: it is assumed that a mushy zone exists at the interface between the liquid pool and the concrete, including a convection zone and a conduction zone. In this approach, the interface temperature used for convective heat transfers from pool to interface is the threshold temperature at the border between the convective part of the pool and the conductive part of the mushy zone ( $T_{\text {solidification }}$ on Figure 5.41). As no model can satisfactorily determine this interface temperature in all circumstances, it is arbitrarily set by the user between the liquidus temperature and the solidus temperature, or deduced from a threshold value for the molten fraction of pool corium. The extreme options correspond to the interface model in TOLBIAC (liquidus temperature) and that adopted in CORCON (solidus temperature). MEDICIS validation leads to recommending an interface temperature value a little lower than the liquidus temperature, or a molten fraction threshold of approximately $50 \%$. Phase segregation in the crusts is not taken into account, as the crusts are usually thin at the coriumconcrete interface; however, liquidus and solidus temperatures and the relationship between the molten corium fraction, its composition and its temperature are assessed using the GEMINI2 code prior to an $\mathrm{MCCl}$ calculation. It is also assumed that a thin layer of decomposed concrete (the "slag layer") exists between the concrete and the pool (with or without crusts).

The main steps of an $\mathrm{MCCl}$ calculation are as follows:

- calculate the physical properties of the pool;

- calculate the (possible) solid fraction in the pool;

- determine the interface temperature;

- calculate the heat transfer coefficients;

- estimate the concrete erosion rates;

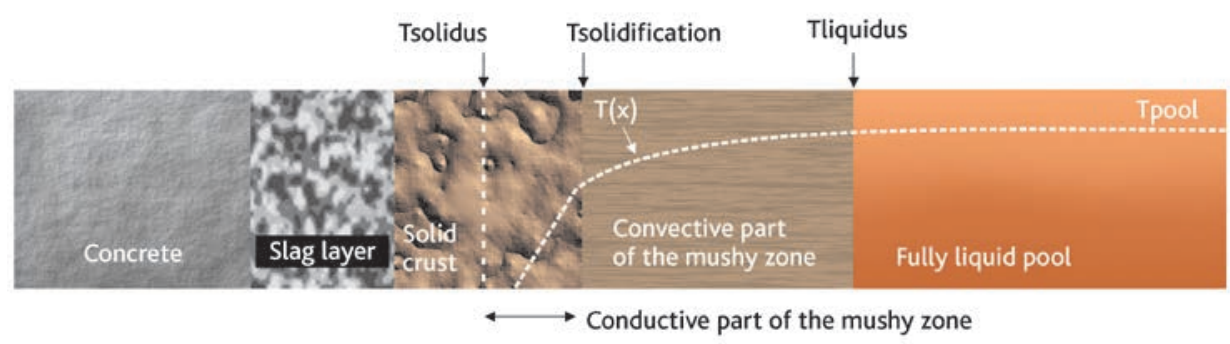

Figure 5.41. Model of the corium-concrete interface used in the MEDICIS code. 
- perform a mass balance (taking chemical reactions into account) and an energy balance (including radiative heat transfer from the surface) to obtain the composition and temperature of each pool zone;

- calculate the thicknesses of crusts and erosions;

- update the form of the cavity and the heat transfer surfaces.

Simulation software is validated using the test results presented in the previous section. For integral tests, this validation process is made more complex by the numerous phenomena observed during these tests that are not covered by the computer models (such as corium ejection and deposits of matter on the walls of the test sections) and the specifics of the experimental set-ups, as mentioned previously.

Generally, the validity of simulation software for application to a power reactor is limited by uncertainties on scale effects, as the models implemented in this code have only been validated using test results at a scale 10 to 20 times smaller than that of a power reactor. The obvious solutions for overcoming this difficulty are the performance of larger-scale tests with prototypic materials, or the development of mesh-based simulations able to represent the thermal-hydraulics and heat transfer physics at various scales, in order to confirm extrapolation from the scale of the tests to that of a power reactor. The first solution runs into issues of technical feasibility and cost. The second solution assumes development and validation of turbulence models applicable to a pool with gas bubbling; these models would only be applicable to idealised situations with regard to the structure of the pool interfaces and would require the implementation of simulations that may not be available for many years.

\subsubsection{Application to a power reactor}

As an example, this section presents application to a 900 MWe PWR performed using the MEDICIS code, see [27] and [28], for the case of a reinforced siliceous-concrete basemat with an axial thickness of $4 \mathrm{~m}$. Conservative bounding assumptions have been used for the initial conditions to obtain bounding results in terms of concrete erosion; in particular, all the reactor core that becomes corium is assumed to be present in the reactor pit at the beginning of $\mathrm{MCCl}$ and the effects of any water present and of radial erosion of the basemat are ignored.

The main calculation assumptions adopted are similar to those used for interpreting the $\mathrm{MCCl}$ tests of the $\mathrm{MCCl}$ programme at the ANL, see [16], leading to 2D isotropic erosion, see [29]. For a uniform pool, a heat transfer model is adopted that is independent of the orientation of the interfaces, and an interface temperature slightly below the liquidus temperature is used. The convective heat transfer coefficient between the oxide and metal layers, which applies to the stratified configuration, has been deduced using Greene's correlation, see [7], which tends to overestimate heat transfer.

Large uncertainties exist regarding pool configuration and how it changes over time. For this reason, three very different scenarios have been considered for the concrete erosion calculation. 
(1) A scenario with a uniform pool maintained throughout $\mathrm{MCCl}$ (see Figure 5.42), which leads to slow erosion and a basemat penetration time of approximately 5 to 9 days, depending on the thickness of concrete to be eroded ( $3 \mathrm{~m}$ to $4 \mathrm{~m}$ ).

Axial and radial erosion rates remain low due to the uniform distribution of heat flux at the pool-concrete interfaces, leading to uniform erosion and a very large zone of eroded concrete as shown in Figure 5.42.

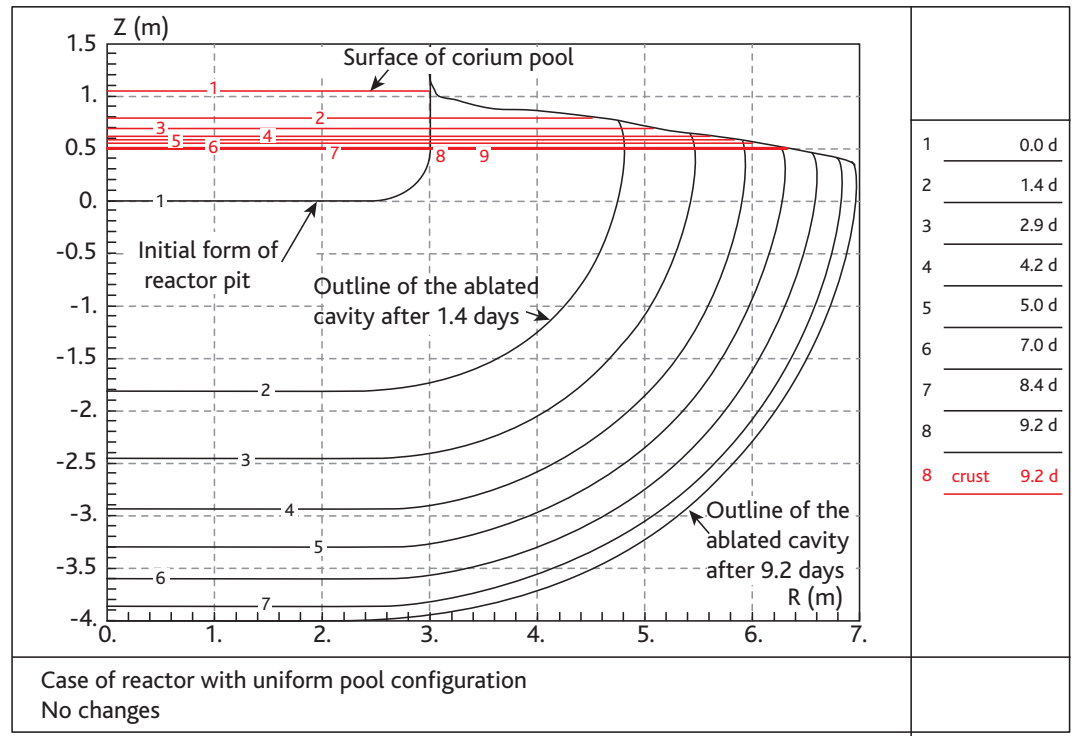

Figure 5.42. Case of a power reactor with a uniform pool configuration changes calculated for the cavity resulting from concrete erosion (axial erosion along the $Z$-axis and radial erosion along the $\mathrm{R}$-axis) until basemat penetration after 9.2 days. The last curve corresponds to the time that axial basemat penetration occurs.

(2) For illustrative purposes, an unrealistic scenario with a stratified pool where the metal layer is assumed to be below the oxide layer from the start of the interaction, which leads to a very high rate of axial erosion, with a basemat penetration time of between 14 and 24 hours depending on its thickness. The reason for rapid erosion in this case is the high heat transfer coefficient at the metal-oxide interface, which leads to residual heat removal being concentrated at the bottom of the pool, thereby promoting axial erosion (see Figure 5.43).

(3) A more realistic scenario, which involves four phases with changing pool configurations (see Figure 5.44). In this scenario, the pool is assumed to be initially stratified with the oxide layer below the metal layer due to the higher density of the oxides (initial short-term phase), then it mixes and becomes uniform due to significant gas bubbling (second medium-term phase); then, in a third phase (start of the long-term phase), the pool become stratified again but with the metal layer below the oxide layer due to the reduction in oxide density caused by the addition of compounds from concrete erosion; 


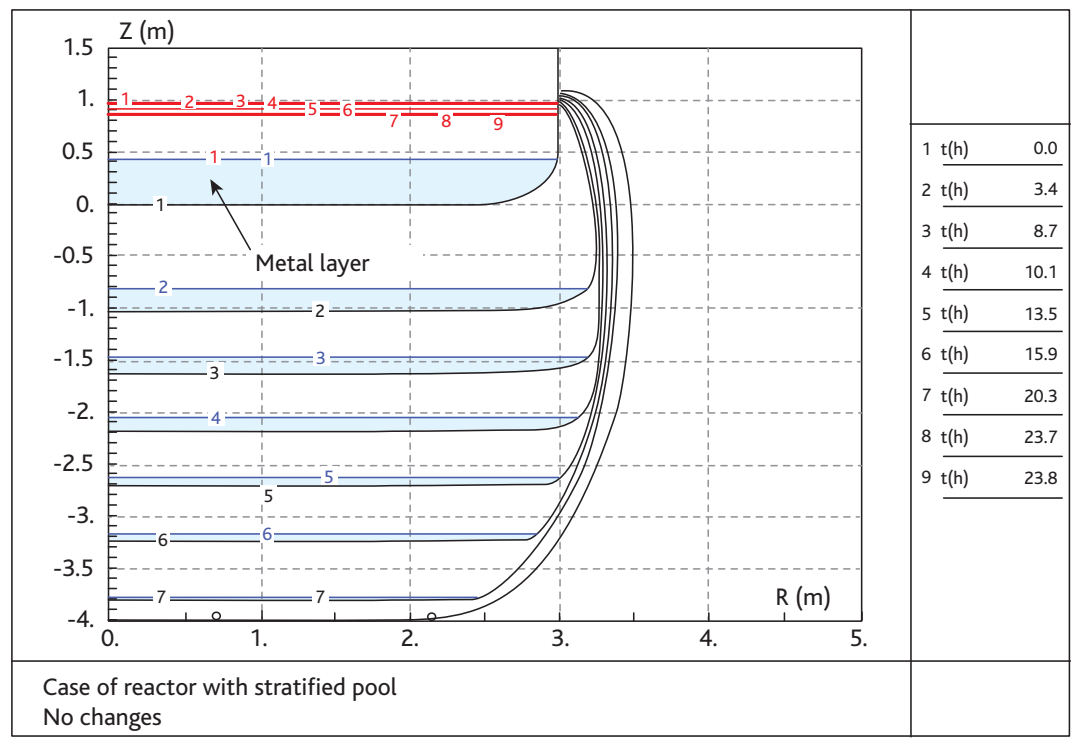

Figure 5.43. Case of a power reactor with a stratified configuration - changes calculated for the cavity resulting from concrete erosion (axial erosion along the $\mathrm{Z}$-axis and radial erosion along the $\mathrm{R}$-axis) in approximately 3 -hours steps, with axial penetration after approximately 24 hours. The last curve corresponds to the time that axial basemat penetration occurs.

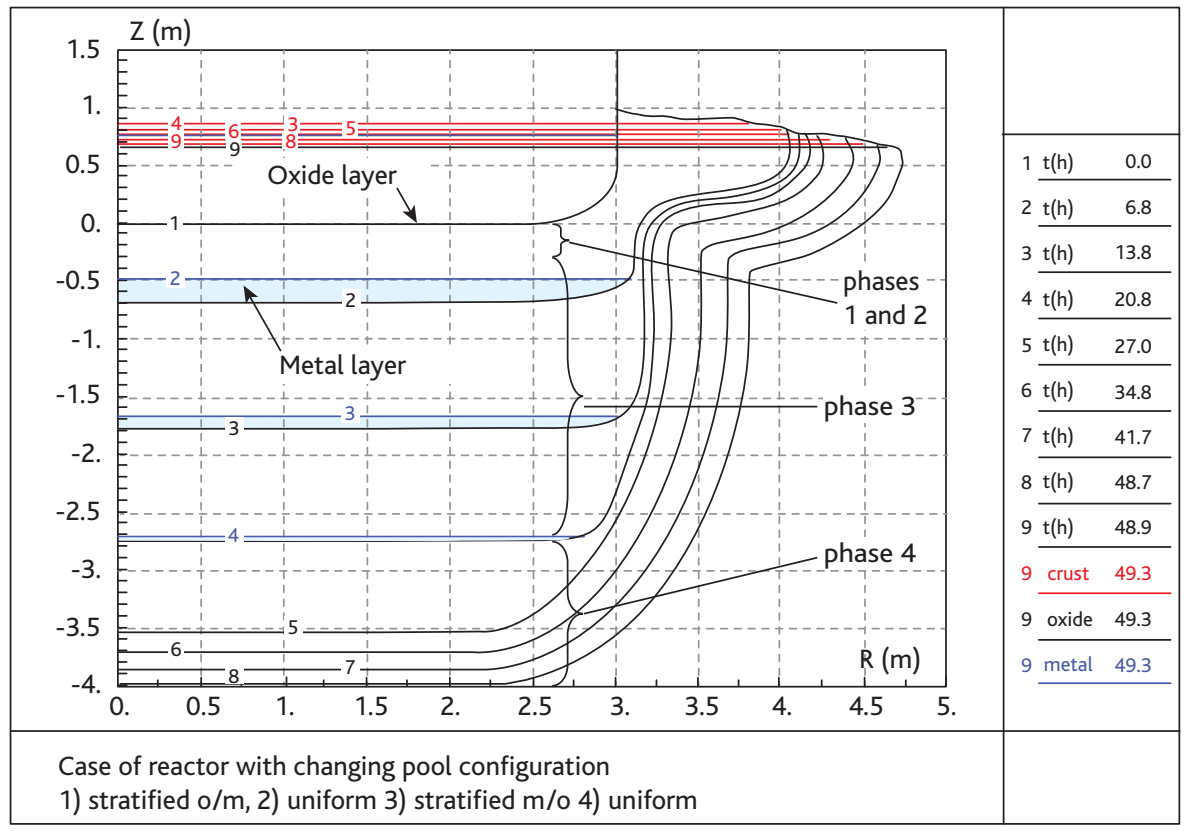

Figure 5.44. Case of a power reactor with changing pool configuration - changes calculated for the cavity resulting from concrete erosion in approximately 6 -hours steps, with axial penetration after approximately 49 hours (o/m: the oxide layer is above the metal layer; $\mathrm{m} / \mathrm{o}$ : the metal layer is above the oxide layer). 
finally in a fourth longer-term phase, the pool becomes uniform again as the metal layer disappears due to oxidation. Changes in pool configuration are determined using criteria deduced from the BALISE tests mentioned above in Section 5.3.3.1, see [15]. When configuration changes are taken into account, basemat penetration time is extended by at least 24 hours with respect to a fixed stratified configuration with the metal layer below the oxide layer (compare Figures 5.43 and 5.44).

The results of basemat penetration time calculations are given in Figure 5.45 below. This figure shows that the effect of pool stratification on basemat penetration time would only disappear if the heat transfer coefficient between the oxide and metal layers was very small (by a factor of more than 20) compared with the available experimental data. However, high values of the oxide-metal heat transfer coefficient due to the mixing caused by gas bubbling have been confirmed (at least in terms of order of magnitude) by the experiments in the ABI programme cited in Section 5.3.3.1, see [9].

It should be noted that the calculations given above are based on certain conservative assumptions:

- the assessment criteria for pool configuration assumes that its stratification occurs from the beginning of separation of the oxide and metal phases and that this stratification is maintained even for a thin metal layer; a more realistic criterion for configuration changes, taking into account limitation of stratification in the event of a thin metal layer which is still to be confirmed, would probably lead to axial penetration times of several days;

- the heat transfer coefficient at the pool-concrete interface is assumed to be independent of the orientation of this interface for an oxide pool (and for a metal pool). However, for a siliceous concrete and in an oxide pool configuration, heat transfers could be less at the lower interface than at the lateral interface, as shown by certain results from the $\mathrm{MCCl}-\mathrm{OECD}$ programme, see [16]; a model taking these results into account leads to a reduction in axial erosion rates;

- corium reflooding in the event of water injection is ignored.

Figure 5.45 shows that penetration of the reactor-pit walls (leading to partial spillage of corium outside the reactor pit into the containment building) takes place before axial penetration in the event of slow to moderate axial erosion, and slows later axial erosion by reducing the corium inventory in the reactor pit.

Finally, it should be noted that axial erosion is slower for a silico-calcareous concrete than for a siliceous concrete:

- gas velocity is greater for a silico-calcareous concrete due to the concrete's greater gas content, which has the effect of reducing the period during which stratification is possible;

- the decomposition enthalpy is higher, which reduces axial and radial erosion rates in a uniform configuration. 


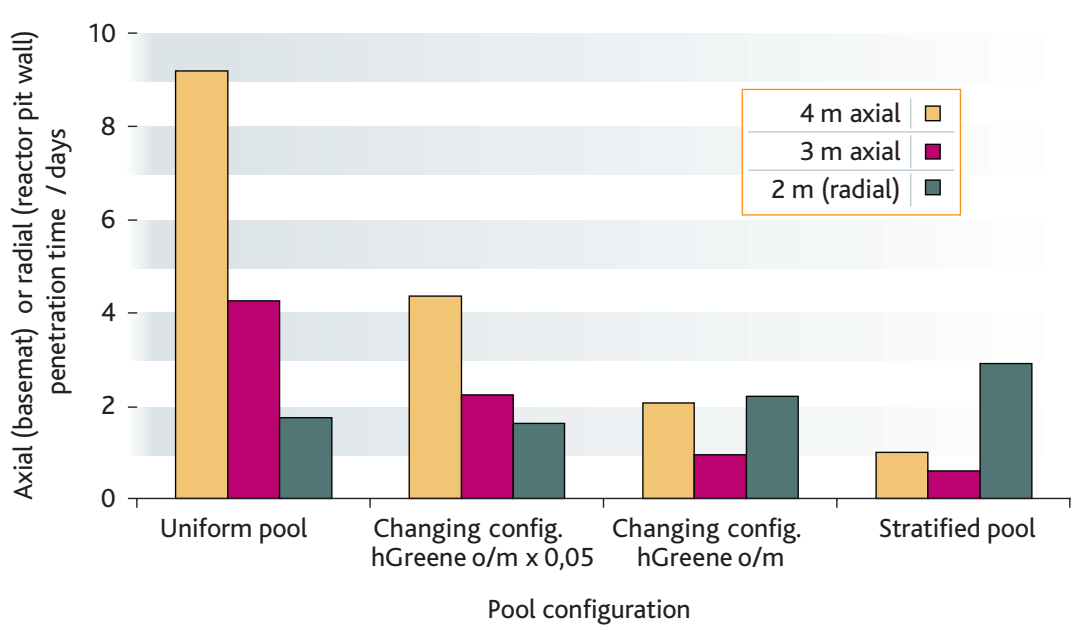

Figure 5.45. Reactor-pit basemat and wall penetration times as a function of pool configuration: uniform pool (see Figure 5.42); stratified pool (see Figure 5.43); changing pool configuration for a calculation performed using a convective heat transfer coefficient between the oxide and metal layers deduced from Greene's correlation (hGreene o/m, see Figure 5.44); changing pool configuration for a calculation performed using a heat transfer coefficient reduced by a factor of 20 compared with that given by Greene's correlation (hGreene o/m x 0.05) and convective heat transfers between the oxide and metal layers.

\subsubsection{Summary and outlook}

The results of experiments and calculations performed for a power reactor using the MEDICIS and TOLBIAC-ICB code bring to light the following main areas of uncertainty, see [31]:

- the nature and properties of the corium pool interfaces: pool solidification temperature, and heat and mass transfers at the corium-concrete interfaces;

- the 2D (radial and axial) distribution of convective heat fluxes in a uniform pool;

- heat and mass transfers between metal and oxide layers in a stratified configuration;

- changes in pool configuration (stratification).

Knowledge of the interface structure has progressed over the last decade but remains inadequate. Indeed, analysis of the ARTEMIS 1D experiments, performed with a uniform pool and a horizontal interface, shows that the phase segregation model at thermal equilibrium (with a pool-crust interface temperature close to the liquidus temperature) applies well to a case of slow concrete erosion and low gas velocities, a situation that could correspond to the long-term phase for a power reactor; however, the high pool viscosity in this phase slows diffusion of chemical species and could lead to a different composition at the interface than that for thermodynamic equilibrium. For faster erosion, a situation that corresponds to the short- and medium-term phases for a power reactor, the phase segregation model is no longer suitable due to being far from thermodynamic equilibrium. Furthermore, analysis of 2D MCCl tests performed with real 
materials also shows that the pool is often mushy and the pool-crust interface temperature lower than the liquidus temperature, in particular for siliceous concrete, see [29]; in addition, associated inspections did not bring to light a crust on any corium-concrete interface, including the horizontal interface, contrary to what was observed during tests with simulant materials (ARTEMIS 1D tests).

Major uncertainties also exist regarding the last three points mentioned above, i.e. the distribution of heat fluxes at pool interfaces, heat transfers between the metal and oxide layers in the stratified configuration, and changes in pool configuration. In particular, improved understanding of heat transfers between the metal and oxide layers and of the types of pool configuration and their changes, would strongly reduce uncertainties regarding axial and radial erosion rates for a stratified pool configuration, which remain major, see [33].

In 2015, end of the VULCANO MCCI experiments (with materials representative of a power-reactor corium) and associated work - such as interpretation of the tests and comparison of the results obtained with various code packages - provided further understanding of the physical phenomena that govern the structure of the interfaces, and supplemented knowledge of the 2D distribution of heat fluxes for a uniform pool configuration. Additional $\mathrm{MCCl}$ tests for stratified pool configurations are envisaged to contribute to reducing remaining uncertainties by providing results regarding heat transfers between oxide and metal layers and regarding changes to the pool configuration.

The CLARA programme, which ended in 2012 and used simulant materials, aimed for better understanding of 2D erosion for a uniform pool, by detailed study of convective heat transfers between a heated pool and a bubbling porous wall, in a 2D situation with simplified boundary conditions (without erosion) over a large range of pool viscosities.

Qualification using a large-scale test would be necessary, due to probable scale effects on convective heat transfer and on the structure of the corium-concrete interfaces. Such a test, with an initial pool size of around one metre, was planned in Russia in 2011 in the context of the programmes of the International Science and Technology Center (ISTC), but the project was not completed due to administrative difficulties.

Pool stratification criteria should also be better defined and better validated, in particular the superficial gas velocity threshold and maximum thickness of metal below which stable pool stratification appears.

Furthermore, a programme of additional studies aiming to reduce uncertainties on the thermochemical properties of corium was performed in the context of the ISTC programme (the PRECOS project) and mainly involved determination of the phase diagrams for certain mixtures of oxides and metals of compositions selected in a range where thermochemical data is inadequate or uncertain. Analysis of the associated experimental results should provide additional data for the thermochemical databases used by software (such as GEMINI2, see [32]) to calculate thermodynamic values for corium. 


\section{Reference documents}

[1] S.S. Kutateladze, Boiling and bubbling heat transfer under free and forced convection of liquid, Int. J. Heat Mass Transfer 22, 1979.

[2] M.R. Duignan, G.A. Greene, T.F. Irvine Jr, Heat transfer from a horizontal bubbling surface to an overlying water pool, Chem. Eng. Comm. 87, 1990.

[3] J.M. Bonnet, Thermal-hydraulic phenomena in corium pools for ex-vessel situations: the BALI experiments, 8th Int. Conf. On Nuclear Engineering (ICONE), Baltimore, USA, April 2-6, 2000.

[4] D.K. Felde, H.S. Kim, S.I. Abdel-Khalik, Convective heat transfer correlations for molten core debris pools growing in concrete, Nuclear Engineering and Design 58, 1980.

[5] B. Tourniaire, O. Varo, Assessment of two-phase flow heat transfer correlations for molten-core concrete interaction study, Nuclear Technology 164, 2008.

[6] M. Amizic, E. Guyez, J-M. Seiler, Experimental investigation on heat transfer for two-phase flow under gas-driven convection, Proceedings of ICONE20PWER2012, 20th Int. Conf. on Nuclear Engineering, July 30-August, 2012, Anaheim, California, USA.

[7] G.A. Greene, Heat, mass and momentum transfer in a multi-fluid bubbling pool, Advances in Heat Transfer 21, 1991.

[8] H. Werle, Enhancement of heat transfer between two horizontal liquid layers by gas injection at the bottom, Nuclear Technology 59, 1982.

[9] J. Excoffon, Rapport d'essais ABI-Gallium, Rapport CEA/ DEN/DTN/SE2T/ LPTM/ RT/008-312a - 2008 - Reference not publicly available.

[10] J.M. Veteau, ARTEMIS program: investigations of $\mathrm{MCCl}$ by means of simulating materials experiments, Proceedings of ICAPP '06, Reno, NV USA, June 4-8, 2006.

[11] M. Guillaumé, H. Combeau, J.-M. Seiler, An improved interface model for MCCI for LCS or Limestone concrete, Nuclear Engineering and Design 239 (6), 1084-1094, 2009.

[12] B. Michel, M. Cranga, Interpretation and calculations for the first series of tests for the ARTEMIS program (corium-concrete interaction with simulating materials), Nuclear Engineering and Design 239 (3), 600-610, 2009.

[13] M. Epstein, D.J. Petrie, J.H. Linehan, G.A. Lambert, D.H. Cho, Incipient stratification and mixing in aerated liquid-liquid or liquid-solid mixture, Chem. Eng. Science 36, 1981.

[14] J.L. Casas, M.L. Corradini, Study of void fractions and mixing of immiscible liquids in a pool configuration by an upward gas flow, Nuclear Technology 99, 1992. 
[15] B. Tourniaire, J.M. Bonnet, Study of the mixing of immiscible liquids by sparging gas: results of the BALISE experiments, 10th International Meeting on Nuclear Reactor Thermal-Hydraulics (NURETH10), Seoul, Korea, October 5-9, 2003.

[16] M.T. Farmer, S. Lomperski, S. Basu, A summary of findings from the melt coolability and concrete interaction (MCCI) program, Proceedings of ICAPP07, Nice, France, May 13-18, 2007.

[17] C. Journeau, J.M. Bonnet, E. Boccaccio, P. Piluso, T. Sevón, P.H. Pankakovski, S. Holmström, J. Virta, Current European Experiments on 2D Molten Core Concrete Interaction: HECLA and VULCANO, Proc. ICAPP'08, Anaheim, California, 2008.

[18] M. Farmer, S. Lomperski, The results of the $\mathrm{CCl} 2$ reactor material experiment investigating 2-D core-concrete interaction and debris coolability, 11th International Topical Meeting on Nuclear Reactor Thermal-hydraulics (NURETH-11), Avignon, France, 2005.

[19] $H$. Alsmeyer, BETA experiment in verification to the WECHSL code: experimental results on the melt concrete interaction, Nuclear Engineering and Design 103, 1987.

[20] C. Journeau, P. Piluso, J. F. Haquet, E. Boccaccio, S. Saretta, J.M. Bonnet, OxideMetal Corium-Concrete Interaction Test in the VULCANO facility, Proc. ICAPP'07, Nice, France, 2007.

[21] J.M. Seiler, K. Froment, Material effects on multiphase phenomena in late phases of severe accidents of nuclear reactor, Multiphase Science and Technology 12, 2000.

[22] Ch. Journeau, C. Jegou, J. Monerris, P. Piluso, K. Frolov, Phase macrosegregation during the slow solidification of prototypic corium, 10th International Meeting on Nuclear Reactor Thermal-Hydraulics (NURETH10), Seoul, Korea, October 5-9, 2003.

[23] D.R. Bradley, Modelling of heat transfer between core debris and concrete, ANS Proceedings of the 1988 ASME Nat. Heat Transfer Conf., Houston, USA, June 1988.

[24] B. Tourniaire, A heat transfer correlation based on a surface renewal model for molten core concrete interaction study, Nuclear Engineering and Design 236, 2006.

[25] F.G. Blottner, Hydrodynamics and heat transfer characteristics of liquid pools with bubbles agitation, NUREG Report CR-0944, 1979.

[26] B. Spindler, B. Tourniaire, J.M. Seiler, K. Atkhen, $\mathrm{MCCl}$ analysis and applications with the TOLBIAC-ICB code based on phase segregation model, ICAPP'5, Seoul, Korea, May 15-19, 2005.

[27] M. Cranga, R. Fabianelli, F. Jacq, M. Barrachin, F. Duval, The MEDICIS code, a versatile tool for MCCI modelling, ICAPP'5, Seoul, Korea, May 15-19, 2005. 
[28] M. Cranga, B. Michel, F. Duval, C. Mun, Relative impact of MCCI modeling uncertainties on reactor basemat ablation kinetics, MCCI-OECD seminar, Cadarache, StPaul-lez-Durance, France, October 10-11, 2007.

[29] M. Cranga, C. Mun, B. Michel, F. Duval, M. Barrachin, Interpretation of real material 2D MCCl experiments in homogeneous oxidic pool with the ASTEC/MEDICIS code, Proc. ICAPP'08, Anaheim, California, June 8-12, 2008.

[30] D.R. Bradley, D.R. Gardner, J.E. Brockmann, R.O. Griffith, CORCON-MOD3: an integrated computer model for analysis of molten core concrete interactions, NUREG Report CR-5843, 1993.

[31] B. Tourniaire, B. Spindler, V. Coulon, A.C. Augé, M. Cranga, Transfert de chaleur entre le bain de corium et le béton en cours d'interaction corium/béton - Analyse du groupe de travail CLARA, Rapport CEA/DEN/DTN/SE2T/LPTM/05-105 - 2005 Reference not publicly available.

[32] B. Cheynet, P.Y. Chevalier, E. Fischer, Thermo suite, Calphad 26 (2), 167-174, 2002.

[33] M. Cranga, L Ferry, J.F. Haquet, C. Journeau, B. Michel, C. Mun, P. Piluso, G. Ratel, $\mathrm{K}$. Atkhen, $\mathrm{MCCl}$ in an oxide-metal pool: lessons learnt from VULCANO, Greene and BALISE experiments, ERMSAR-10 Conference, Bologna, Italy, May 11-12, 2010. 


\subsection{Retention and cooling of corium inside and outside the reactor vessel}

\subsubsection{In-vessel corium retention}

\subsubsection{Physical phenomena and associated safety issues}

In-vessel corium retention assumes that reactor vessel integrity is preserved during an accident that causes reactor core melt.

Corium may be retained in the vessel either as a result of core reflooding leading to interruption of its melting, or flooding of the reactor pit with the aim of removing heat from the corium (debris or pool) while it is in the lower plenum of the vessel and thereby preventing vessel failure.

Research into in-vessel corium retention became one possible research option after the Three Mile Island 2 (TMI-2) accident in 1979 (see Section 7.1). During this accident, part of the core (approximately 20 tonnes of corium) was found at the bottom of the reactor vessel and the vessel did not fail, see [1]. The resistance of the reactor vessel to the thermal stresses caused by the residual heat released by this corium was attributed [2] to the fact that the molten corium flow at the bottom of the vessel was underwater (reactor flooded and pressurised ( 100 bar)), but this has never been completely confirmed.

However, core reflooding may not be beneficial in all conditions. The following phenomena can occur during reflooding:

- massive steam generation, with hydrogen production and an increase in reactor coolant system pressure;

- steam explosion through corium-water interaction;

- continuation of core melt, despite water inflow;

- faster release of fission products.

Theoretically, reflooding could take place in all possible core configurations (fuel rods intact, rods slightly damaged but with ballooned cladding, rods melted leading to one or more flows of molten material, debris bed, corium pool, etc.). It is therefore necessary to determine the effects of reflooding on the subsequent development of the accident, based on the core configuration at the time when water is injected into the core.

After the TMI-2 accident, studies into the possibility of in-vessel corium retention following reactor pit flooding (cooling from outside the vessel) led to reactor designs 15 years later that incorporated this possibility (examples include the Westinghouse AP600 and AP1000 in the USA [3], the KAERI APR1400 in South Korea and the European ESBWR. However, it remains difficult to demonstrate the effectiveness of external cooling in retaining corium inside the vessel. 


\subsubsection{In-vessel corium retention through RCS flooding}

\subsection{Physical phenomena and state of current knowledge}

\section{- Conditions with fuel rods intact or only slightly damaged}

If the core is reflooded when the fuel rods are intact or only slightly damaged (rod temperatures between approximately $1200^{\circ} \mathrm{C}$ and $1800^{\circ} \mathrm{C}$ ), high levels of hydrogen can be generated, as demonstrated by the QUENCH test results by Forschungszentrum Karlsruhe (FzK) in Germany (programme described in Section 5.1.1.3.1). The speed of the cladding oxidation reaction caused by the steam depends on the cladding temperature and the steam flowrate through the core, which is itself related to the progress of the quench front. Current software is able to satisfactorily estimate the progress of the quench front for a geometry with fuel rods intact. For these conditions, the model has been validated by various experimental results [25] (including the PERICLES tests by the CEA and the RBHT tests at the University of Pennsylvania in the United States). The thermal-hydraulic models are still sufficiently accurate when the fuel rod cladding begins to undergo deformation or the first molten material flows appear, because these deformations are not significant enough to lead to major disruption of the flow patterns. The main uncertainties are due to imprecision regarding rod geometry at the time of reflooding (in particular, the heat exchange surface) and the related laws of heat exchange. For these conditions in which core geometry has not been significantly altered, if the flowrate is high enough, core damage is likely to be halted, provided that reflooding does not cause the mechanical destruction and collapse of a large proportion of the fuel rods due to thermal shock. Any debris bed obtained in this way could no longer be properly cooled. The conditions under which the fuel rods might collapse and the size of the resulting debris are unknown, but interesting data has been deduced from test results from an OECD programme performed in the HALDEN reactor at the Norway Institute for Energy Technology (accumulation of irradiated fuel pellet debris in a rod that swelled during a LOCA). The ISTC-1648 test programme, funded by the International Science and Technology Centre (ISTC) and performed by NIIAR in Russia (Research Institute of Atomic Reactors), which aimed to study the reflooding of a length of irradiated fuel rod (see Section 5.1.1.3.1) also provided some data. The evidence gathered can be summarised briefly as follows, based on three fuel rod temperature ranges:

- below $1200^{\circ} \mathrm{C}$, it is unlikely that the fuel rods will fragment and only small amounts of hydrogen will be released due to cladding oxidation; the core can therefore be cooled if the water flowrate is high enough;

- between $1200^{\circ} \mathrm{C}$ and $1600^{\circ} \mathrm{C}$, the fuel rods may become fragmented and collapse, forming a debris bed if the cladding is embrittled by significant oxidation; if the rods do not collapse, hydrogen production remains low and the core can without doubt still be cooled if the steam flowrate is high enough;

- above $1600^{\circ} \mathrm{C}$, oxidisation of the zirconium alloy cladding leads to a runaway oxidation reaction, resulting in high hydrogen production and major rod damage, possibly with flows of liquefied materials. The core can no longer be cooled, at least locally in the places with molten material flows had occurred. 


\section{Conditions with debris bed formation}

If the fuel rods collapse inside the core, the fuel fragments form a porous medium known as a debris bed. If a debris bed forms, the pressure loss increases significantly and makes it a lot more difficult to access the collapsed areas. If the flooding water cannot reach some parts of the debris bit, these parts can only be cooled if the steam flow produced downstream at the quench front is sufficient, otherwise they heat up to melting temperature, creating a molten pool of core material. A debris bed can also form at the bottom of the reactor vessel when the corium flows through the water. The maximum heat that can be removed from a debris bed by water, before it dries out and melting occurs, is called the "critical heat flux". It is expressed per $\mathrm{m}^{2}$ of the upper surface of the debris bed. The phenomena that occur when a debris bed is reflooded are satisfactorily understood, because a number of experiments have been performed and various models developed since the 1980s. However, the only data developed are point models or 1D models, validated with 1D experimental results. There is still uncertainty about the extrapolation of reflooding calculation results to multi-dimensional and heterogeneous geometries. In particular, some experimental calculations and observations, which unfortunately are incomplete, suggest that the heat removed from a debris bed for a multi-dimensional configuration may be higher than the heat removed from a debris bed in a one-dimensional configuration (possibly as much as twice as high), and that even after the debris bed has dried out, the steam flowing through the bed may keep some of the debris below melting point. However, much uncertainty remains, because in the TMI-2 accident (discussed in detail in Section 7.1), the heterogeneity of the debris formed (including the presence of liquid "pockets") and the presence of small debris ( $<1 \mathrm{~mm}$ ) may be the reason why corium melt could not be prevented after reflooding. Reflooding of a heavily damaged core or a debris bed remains poorly modelled by calculation software.

The main multi-dimensional thermal-hydraulic models that exist for a porous medium are included in the ICARE/CATHARE (IRSN), WABE (IKE/GRS) and MC3D (CEA/ IRSN) software packages. The multi-dimensional effects on heat removal through reflooding in particular remain to be confirmed with experimental data from sufficiently large experimental set-ups that can provide reliable local temperature measurements and steam generation during reflooding. This is the aim of the PEARL programme of experiments, initiated by IRSN in 2010, in partnership with EDF, with the participation of the European network SARNET-2.

\section{Conditions with a liquid corium pool}

What happened at the TMI-2 accident? When the corium flowed to the bottom of the reactor vessel, the vessel was full of water. Around ten tonnes of corium in oxide form (approx. $1 \mathrm{~m}^{3}$ ) had flowed in compact form to the bottom of the reactor vessel and around ten further tonnes of debris were above the corium in compact form. Analysis of reactor vessel samples showed that the temperature of the internal surface in contact with the compact corium mass at the bottom of the vessel reached approximately $1100^{\circ} \mathrm{C}$ and the external surface reached approximately $800^{\circ} \mathrm{C}$. The internal pressure in the reactor vessel was around 100 bar at the time. The vessel then cooled 
very slowly. Assuming perfect contact between the compact corium and the reactor vessel, all thermal calculations have shown that the reactor vessel temperature should have continued to rise, eventually causing vessel failure. The explanation put forward as to how the reactor vessel withstood these conditions assumes that a gap formed between the corium and the vessel. According to this assumption, the gap would have formed due to two phenomena:

- traces of water in porosities within the steel boiling and preventing contact between the corium and the steel;

- a process of differential expansion between the solidifying corium and the reactor vessel, which was heating up.

It is thought that the ingress and flow of water in this gap cooled the reactor vessel sufficiently and sustainably enough to prevent failure.

Some experiments have been performed to try to confirm this hypothesis of a gap between the corium and the reactor vessel in the TMI-2 accident. Small-scale tests have been performed on corium flows at the bottom of reactor vessels containing water, to reproduce the TMI- 2 corium flow conditions and analyze the results. Such tests have been performed by FAI (FAUSKE \& Associates, Illinois, USA) [11], JAERI (Japan) and KAERI (South Korea) [12]. All these tests were carried out with an alumina thermite mixture to simulate the corium. Other tests to determine the maximum power (or critical heat flux) that could be removed be water flowing in a gap between the corium and the reactor vessel have been carried out by IBRAE (Russia) [13], Siemens (Germany) [14] and KAERI [15].

These tests have not been highly conclusive and the main finding is that the gap is likely to have been formed solely by the traces of water boiling. The hypothesis of differential expansion appears less plausible. However, as suggested by a CEA study [4], the possibility of heat removal through water boiling in a gap is also very slim. It remains difficult to explain with certainty why the reactor vessel withstood failure in the TMI-2 accident conditions.

In more general terms, for a power reactor core meltdown accident, this CEA study shows that the heat (or critical heat flux) that can be removed by boiling water in a gap is very approximately proportional to the square root of the pressure. For instance, for a $3 \mathrm{~mm}$ gap and pressure of $1 \mathrm{bar}$, the critical flux is of the order of $0.02 \mathrm{MW} / \mathrm{m}^{2}$, which should be compared with the $0.5 \mathrm{MW} / \mathrm{m}^{2}$ that needs to be removed if half the mass of the core were at the bottom of the reactor vessel in the form of a corium pool. The conclusion is that too little is known about the real conditions at the bottom of the reactor vessel (Is water present permanently or not? What is the critical flux value? Is there a gap in the event of meltdown? etc.) for the cooling mechanism through gap formation to be considered plausible for most foreseeable core meltdown accident conditions on a PWR at low pressure.

Without more pertinent experimental results, with the reactor coolant system depressurised and with no reactor pit reflooding, it would appear difficult to demonstrate 
that reflooding the reactor coolant system would prevent reactor vessel failure once a large pool of molten material has formed within the core.

\subsection{Experimental programmes}

The main programmes of experiments studying core reflooding for pressurised water reactors are LOFT-FP, PBF-SFD, CORA, QUENCH, ISTC 1648 (QUENCH) and PARAMETER. These programmes are briefly described in Section 5.1.1.3.1.

\subsection{Review and future outlook}

Two reviews [22, 23], dating from 2005 and 2006, summarise current knowledge of the various risks associated with PWR core reflooding. These documents identify the main uncertainties and the R\&D programmes that will be required.

The themohydraulics and fuel behaviour during a core meltdown accident require finer modelling in order to better understand accident development in the core of a power reactor. This implies more precise and detailed modelling of transient conditions, in particular the two "key" transitions from a damaged core to a molten pool and then from a molten pool in the core to a molten pool at the bottom of the reactor vessel. The models used in the software for fuel rod deterioration in the core are based on a multidimensional description of the material transfers in order to better calculate the transient changes to materials in the reactor vessel, but there are no experimental results from relatively large-scale tests to deal with the scale effects and validate these multidimensional models.

The three priorities for further study are as follows:

1. the geometric evolution of a heavily damaged core or a debris bed during reflooding (can a damaged core be cooled or not?); tests will be required to more clearly understand the progress of the quench front in a damaged core, according to its geometry, particularly for conditions involving a debris bed and the specific geometric features of debris from irradiated fuel rods. The size distribution of the debris will be a significant result that could be obtained through additional out-of-pile tests with real rods. This is the aim of the reflooding tests with lengths of fuel rods under the ISTC 1648 (QUENCH) programme;

2. the evolution of a dry debris bed and its transformation into a molten pool (if it cannot be cooled); it would be good to study dissolving and oxidation, two phenomena that have an impact on stratification in the pool;

3. the arrival of corium at the bottom of the reactor vessel, in particular when it is full of water; it would be good to study corium fragmentation, oxidation and cooling when it gets into the water and when it spreads at the bottom of the vessel. These issues were partially examined in the programmes that looked at steam explosion (see Section 5.2.3). 


\subsubsection{In-vessel retention with reactor pit flooding}

\subsection{General approach: orders of magnitude}

Two main parameters affect the integrity or otherwise of the reactor vessel under core melt accident conditions with molten corium flowing to the bottom of the vessel:

- the mechanical strength of the reactor vessel at all points, particularly in areas subjected to the highest thermal load;

- the mechanical strength of the reactor vessel to withstand a steam explosion caused by an in-vessel corium water interaction.

Order of magnitude calculations have shown that, following core degradation, the materials in the core of a PWR 900 would take up a volume of a similar order of magnitude to the hemispherical vessel bottom, if they formed a very compact mass at the bottom of the reactor vessel with no voids (e.g. a corium pool). Assuming that the residual power of these materials is $20 \mathrm{MW}$ and that they emit a uniform heat flux, the heat flux calculated at the edge of the pool is of the order of $0.8 \mathrm{MW} / \mathrm{m}^{2}$. This heat flux is extremely high and can only be removed if there is efficient convection at the free surface of the corium pool and the interfaces between the corium pool and the reactor vessel. Even in this case, part of the vessel wall would melt and its residual solid thickness would only be a few centimetres. With a simple calculation, it can also be shown that if this heat flux is not efficiently removed (e.g. if there is no steam flow above the corium pool), the reactor vessel will be perforated after only a few minutes. Ensuring vessel integrity therefore requires a way of removing the heat flux from the corium pool at all points in the reactor vessel. This condition is essential, but it is not the only criterion. The weakened vessel also needs to continue to withstand the pressure. Given that the residual thickness of the steel is reduced, the reactor vessel cannot resist high pressure in the reactor coolant system, requiring the RCS to be depressurised. The mechanical strength of the reactor vessel is therefore assessed at final pressure, after depressurisation, taking into account the thermomechanical loads caused by the corium pool. It also needs to be evaluated for a pressure peak in the reactor coolant system. A pressure peak could, for example, result from a steam explosion following inflow of water from the RCS onto the corium pool at the bottom of the reactor vessel [10].

\subsection{Mechanical strength of the vessel depending on corium pool configuration}

To assess the mechanical strength of the reactor vessel when in contact with a corium pool in core melt accident conditions, vessel behaviour is studied under the worst-case limit conditions, which are no core reflooding, flow of all corium mass to the vessel bottom and stationary thermal-hydraulic conditions in the molten pool. These are the conditions in which the highest heat flux is received by the reactor vessel.

The heat flux distribution on the vessel wall depends on the configuration of the corium at the vessel bottom (whether or not it is stratified). The core materials can be distributed 
according to their respective densities in order to define the various possible corium configurations for a given core inventory (masses of oxides, zirconium and steel in the core). There are however other parameters that affect the corium pool configuration:

- the degree of zirconium oxidation (which can range between $25 \%$ and $80 \%$ depending on the accident scenarios considered, see Section 5.1.2.1);

- the mass of molten steel (between a few tonnes and several tens of tonnes);

- the possibility of solid layers (debris and solid crusts), in particular at the corium pool interfaces.

One of the most critical configurations for the reactor vessel is when low-density molten metals (mainly containing steel) float on top of a pool of high-density corium "oxides" (approximately $8000 \mathrm{~kg} / \mathrm{m}^{3}$ ) (Figure 5.46). These are the bounding conditions in terms of thermal loading on the reactor vessel that have been most extensively studied and for which the limit conditions and heat transfer to the pool have been determined. This configuration was also used to support the first external vessel cooling studies, in particular the AP600 concept. This configuration will be referred to as the "reference configuration" hereinafter.

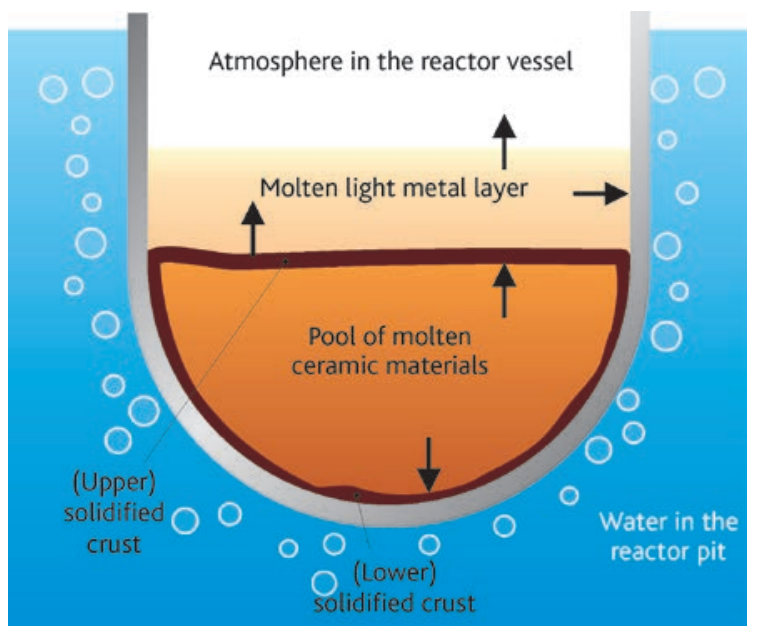

Figure 5.46. Configuration of the corium pool at the bottom of the reactor vessel with external cooling.

\subsection{Study of the corium pool stratified configuration}

\section{- Heat flux distribution and cooling for the stratified configuration}

For any given corium configuration, the heat flux distribution depends on the limit conditions between the melting mass and the solid wall (either the crust or the steel of the vessel) and the coefficients of heat transfer by natural convection. The temperatures at the edge of a corium pool have been determined in various studies, which are summarised in [5]. The main difficulty in determining the temperatures is related to the fact that the melting materials are a mixture of oxides and metals. These mixtures melt over a relatively 
wide range of temperatures that depends on the composition of the mixture. Such a mixture may also contain a soft zone, between the molten pool and the solid crust by the vessel wall, which could affect heat transfer. Reference [5] has shown that in steady-state thermal-hydraulic conditions (i.e. when the heat fluxes have been established), no such soft zone can exist, because the pool composition becomes homogeneous and will solidify in the same way as a pure body (with a flat interface between the solid and liquid). In addition, when there is sufficient external cooling, the solid crust has a constant thickness (i.e. the speed of progress of the solidification front is zero). In this case, the temperature at the liquid-solid interface tends towards the liquidus temperature corresponding to the liquid mixture. There is a clear separation between the solid and liquid. Experimental confirmation of this conclusion has been provided by various tests (PHYTHER by the CEA (described in [5], RASPLAV (Kurchatov Institute, Russia) [16], and SIMECO (Royal Institute of Technology, Sweden). The solidification transient was studied by IRSN in 2005 [17].

The assumption of thermochemical equilibrium in determining the interface temperatures also applies to the metallic layer of a stratified corium pool. If the liquidus temperature corresponding to the composition of the metallic layer (chiefly formed of steel and zirconium) is lower than the melting point of steel, the steel may be dissolved by the molten metal. The interface temperature with the solid steel of the reactor vessel establishes itself at this liquidus temperature. To put things simply, depending on the composition of the liquid metal layer, the temperature of the inner surface of the reactor vessel wall may be substantially lower than the melting point of steel. Temperatures at the liquid-solid interface are calculated with thermodynamic software (such as GEMINI) on the basis of the composition of the liquid layer in question. The corollary of this choice is that the pool is completely liquid and the heat transfer laws identified from tests with simulation materials (pure bodies like water) can be transposed to the real materials.

Heat transfer correlations have been deduced from tests with simulation materials (BALI, COPO, ACOPO, RASPLAV-Salt, etc.) for various geometrical configurations [9]. Efforts have also been made to validate CFD software for natural convection. The results are encouraging, but further improvements to the turbulence model are still required in order to improve the precision of the results. The use of such software on the scale of a power reactor vessel gives results with a wide uncertainty interval. Given the current state of knowledge, it is preferable to use a simpler approach based on correlations from the tests.

\section{Order of magnitude of the heat fluxes and focusing effect}

To give an order of magnitude, for the reference configuration shown in Figure 5.46, the residual heat is distributed as follows, assuming that the entire mass of oxides from the core is at the bottom of the reactor vessel:

- half the residual heat released from the pool of oxides is transferred to the bottom of the vessel;

- the other half is transferred from the pool of oxides to the upper layer of liquid metals. 
If there is no water inside the reactor vessel, the metal layer transfers most of the heat received from the pool of oxides and the internal heat it releases to the steel vessel wall, which is in contact with the liquid metal layer. The metal layer can generate a heat flux "focusing effect" on the wall surface that is in contact with the liquid metal. At the point of contact with the metal layer, the heat flux is very approximately inversely proportional to the thickness of the metal layer. For a thickness of more than $50 \mathrm{~cm}$ (corresponding to approximately 50 tonnes of steel), the heat flux is below $1.5 \mathrm{MW} / \mathrm{m}^{2}$. Reactor vessel integrity is only assured if the heat flux transferred to it can be removed by two-phase natural convection from the cooling water outside the vessel. This naturally raises the question of the critical flux on the external vessel wall (upper limit higher than the heat flux that can be removed by external reactor vessel flooding).

\section{- Critical flux for natural external water circulation}

The critical heat flux associated with external cooling of the reactor vessel, in particular in the area around the metallic layer, will therefore by the limiting factor for heat removal from the vessel. Significant efforts have been made around the world to determine this critical flux and to increase it. Various tests have been performed (with $2 \mathrm{D}$ or $3 \mathrm{D}$ geometries and different wall heating modes). The most interesting of these include tests by ULPU (University of California, Santa Barbara) [19], the SULTAN tests (CEA) [18] and tests by KAIST (Korea Advanced Institute of Science and Technology, South Korea).

The first phenomenon that determines the critical flux value if the reactor pit is reflooded is the water circulation by natural convection within the reactor pit. Simply reflooding the reactor pit is not enough to cool the reactor vessel. The water circulation needs to be organised such as to "maximise" liquid flowrate along the vessel walls. This implies the existence of a "rising hot leg" (the reactor vessel) and a cold leg. The geometry of the vessel (radius and spherical or elliptical shape of the vessel bottom) and the presence of insulating materials around the vessel may affect water circulation and pressure loss. For a geometry that maximises water circulation and in the absence of elements to hinder flow, maximum critical heat flux is obtained when the water flow-rate is high enough to limit boiling close to the wall in the heating zone (no mass boiling in this area). However, above the heating zone, boiling should be higher to create a strong enough "chimney effect", whereby the steam generated drives an increased liquid flow. If water flowrate is not high enough, there is mass boiling around the heating zone and the critical flux is reduced because the heat is removed less effectively. Having said that, the water flowrate cannot exceed the flow created by the chimney effect related to mass boiling above the heating zone. This maximum flowrate corresponds to a maximum critical heat flux of the order of $1.5 \mathrm{MW} / \mathrm{m}^{2}$.

Analysis of the test results mentioned above show that the spread of estimated critical flux values is often fairly high. Results from the ULPU tests give values close to $2 \mathrm{MW} / \mathrm{m}^{2}$ (but with a wide spread of experimental results), whereas results from the SULTAN and KAIST tests show critical flux values on a vertical wall that range from 1.2 to $1.5 \mathrm{MW} / \mathrm{m}^{2}$. 
Various effects have been studied in an attempt to identify provisions that could increase the critical heat flux, in particular effects linked to the condition of the reactor vessel's outer surface. According to some authors, [6], a spray-on porous metal coating on the outer surface of the reactor vessel could significantly increase the critical flux (by a factor of up to 2). However, this conclusion is not universally shared and experimental verification is still required.

\section{Limitation linked to vessel mechanical strength}

For a heat flux of $1.5 \mathrm{MW} / \mathrm{m}^{2}$, the vessel thickness supporting the mechanical load (i.e. the place where the temperature is below $600^{\circ} \mathrm{C}$ ) is 1 centimetre. This thickness can withstand pressures up to a few tens of bar. An increase in critical flux would lead to an inversely proportional decrease in the thickness supporting the mechanical load, and a consequent reduction in the yield pressure of the reactor vessel. These considerations strongly temper the potential benefits of any work to demonstrate critical flux values of above 2 or $3 \mathrm{MW} / \mathrm{m}^{2}$.

\section{Limitation linked to the minimum mass of molten steel}

One of the key parameters that determines the thickness of the metallic layer above the oxide pool, and hence the highest thermal loads on the reactor vessel, is the mass of molten steel in the corium produced by core melt. For a critical heat flux of 1.3 to $1.5 \mathrm{MW} / \mathrm{m}^{2}$, the minimum thickness of molten steel required to prevent the thermal focusing effect is of the order of 50 to $60 \mathrm{~cm}$ for a 1000 MWe PWR. Given the characteristics of these reactors, this thickness corresponds to a mass of molten steel of the order of 50 to 60 tonnes. According to studies by Westinghouse for the AP600 and AP1000, this quantity of steel would be found at the bottom of the reactor vessel after the lower in-vessel structures and part of the vessel walls have melted. Findings from the OECD MASCA programme [20] suggest that complex physical phenomena could reduce the mass of metal and lead to a focusing effect. These phenomena are as follows:

- part of the liquid metals (e.g. the lower in-vessel structures) getting trapped in solid oxide debris;

- part of the molten metal flowing to the bottom of the reactor vessel due to physico-chemical effects related to the presence of non-oxidised zirconium (details below);

- for a fixed quantity of metal, this would lead to reduced thickness of the metallic layer on the top of the corium pool (see Figure 5.47).

The physico-chemical effects are linked to the presence of non-oxidised zirconium in a metallic phase. This zirconium can react with the uranium dioxide in the oxide phase and lead to the formation of a uranium metal phase. This phase can mix with the liquid steel and lead to the formation of a liquid metal layer that is denser that the pool of oxides that would now be at the bottom of the vessel. By using thermodynamic software (such as GEMINI2 from Thermodata), the composition of complex 
metal-oxide mixtures can be calculated in equilibrium at various temperatures. If the density of the phases resulting from these calculations is determined, the maximum mass of metal that might end up below a pool of oxides can be estimated and, by subtraction, for any given quantity of steel, the mass of metal present in the upper layer. This method was used by CEA and IRSN to calculate the mass of metal necessary to prevent the heat flux transferred from the metal layer to the reactor vessel exceeding the critical flux [7]. Calculations were performed for different reactor types: the French 900 MWe and 1300 MWe PWRs, the AP600 and AP1000 reactors developed by Westinghouse, and the Korean APR1400 reactor. The results showed that one key parameter is the fraction of non-oxidised zirconium present in the molten pool. The higher this fraction, the greater the mass of metallic uranium produced and the greater the mass of metal at the bottom of the reactor vessel. The question of keeping the corium inside the vessel is thus more complex if the mass of metallic zirconium is higher. The results are also sensitive to the databases used for thermodynamic calculations and the critical flux values outside the vessel. In particular, for reactors of greater than $600 \mathrm{MWe}$, a natural circulation system needs to be set up in order to remove a high heat flux.

It should be noted that the above studies were performed for a stationary corium pool configuration. The formation of metallic layers and the pool of oxides will necessarily involve transients of growth in the metal layer thickness and increase in the heat released by the pool of oxides. These transients were not incorporated in the calculations, but they could cause the critical heat flux to be reached.

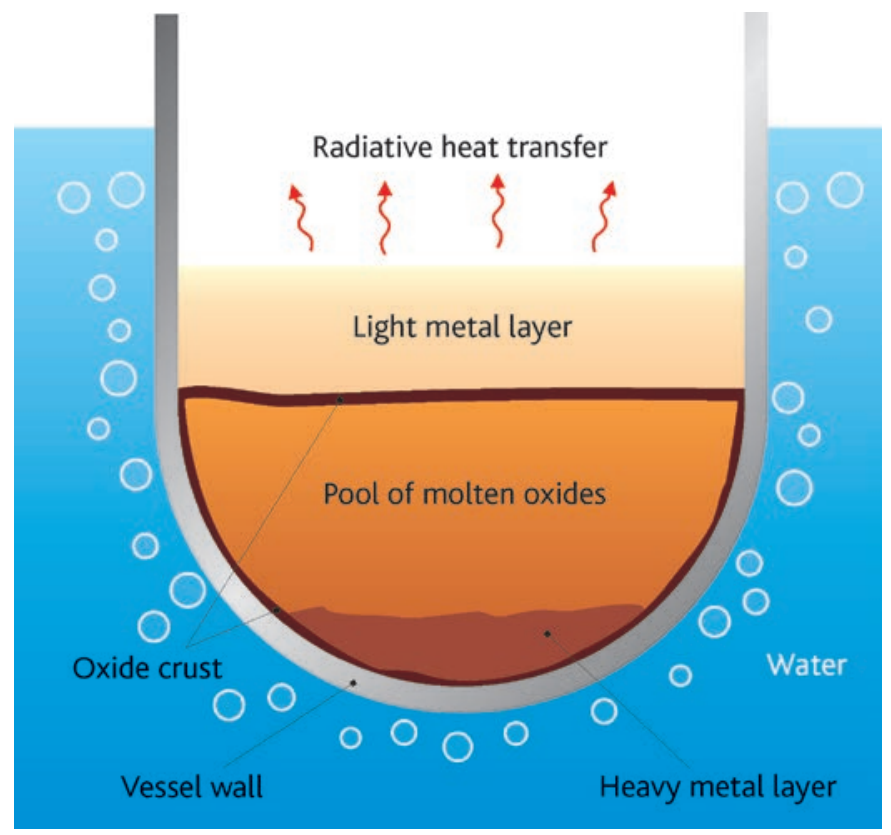

Figure 5.47. Corium recovery from the bottom of the vessel with inversed stratification of metals and oxides. 


\subsection{Possible progress for in-vessel corium retention with reactor pit flooding}

The studies described in the foregoing paragraph do not yet demonstrate that reactor pit flooding would ensure, for any given reactor type, that the corium would be retained inside the reactor vessel for all foreseeable core melt accidents. Further studies are required on the following issues, in particular:

- more realistic corium configurations, in which the metallic layer can be in various positions (above or below the pool of oxides) over time;

- the possibility of simultaneous external (reactor pit) flooding and internal core reflooding;

- conditions that could lead to several successive corium flows within the reactor pit, for which the heat fluxes on the reactor vessel may differ significantly from the very schematic situation usually considered (see Figure 5.46).

An inflow of water onto the corium pool inside the vessel could eliminate the heat flux focusing effect. The ANAIS tests by CEA [8] have shown that, in this case, the metal layer on the surface could solidify, transferring a significant proportion of the residual heat to the water. These same ANAIS tests also showed that, under these conditions, the steam explosion risk would be limited to the area in which the water spray hit the liquid corium. A large explosion following accumulation of water seems unlikely because the surface of the corium pool would quickly be solidified by a significant inflow of water.

In order to better assess the possibility of in-vessel corium retention for reactor pit flooding, it will be necessary to improve the model of corium flow to the bottom of the reactor vessel and development of the corium pool at the vessel bottom.

For $900 \mathrm{MWe}$ and $1300 \mathrm{MWe}$ reactors, there are not currently provisions to ensure in-vessel corium retention for all foreseeable core melt accidents. Reactor vessel failure (Section 5.1.3) and the possibility of cooling the corium outside the vessel (Section 5.4.2) at the time of molten core-concrete interaction ( $\mathrm{MCCl}$ ) have therefore been studied in detail.

For the EPR reactor design, specific provisions have been adopted (the corium spreading and cooling compartment, presented in Section 5.4.3) in order to cool the corium outside the vessel.

\subsubsection{Cooling of corium under water during $\mathrm{MCCl}$}

\subsubsection{Physical phenomena involved}

One possibility for accelerating cooling of a corium pool during $\mathrm{MCCl}$ (see Section 5.3), and stopping its development, would be to direct water into the reactor pit onto the corium surface. 
Radiative heat transfer between the corium pool and the reactor-pit walls leads to the formation of a crust on the surface of the corium, due to the high solidification temperature of corium (around $2400 \mathrm{~K}$ for a corium containing little concrete). This crust would apparently be thicker if the corium were covered by water, but would also act as an insulator between the corium pool and the water, thereby restricting heat transfer between corium and coolant. Order of magnitude calculations show that if heat transfer between pool and water were only by conduction via the crust, then the slowing of concrete erosion due to directing water onto the corium would be minimal. For the cooling of corium under water to be truly effective, other heat transfer mechanisms would need to be involved. The purpose of R\&D work (experiments and models) performed on the subject is to identify and quantify the effectiveness of these other modes of heat transfer.

\subsubsection{Experimental programmes}

The main experimental programmes that have been performed on this subject are: the Melt Attack and Coolability Experiments (MACE, see [26]) programme performed at the Argonne National Laboratory (ANL, USA) from 1989 to 2010 using real materials, MSET (see [27]) and OECD-MCCI (see [28] and [29]) - with the last programme divided into three sub-programmes, namely SSWICS, MET and CCI -, plus CEA's PERCOLA programme using simulation materials, see [30]. The ANL programmes involve both integral experiments and more analytical tests.

\subsubsection{1. $\mathrm{MACE}$ and $\mathrm{CCl}$ tests}

These integral tests aimed to study the possibility of cooling the corium during an $\mathrm{MCCl}$ by directing water onto the pool surface, using materials representative of corium formed during a core melt accident on a power reactor. Three tests were performed with 1D devices (concrete erosion only in the downwards direction: M1B, $\mathrm{M} 3 \mathrm{~B}$ and $\mathrm{M} 4$ ) and five tests with 2D devices (concrete erosion downwards and on the sides: $\mathrm{MO}$ in the MACE programme, and $\mathrm{CCl}-1, \mathrm{CCl}-2, \mathrm{CCl}-3$, and $\mathrm{CCl}-4$ in the OECD$\mathrm{MCCl}$ programme). Test performance was essentially the same for all tests; it initially involved forming a corium pool, with a composition representative of that of a core melt accident on a power reactor at the beginning of $\mathrm{MCCl}$, by using a thermite reaction (a highly exothermic reaction, which for these tests involved a mixture of $\mathrm{U}_{3} \mathrm{O}_{8^{\prime}}$ $\mathrm{CrO}_{3}, \mathrm{CaO}, \mathrm{SiO}_{2}$, silicon, zirconium and aluminium) that produces a molten mixture mainly made up of $\mathrm{UO}_{2}$ and $\mathrm{ZrO}_{2}$ along with a smaller proportion of oxides representative of concrete erosion (mainly $\mathrm{SiO}_{2}, \mathrm{CaO}$, etc.), alumina and chromium oxide. The corium pool was then maintained in a molten state by direct heating. Concrete erosion was initially obtained via a dry $\mathrm{MCCl}$. Water was then directed onto the corium after a time delay or a maximum specified ablation, and $\mathrm{MCCl}$ continued under water. The effectiveness of directing water onto the corium can be understood by comparing concrete erosion rates with and without water, and by measuring the heat flux at the surface of the corium pool (associated with the quantity of steam produced). Pool temperature is also an indicator of the effect of water supply. However, it is important not to directly extrapolate test results to the case of a power reactor, to the extent 
that tests involve non-representative aspects: in particular, the corium is heated via the Joule effect in the liquid corium, whereas for a power reactor, the residual heat would be spread between the liquid (pool) and the solid (crust).

The tests mentioned above brought to light several possibilities for corium cooling by water:

- during numerous tests ( $\mathrm{MO}, \mathrm{M} 3 \mathrm{~B}$ and $\mathrm{CCl} 2$ ), part of the corium pool was entrained by the gases produced by concrete decomposition and ejected above the pool's upper crust, forming a bed of centimetre-sized debris. Furthermore, analytical tests have shown that it is possible to cool debris of this size dispersed in water but it has not been shown that cooling of a thick bed of debris emitting significant residual heat would be as effective as cooling of dispersed debris;

- the pool's upper crust could crack and water could penetrate under this crust, due to the effect of temperature differences between the water and the corium and thermomechanical stresses. This water could propagate in the pool and cool it completely (a mechanism called "water ingression"). However, models that describe this mechanism suggest that the cracks created by temperature differences would be too small for water ingression alone to effectively cool a corium pool, see [31]. Nevertheless, the presence of cracks plays an important role in the thermomechanical behaviour of the crust (cracks reduce the mechanical resistance of the crusts) and could contribute to corium cooling;

- effective cooling of the corium surface has been measured during direct contact between water and liquid corium. This highly transient phenomenon can occur during sudden mechanical failures of the crust or when water first arrives on the corium pool. However, during the tests performed, it may have been promoted by the geometry of the experimental set-up; it is not possible to directly extrapolate this result to a power reactor.

Under these conditions, it is not possible to conclude on the effectiveness of cooling of a corium pool during an $\mathrm{MCCl}$ by directing water onto the surface of the pool for a power reactor, although it would seem that the various phenomena mentioned above would tend to slow concrete erosion. The performance of more representative tests runs up against technological difficulties that limit the scope of the experiments and study of the phenomena:

- given the limited scale of existing test equipment, in most cases a crust forms on the upper part of the pool and bonds to the walls of the test section. As concrete erosion progresses, the liquid corium descends and separates from the crust; this separation limits the effectiveness of corium ejection. In the case of a power reactor, it is more likely that the crust would remain in contact with the liquid corium due to the size of the reactor pit;

- direct corium heating means that it is not possible to heat the solid crusts. The solidification observed during the tests is therefore not representative of that which might occur on a power reactor. 


\subsection{MSET test}

The purpose of the MSET test, performed in 2001, was to study corium ejection through the crust, a phenomenon brought to light during the MACE tests. The MSET test was performed with materials representative of corium formed during a core melt accident on a power reactor, without concrete erosion and with water directed onto the upper part of the pool. Gas release was simulated by using a porous material at the base of the corium pool, through which gas was injected at a controlled rate.

The MSET test led to the formation of bed of debris but no corium ejection was observed for superficial gas velocities below $10 \mathrm{~cm} / \mathrm{s}$, which posed the question of the effectiveness of such a phenomenon for a power reactor, where the superficial gas velocity would be less than $5 \mathrm{~cm} / \mathrm{s}$ during the long-term $\mathrm{MCCl}$. However, analysis of the MSET results brought to light as possible causes of this behaviour:

- bonding of the crust onto the walls of the test section, leading to separation of pool and crust;

- the presence of a significant solid fraction, due to pool temperature (well below the liquidus temperature).

The results of this test do not therefore provide insight into the importance of corium ejection for the cooling of corium during an $\mathrm{MCCl}$ on a power reactor.

\subsection{SSWICS tests}

The purpose of the SSWICS tests (see [31]), performed with materials representative of corium formed during a core melt accident on a power reactor, was to study the mechanism of water ingression after thermomechanical cracking of the corium pool's upper crust. Water penetrates via this mechanism into the cracks which form in the upper crust when cold water comes into contact with the hot crust; the cooling of corium under the crust leads to its solidification, which increases crust thickness.

Under the SSWICS programme, separate-effect tests were performed without heating the corium pool, and with simulated release of concrete gases for some tests. The corium pool, which was produced in a test section using a thermite reaction similar to the one described in Section 5.4.2.2.1, sat on an inert support. Water was gradually directed onto the corium pool and the cooling kinetics were deduced from the water vaporisation rate. The effectiveness of water ingression was assessed by comparing the heat flux extracted during the tests with that obtained under conditions where only conduction was involved (thermite cooling without water). The permeability of the crust was measured after the tests, which meant that the removed heat fluxes could be assessed using specific models.

The tests performed (see Figures 5.48 and 5.49) enabled quantification of the influence of concrete type (siliceous or silico-calcareous), corium pool composition (between $4 \%$ and $25 \%$ concrete by mass), gas injection, and pressure (between 1 and 4 bar). The lumps of corium obtained at the end of the tests were cut into pieces and subjected to mechanical resistance tests. 
The main lessons drawn from the SSWICS tests were the following:

- these tests confirmed that cracking of the upper crust and water ingression into these cracks cools the corium in certain cases (increasing crust thickness). With no gas injection, corium cooling is only effective for low concrete concentrations in the corium (less than $15 \%$ by mass); for a power reactor, these conditions would correspond to water arriving soon after the corium had flowed into the reactor pit during a core melt accident. The tests also demonstrated the effects of gas injection into the corium; indeed, the programme's last tests performed with countercurrent gas flow in the corium showed more effective corium cooling for lower concrete concentrations. This was the case in the SSWICS-11 test performed with $15 \%$ concrete, which led to high heat-flux removal, similar to that obtained without gas injection for a low (4\%) concrete concentration (Figure 5.48). Gas

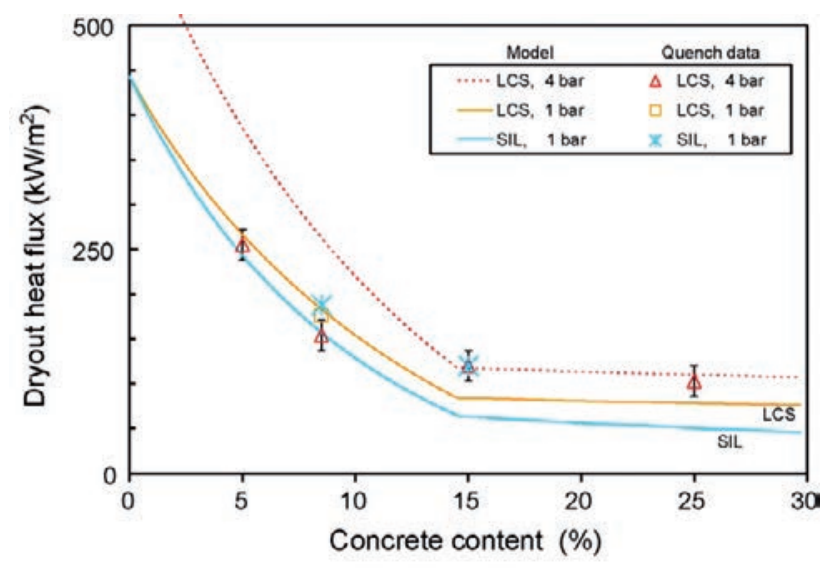

Figure 5.48. Measurement of heat fluxes removed by water ingression during SSWICS tests, as a function of concrete concentration in the corium (without gas injection into the corium), see [31].

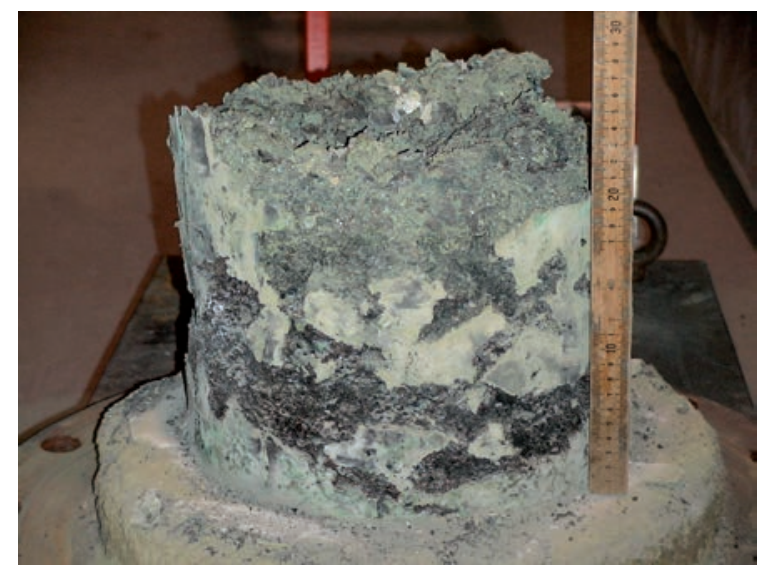

Figure 5.49. Appearance of the resolidified lump of corium at the end of the SSWICS-11 test, performed with gas injection into the corium, see [32]; reproduced by permission of OECD. 
flow could lead to the opening of pores in the corium during solidification, which would facilitate its cooling. However, it should be noted that, due to the lack of heating, SSWICS tests did not reproduce effects associated with residual heat in the pool and crust, effects which could be significant for a power reactor;

- measurements of mechanical stresses leading to crust failure (see [33]), in particular, the in situ measurements obtained during certain $\mathrm{CCl}$ tests show that crust failure occurs for low levels of stress. For a power reactor, it is very unlikely that the crust would remain a single block and bond to the reactor-pit walls.

During $\mathrm{MCCl}$ tests performed under more representative conditions with sustained corium heating (in particular during the $\mathrm{CCl}$ tests, see [29]), water ingression and corium ejection phenomena occurred simultaneously and were difficult to distinguish, as the corium ejections were close together.

\subsection{PERCOLA programme}

The PERCOLA experimental programme was performed by CEA between 1999 and 2002. Drawing lessons from the MACE tests and the results of calculations (see [34]) showing that it would be possible to cool a corium pool which would transform into a bed of debris, the purpose of this programme was to study corium ejection above a cracked crust caused by gases coming from concrete erosion. This analytical programme, performed with simulant materials (water, oil) brought to light several ejection regimes and meant that the influence of numerous parameters (see [30]) could be quantified, such as:

- fluid viscosity (a parameter representative of the increasing quantity of concrete in the corium as $\mathrm{MCCl}$ progresses);

- superficial gas velocity (a parameter representative of the type of concrete and the decreasing gas flowrate during $\mathrm{MCCl}$ );

- hole density in the crust (a parameter little understood for a power reactor);

- hole diameter (a parameter little understood for a power reactor);

- thicknesses of crust and bed of debris (parameters representative of the thickening of the crust and the bed of debris during $\mathrm{MCCl}$ after ejection).

The results of the PERCOLA programme have enabled development of an analytical model covering corium ejection during $\mathrm{MCCl}$ (this model is described in the next section).

\subsubsection{Modelling}

The main modelling work has covered corium ejection via holes in the upper crust and water ingression into corium.

An analytical model taking into account corium ejection ${ }^{9}$ was developed in the context of the PERCOLA programme in 2004, see [35]. It takes into account the effect of

9. This model provides an estimate of the corium entrainment rate, i.e. the ratio of the volumetric flowrate of the liquid ejected and the volumetric flowrate of gases released during $\mathrm{MCCl}$. 
the major physical parameters for $\mathrm{MCCl}$ (superficial gas velocity, pool viscosity etc.) and the geometry of the ejection holes which were not covered in the Ricou and Spalding model (see [36]), which was used prior to the PERCOLA programme and describes liquid entrainment by a turbulent gas jet in a specific geometry. Application of the PERCOLA model to power-reactor scenarios tends to show that a bed of debris could quickly form if corium ejection is effective, see [37]. The stability of this bed of debris would then depend on the size of the debris particles formed. The PERCOLA model has been validated using the results of PERCOLA tests, but requires validation on the basis of more representative tests (with concrete erosion and prototypic compositions). To this end, large scale tests have been performed since 2012 at the Argonne National Laboratory (ANL in the USA); these are described in Section 5.4.2.4. Some of the model's input parameters are subject to very large uncertainties, such as the density and size of holes in the crust through which corium can pass. They are the subject of a specific model proposed by Farmer, see [38]. However, there is no experimental data that is sufficiently representative to validate these models for a power reactor.

In order to ensure the validity of the PERCOLA model in the long-term cooling phase for a power reactor, the model should also be supplemented to cover development of the bed of debris, in particular the effect of its thickening on corium ejection ${ }^{10}$.

With regard to water ingression, it should be noted that a critical heat flux correlation, deduced from a model of crust cracking during water ingression, has been developed as part of the SSWICS programme, see [31]. This correlation has been adjusted using the results of tests performed without gas injection during corium solidification. On the basis of this correlation, it would appear that water ingression is much less effective for corium cooling than corium ejection.

As the possibility of cooling corium under water is strongly associated with $\mathrm{MCCl}$, the modelling of cooling under water is covered by the same software as used for modelling $\mathrm{MCCI}$. For example, the TOLBIAC-ICB code (see [39]) contains the corium ejection model developed after the PERCOLA test programme. Similarly, most models developed in the context of studies on the possibility of cooling corium by directing water onto it have been implemented in the CORQUENCH code (see [40]) developed by ANL to simulate 1D concrete erosion and the coupling between $\mathrm{MCCl}$ and heat transfer phenomena in the presence of water at the surface of the corium pool. Simplified models concerning water ingression into the upper crust and corium ejection, drawn from the first version of the CORQUENCH code, have been integrated into the MEDICIS code developed by IRSN, see [41]. More detailed models have subsequently been developed for the MEDICIS code, based on the PERCOLA model for hydrodynamics, see [35], and the literature available for assessing the geometry (density and diameter) of holes through which corium can be ejected, see [38] and [47]. Applications to a power reactor show that corium ejection is the dominant mechanism for corium cooling, and can significantly slow concrete erosion, especially in the case of a siliceous concrete, without stopping it completely, see [38] and [43].

10. The PERCOLA model assumes that gases and corium escape along vertical channels (or "chimneys") which develop in the bed of debris regardless of its thickness. 


\subsubsection{Summary and outlook}

As shown by the overview above, in 2015, it is not possible to draw conclusions on the possibility of stabilising and cooling a corium pool during an $\mathrm{MCCl}$ by directing water onto the surface on the basis of the results of the tests performed (1D and 2D integral tests, corium ejection tests, and water ingression tests).

Progress in this area is hindered by the technological difficulties surrounding the performance of sufficiently large-scale tests with real materials (scale effects on the corium pool, crust bonding onto test set-up walls, representativeness of the corium heating mechanism etc.).

Given the results obtained and in the face of the difficulties encountered, other specific provisions aiming to cool corium were proposed and studied over the years 1995 to 2010.

Three very different types of corium cooling device have been considered:

- the first type is a corium spreader, that collects all the corium leaving the vessel and spreads it out on a large-surface "spreading compartment" to reduce the heat to be removed per unit surface area and to cool it using a passive water circulation system, as planned for the EPR, see [42]; this system has been studied in depth and is described in detail in Section 5.4.3;

- the second type of device is a core catcher in the form of a crucible, see [44], made up of a large cavity covered with a thick layer of "sacrificial" refractory materials (materials that are eroded by the corium), which reduces heat flux via corium "dilution" (due to the addition of the sacrificial materials) and cools the corium using a passive water circulation system outside the core catcher; an example of such a device is the one implemented in the VVER reactor on the Tianwan Nuclear Power Plant in China;

- a third type of device, based on corium cooling by directing water at the bottom, has been successfully tested on the COMET facility at Forschungszentrum Karlsruhe in Germany, using simulant materials, see [45], and also in Cadarache with materials more representative of corium that could form during a core melt accident on a power reactor, see [46]. In the tested device, corium is collected in a porous concrete core catcher, covered with sacrificial concrete. Once this layer has eroded, the corium is reflooded by a passive system that directs water via the porous concrete and fragments the corium; corium spreading is not necessary for cooling and such a device can be installed in the reactor pit, just under the reactor vessel.

Experiments performed on these types of devices, in particular those performed on the core catcher and spreader system described in Section 5.4.3, show that, during a core melt accident on a power reactor, the devices should be able to effectively cool the corium after reactor-vessel failure and prevent the basemat penetration which could result from $\mathrm{MCCl}$. Such devices are implemented in some new generation reactors; in particular, this is the case for EPRs, which are fitted with a core catcher and spreader system. 
At least in the short term, it is not planned that such corium-cooling devices be installed on second-generation reactors in the operating fleet, because such installation would involve expensive, complex modifications. Furthermore, the significant worker exposure to ionising radiation that would result from such installation work should be taken into account. For this reason, studies are also being pursued with regard to cooling corium by directing water onto it, especially by using existing spray systems in the containment building. In particular, a new large-scale test programme was launched at ANL in 2011, dedicated to the study of corium cooling during $\mathrm{MCCl}$ by directing water from above under representative conditions, especially with regard to changes in residual heat in the pool during its flooding with water; this programme is part of collaboration between EDF, IRSN and the US Nuclear Regulatory Commission (NRC). In the case where corium cooling by existing devices that can direct water from above is found to be inadequate, recourse to other corium cooling devices and, in particular, those studied in the COMET facility could be considered, including for second-generation reactors.

\subsubsection{Corium spreading for the EPR}

\subsubsection{Physical phenomena involved}

Development of a core catcher with a corium spreader for the EPR required a European R\&D programme. The purpose of the spreading is to prevent reactor-building basemat penetration by facilitating corium cooling. To achieve this, spreading aims to ensure a sufficiently thin layer of corium, which minimises the surface heat flux due to residual heat to be removed.

Studies on corium spreading have therefore been performed to understand the ability of corium to spread on a substrate of fixed geometry and composition, with the corium flow conditions on the spreading surface determined by the accident sequence. The key parameters for corium spreading are the compositions of corium and substrate, the initial temperature and flowrate of the corium, and the geometry of the spreading compartment. References [60] and [76] give a summary of the work performed on this subject.

\subsubsection{Description of the EPR core catcher}

The concept used is based on spreading the corium over a large surface area, with the corium flooded and cooled by water from the In-containment Refuelling Water Storage Tank (IRWST) located in the containment building (see Figure 5.50 and Section 2.3.2.4 for a description of the EPR's engineered safeguard systems).

To promote corium spreading, the EPR core catcher temporarily retains the corium in the reactor pit before spreading. During this phase, the corium erodes a layer of "sacrificial" concrete, which is approximately $50 \mathrm{~cm}$ thick, before flowing into the melt discharge channel that connects the reactor pit to the "spreading compartment". This layer of sacrificial concrete is laid on a protective 10-to-14-cm-thick zirconium layer, which aims to ensure the integrity of reactor-pit concrete structures, even in the event 

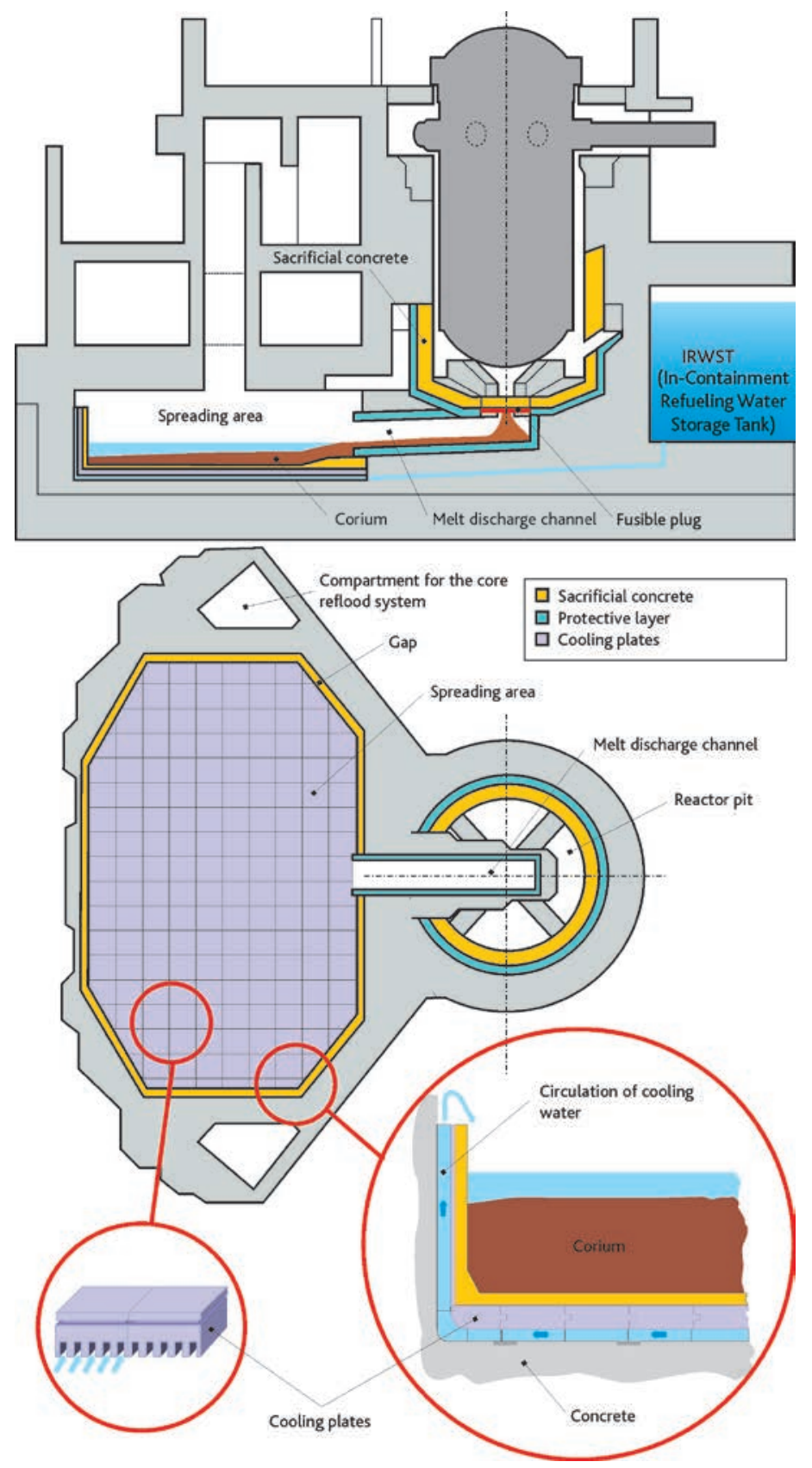

Figure 5.50. The upper part of the figure represents a cross-section view of the main components of the EPR core catcher (from [78]). The lower part of the figure represents the cooling system for the EPR core catcher with details: lower right, a vertical cross-section of the walls of the spreading compartment showing how the cooling water circulates under these walls; lower left, a vertical cross-section of the horizontal cooling channels located under the spreading compartment. The central part shows a top view of reactor pit, melt discharge channel and spreading compartment. 
of non-uniform erosion of the sacrificial concrete by the corium (see Figure 5.50). During this temporary retention, the physico-chemical properties of the corium are modified (becoming more fluid, uniform in composition and of low viscosity) to facilitate its flow in the melt discharge channel and the spreading phase itself. If there are several successive corium flows following reactor-vessel failure, this temporary retention also means that the corium from the various flows can be gathered to obtain a uniform corium and a single flow towards the spreading compartment. In the zirconium layer under the sacrificial concrete at the bottom of the reactor pit, there is a wire-mesh insert which acts as a melt plug. This "gate" gives access to the melt discharge channel; it is a by-design weak point, as it is the only place where the sacrificial concrete is not reinforced by a protective layer, and it therefore fails relatively quickly on contact with the corium (after erosion of the sacrificial concrete), providing a sufficiently wide flow cross-section for rapid flow of all the corium into the spreading compartment.

The spreading compartment has a surface area of approximately $170 \mathrm{~m}^{2}$. The floor and sidewalls of this compartment are assembled from a large number of individual elements made of cast iron. This structure is largely insensitive to thermal expansion and steep temperature gradients. The floor elements have rectangular, horizontal cooling channels. The inside of the spreading compartment is covered with a layer of sacrificial concrete. The arrival of corium triggers the opening of valves that initiate gravity-driven flow of water from the IRWST into the spreading compartment. The water first fills the horizontal cooling channels below the spreading compartment, and then fills the space behind the side-wall cooling structure before reflooding the corium from above. The system is shown in Figure 5.50.

\subsubsection{Physics of corium spreading}

Corium spreading is governed by competition between hydrodynamic driving forces (hydrostatic pressure and, to some extent, inertia), which promote progress and thinning of the flow, and gradual corium solidification, which leads to increasing apparent viscosity and the appearance of crusts in contact with the substrate and surface.

The hydrodynamics of lava spread has been studied by several authors in the field of volcanology, see [48], [49] and [50]. Numerical models and semi-analytical solutions have been developed for the flow of a fluid whose properties remain constant during the flow. Spreading on a horizontal surface is a free-surface flow, whose driving force is a function of the downslope. Corium flow during a core melt accident depends on gravity, inertia (at high flowrates) and viscous friction forces (at lower flowrates).

Corium rheology, see [73] and [74], changes strongly during its cooling, in particular below the liquidus temperature when crystalline phases appear. It depends on both the viscosity of the liquid phase (a mixture in which the silicate ions from the sacrificial concrete increases the viscosity by forming networks), which has been described by Urbain in [51] for example, and on the effect of crystals which solidify during the flow (the type of complex fluid formed, called semi-solid, is described by Flemmings in [52] and an empirical viscosity formula has been proposed for corium, see [73] and [77]). 
Corium cooling is due to radiative heat transfer from the surface of the flow and by convection in contact with the substrate. Crusts may form at these two interfaces and contribute to slowing the flow. Nevertheless, there is significant thermal contact resistance, of around $5.10^{-3} \mathrm{~m}^{2} . \mathrm{K} / \mathrm{W}$, at the corium-substrate interface, which contributes to reducing corium cooling in contact with the substrate, see [53]. The effect of residual heat is small, given the short duration of spreading (no more than a few minutes).

In reference [54], Griffiths and Fink have published a detailed study of the various models of the spreading of solidifying lavas as a function of dominant forces (gravity and inertia, gravity and viscosity, gravity and complex rheology, gravity and crust strength etc.). These models mean that the speed of corium spreading can be assessed as a function of its flowrate in the melt discharge channel and its viscosity. They are used to assess the validity of corium spreading calculations performed for simplified boundary conditions, that do not take corium cooling into account.

\subsubsection{Experimental programmes, modelling and simulation software}

\subsection{Experimental programmes}

The first test programmes regarding spreading corium from a core melt accident on a power reactor were performed at Brookhaven in the USA, see [55]. Their purpose was to study corium spreading on the bottom of a reactor pit on a Mark I BWR. In Europe, experimental and numerical studies of spreading have been performed with a view to development of a core catcher for the EPR. Most of this work has been performed in the context of European projects: COMAS, large-scale corium cooling tests performed by AREVA, see [57]; Corium Spreading and Coolability (CSC), qualification tests for the concept of a core catcher with corium spreading and of the COMET concept of reflooding from below, see [56]; and Ex-vessel COre melt STAbilisation Research (ECOSTAR), tests pertaining to the study of the physico-chemical phenomena that occur during spreading and the effectiveness of reflooding spread corium by directing water onto the top or bottom, see [58].

Experimental programmes include analytical experiments that aim to study the effect of various physical phenomena involved in corium spreading and cooling (for example, the CORINE programme using simulant materials performed at CEA Grenoble and jointly funded by IRSN, see [59] and [60]), semi-analytical experiments with simulant materials and tests with prototypic materials ${ }^{11}$. Tables 5.6 and 5.7 present the characteristics of main test programmes, whether with simulant materials or with prototypic corium compositions. As an example, Figure 5.51 illustrates a corium spreading test.

These experimental programmes (in particular, the CORINE, VULCANO and KATS programmes) cover the greater part of the range of possible variations of the parameters accessible to experimentation with regard to the geometry, properties of materials and boundary conditions.

11. (Non-radioactive) corium of identical chemical composition to that expected during a core melt accident, but of different isotopic composition (for example using depleted or natural uranium instead of enriched uranium). 
Table 5.6. Experimental spreading programmes performed with simulant materials.

\begin{tabular}{|c|c|c|c|c|c|}
\hline Programme & Laboratory & Materials & $\begin{array}{l}\text { Scale } \\
\text { (volume } \\
\text { poured) }\end{array}$ & Geometry & $\begin{array}{l}\text { Parameters or effects } \\
\text { studied }\end{array}$ \\
\hline $\begin{array}{l}\text { CORINE } \\
{[59,60]}\end{array}$ & $\begin{array}{l}\text { CEA } \\
\text { (France) }\end{array}$ & $\begin{array}{l}\text { Low-temperature } \\
\text { simulant materials } \\
\text { (water, glycerol, } \\
\text { low-melting point } \\
\text { metal alloys) }\end{array}$ & $\sim 50$ litres & $\begin{array}{l}19^{\circ} \text { angular } \\
\text { sector }\end{array}$ & $\begin{array}{l}\text { - Flowrate } \\
\text { (from } 0.5 \text { to } 3 \mathrm{~L} / \mathrm{s} \text { ) } \\
\text { - Effect of material } \\
\text { (viscosity, single sub- } \\
\text { stances or non-eutectic } \\
\text { mixtures). } \\
\text { - Cooling from above } \\
\text { or below. } \\
\text { - Effect of a gas flow } \\
\text { coming from the } \\
\text { substrate. }\end{array}$ \\
\hline Greene [55] & BNL (USA) & Lead & $\sim 1$ litre & $\begin{array}{l}\text { Square } \\
\text { cross-sec- } \\
\text { tion }\end{array}$ & $\begin{array}{l}\text { - Spread mass. } \\
\text { - Heating. } \\
\text { - Effect of water depth. }\end{array}$ \\
\hline S3E [61] & $\begin{array}{l}\text { KTH } \\
\text { (Sweden) }\end{array}$ & $\begin{array}{l}\text { Low- and interme- } \\
\text { diate-temperature } \\
\left(1200^{\circ} \mathrm{C}\right) \text { simulant } \\
\text { materials }\end{array}$ & $\begin{array}{l}5 \text { to } \\
20 \text { litres }\end{array}$ & $\begin{array}{l}\text { Rectangular } \\
\text { channels }\end{array}$ & $\begin{array}{l}\text { - Flowrate. } \\
\text { - Heating. } \\
\text { - Effect of material. } \\
\text { - Effect of (concrete) } \\
\text { substrate. } \\
\text { - Effect of water, with } \\
\text { or without boiling. }\end{array}$ \\
\hline SPREAD [62] & $\begin{array}{l}\text { Hitachi } \\
\text { Energy } \\
\text { Research } \\
\text { Laboratory } \\
\text { (Japan) }\end{array}$ & Steel & 1 to 15 litres & $\begin{array}{l}\text { Rectangular } \\
\text { channel } \\
\text { Half-disk }\end{array}$ & $\begin{array}{l}\text { - Spread mass. } \\
\text { - Heating. } \\
\text { - Flowrate. } \\
\text { - Effect of inlet geometry } \\
\text { - Effect of substrate. } \\
\text { - Effect of water depth. }\end{array}$ \\
\hline $\begin{array}{l}\text { KATS } \\
{[63-65]}\end{array}$ & $\begin{array}{l}\text { FzK } \\
\text { (Germany) }\end{array}$ & $\begin{array}{l}\text { Aluminium ther- } \\
\text { mite } \\
\left(\mathrm{Al}_{2} \mathrm{O}_{3}+\mathrm{Fe}\right) \\
\text { around } 2000^{\circ} \mathrm{C}\end{array}$ & $\begin{array}{l}\text { Up to } \\
850 \text { litres }\end{array}$ & $\begin{array}{l}\text { Rectangular } \\
\text { channel } \\
90^{\circ} \text { angular } \\
\text { sector }\end{array}$ & $\begin{array}{l}\text { - Spread mass. } \\
\text { - Flowrate. } \\
\text { - Effect of substrate. } \\
\text { - Effect of adding } \\
\text { "sacrificial materials" } \\
\text { - Type of phase(s) spread } \\
\text { (oxide or metal). } \\
\text { - Reflooding. }\end{array}$ \\
\hline
\end{tabular}

Table 5.7. Experimental programmes performed with prototypic materials.

\begin{tabular}{|l|l|l|l|l|l|}
\hline Programme & Laboratory & Materials & $\begin{array}{c}\text { Scale } \\
\text { (volume } \\
\text { poured) }\end{array}$ & Geometry & \multicolumn{1}{|c|}{$\begin{array}{l}\text { Parameters or effects } \\
\text { studied }\end{array}$} \\
\hline COMAS [57] & $\begin{array}{l}\text { Siem- } \\
\text { pelkamp } \\
\text { (Germany) }\end{array}$ & $\begin{array}{l}\text { Corium-concrete- } \\
\text { iron mixtures } \\
\text { Liquidus } \\
\text { temperature } \\
\text { around } 1900^{\circ} \mathrm{C}\end{array}$ & $\begin{array}{l}20 \text { to } \\
300 \text { litres }\end{array}$ & $\begin{array}{l}\text { Rectangular } \\
\text { channels } 45^{\circ} \\
\text { angular } \\
\text { sector }\end{array}$ & $\begin{array}{l}\text { - High flowrates } \\
\text { (>150 kg/s). } \\
\text { Effect of silica. } \\
\text { - Effects of substrate } \\
\text { (ceramic, metal } \\
\text { or concrete). }\end{array}$ \\
\hline
\end{tabular}




\begin{tabular}{|c|c|c|c|c|c|}
\hline Programme & Laboratory & Materials & $\begin{array}{c}\text { Scale } \\
\text { (volume } \\
\text { poured) }\end{array}$ & Geometry & $\begin{array}{c}\text { Parameters or effects } \\
\text { studied }\end{array}$ \\
\hline FARO [66] & $\begin{array}{l}\text { CCR Ispra } \\
\text { (European } \\
\text { Commis- } \\
\text { sion) }\end{array}$ & $\begin{array}{l}\mathrm{UO}_{2}+\mathrm{ZrO}_{2} \\
\text { Liquidus } \\
\text { temperature } \\
\text { around } 2700{ }^{\circ} \mathrm{C}\end{array}$ & $\sim 20$ litres & $\begin{array}{l}19^{\circ} \text { angular } \\
\text { sector }\end{array}$ & $\begin{array}{l}\text { - Presence or otherwise of } \\
\text { a thin layer of water. } \\
\text { - Effect of a metal sub- } \\
\text { strate. }\end{array}$ \\
\hline $\begin{array}{l}\text { VULCANO } \\
{[67]}\end{array}$ & $\begin{array}{l}\text { CEA } \\
\text { (France) }\end{array}$ & $\begin{array}{l}\mathrm{UO}_{2}+\mathrm{ZrO}_{2} \\
+ \text { concrete } \\
\text { erosion products } \\
\text { Liquidus } \\
\text { temperature of } \\
1900 \text { to } 2700^{\circ} \mathrm{C}\end{array}$ & $\begin{array}{l}3 \text { to } \\
10 \text { litres }\end{array}$ & $\begin{array}{l}19^{\circ} \text { angular } \\
\text { sector }\end{array}$ & $\begin{array}{l}\text { - Flowrate. } \\
\text { - Corium composition. } \\
\text { - Effects of } \\
\text { the substrate. }\end{array}$ \\
\hline
\end{tabular}

The spreading experiments performed show that, for corium flows during solidification, the liquid and solid phases remain mixed (there is no macrosegregation, unlike that which occurs during slower transitions). The solid fraction varies continually during flow. Furthermore, for a corium where the difference between solidus and liquidus temperatures is large, a "skin" forms in a mushy (liquid-solid) state rather than as a solid crust, at least initially. Conversely, in the case of a more refractory corium where the solidus and liquidus temperatures are close, a solid crust forms on the upper flow surface, which cracks and lets molten corium pass. In this case, the phenomena observed depend strongly on the scale of the flow, which means that the available experimental data remains inadequate on this specific point of the effect of the crust on flow dynamics, as it only involves small-scale tests with masses at least 1000 times smaller than those which would be involved in the case of a power reactor. Erosion of the concrete substrate during spreading remains minor; an effect on the spreading speed has been brought to light but is of little importance.

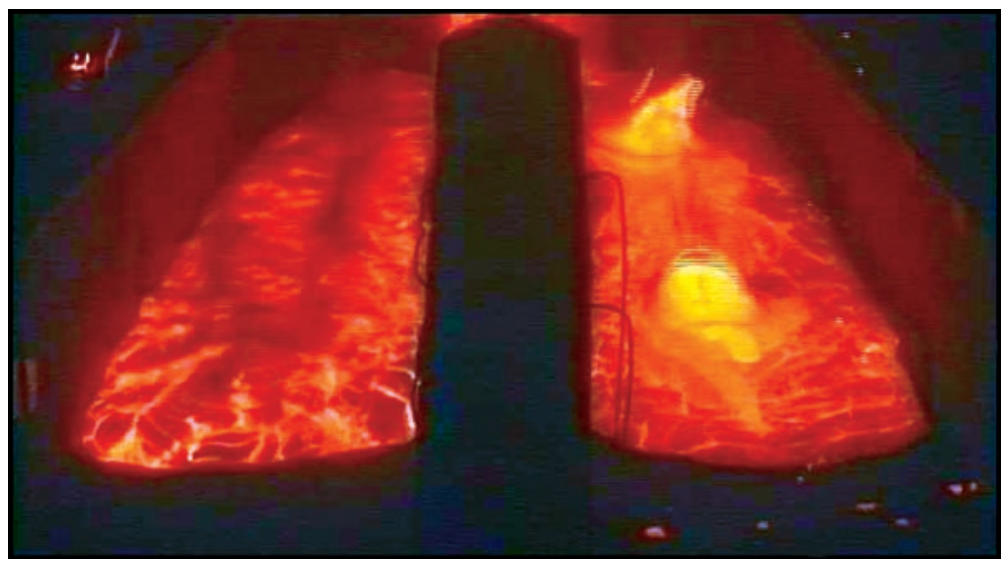

Figure 5.51. Spreading of corium representative of that produced during a core melt accident on a power reactor onto ceramic (left) and concrete (right) substrates, from the VULCANO VE-U7 spreading test performed by CEA with a mixture of $\mathrm{UO}_{2}, \mathrm{ZrO}_{2}$ and concrete erosion products, see [58]; credit: CEA. 
Knowledge of dry corium spreading for the case of a large difference between solidus and liquidus temperatures (i.e. for corium rich in non-refractory materials from sacrificial concrete) is sufficient to validate calculation software and extrapolations to the case of a power reactor.

With regard to corium spreading under water, CORINE tests, performed with simulant materials and a water depth of around $10 \mathrm{~cm}$, show that there could be an accumulation of corium whose thickness could reach that of the depth of water downstream of the corium flow, but that this would have little effect on the spreading. However, extrapolation of these results concerning spreading under water, which depend on scale (in particular the flow height), to the case of a power reactor is not possible with existing knowledge.

\subsection{Models and simulation software}

Several simulation software packages have been developed in Europe to model corium spread. Table 5.8 presents their main characteristics. This software has been the subject of significant validation work using the results of flow tests performed using simulant or prototypic materials. For example, comparison exercises for the calculation results produced using different software systems on the basis of the VULCANO VE-U7 test (with prototypic corium compositions, see [72]) and calculations performed on the basis of the ECOKATS-1 test (with simulant materials, see [64]) have shown that the software produces a good estimate of the spreading surfaces observed during tests; the uncertainty is around $20 \%$.

The Stockholm Royal Institute of Technology (KTH) has developed a simplified analytical model for corium spreading, which has been satisfactorily validated (the mean precision is around $\pm 50 \%$ on the spreading surface calculations), see [61] and [76].

To supplement the modelling of corium spreading, an R\&D programme was performed by CEA at the end of the 1990s, dedicated to the study of corium rheology during its solidification, taking into account the variation of corium viscosity as a function of the corium spreading speeds along the vertical axis, see [73]. This means that viscosity models applicable to liquids with or without silica can be applied to corium, and therefore the viscosity of semi-solid corium as a function of the solid volume fraction can be predicted with adequate accuracy (i.e. within a factor of 3), see [73], [74] and [75]. These calculation results for the viscosity of corium are used in the spreading calculations.

All this work has led to a level of corium-spreading modelling that is sufficient to predict the spreading kinetics under the conditions of a core melt accident on a power reactor. In particular, the software developed is used to check, with reasonable uncertainty, the correct spreading of corium as a function of the boundary conditions of various accident scenarios, especially as a function of corium temperature and changes in corium flowrate. 
Table 5.8. The main simulation software for corium spreading.

\begin{tabular}{|c|c|c|c|c|}
\hline Code & Origin & Geometry & Characteristics & Validation \\
\hline $\begin{array}{l}\text { MELTSPREAD } \\
{[68]}\end{array}$ & $\begin{array}{l}\text { ANL for } \\
\text { EPRI } \\
\text { (USA) }\end{array}$ & 1D & $\begin{array}{l}\text { - Covers substrate erosion and } \\
\text { corium oxidation. }\end{array}$ & $\begin{array}{l}\text { - Mainly based on } \\
\text { the results of } \\
\text { Greene's tests. }\end{array}$ \\
\hline THEMA [60] & $\begin{array}{l}\text { CEA } \\
\text { (France) }\end{array}$ & $\begin{array}{l}\text { 2D } \\
\text { temperature and } \\
\text { horizontal speed } \\
\text { averaged over the } \\
\text { vertical axis }\end{array}$ & $\begin{array}{l}\text { - Covers corium solidification } \\
\text { (in mass and in crusts) and } \\
\text { substrate erosion. } \\
\text { - 3D resolution of heat equa- } \\
\text { tions in the substrate. }\end{array}$ & $\begin{array}{l}\text { - Analytical tests. } \\
\text { - Tests with } \\
\text { simulant } \\
\text { materials and } \\
\text { prototypic } \\
\text { corium } \\
\text { compositions. }\end{array}$ \\
\hline LAVA [69] & $\begin{array}{l}\text { GRS } \\
\text { (Ger- } \\
\text { many) }\end{array}$ & $\begin{array}{l}\text { 2D temperature } \\
\text { and horizontal } \\
\text { speed averaged } \\
\text { over the vertical } \\
\text { axis }\end{array}$ & $\begin{array}{l}\text { - Detailed analysis of corium } \\
\text { cooling and rheology. }\end{array}$ & Idem \\
\hline CROCO [70] & $\begin{array}{l}\text { IRSN } \\
\text { (France) }\end{array}$ & $\begin{array}{l}\text { 2D } \\
\text { horizontal and } \\
\text { vertical }\end{array}$ & $\begin{array}{l}\text { - Detailed modelling of } \\
\text { convection in the flow. } \\
\text { - Calculation of the free } \\
\text { surface using Lagrangian } \\
\text { modelling and resolution } \\
\text { of conservation equations on } \\
\text { a Eulerian mesh. }\end{array}$ & Idem \\
\hline $\begin{array}{l}\text { CORFLOW } \\
\text { [71] }\end{array}$ & $\begin{array}{l}\text { FzK } \\
\text { (Ger- } \\
\text { many) }\end{array}$ & 3D & $\begin{array}{l}\text { - Detailed modelling of } \\
\text { convection in the flow. } \\
\text { - Free surface represented by } \\
\text { a "corium height" function } \\
\text { deduced from the equations } \\
\text { for conservation of mass and } \\
\text { momentum. }\end{array}$ & Idem \\
\hline
\end{tabular}

\subsubsection{Summary and outlook}

R\&D programmes performed to study corium spreading have established that dry spreading of the corium formed during a core melt accident on a power reactor enables its later cooling (the corium layer produced is sufficiently thin). It has been found, in particular during VULCANO tests, that even when the temperature of a corium-concrete mixture is 100 to $200^{\circ} \mathrm{C}$ below the liquidus temperature, this mixture spreads adequately, as long as the flowrate is sufficiently high.

The presence of a thin water layer (simulating the water which would condense in the reactor building during an accident) or that of a concrete substrate (releasing steam and $\mathrm{CO}_{2}$ during its interaction with the corium) have little effect on spreading. However, the influence of a deeper layer of water on corium spreading cannot be determined on the basis of existing knowledge. In this case, corium flow depends on the mechanical behaviour of the crusts formed on the surface and at the front of the flow (in particular 
their cracking), and on fragmentation of the corium; study of the behaviour of crust and corium would require additional tests to provide a validated model.

Due to uncertainties concerning the ability of a layer of corium to spread under water, design provisions were taken for the EPR, aiming to ensure collection of corium from the reactor vessel in the reactor pit, followed by its dry spreading (no water in the spreading compartment before the corium arrives) then its cooling by water circulating in cooling channels located under the spreading compartment and finally its cooling by reflooding from above.

\section{Reference Documents}

[1] Nuclear Technology, Special edition devoted to TMI-2, 87, 1989.

[2] Three Mile Island reactor pressure vessel investigation project, Proc. of an Open Forum Sponsored by OECD NEA and US NRC, 1993.

[3] NUREG/CR-6849, Analysis of in-vessel retention and ex-vessel fuel coolant interaction for AP1000, 2004.

[4] J.M. Seiler, Analytical model for CHF in narrow gaps on plates and in hemispherical geometries, Nuclear Engineering and Design 236 (19-21), 2211-2219, 2006.

[5] J.M. Seiler, K. Froment, Material effects on multiphase phenomena in late phase of severe accidents of nuclear reactor, Multiphase Science and Technology 12, 2000.

[6] F.M. Cheung, Limiting factors for external vessel cooling, 10th Int. Topical Meeting on Nuclear Reactor Thermalhydraulics (NURETH 10), 2003.

[7] J.M. Seiler, B. Tourniaire, F. Defoort, K. Froment, Consequences of physicochemistry effects on in-vessel retention issue, 11th Topical Meeting on Nuclear Reactor Thermalhydraulics (NURETH 11), 2005.

[8] M. Amblard, K. Froment, J.M. Seiler, B. Tourniaire, ANAIS experiment: consequence of water injection on a molten metal layer in the lower head, 10th Int. Topical Meeting on Nuclear Reactor Thermalhydraulics (NURETH 10), 2003.

[9] J.M. Bonnet, J.M. Seiler, In-vessel corium pool thermalhydraulics for the bounding case, Salt Expert Group Meeting RASPLAV Seminar, 2000.

[10] T. Laporte, Synthèse des études réalisées au DMT sur les conséquences d'une explosion de vapeur en cuve ou hors cuve en cas d'accident grave de REP, CEA/ DEN/DMT/LM2S/RT/00-039, 2000.

[11] E.H. Henry, R.J. Hammersley, An experimental investigation of possible In-Vessel cooling mechanisms, FAI note I:IHPAI97-1, 1997.

[12] K.H. Kang, R.J. Park, S.D. Kim, H.D. Kim, Simulant melt experiments on the coolability through external vessel cooling strategy, ICAPP' 05 conference, Seoul, Korea, May 15-19, 2005. 
[13] V. Asmolov, L. Kobzar, V. Nickulshin, V. Strizhov, Experimental study of heat transfer in the slotted channel at CTF facility, OECD/CSNI Workshop on In-Vessel Core Debris Retention and Coolability, Garching, Germany, March 3-6, 1998.

[14] W. Köhler, H. Schmidt, O. Herbst, W. Krätzer, Thermohydraulische Untersuchungen zur Debris/Wand-Wechselwirkung (DEBRIS), Abschlussbericht Project $\mathrm{N}^{\circ}$ 150 1017, November, 1998.

[15] J.H. Jeong, R.J. Park, K.H. Kang, S.B. Kim, H.D. Kim, Experimental study on CHF in a Hemispherical Narrow Gap, OECD/CSNI Workshop on In-Vessel Core Debris Retention and Coolability Garching, Germany, March 3-6, 1998.

[16] S.S. Abalin, I.P. Gnidoi, A.I. Surenkov, V.F. Strizhov, Data base for 3rd and 4th series of RASPLAV salt tests, OECD RASPLAV Report, 1998.

[17] P. Roux, F. Fichot, S. De Pierrepont, D. Gobin, B. Goyeau, M. Quintard, 2005 Modelling of binary mixture phase change: assessment on RASPLAV Salt Experiments, NURETH 11, Avignon, 2-6 October, 2005.

[18] S. Rougé, SULTAN test facility; Large scale vessel coolability in natural convection at low pressure, NURETH 7, Saratoga Springs September 10-15, 1995.

[19] T.N. Dinh, T.G. Salmassi, T.G. Theofanous, The limits of coolability in AP 1000 related ULPU-2400 confi V facility, Proceedings of the 10th Intern Topical Meeting on Nuclear Reactor Thermalhydraulics, October 5-9, 2003, Séoul, Korea.

[20] J.M. Seiler, A. Fouquet, K.F. Froment, F. Defoort, Theoretical analysis for corium pool with miscibility gap, Nuclear Technology 141 (3), 233-243, 2003.

[21] J.L. Rempe, K.H. Suh, F.B. Cheung, Insights from investigations of In-Vessel retention for high powered reactors, NURETH 11, Avignon, octobre 2-6, 2005.

[22] J.M. Seiler, G. Ducros, Reflooding of a PWR core assessment of knowledge and R\&D needs. Potential contribution by Phébus, DEN/DTN/SE2T/LPTM/05-117, 2005.

[23] M. Zabiego, F. Fichot, Experimental needs for reflooding models validation, NT SEMCA 2006/257, IRSN/DPAM, 2006.

[24] K. Atkhen, G. Berthoud, Experimental and numerical investigations based on debris bed coolability in a multidimensional and homogeneous configuration with volumetric heat source, Nuclear Technology 142, June 2003.

[25] N. Chikhi, F. Fichot, Reflooding model for quasi-intact rod configuration quench front tracking and heat transfer closure laws, Nuclear Engineering and Design 240 (10), 3387-3396, 2010.

[26] M.T. Farmer, B.W. Spencer, J.L. Binder, D.J. Hill, Status and Future Direction of the Melt Attack and Coolability Experiments (MACE) Program at the Argonne National Laboratory, Proc. of 9th Int. Conf. on Nuclear Engineering, ICONE-9697, April 2001. 
[27] M.T. Farmer, D.J. Kilsdonk, R.W. Aeschliman, MSET-1 test data report, MACETRD18, 2002 - Reference not publicly available.

[28] M.T. Farmer, S. Lomperski, S. Basu, Results of reactor material experiments investigating 2D core-concrete interaction and debris coolability, Proc. of 4th Int. Conf. on Advances in Nuclear Power Plants, 2004.

[29] M.T. Farmer, S. Lomperski, S. Basu, A summary of findings from the melt coolability and concrete interaction (MCCI) program, Proceedings of ICAPP07, Nice, France, May 13-18, 2007.

[30] B. Tourniaire, J.M. Seiler, J.M. Bonnet, M. Amblard, Experimental study and modelling of liquid ejection through orifices by sparging gas, Nuclear Engineering and Design 236 (19-21), 2281-2295, 2006.

[31] S. Lomperski, M.T. Farmer, Experimental evaluation of the water ingression mechanism for corium cooling, Nuclear Engineering and Design 237 (9), 905-917, 2007.

[32] S. Lomperski, M.T. Farmer, D. Kilsdonk, R. Aeschlimann, Small-Scale Water Ingression and Crust Strength Tests (SSWICS) SSWICS-11 Test Data Report: Thermal Hydraulic Results, OECD/MCCI-2009-TR01, Rev. 2, September, 2009.

[33] S. Lomperski, M.T. Farmer, Measurement of the mechanical strength of corium crusts, Proc. of 8th Int. Conf. on Advances in Nuclear Power Plants, Seoul, Korea, June 8-12th, 2008.

[34] J.M. Bonnet, J.M. Seiler, Coolability of corium spread onto concrete under water, the PERCOLA model, Proc. of the 2nd OECD (NEA) CSNI specialist meeting on Core Debris-Concrete Interaction, 1992.

[35] B. Tourniaire, J.M. Seiler, Modeling of viscous and inviscid fluid ejection through orifices by sparging gas, Proc. of 4th Int. Conf. on Advances in Nuclear Power Plants, 2004.

[36] F.P. Ricou, D.B. Spalding, Measurements of entrainment by axisymetrical turbulent jets, Journal of Fluids Mechanics, 1961.

[37] B. Tourniaire, Application of the PERCOLA ejection model to reactor scenario of molten core concrete interaction under water, Proc. of 5 th Int. Conf. on Advances in Nuclear Power Plants, 2005.

[38] M.T. Farmer, Phenomenological Modeling of the Melt Eruption Cooling Mechanism during Molten Corium Concrete Interaction, ICAPP'06, Reno, Nevada, USA, June 2006.

[39] B. Spindler, B. Tourniaire, J.M. Seiler, K. Atkhen, $\mathrm{MCCl}$ analysis and applications with the TOLBIAC-ICB code based on phase segregation model, Proc. of 5th Int. Conf. on Advances in Nuclear Power Plants, 2005. 
[40] M.T. Farmer, B.W. Spencer, Status of the CORQUENCH model for calculation of ex-vessel corium coolability by an overlying water layer, OECD Workshop on Exvessel Debris Coolability, 1999.

[41] M. Cranga, R. Fabianelli, F. Jacq, M. Barrachin, F. Duval, The MEDICIS code, a versatile tool for MCCI modelling, Proc. of 5th Int. Conf. on Advances in Nuclear Power Plants, Seoul, Korea, May 15-19, 2005.

[42] M. Fischer, The severe accident mitigation concept and the design measures for core melt retention of the European pressurized water reactor (EPR), Nuclear Engineering and Design 230 (1-3), 169-180, 2004.

[43] M. Cranga, B. Michel, F. Duval, C. Mun, Relative impact of $\mathrm{MCCl}$ modeling uncertainties on reactor basemat ablation kinetics, MCCI-OECD seminar, Cadarache, StPaul-lez-Durance, France, October 10-11, 2007.

[44] J.M. Seiler, B.R. Sehgal, H. Alsmeyer, O. Kymäläinen, B. Turland, J.L. Grange, M. Fischer, G. Azarian, M. Bürger, C.J. Cirauqui, European Group for Analysis of Corium recovery Concepts (EUROCORE), FISA Conference, 2003.

[45] H. Alsmeyer, C. Adelhelm, H. Benz, T. Cron, G. Dillmann, W. Tromm, S. SchmidtStiefel, H. Schneider, G. Schumacher, T. Wenz, F. Ferderer, Corium cooling by bottom flooding: Results of the COMET investigations, Proc. OECD Workshop on Ex-Vessel Debris Coolability, Karlsruhe, Germany, Nov. 1999, FZKA 6475, pp. 345355, 356-364 (2000).

[46] C. Journeau, H. Alsmeyer, Validation of the COMET Bottom-Flooding CoreCatcher with Prototypic Corium, Proc. of 6th Int. Conf. on Advances in Nuclear Power Plants, Reno, NV USA, June 4-8th 2006.

[47] K.R. Robb, M.L. Corradini, Towards understanding melt eruption phenomena during molten corium concrete interactions, Proc. Of ICONE 18 Conf. Xi'an, China, May 2010.

[48] M. Dragoni, M. Bonafede, E. Boschi, Downslope flow models of a Bingham liquid: Implications for lava flows, J. Volcanol. Geotherm. Res. 30, 305-325, 1986.

[49] H.E. Huppert, The propagation of two-dimensional and axisymmetric viscous gravity currents over a rigid horizontal surface, J. Fluid Mech. 121, 43-58, 1982.

[50] N. Didden, T. Maxworthy, The viscous spreading of plane and axisymmetric gravity currents, J. Fluid Mech. 121, 27-42, 1982.

[51] G. Urbain, Viscosity estimation of slags, Steel Res. 58, 111-116, 1987.

[52] M.C. Flemmings, Behavior of metal alloys in the semisolid state, Metall. Tran. 22B, 269-293, 1991.

[53] G. Berthoud, Freezing of Pure Melt Flowing into Tubes, In: Ehrhard, P., Riley, D.S., Steen, P.H., Édition, Interactive Dynamics of Convection and Solidification, Kluwer Acad. Publ., Dordrecht, NL, pp. 249-26, 2001. 
[54] R.W. Griffiths, J.H. Fink, Effects of Surface Cooling in the Spreading of lava flows and domes, J. Fluid Mech. 252, 667-702, 1993.

[55] G.A. Greene, C. Finrock, J. Klages, C.E. Schwarz, S. B. Burton, Experimental Studies on Melt Spreading, Bubbling Heat Transfer and Coolant Layer Boiling, Proc. 16th Water Reactor Safety Meeting, NUREG/CP-0097, pp. 341-358, 1988.

[56] G. Cognet, A. Alsmeyer, W. Tromm, D. Magallon, R. Wittmaack, B.R. Sehgal, W. Widmann, L. De Cecco, R. Ocelli, G. Azarian, D. Pineau, B. Spindler, G. Fieg, H. Werle, C. Journeau, M. Cranga, G. Laffont, Corium spreading and coolability: CSC Project, Nuclear Engineering and Design 209, 127-138, 2001.

[57] W. Steinwarz, A. Alemberti, W. Häfner, Z. Alkan, M. Fischer, Investigations on the phenomenology of ex-vessel core melt behaviour, Nuclear Engineering and Design 209 (1-3), 139-146, 2001.

[58] H. Alsmeyer, G. Alberecht, L. Meyer, W. Häfner, C. Journeau, M. Fischer, S. Hellmann, M. Eddi, H.-J. Allelein, M. Bürger, B.R. Sehgal, M.K. Koch, Z. Alkan, J.B. Petrov, M. Gaune-Escart, E. Altstadt, G. Bandini, Ex-vessel core melt stabilization research (ECOSTAR), Nuclear Engineering and Design 235 (2-4), 271-284, 2005.

[59] J.M. Veteau, R. Wittmaack, CORINE experiments and theoretical modelling. In: G. Van Goetem, W. Balz, E. Della Loggia (Eds) FISA 95 EU Research on severe accidents, Official Publ. Europ. Communities, Luxembourg, 1996, p. 271-285.

[60] B. Spindler, J.M. Veteau, Simulation of spreading with solidification: assessment synthesis of THEMA code, Rapport CEA-R6053, 2004.

[61] T.N. Dinh, M.J. Konovalikhin, B.R. Sehgal, Core Melt Spreading on a reactor Containment Floor, Progr. Nucl. Energ. 36 (4), 405-468, 2000.

[62] H. Suzuki, T. Matsumoto, I. Sakaki, T. Mitadera, M. Matsumoto, T. Zama, Fundamental experiment and analysis for melt spreading on concrete floor, Proc. 2nd ASME/JSME, Nucl. Eng. Conf. 1, 403-407, 1993.

[63] G. Engel, G. Fieg, H. Massier, U. Stiegmaier, W. Schütz, KATS experiments to simulate corium spreading in the EPR code catcher concept, OECD Workshop Ex-Vessel Debris Coolability, Karlsruhe, Allemagne, 15-18/11/1998, 1999.

[64] C. Spengler, H.-J. Allelein, J.-J. Foit, H. Alsmeyer, B. Spindler, J.M. Veteau, J. Artnik, $M$. Fischer, Blind benchmark calculations for melt spreading in the ECOSTAR project, Proc. ICAPP '04 (Int. Conf. Advances in nuclear Power Plants), Pittsburg, PA, Communication $n^{\circ} 4105,2004$.

[65] H. Alsmeyer, T. Cron, G. Messemer, W. Häfner, ECOKATS-2: A Large Scale Experiment on Melt Spreading and Subsequent Cooling by Top Flooding, Proc. ICAPP '04 (Int. Conf. Advances in nuclear Power Plants), Pittsburg, PA, Communication n 4134.

[66] W. Tromm, J.J. Foit, D. Magallon, Dry and wet spreading experiments with prototypic materials at the FARO facility and theoretical analysis, Wiss. Ber. FZKA, 6475, 2000, pp. 178-188. 
[67] C. Journeau, E. Boccaccio, C. Brayer, G. Cognet, J.-F. Haquet, C. Jégou, P. Piluso, J. Monerris, Ex-vessel corium spreading: results from the VULCANO spreading tests, Nuclear Engineering and Design 223 (1), 75-102, 2003.

[68] M.T. Farmer, J.J. Sienicki, C.C. Chu, B.W. Spencer, The MELTSPREAD-1 computer code for the analysis of transient spreading and cooling of high temperature melts, Rapport EPRI TR-103413, 1993.

[69] H.-J. Allelein, A. Breest, C. Spengler, Simulation of core melt spreading with LAVA: Theoretical background and Status of Validation, Wiss. Ber. FZKA, 6475, 189-200, 2000.

[70] B. Piar, B.D. Michel, F. Babik, J.-C. Latché, G. Guillard, J.-M. Ruggierri, CROCO: A Computer Code for Corium Spreading, Proc. Ninth International Topical Meeting on Nuclear Thermal Hydraulics (NURETH-9), San Francisco, Ca., USA, 1999.

[71] R. Wittmaack, CORFLOW: A code for the numerical simulation of free-surface flow, Nucl. Technol. 116, 158-180, 1997.

[72] C. Journeau, J.-F. Haquet, B. Spindler, C. Spengler, J. Foit, The Vulcano VE-U7 corium spreading benchmark, Progr. Nucl. Energ. 48, 215-234, 2006.

[73] M. Ramacciotti, C. Journeau, F. Sudreau, G. Cognet, Viscosity models for corium melts, Nuclear Engineering and Design 204 (1-3), 377-389, 2001.

[74] J.M. Seiler, J. Ganzhorn, Viscosities of corium-concrete mixtures, Nuclear Engineering and Design 178 (3), 259-268, 1997.

[75] M. Perez, J.C. Barbé, Z. Neda, Y. Bréchetr, L. Salvo, Computer simulation of the microstructure and rheology of semi-solid alloys under shear, Acta Mat. 48 (14), 3773-3782, 2000.

[76] C. Journeau, L'étalement du corium: hydrodynamique, rhéologie et solidification d'un bain d'oxydes à haute température, Doctoral thesis, University of Orléans, 2006.

[77] C. Journeau, G. Jeulain, L. Benyahia, J.-F. Tassin, P. Abélard, Rheology of mixtures in the solidification range, Rhéologie 9, 28-39, 2006.

[78] M. Fischer, A. Henning, EPR ${ }^{T M}$ engineered features for core melt mitigation in severe accidents, Proc. ICAPP'09, Tokyo, Japon, 2009. 


\subsection{Release of fission products during a core melt accident}

This section deals with releases of fission products (FPs) from degraded fuel or corium during an in-vessel or ex-vessel core melt accident. In the latter case, the accident is considered to lead to vessel failure and relocation of corium into the containment. It also discusses the transfer of FPs from the reactor to the containment via the gas mixture produced during the progression of the accident in the core (mixture of steam and hydrogen; this hydrogen is produced primarily by oxidation of the zirconium $[\mathrm{Zr}]$ in the cladding) in the event of an RCS break. Lastly, it describes the behaviour of FPs in the containment.

Figure 5.52 summarises the sequence of the processes involved in the release and transfer of FPs to the environment during a core melt accident. The main parameters governing these processes are also listed in Figure 5.52. Their effects on the release of FPs from the reactor core, their transport in the RCS and their behaviour in the containment are discussed in greater detail in the following sections.

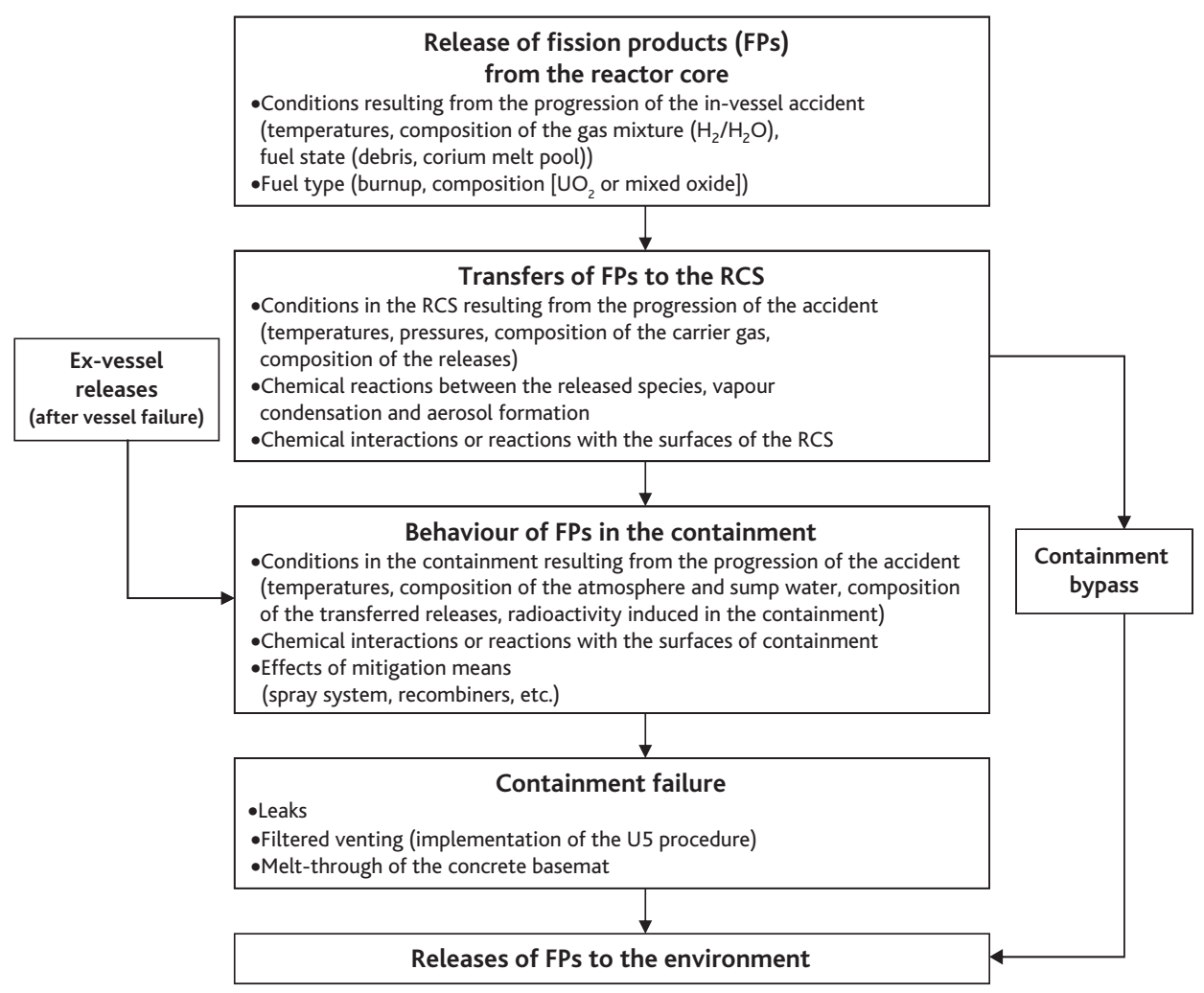

Figure 5.52. Summary description of the processes involved in the release and transfer of FPs to the environment during a core melt accident. 
OECD/CSNI reports published in 1994 [1] and 2000 [2] provide an overview of the matter. More recent state-of-the-art reports are available on iodine chemistry [3] and nuclear aerosols [4].

\subsubsection{Inventory and relative importances of FPS}

Fission products are produced during fission reactions caused by the effect of neutrons on fuel. Each FP has a specific yield that depends on the type of fission (thermal neutrons for ${ }^{235} \mathrm{U}$ or ${ }^{239} \mathrm{Pu}$, fast neutrons for ${ }^{238} \mathrm{U}$, etc.). It should be noted that, fission yields of some FPs, such as ruthenium $(\mathrm{Ru})$, can differ greatly from one isotope to another depending on whether fission concerns ${ }^{235} \mathrm{U}$ or ${ }^{239} \mathrm{Pu}$. For example, the fission yield (in percent) of ${ }^{103} \mathrm{Ru}$ is $5.8 \%$ from ${ }^{239} \mathrm{Pu}$ and $3.0 \%$ from ${ }^{235} \mathrm{U}$. However, the yield of ${ }^{106} \mathrm{Ru}$ is $5.0 \%$ from ${ }^{239} \mathrm{Pu}$ but only $0.38 \%$ from ${ }^{235} \mathrm{U}$.

The inventory of FPs in terms of mass or number of atoms increases virtually in a near-linear fashion depending on the burnup rate (around $75 \mathrm{~kg} /(\mathrm{GWd} / \mathrm{t})$ ) to around 2 tonnes of FPs in the core of a 900 MWe PWR at balance. Table 5.9 lists this inventory for each fission product and each heavy nucleus together with the change in total core activity from the time of reactor shutdown to one month later.

Under nominal burnup conditions of a PWR, the FPs in the fuel matrix are at various chemical states [5]:

- in the form of dissolved oxides for nearly half and in particular strontium ( $\mathrm{Sr}$ ), yttrium (Y), zirconium ( $\mathrm{Zr}$ ), lanthanum (La), cerium (Ce) and neodymium (Nd);

- in the form of oxide precipitates primarily for barium (Ba) and niobium ( $\mathrm{Nb}$ );

- in the form of metal precipitates for molybdenum (Mo), technetium (Tc), ruthenium (Ru), rhodium (Rh) and palladium (Pd);

- mainly in the form of dissolved atoms for the volatile FPs: bromine $(\mathrm{Br})$, rubidium $(\mathrm{Rb})$, tellurium (Te), iodine (I) and caesium (Cs). However, the chemical state of these FPs is not fully known. Above a certain temperature, they can migrate radially into the fuel pellets and condense in the colder sections, where they form more complex compounds with fuel elements or other FPs. For example, caesium can form compounds such as caesium molybdates and uranates;

- in the form of dissolved atoms or intergranular or intragranular gas bubbles: xenon (Xe) and krypton $(\mathrm{Kr})$ in the case of the fission gases. It should be noted that gases that accumulate at the grain boundaries are more easily released during accident situations.

Radioactive FPs, especially those with short half-lives, have a smaller mass but generate most of the radioactivity and residual heat. Their relative importance can be assessed using two main criteria:

- their dosimetric impact if released to the environment: this impact varies depending on the half-life and type of radiation emitted. For example, Figure 5.53 shows the relative importance of FPs and actinides on the dose to the lungs. Figure 5.54 
Table 5.9. Change in the activities of the FPs and actinides in a 900 MWe PWR (1) after reactor shutdown (RT = reactor trip).

\begin{tabular}{|c|c|c|c|c|c|}
\hline \multirow[b]{2}{*}{ Fission products } & \multirow[b]{2}{*}{ Total mass at $\mathrm{RT}$, in $\mathrm{kg}(2)$} & \multicolumn{4}{|c|}{ Activities as a fraction of the total activity } \\
\hline & & at RT & at 1 hour & at 1 day & at 1 month \\
\hline As & $7.39 \mathrm{E}-03$ & $0.20 \%$ & $0.01 \%$ & $0.00 \%$ & $0.00 \%$ \\
\hline Se & $3.14 \mathrm{E}+00$ & $0.58 \%$ & $0.02 \%$ & $0.00 \%$ & $0.00 \%$ \\
\hline $\mathrm{Br}$ & $1.16 \mathrm{E}+00$ & $1.17 \%$ & $0.20 \%$ & $0.00 \%$ & $0.00 \%$ \\
\hline $\mathrm{Kr}$ & $2.21 \mathrm{E}+01$ & $2.32 \%$ & $1.46 \%$ & $0.03 \%$ & $0.06 \%$ \\
\hline $\mathrm{Rb}$ & $2.03 \mathrm{E}+01$ & $3.22 \%$ & $0.84 \%$ & $0.01 \%$ & $0.00 \%$ \\
\hline $\mathrm{Sr}$ & $5.51 \mathrm{E}+01$ & $4.50 \%$ & $3.85 \%$ & $2.57 \%$ & $6.10 \%$ \\
\hline $\mathrm{Y}$ & $2.89 \mathrm{E}+01$ & $5.84 \%$ & $5.11 \%$ & $3.40 \%$ & $8.16 \%$ \\
\hline $\mathrm{Zr}$ & $2.10 E+02$ & $4.73 \%$ & $3.83 \%$ & $4.63 \%$ & $10.30 \%$ \\
\hline $\mathrm{Nb}$ & $3.24 \mathrm{E}+00$ & $7.09 \%$ & $5.68 \%$ & $5.93 \%$ & $13.18 \%$ \\
\hline Mo & $1.84 \mathrm{E}+02$ & $4.28 \%$ & $2.28 \%$ & $2.90 \%$ & $0.01 \%$ \\
\hline Tc & $4.52 \mathrm{E}+01$ & $4.82 \%$ & $2.50 \%$ & $2.77 \%$ & $0.01 \%$ \\
\hline $\mathrm{Ru}$ & $1.37 \mathrm{E}+02$ & $1.85 \%$ & $3.11 \%$ & $3.67 \%$ & $10.27 \%$ \\
\hline $\mathrm{Rh}$ & $2.36 \mathrm{E}+01$ & $2.30 \%$ & $3.42 \%$ & $4.96 \%$ & $10.26 \%$ \\
\hline $\mathrm{Pd}$ & $5.93 \mathrm{E}+01$ & $0.19 \%$ & $0.33 \%$ & $0.18 \%$ & $0.00 \%$ \\
\hline $\mathrm{Ag}$ & $3.97 \mathrm{E}+00$ & $0.14 \%$ & $0.11 \%$ & $0.12 \%$ & $0.05 \%$ \\
\hline $\mathrm{Cd}$ & $4.00 \mathrm{E}+00$ & $0.03 \%$ & $0.02 \%$ & $0.01 \%$ & $0.00 \%$ \\
\hline In & $8.20 \mathrm{E}-02$ & $0.13 \%$ & $0.03 \%$ & $0.01 \%$ & $0.00 \%$ \\
\hline Sn & $2.65 \mathrm{E}+00$ & $0.66 \%$ & $0.15 \%$ & $0.02 \%$ & $0.01 \%$ \\
\hline $\mathrm{Sb}$ & $8.98 \mathrm{E}-01$ & $1.76 \%$ & $0.68 \%$ & $0.17 \%$ & $0.06 \%$ \\
\hline $\mathrm{Te}$ & $2.62 \mathrm{E}+01$ & $3.85 \%$ & $4.16 \%$ & $2.88 \%$ & $0.69 \%$ \\
\hline 1 & $1.27 \mathrm{E}+01$ & $5.70 \%$ & $8.94 \%$ & $6.39 \%$ & $0.65 \%$ \\
\hline $\mathrm{Xe}$ & $3.07 \mathrm{E}+02$ & $4.33 \%$ & $3.60 \%$ & $5.12 \%$ & $0.41 \%$ \\
\hline Cs & $1.61 \mathrm{E}+02$ & $3.82 \%$ & $1.27 \%$ & $0.46 \%$ & $1.61 \%$ \\
\hline $\mathrm{Ba}$ & $8.21 \mathrm{E}+01$ & $4.67 \%$ & $3.75 \%$ & $3.46 \%$ & $3.45 \%$ \\
\hline La & $6.99 \mathrm{E}+01$ & $4.71 \%$ & $5.22 \%$ & $3.57 \%$ & $3.25 \%$ \\
\hline $\mathrm{Ce}$ & $1.63 E+02$ & $3.61 \%$ & $5.04 \%$ & $7.41 \%$ & $16.01 \%$ \\
\hline $\mathrm{Pr}$ & $6.21 \mathrm{E}+01$ & $3.10 \%$ & $4.63 \%$ & $5.49 \%$ & $11.76 \%$ \\
\hline $\mathrm{Nd}$ & $2.07 \mathrm{E}+02$ & $0.68 \%$ & $1.07 \%$ & $1.25 \%$ & $0.82 \%$ \\
\hline $\mathrm{Pm}$ & $1.24 \mathrm{E}+01$ & $0.65 \%$ & $1.22 \%$ & $1.65 \%$ & $1.48 \%$ \\
\hline $\mathrm{Sm}$ & $3.57 \mathrm{E}+01$ & $0.21 \%$ & $0.46 \%$ & $0.54 \%$ & $0.00 \%$ \\
\hline $\mathrm{Eu}$ & $8.90 \mathrm{E}+00$ & $0.08 \%$ & $0.19 \%$ & $0.29 \%$ & $0.36 \%$ \\
\hline \multicolumn{6}{|l|}{ Actinides } \\
\hline$U$ & $6.99 \mathrm{E}+04$ & $9.37 \%$ & $3.91 \%$ & $0.00 \%$ & $0.00 \%$ \\
\hline $\mathrm{Np}$ & $3.15 \mathrm{E}+01$ & $9.37 \%$ & $22.76 \%$ & $29.86 \%$ & $0.02 \%$ \\
\hline $\mathrm{Pu}$ & $5.89 \mathrm{E}+02$ & $0.05 \%$ & $0.11 \%$ & $0.19 \%$ & $0.80 \%$ \\
\hline $\mathrm{Am}$ & $6.18 \mathrm{E}+00$ & $0.00 \%$ & $0.00 \%$ & $0.00 \%$ & $0.00 \%$ \\
\hline $\mathrm{Cm}$ & $2.09 \mathrm{E}+00$ & $0.01 \%$ & $0.03 \%$ & $0.06 \%$ & $0.21 \%$ \\
\hline
\end{tabular}

(1) $900 \mathrm{MWe}$ PWR with $\mathrm{UO}_{2}$ fuel enriched to $3.70 \%$ of ${ }^{235} \mathrm{U}, 72.5$ tons of initial uranium, with the fuel loaded into four regions of the core (burnup rate of the assemblies: $10.5 \mathrm{GWd} / \mathrm{tU}$ for the first region [one burnup cycle], $21 \mathrm{GWd} / \mathrm{tU}$ for the second region [two cycles], $31.5 \mathrm{GWd} / \mathrm{tU}$ for the third region (three cycles) and $42 \mathrm{GWd} / \mathrm{tU}$ for the last region [four cycles]).

(2) Total mass of the stable isotopes and the radioactive isotopes. 


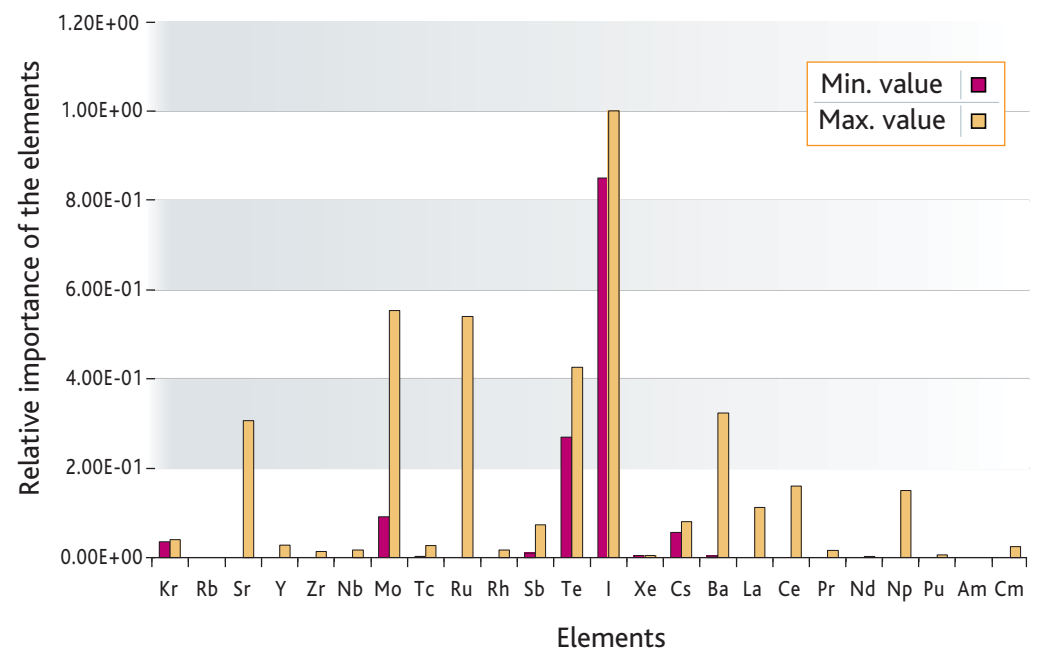

Figure 5.53. Relative importance of the elements released during a PWR core melt accident ( $100 \%$ core melt) on the dose to the lungs.

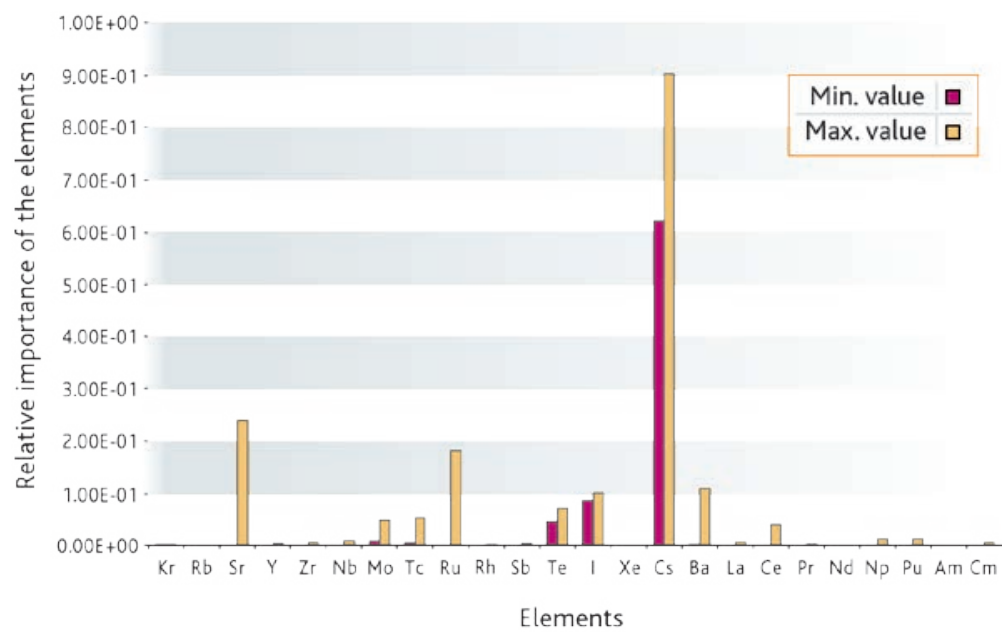

Figure 5.54. Relative importance of the elements released during a PWR core melt accident ( $100 \%$ core melt) on latent cancers (long-term exposure).

shows the same information, but for the long-term consequences (latent cancer). The relative importance indicated for each element are derived from studies conducted by the US NRC [6]. The minimum and maximum values shown on the graphs are derived from studies conducted by IRSN on the variability and uncertainty of the release rates;

- their contribution to the residual heat generated in fuel or corium, which is illustrated by Figure 5.55. Residual heat influences accident progression, such as the moment of vessel failure or the moment of corium melt-through of the containment basemat. 


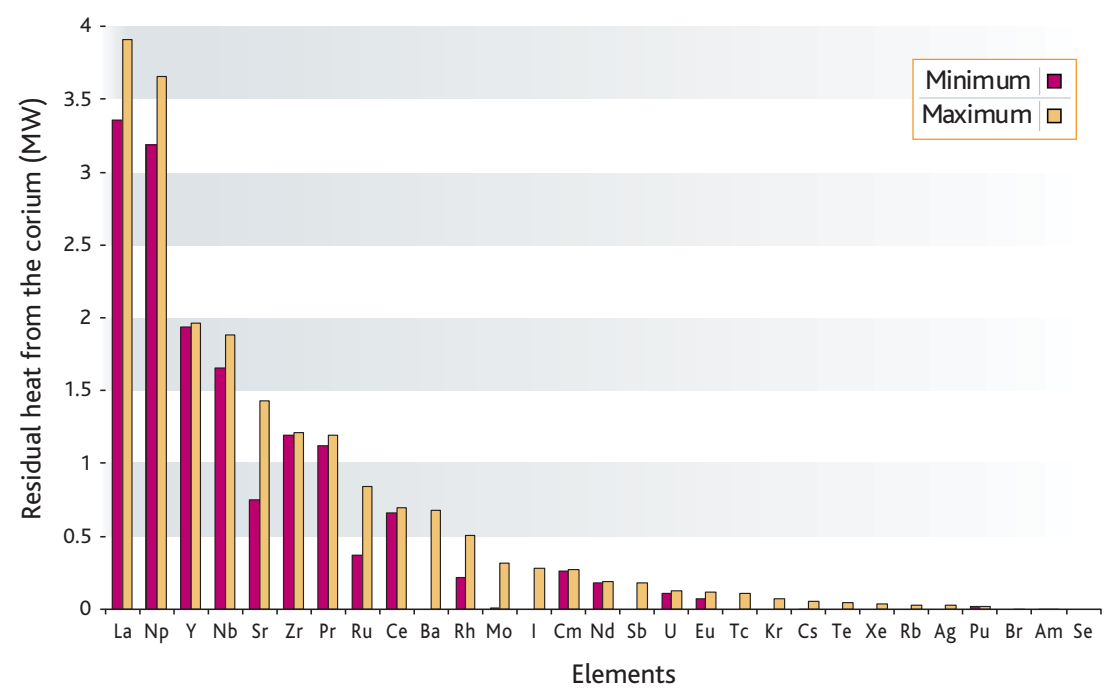

Figure 5.55. Minimum and maximum residual heat associated with the elements in corium at the time of vessel failure during a large-break LOCA in the RCS.

Stable FPs, which have a higher mass, can influence core degradation because the formation of eutectic mixtures of uranium dioxide-fission product $\left(\mathrm{UO}_{2}-\mathrm{FP}\right)$ seems to lower the fuel-melting temperature [7]. The concentration of FPs in the fuel is not negligible at high burnup (they may account for more than $10 \%$ of the total number of atoms beyond $50 \mathrm{GWd} / \mathrm{t}$ ). Furthermore, under oxidising conditions, the hyperstoichiometry of the fuel (oxygen content greater than the stoichiometric content $\mathrm{UO}_{2}$ ) lowers its melting temperature [8].

\subsubsection{Release of FPs into the reactor vessel}

The chemical state of the FPs initially present in the fuel matrix in the form of dissolved atoms or oxides, oxide precipitates and metal precipitates is not permanent. Some FPs may shift from one chemical state to another depending on the temperature of the fuel, the oxygen content in the fuel (which increases with the burnup rate) and the burnup rate (increase in the concentration of FPs in the fuel matrix). This is especially true for molybdenum, which precipitates in fuel mainly in metal form but can also be in oxidised form (especially on the surface of MOX fuel pellets), and for niobium and strontium, whose oxides may be partly dissolved and precipitated in the fuel.

\subsubsection{Physical phenomena involved in the release of FPs}

\section{Fission gases}

During fuel irradiation, fission gases form as atoms in the grains of $\mathrm{UO}_{2}$. These atoms of gas either diffuse toward the grain boundaries or precipitate into nanometre-sized intragranular bubbles, slowing down their rate of migration towards the grain boundaries. The bubbles may then redissolve under the influence of fission spikes (defects 
created along the path of the fission fragments just after their formation), which speed up the rate at which gas is supplied to the grain boundaries. Once on the grain surface, (mainly by atomic diffusion, but also by bubble migration), the fission gases accumulate to a point where they coalesce to form larger bubbles and fill the boundaries. These bubbles are then capable of moving into the free volume of the rod [9].

At the onset of the accident, the gases consist of:

- gas atoms dissolved in the fuel matrix;

- intragranular gas bubbles with little mobility;

- gases accumulated in the grain boundaries (intergranular bubbles).

Their release is governed by a number of mechanisms. The first release phase (often referred to as "burst release") corresponds to the release of gases accumulated in the intergranular spaces. The fraction already released into the rod plenum during normal irradiation must also be taken into account, ranging from a few percent to $10 \%$, depending on the burnup, the irradiation power and the fuel type. Such releases occur at the beginning of the temperature rise at around $1000^{\circ} \mathrm{C}$, though this is sometimes lower for high burnup fuels.

The second phase involves the release of the intragranular gases via a thermally activated diffusion process that begins with dissolved atoms. The gases trapped in the intragranular bubbles (which are of nanometre size) are the last to be released, which generally occurs when the fuel melts.

It is therefore important to correctly quantify the respective fractions of these three phases when modelling gas releases, which depend on their radial position in the pellet and on the fuel type (high burnup fuels [the granular structure on the periphery of the pellets is degraded, resulting in more pores where the gases can accumulate] and heterogeneous MOX fuels have a higher intragranular fraction).

During a core melt accident, all the fission gases are released from the fuel when it melts.

\section{Non-gaseous FPs}

It is generally accepted that the release of non-gaseous FPs follows a two-phase process: (1) the FPs in solution in the matrix (or the precipitates when the solubility limit has been reached) diffuse as far as the grain boundaries, and then (2) a mechanism of mass vaporisation transfers the FPs from the grain surface outside of the fuel matrix. This mechanism also involves a number of chemical aspects. The potential formation of species (such as molybdates, uranates, zirconates) can determine transfers of FPs (caesium, barium and strontium) in the fuel. Likewise, oxidation or reduction of FP precipitates by water vapour or hydrogen has a significant impact on transfers of these species in the fuel. It should be noted that the basic thermodynamic data on the formation and destruction of these species currently are subject to high uncertainties that affect the 
calculation of FP chemistry - and thus FP transport - in the fuel and, consequently, affect the calculation of FP releases from fuel. The predictive capability of the release models is discussed in Section 5.5.2.3.

Outside the fuel matrix, chemical interactions with the cladding or elements of the core structures can then reduce the volatility of some elements through the formation of more refractory species.

Lastly, once released from the core, a significant fraction of the FPs condenses in the colder sections of the upper core structures before even reaching the hot legs of the RCS or the containment. This is especially true for low-volatile FPs.

Qualitatively speaking, the main physical parameters influencing the release of FPs are as follows:

- the fuel temperature is the main parameter, at least until loss of integrity of the fuel assemblies in the core leads to loss of core geometry;

- the oxidising-reducing conditions have a significant impact on fuel. The release kinetics of volatile FPs are particularly accelerated under oxidising conditions. Furthermore, the overall release of certain FPs is very sensitive to the oxidisingreducing conditions. For example, the release of molybdenum increases in steam, whereas that of ruthenium can be very high in air. Conversely, the release of barium (as for strontium, rhodium, lanthanium, cerium, europium [Eu] and neptunium [Np]) increases under reducing conditions;

- interactions with the cladding and/or elements of the core structures can play a major role. For example, the presence of tin in the cladding delays the emission of the volatile elements tellurium and antimony (Sb). Barium significantly contributes to the decay heat (via its daughter product ${ }^{140} \mathrm{La}$ ) and is also partially trapped in both the cladding (probably due to the formation of zirconates) and in the steels of the structures.

- the burnup accentuates releases, in terms of both the kinetics of volatile FPs, and the magnitude of release of low-volatile species such as niobium ( $\mathrm{Nb})$, ruthenium, cerium and neptunium $(\mathrm{Nb})$;

- The fuel type also has a significant impact: MOX releases tend to be higher than those of $\mathrm{UO}_{2}$. This phenomenon is probably related to its heterogeneous microstructure, with the presence of plutonium (Pu)-rich agglomerates where the local burnup can be very high;

- Last of all, the physical state of the fuel (fragmented, solid, liquid) during its invessel degradation has a significant influence. The transition from a "degraded rod" geometry to a "debris bed" geometry also involves an increase in releases via the increase in the surface-to-volume ratio. Conversely, the transition from a debris bed to a molten pool slows down the release of FPs as a solid crust forms on the surface of the molten corium pool. 


\section{Degrees of volatility of the various FPs}

The current state of knowledge, obtained in particular thanks to the analytical experiments of the VERCORS programme and the integral tests of the Phebus programme (Section 7.3), make it possible to schematically classify FPs and fission gases into four categories of decreasing volatility (Figure 5.56):

- fission gases and volatile FPs ( $\mathrm{Kr}, \mathrm{Xe}, \mathrm{I}, \mathrm{Cs}, \mathrm{Br}, \mathrm{Rb}$, as well as Te, Sb and silver [Ag]): almost all of these products are released even before reaching molten pool conditions. The release kinetics of these elements are accelerated under oxidising conditions and are slightly retarded for Te and Sb than for the other volatile FPs due to interactions with tin in the cladding;

- semi-volatile FPs (Mo, Ba, Y, Rh, Pd, Tc): their release rates can be very high and are sometimes equivalent to those of volatile FPs yet are highly sensitive to the oxidising-reducing conditions and result in significant retention in the upper vessel internals;

- low-volatile FPs ( $\mathrm{Sr}, \mathrm{Nb}, \mathrm{Ru}, \mathrm{La}, \mathrm{Ce}, \mathrm{Eu}, \mathrm{Np}$ ): they are characterised by low but significant levels of release, ranging from a few percent to $10 \%$ during the fuel-rod degradation phase (prior to loss of fuel rod geometry). Nevertheless, some of these releases can reach much higher levels for fuels with very high burnups under specific conditions (this is especially the case of Ru in air). Retention of these FPs is nevertheless expected to be significant in the upper vessel internals;

- non-volatile FPs ( $\mathrm{Zr}, \mathrm{Nd})$ : to date, no significant release of these two elements has been demonstrated experimentally. These are the two most refractory FPs.

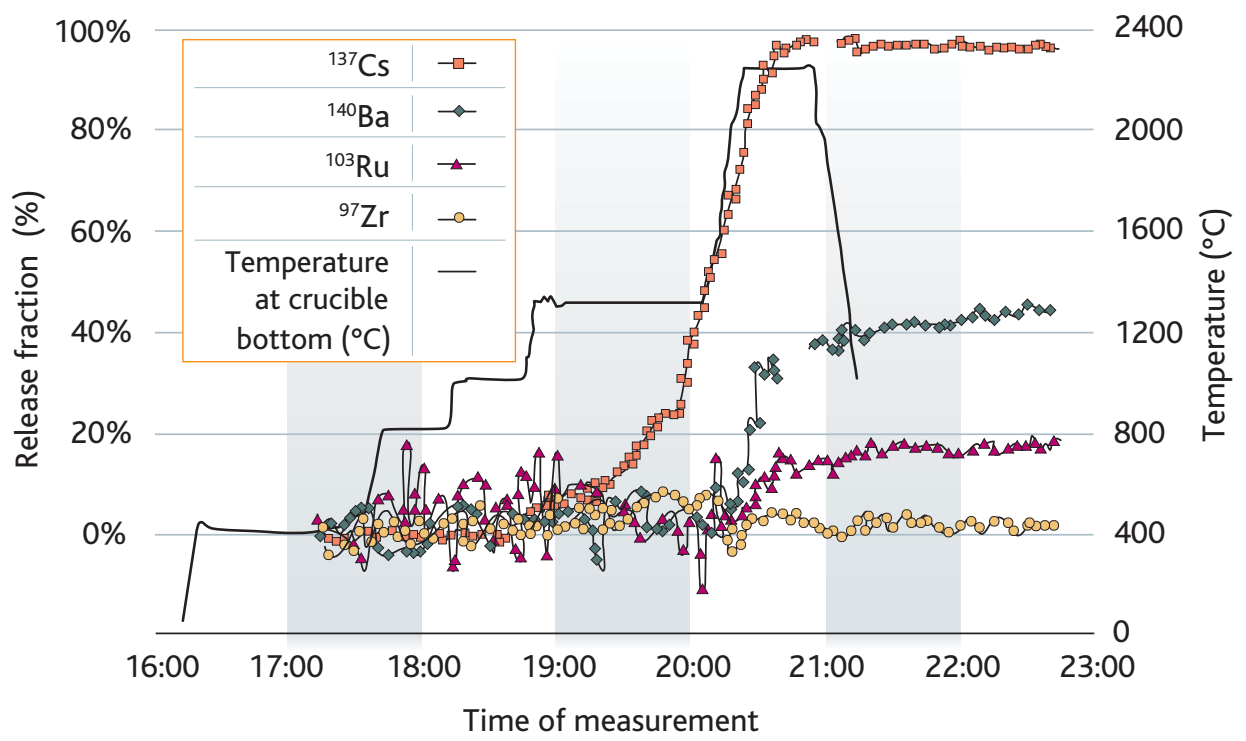

Figure 5.56. Illustration of the four volatility categories for FPs according to the results of a VERCORS test [10]. 


\section{Actinides}

Most of the quantitative data on releases of actinides during a core melt accident come from the VERCORS programme [10]. The behaviour of uranium and neptunium is similar to that of low-volatile FPs whereas the behaviour of plutonium is rather more similar to that of non-volatile FPs.

\subsubsection{Experimental programmes}

Experimental programmes on FP releases have mainly relied on analytical experiments performed on sections of irradiated fuel. They were eventually supplemented by integral tests performed on reduced-scale fuel assemblies particularly to study the effects of changes in core geometry (particularly debris bed and molten pool formation) during core degradation on the release of FPs.

\section{Analytical experiments}

Five major analytical programmes have been conducted since the late 1970s: SASCHA in Germany [11], HI/VI in the United States [12], CRL in Canada [13], VEGA in Japan [14] and HEVA/VERCORS [15] in France. The HEVA/VERCORS programme is described in greater detail on account of its significant contributions to the development and validation of the FP release models developed by IRSN (Section 5.5.2.3):

- the first analytical experiment of its kind, the SASCHA programme was performed by FZK on unirradiated $\mathrm{UO}_{2}$ fuel under various atmospheres, including argon, air and steam. The $\mathrm{UO}_{2}$ pellets were specially manufactured with additives that simulate FPs. Although the SASCHA programme was not really representative of the real location of the FPs in fuel during irradiation, it did provide a series of preliminary estimates for iodine and caesium releases up to $2000^{\circ} \mathrm{C}$;

- ORNL conducted the HI/VI programme between 1981 and 1993 (13 tests in total). The experimental configuration, at least for the VI tests, was similar to that of the VERCORS programme, i.e., a test loop equipped with thermal-gradient tubes (TGT) to collect condensable gases (these samples were used to determine the condensation concentrations and temperatures), a series of filters to trap aerosols and a condenser and cartridges to trap fission gases. The fuel samples were cladded sections of irradiated $\mathrm{UO}_{2}$ measuring around $15 \mathrm{~cm}$ in length and sealed at the ends. A hole was drilled in the cladding at midplane height. This programme provided highly representative results on the release of FPs, but only in relation to long-lived FPs (mainly ${ }^{85} \mathrm{Kr},{ }^{106} \mathrm{Ru},{ }^{125} \mathrm{Sb},{ }^{134} \mathrm{Cs},{ }^{137} \mathrm{Cs},{ }^{144} \mathrm{Ce}$ and ${ }^{154} \mathrm{Eu}$ ) as the samples were not re-irradiated prior to the tests;

- AECL's CRL programme was a highly analytical programme conducted to study CANDU fuels. It consisted of many tests on fragments of irradiated fuel (from $100 \mathrm{mg}$ to $1 \mathrm{~g}$ ) and on short sections of cladded fuel. The resistive furnace used during the tests limited temperatures to a maximum of $2100{ }^{\circ} \mathrm{C}$. Some samples were pre-irradiated to measure the release of short-lived FPs. One of the 
important results of this programme was the first quantification of the very high release of ruthenium in air;

- performed by JAERI (Japan), the VEGA programme was very similar to the VERCORS programme in terms of its experimental configuration and conditions, especially the VERCORS HT series (see next paragraph). A total of 10 tests were carried out: eight on $\mathrm{UO}_{2}$ fuel and two on MOX fuel. Some of the tests were carried out in a steam atmosphere up to fuel melting temperatures. Some of the samples were re-irradiated prior to the tests but under less than optimal conditions. The irradiation time, which was shorter than the in-reactor irradiation time, and the long decay time did not result in a sufficient quantity of short-lived FPs. A unique feature of these tests was the inclusion of tests at a pressure of $10 \mathrm{bar}$, which notably demonstrated a reduction in caesium releases;

- the HEVA/VERCORS programme, performed by the CEA and financed by IRSN (IPSN at the time) and EDF, aimed at quantifying releases of FPs and actinides (kinetics and total release rates) from irradiated nuclear fuel under conditions representative of a core melt accident. These tests were performed in a highactivity cell on different types of fuel sample irradiated in a PWR (around $20 \mathrm{~g}$ of fuel) under a range of experimental conditions. Most of the samples were reirradiated for a few days at low power in an experimental reactor in order to build up an inventory of short-lived FPs. These samples were then heated in an induction furnace under a variable atmosphere of steam and hydrogen simulating core melt accident conditions (Figure 5.57). FP releases from the fuel samples were measured by gamma spectrometry of the decrease of the FPs in the fuel samples during the test. Twenty-five tests were carried out between 1983 and 2002 in three phases: (1) eight HEVA tests (release of volatile and semi-volatile FPs up to $2100^{\circ} \mathrm{C}$ ); (2) six VERCORS tests (release of volatile and semi-volatile FPs and some low-volatile FPs up to $2300^{\circ} \mathrm{C}$, the limit for the onset of fuel collapse in the sample), (3) eleven HT/RT tests (release of all types of FP until the melting point was reached). These tests resulted in the compilation of an extensive database on the release of FPs: the parameters that varied during these tests were the maximum temperature reached (below or above fuel melting temperature), the oxidising-reducing conditions, the burnup, the fuel type (usually $\cup_{2^{\prime}}$ although MOX was used in two tests) and the initial fuel geometry (intact fuel or fuel debris to simulate the formation of a debris bed during a core melt accident).

There still are, however, uncertainties about the release of FPs. This is particularly the case for very-high-burnup $\mathrm{UO}_{2}$ fuels (70 GWd/t and beyond), MOX fuels, and accidents with in-vessel ingress of air or in-vessel fuel reflooding.

The VERDON programme, conducted at the CEA facility of the same name as part of the International Source Term Programme (ISTP) [16], aims to address these issues, apart from aspects related to reflooding. Tests on FP releases from samples of high burnup fuels, MOX fuel samples and fuel samples in an air atmosphere have been conducted since 2011 at a facility similar to that where the VERCORS HT tests were carried out. 


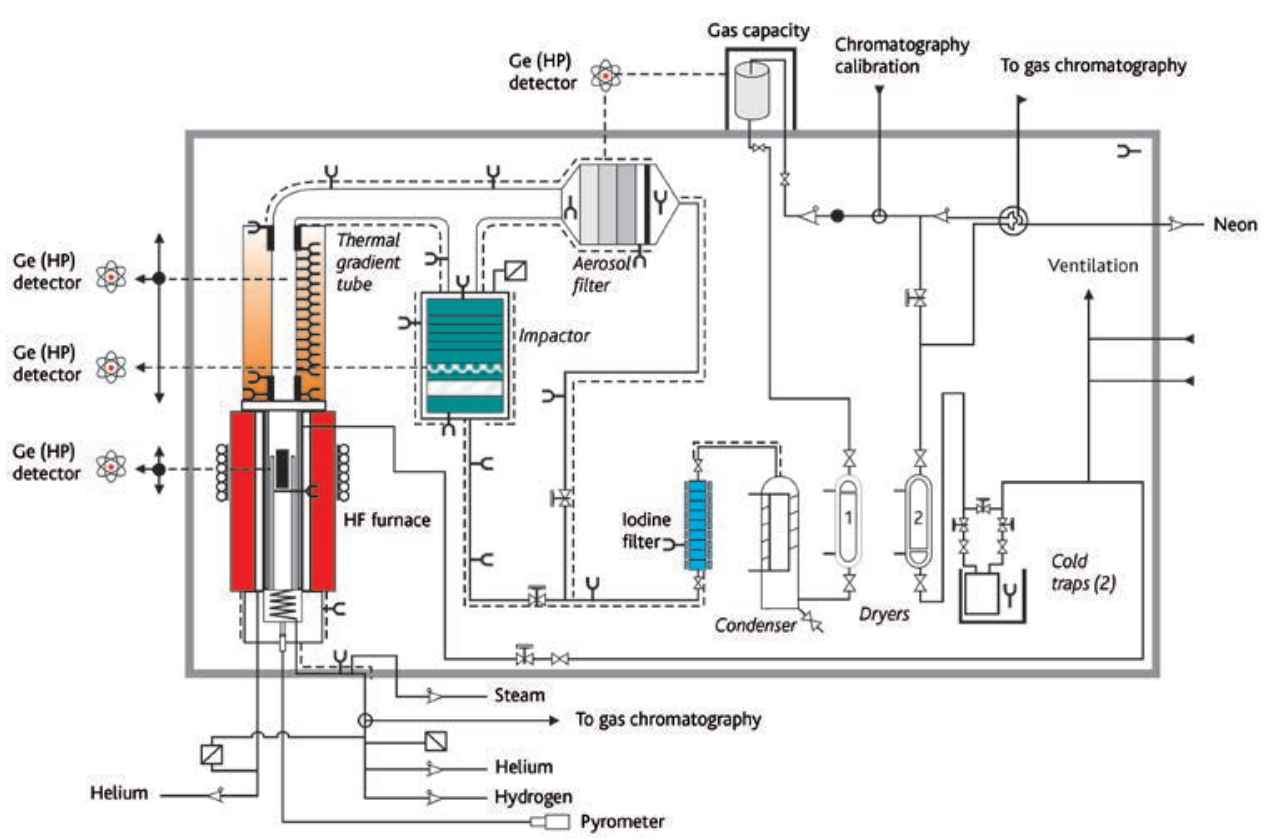

Figure 5.57. The VERCORS HT loop [15].

\section{Integral tests}

Among the experimental programmes devoted to fission product releases, the Phebus FP programme is one of the most representative of core melt accident conditions, particularly with regard to releases from fuel, transport in the RCS and the behaviour of FPs in the containment [16]. Four bundles of 20 fuel rods (three of which were re-irradiated in order to obtain inventories representative of the short-lived FPs) with burnup of between 20 and $40 \mathrm{GWd} / \mathrm{tU}$ were brought to fuel melting conditions. In three tests, the bundles were brought to molten pool conditions. A specific test was conducted to study degradation of a debris bed up to molten pool conditions. The programme and the lessons learnt are described in Section 7.3.

In terms of in-vessel FP releases, the Phebus FP programme made a huge contribution in addition to the analytical tests by providing better understanding of two aspects: (1) releases of FPs depending on the progression of the accident in the vessel and (2) the effect, on such releases, of the chemical interactions with the cladding material or structural steels in the core. For example, lower FP releases were observed with molten corium melt pools than with releases from solid fuels. In-core fuel collapse during degradation (collapse of the fuel rods with the formation of debris and the relocation of corium to the cool areas at the bottoms of the bundles) results in spikes in FP releases. The case of barium is a good example in terms of the effects of the chemical interactions, with these releases being much lower than those recorded 
in the analytical tests. This difference in behaviour is ascribed to interactions with the fuel rod cladding and possibly iron from the molten structural steels of the core, which reduced the volatility of the barium.

For the other fission products, the total releases were highly consistent with those obtained from the analytical tests.

\subsubsection{Physical models and simulation codes}

Two approaches are used in computer codes to model FP releases: (1) a simplified approach that allows models to be easily integrated into integral codes (see Chapter 8), and (2) a mechanistic approach that describes, at best, all the physical phenomena that come into play. Both approaches can be illustrated by two tools used at IRSN: (1) the Franco-German ASTEC code, which uses semi-empirical release models, and (2) the MFPR mechanistic code developed jointly by IRSN and the Russian institute IBRAE.

\section{Simplified approach used in the ASTEC code}

The ASTEC code [17] models releases of FPs according to three categories:

- so-called volatile FP releases ( $\mathrm{Xe}, \mathrm{Kr}, \mathrm{I}, \mathrm{Br}, \mathrm{Cs}, \mathrm{Rb}, \mathrm{Sb}, \mathrm{Te})$ are governed by their diffusion in fuel grains. Their diffusion coefficient is a function of the temperature and oxygen content of fuel. This coefficient is the same for all FPs, excepting Sb and $\mathrm{Te}$, for which a release delay is applied to take into account their retention in the cladding provided the latter has not oxidised completely;

- so-called semi-volatile FP releases are governed by mass transfers induced by their vaporisation at grain boundaries. Their vapour pressures are determined using thermodynamic correlations made with the GEMINI2 ( $\mathrm{Sr}, \mathrm{Ru}, \mathrm{Ba}$ and $\mathrm{La}$ ) or FACT (Mo, Ce and Eu) solvers, which calculate the equilibrium state of the chemical system involved by minimising its free enthalpy (Gibbs free energy). The same mass-transfer mechanism is applied to all FPs released from a molten corium pool;

- so-called non-volatile FP releases are governed by the vaporisation of $\mathrm{UO}_{2}$ when it becomes hyperstoichiometric $\left(\mathrm{UO}_{2+x}\right.$ with an oxygen content higher than that of stoichiometric $\mathrm{UO}_{2}$ ) and oxidises until $\mathrm{UO}_{3}$ forms. This category also covers the actinides $\mathrm{U}, \mathrm{Np}, \mathrm{Pu}, \mathrm{Am}$ and $\mathrm{Cm}$.

\section{Mechanistic approach of the MFPR code}

MFPR [18] is an 0-D mechanistic code designed to simulate FP releases from solid $\mathrm{UO}_{2}$ fuel. FPs are assumed to be present in fuel in atomic or oxide form. Two types of modelling are performed: one for fission gases, the second for other FPs.

Modelling of FPs includes all the physical phenomena described in Section 5.5.2.1: intragranular diffusion of atoms and bubbles to the grain boundaries with modelling of the bubble formation (nucleation, growth) and destruction (return to solution form) 
mechanisms. Releases from the grain boundaries occur after coalescence and interconnection of the gas bubbles.

In 2015, modelling of other FPs involved 13 elements: Cs, I, Te, Mo, Ru, Sb, Ba, Sr, Zr, $\mathrm{La}, \mathrm{Ce}, \mathrm{Nd}$ and Eu. They are assumed to diffuse to the surface of the grain boundaries, with some oxidation occurring during their transfer to the fuel matrix. They then form three distinct phases: a metallic phase, a ternary phase (known as the grey phase and composed of FP oxides) and a specific phase for Csl (caesium iodide). Releases from fuel are governed by the thermodynamic equilibrium of these three phases, with the gas contained in spaces between the grains (grain boundaries).

Much progress has been made in the validation of the simplified and mechanistic release models. The experimental observations are well reproduced by the calculated releases of the volatile FPs. However, the ASTEC results slightly underestimate the releases at intermediate temperature (between 1000 and $1500^{\circ} \mathrm{C}$ ) because the model does not take into account the intergranular inventory. The greatest uncertainties relate to the results for the semi-volatile and low-volatile FPs and are due in particular to the difficulty in properly addressing the chemical reactions with the structural elements of the core (control rods, reactor core internals, etc.).

\subsubsection{Releases of structural materials}

The radioactivity of structural materials, due mainly to their activation, is relatively low. Nonetheless, it is important to evaluate releases of these materials for two reasons: (1) they may chemically react with FPs, such as iodine with the silver in silver-indiumcadmium (SIC) control rods or tellurium with the tin in cladding, and (2) they significantly contribute to the quantity of aerosols released into the containment. Structural materials agglomerate with FP-laden aerosols, increasing the average size of the particles and contributing to increasing their gravitational settling.

Releases of components from SIC control rods (rods in French 900 MWe reactors and in many other PWRs of Western design) depend primarily on their degradation mechanisms described in Section 5.1.1.2. When the cladding and guide tubes of SIC rods fail, the liquid SIC alloy inside comes into contact with the surrounding fluid and vaporises. The release rates then depend on the vapour pressures of these three metals. This is well known and correctly modelled. What remains uncertain is the degradation phenomena of the control rods and guide tubes. Depending on the level of degradation of these components, the liquid alloy may remain at high temperature for a variable period of time before flowing to the colder sections in the lower end of the core and solidifying. This has an effect on the quantities that are vaporised.

The boron carbide in other types of control rod (those used in French $1300 \mathrm{MWe}$ reactors along with SIC rods, also in BWRs, and in VVERs (PWRs of Russian design)) begin to oxidise when it comes into contact with the surrounding fluid, i.e., after cladding and guide-tube failure. The resulting oxidation products are boric oxide and carbon monoxide or carbon dioxide (depending on the oxidising potential of the fluid). The boric oxide is converted into boric acid as it is transferred from the RCS to the containment. 
Theoretically, the carbon monoxide could turn into methane in the RCS if reducing conditions prevail there. In practice, the formation of methane in the RCS remains negligible at low pressure and is very low at high pressure because the reactions that allow it to form are too slow to achieve a significant yield.

In the case of Zircaloy fuel-rod cladding, significant amounts of tin are released (tin is a minor component of Zircaloy). It is the form $\mathrm{SnO}_{2}$ (tin dioxide) that is volatile and released. The degradation mechanisms of the cladding govern the releases of tin. Satisfactory models are obtained by taking into consideration that the release kinetics of tin follow those of the oxidation of Zircaloy cladding.

\subsubsection{Summary and Outlook}

The experimental database of analytical tests performed on sections of irradiated fuel is relatively broad in the case of $\mathrm{UO}_{2}$ fuels with average burnups. It is supplemented by integral Phebus FP type tests. These experiments have helped improve understanding of the effects of the different parameters influencing releases, such as temperature, oxidising-reducing conditions, interactions with structural materials (especially cladding), burnup and the type ( $\mathrm{UO}_{2}$ or MOX) and state of the fuel (solid or liquefied).

These results have made it possible to develop and validate two types of model. Mechanistic models are used to describe most of the interactions in the fuel and above all to interpret the tests. Simplified models describing the main phenomena can be derived from these mechanistic models and used in integral codes such as ASTEC (see Chapter 8).

The hypotheses formulated to interpret the tests are based mainly on the physicochemical changes in the fuel and make it possible to correctly reproduce the influence of the various parameters on releases (temperatures, burnup, composition of the atmosphere surrounding the fuel). Apart from predicting the behaviour of fission gases, the MFPR code is used to determine variations in the composition of the different phases containing FPs inside the fuel as well as the chemical species of the elements involved. However, these hypotheses still lack sufficient validation. Such validation should be made possible by the fuel sample microanalysis performed in one part of the ISTP (the aim is to determine FP distributions and, if possible, the chemical species of FPs in matrices of fuel-samples obtained from fuel degradation tests conducted as part of the VERCORS and VERDON programmes).

The experimental database has been extended to cover MOX fuel (two tests) and high-burnup $\mathrm{UO}_{2}$ fuel (one test) in the VERDON programme, which is part of the ISTP and which ended in 2014.

Releases during reflooding of solid high-burnup fuels were experimentally studied in the QUENCH-ISTC programme. This programme did not provide any significant lessons about releases.

The case of accidents with air ingress into the vessel, such as when the reactor is shut down, is also explored. The available data, primarily Canadian, show that in such 
accidents ruthenium behaves like a volatile FP and may be almost completely released from fuel [19]. Models have been developed and in 2012 a specific test in the VERDON programme was conducted to study releases in air from MOX fuel, another one in 2015 will study releases in air from high burn up $\mathrm{UO}_{2}$ fuel.

\subsubsection{Fission product transport in the reactor coolant system and secondary loops (fission gases excluded)}

FPs and structural materials are released primarily as gases or vapours. These vapours cool in the vessel upper head and then in the RCS. A number of phenomena occur during this cooling:

- the vapours condense on nuclei and form fine particles in a phenomenon commonly known as homogeneous nucleation;

- the vapours condense on pre-existing particles in a phenomenon commonly known as heterogeneous nucleation;

- the vapours condense on the walls, forming deposits.

The temperatures at which these phenomena occur depend on the chemical form of the FPs and structural materials. Fission product chemistry is discussed in Section 5.5.6. After the vapours condense, the FPs and structural materials are entrained into the RCS primarily in aerosol form. Notable exception are iodine and ruthenium, which can in some circumstances remain in gas form. The main processes involved in such transfers are shown in Figure 5.58.

\section{- Cooler temperature}

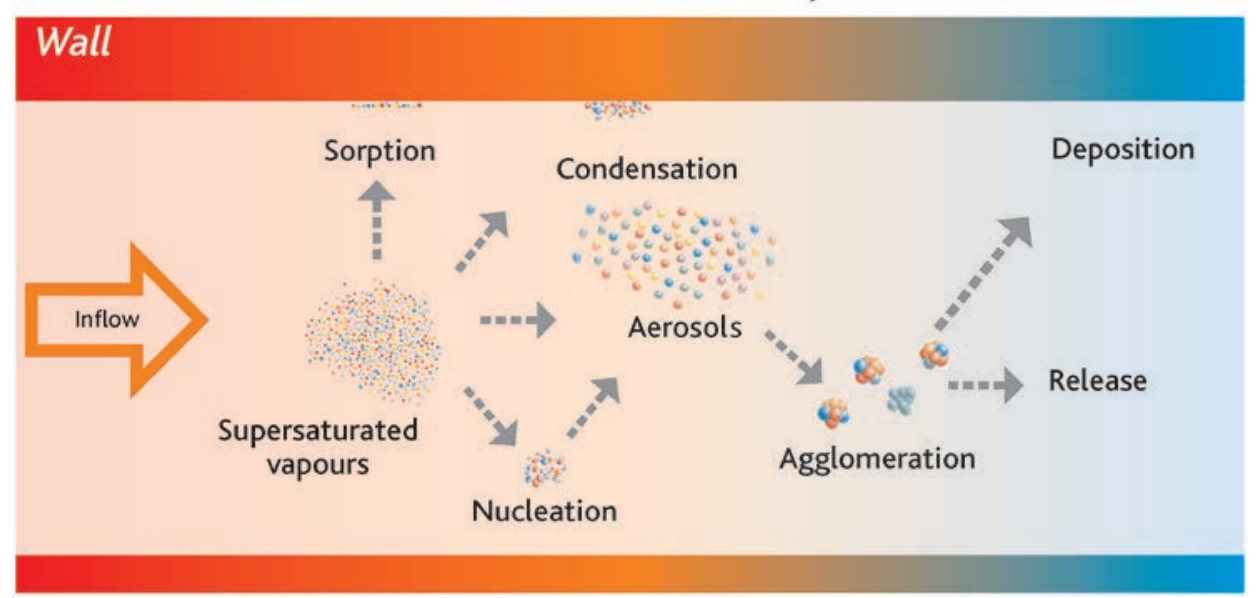

Gas-phase chemical reactions

Figure 5.58. Process determining FP transfers to the RCS in aerosol form. 


\subsubsection{Physical phenomena involved in aerosol transfers}

\section{Nucleation phenomena}

The formation of particles through homogeneous nucleation can be described at the scale of the atoms and molecules produced or at a more macroscopic scale by directly taking into account particle formation. This macroscopic description is easier to model and yields results similar to those of the atomic-scale description. As a result, it is generally used in computer codes to analyse homogeneous nucleation.

In heterogeneous nucleation, vapours condense on existing aerosol particles consisting of less-volatile elements that have condensed at higher temperatures. The existing models, which analyse the diffusion of molecules in a carrier fluid, are considered to be satisfactory.

\section{- Coagulation (or agglomeration) phenomena}

The motion of aerosols formed through nucleation is relative to the fluid carrying them and due especially to Brownian diffusion, turbulence and gravitational settling (sedimentation). This motion leads aerosol particles to collide with each other and stick together (agglomeration). The aerosols grow as they are carried and typically reach a size of a few micrometres in the RCS.

These phenomena are well understood and the available models yield computational results that are satisfactory for the experimental conditions. It should be noted however that some parameters of the models, such as the form factor of the particles (which indicates their deviation from sphericity) are poorly known. However, this lack of understanding does not give rise to any significant uncertainties.

\section{- Deposition by vapour condensation}

Part of the FPs and structural materials released as vapours from the reactor core will condense and deposit on the cool walls. This deposition phenomenon is generally modelled using an analogy of mass transfers and heat transfers whereby the values of the dimensionless numbers governing these transfers (Sherwood and Nusselt numbers) are considered to be the same. This assumes that the properties of the vapour species involved, especially their saturation pressure, are known. The associated chemical aspects are discussed in Section 5.5.6.

Prior to the Phebus FP integral tests, there was a high degree of confidence in the deposition-by-condensation models. But these tests have shown that deposition by condensation was underestimated by a factor of as much as two. A number of assumptions have been explored by CFD calculations. These calculations have made it possible to conclude that this underestimation was caused by effects related to the fact that the flow of fluid in the system was neither thermally nor hydraulically stable [20]. In such situations, the heat-exchange and mass-transfer coefficients are increased, leading to a corresponding increase in the deposits. 


\section{Deposition by gravitational settling (sedimentation)}

Aerosols move under the action of gravity and settle on horizontal surfaces. This deposition phenomenon is only significant when the carrier fluid velocity is low and thus the system transit time is long.

This phenomenon is well understood and the available models yield computational results that are satisfactory under the experimental conditions.

\section{Deposition by Brownian or turbulent diffusion}

Brownian motion of particles, particularly those with a diameter of less than $0.1 \mu \mathrm{m}$, can cause particles to collide with and deposit on walls. This phenomenon is significant only in laminar flows. At high flow rates, aerosols deposit on walls by means of turbulent diffusion. These phenomena are well understood and the available models give computational results that are satisfactory under the experimental conditions.

\section{Deposition by impaction}

This phenomenon occurs especially where there are changes in system geometry: elbows, changes in cross-section, obstacles, etc. The inertia of the particles moves them away from the lines of flow and can cause them to collide with the walls. Aerosol size is an important factor. Deposition by impaction occurs primarily with large aerosols.

In the RCS, most deposition by impaction occurs in elbows and where there are changes in cross-section (e.g., steam generator tube inlets). This deposition is modelled using physical correlations that generally yield satisfactory results. The case of deposition on the secondary side following an SGTR is discussed below.

\section{Deposition by thermophoresis}

When aerosols are carried by a hot fluid into a system where the walls are cooler than the hot fluid, the temperature gradient between the centre of the hot flow and the cooler flow along the walls results in more collisions between the molecules of the carrier fluid and the aerosols at the centre of the flow than in the vicinity of the walls. This causes the aerosols to move towards the walls, favouring deposition there. Many theoretical and experimental studies have made it possible to establish widely accepted formulae for deposition rates by thermophoresis [21]. Examples of past experimental studies include the TUBA thermophoresis tests carried out by IPSN [22].

The models have been satisfactorily validated by the calculation of the TUBA thermophoresis experiments. Nonetheless, the Phebus FP integral tests revealed significant differences between the calculation results and the experimental results for deposition by thermophoresis in steam generators. The calculations overestimate this deposition by a factor of around two. This is true for all the codes used to calculate core melt accidents. A number of areas have been investigated to explain these differences, including 
the influence of the differences between the Phebus tests and those used to validate the models (e.g., the temperature differences between the fluid and the wall or the differences in aerosol concentrations). CFD calculations following the trajectories of aerosols have also been conducted [24], but a convincing explanation has yet to be found. In the case of core melt accidents following a large RCS break, the differences between the calculation results and the experimental results have little impact on the releases calculated in the containment because the retention in the RCS is low. However, retention in pipes has a strong impact on the possible releases in the case of accidents with containment bypass (e.g., V-LOCA; see Section 4.2.1.3).

\section{Deposition by diffusiophoresis}

Condensation occurs when the walls of the RCS are cooler than the saturation temperature of the steam. This condensation causes a flow of gas that carries particles towards the walls [23]. The models available for calculating deposition by diffusiophoresis are based in particular on the results of the TUBA-diffusiophoresis tests performed by IPSN [25]. They yield satisfactory results for calculating deposition in the RCS.

\section{Mechanical resuspension}

A number of phenomena, such as the production of steam during core reflooding, may lead to significant flows in the pipework. Deposited particles may then be mechanically entrained. This entrainment may be high in the case of a highly turbulent flow and dry deposits. Resuspension phenomena are quite complex. To simplify, resuspension occurs when the aerodynamic forces exerted on aerosols deposited on walls are stronger than the forces causing them to adhere to walls. A number of models have been developed, including one that considers a single layer or several layers of aerosol deposits. The validation of these models is based primarily on the results of the STORM tests [26] conducted at the Joint Research Centre in Ispra, Italy.

A state of the art study on aerosol resuspension, conducted as part of the European SARNET network, found that the validation of the models was insufficient, particularly regarding the evaluation of releases from accidents with containment bypass (V-LOCA or SGTR) for which aerosol retention in pipes is an important factor in reducing releases.

\section{Revolatilisation}

This phenomenon is the opposite of deposition by vapour condensation. When the thermodynamic conditions in the RCS (temperature of the fluid carrying the aerosols, oxidising-reducing conditions and vapour concentration in the fluid) change, deposited vapours can revolatilise. Due to the importance of the associated chemical aspects, revolatilisation is discussed in Section 5.5.6.

It should be noted that this phenomenon was clearly demonstrated during the Phebus FP integral tests and in the VERCORS tests. 


\section{Deposits in the secondary loop (steam generators and tubes)}

During an SGTR (initial or induced rupture), the secondary side of the affected steam generator may be dry or flooded. This can have a significant effect on aerosol deposits in the secondary loop and thus on releases. Considering that very few experiments have been conducted under representative conditions, lower-bound deposition assumptions are currently being used to evaluate aerosol retention in the secondary side of damaged steam generators (these assumptions thus increase the calculated releases). A more realistic assessment of aerosol retention in the secondary side of damaged steam generators was therefore deemed necessary. As a result, the ARTIST experimental program [27] was conducted at the Paul Scherrer Institute (PSI) in Switzerland as part of an international consortium project. The programme led to the development of a new model of aerosol retention usable for cases where the secondary side of a steam generator is flooded.

\subsubsection{Experimental programmes, physical models and simulation codes}

The aerosol physics phenomena have been the subject of many experimental and theoretical studies often conducted outside the field of nuclear engineering, which have led to the creation of basic models. These models show a good consensus and have been implemented in computer codes used to analyse core melt accidents, such as the SOPHAEROS module of IRSN's ASTEC integral code.

SARNET identified two additional priority areas regarding transfers of aerosols in the RCS and the secondary loop:

- mechanical resuspension: efforts were made to better assess the validity of the models using existing data [28] (the STORM programme conducted by the JRC/IE [Joint Research Centre/Institute for Energy]) in the late 1990s;

- deposition in the secondary sides of damaged steam generators: as mentioned above, this topic was explored in the ARTIST programme conducted by PSI, a partner of IRSN [29]. The design of the experimental steam generator was representative of the design of Framatome steam generators, but with a reduced height of 3.8 metres. The steam generator internals and upper structures (separators and dryers) were of the same scale as that of a real steam generator used in the Beznau nuclear power plant in Switzerland. The experiments studied the aerosol retention in broken tubes near and beyond the break, in the separators and dryers, under dry secondary side conditions. Retention in a flooded steam generator was also investigated. The retention factors deduced from these experiments (dry or flooded secondary side) are used to assess the validity of the models of retention in the secondary side of a damaged steam generator.

\subsubsection{Summary and Outlook}

The phenomena associated with the transport of aerosols in the RCS are now generally well understood and satisfactory models, often based on data from fields other than nuclear engineering, have been developed to describe them. The main deposition 
phenomena, such as thermophoresis and diffusiophoresis, have been the subject of specific experimental programmes conducted to validate the corresponding models.

The models describing the phenomena of mechanical resuspension of deposited particles due to high flow rates are less well validated. An effort is being made to improve these models.

Because aerosol retention in the secondary sides of steam generators remains poorly quantified, lower-bound retention coefficients are used in safety studies. This matter is the subject of supplementary studies based on the findings of the international ARTIST programme.

\subsubsection{Ex-vessel fission product releases}

Ex-vessel releases of FPs and aerosols can be caused by several phenomena that can occur inside the containment:

- releases of aerosols from boiling sump water;

- releases during $\mathrm{MCCl}$;

- resuspension of aerosols deposited on containment walls.

The specific aspects of iodine and ruthenium, both of which have a complex chemistry, are discussed in section 5.5.6.

\subsubsection{Physical phenomena}

\section{- Releases from boiling sump water}

Aerosols released into the containment during a core melt accident end up primarily in the sump water after settling. Resuspension of these aerosols may occur if the sump water begins to boil. The results of past REST tests [30] carried out by FzK (Germany) have been used to develop semi-empirical models for both soluble and insoluble aerosols.

\section{Releases during $\mathrm{MCCl}$}

Such releases primarily relate to semi-volatile FPs and low-volatile FPs, as volatile FPs are released beforehand during in-vessel degradation and core melt. The release rates depend on the composition of corium and particularly its metallic zirconium content, which determines the oxygen potential of the corium and influences the chemical form of the FPs and thus their volatility. The concrete composition (siliceous concrete or silico-calcareous concrete) also plays a role, particularly because of differences in the production of gases during erosion of the concrete.

Releases during $\mathrm{MCCl}$ can be estimated from the FPs vapour pressures calculated using a thermodynamic code such as GEMINI for different corium compositions and concrete types. The highest values are obtained for zirconium-rich corium and siliceous 
concrete. The only elements with significant releases (greater than 1\%) are barium and strontium.

As the release rates are low, it has not been considered necessary to conduct R\&D programmes to refine the results.

\section{Resuspension of aerosols deposited on the containment walls}

Some events, such hydrogen combustion or corium-water interaction may result in high gas velocities near the containment walls and allow resuspension of deposited aerosols. Such resuspension is not addressed by existing models, but experiments are planned to assess if it can to have a significant radiological impact on the environment.

\subsubsection{Experimental programmes, physical models and simulation codes}

The effect of possible releases from a boiling sump and during $\mathrm{MCCl}$ on releases during core melt seems to be relatively low. Specific models for assessing these releases exist, but they are not implemented in the ASTEC integral code presented in Chapter 8.

\subsubsection{Summary and Outlook}

Ex-vessel releases of FPs can occur if sump water boils (aerosol releases) or during $\mathrm{MCCl}$. Studies conducted on these two issues have revealed only low release rates, which are lower than those in-vessel.

Nor has the possible resuspension of aerosols deposited on containment walls during violent events (such as hydrogen combustion) been investigated in detail. The reason is that such resuspension is not expected to significantly contribute to releases to the environment.

\subsubsection{Behaviour of aerosols in the containment}

Aerosols released into the containment are subjected to the phenomena of agglomeration, deposition and, in some cases, resuspension. The basic physical phenomena are the same as those governing the transport of aerosols in the RCS. They depend on thermal-hydraulic conditions in the containment (humidity rate, condensation or noncondensation of steam). The main deposition phenomena are gravitational settling and diffusiophoresis. Some safety systems, such as sprays, can also have a major influence on aerosol concentrations in the containment.

\subsubsection{Physical phenomena}

\section{Hygroscopicity and agglomeration phenomena}

Aerosol agglomeration phenomena are the same as those at play in the RCS. They cause the particles to increase in size, accelerating their deposition by gravitational settling. 
Hygroscopicity can play a major role. Some compounds, such as caesium hydroxide, are able to absorb water molecules and form droplets. This, too, causes aerosol particles to increase in size and accelerate their gravitational settling.

Models for calculating the size of the droplets formed at equilibrium as a function of temperature and relative humidity are available.

A difficulty in using such models lies in the limited knowledge of the chemical species formed by FPs. Prior to the Phebus FP tests, it was generally accepted that caesium was released into the containment in highly hygroscopic hydroxide form. The first two Phebus FP tests showed that this was not the case. Thermodynamic calculations taking account of the molybdenum releases show that the most likely chemical form of caesium is caesium molybdate. This is consistent with the caesium volatility measured during the tests. However, this finding cannot be directly extrapolated to all possible accident situations because the formation of caesium molybdate depends on the oxidising-reducing conditions in the RCS. Furthermore, the same tests show that the aerosols were agglomerates composed of released structural materials and FPs, the majority of which are poorly soluble. These agglomerates are much less hygroscopic than caesium hydroxide.

Aerosol hygroscopicity and assessments of aerosol settling rates in the containment must therefore be considered with caution. Nonetheless, these uncertainties probably have very little effect on the estimation of releases outside the containment.

\section{Washout of deposits by water vapour condensation}

Aerosols deposited on the containment walls can be washed away by water condensed from vapour and be drawn down into the sumps. A simplistic approach to studying this phenomenon in the computer codes considers that insoluble aerosols are not washed out but that soluble aerosols are. However, the difficulty is the same as that described above regarding aerosol hygroscopicity, i.e., uncertainties exist as to the type of chemical species making up the aerosols and thus their solubility. As most of the chemical species of barium and caesium are soluble, both elements are considered to be soluble.

\section{Spray removal of aerosols in the containment}

The main purpose of the containment spray system in France's PWRs is to prevent excessive pressure from building up in the containment. It also significantly lowers the concentration of suspended aerosols in a matter of hours. In the past, airborne concentrations were assessed using simple time-constant models. More recent studies allow current computer codes to obtain a better physical description of the phenomena involved.

Spray removal of aerosols in the containment depends on the characteristics of the droplets, particularly their masses, velocities and temperatures as they fall. Changes in these characteristics depend on evaporation and condensation phenomena as well as coalescence of the droplets. 
The trapping of aerosols by droplets involves the following mechanisms:

- inertial impaction and interception, mechanisms that primarily apply to large aerosols;

- Brownian diffusion, a mechanism that is particularly effective in the case of small particles near droplets;

- phoretic capture, which is associated with movements of particles in a temperature field. This mechanism is particularly effective in the upper part of the containment before the droplets reach thermal equilibrium with the atmosphere.

\subsubsection{Experimental programmes, physical models and simulation codes}

The basic mechanisms involved in aerosol deposition in the containment (deposition by diffusiophoresis and thermophoresis on the containment walls, deposition by gravitational settling) are well known. Models have been developed to describe these basic mechanisms, often using data from outside the field of nuclear engineering. Where necessary, these basic models were validated by specific experiments such as the PITEAS experiments, which were conducted at Cadarache by IPSN to study of the behaviour of aerosols in the containment [31].

More recently, R\&D work conducted in the 2000s have made it possible to explore more deeply issues relating to spray removal of aerosols in order to quantify the kinetics and efficiency of removal of aerosols and gaseous iodine in the containments of France's PWRs. This work includes:

- the CARAIDAS [32] tests conducted by IRSN in a cylindrical enclosure measuring 5 metres high and $0.6 \mathrm{~m}$ in diameter. The tests made it possible to determine the individual efficiencies of various mechanisms for collecting aerosols and gaseous iodine species by drops under steady-state conditions, under various conditions representative of a core melt accident (temperature, pressure, humidity, $\mathrm{pH}$ of the drops, iodine concentration);

- in terms of modelling, the development of a detailed description of the physical change in the drops during their fall as well as the various aerosol capture mechanisms. This description was implemented in the ASTEC integral code. Its thermal-hydraulic aspects were validated using the results of the CSE [33] tests conducted in the USA and its aerosol aspects were validated using the results of the CARAIDAS tests.

\subsubsection{Summary and Outlook}

The various phenomena governing the behaviour of aerosols in the containment are generally well understood and physical models have been developed to describe them, often using data from outside the field of nuclear engineering. The main deposition phenomena, such as diffusiophoresis and gravitational settling, have been the subject of specific experimental programmes conducted to validate the corresponding models. 


\subsubsection{Fission product chemistry}

During a core melt accident, FPs are released from fuel as vapours. The chemical form in which they are released depends on the equilibrium with their condensed phase in the fuel. This equilibrium varies during the course of an accident, mainly due to variations in temperature and oxidising-reducing conditions. Once released, FPs soon find themselves in a different environment during their transport in the RCS, with variations in temperature and in the composition of the carrier fluid and changes in their chemical speciation in the RCS. Most of the chemical reactions take place in the gas phase, but the vapours may also interact with pipe walls. The structural materials released to outside the core also play a role (SIC and/or boron carbide control rod materials, tin in the Zircaloy cladding, etc.).

Most of the FPs are released into the containment either in condensed form (aerosols) or rapidly condense there. The behaviour of aerosols in the containment atmosphere is determined primarily by the deposition processes described in Section 5.5.5.1. The chemistry of the FPs has little effect on these processes. A large fraction of the aerosols is washed down into the sump water, where they dissolve depending on their respective solubility.

lodine [3] and ruthenium are two FPs that exhibit specific behaviour and can be present in significant quantities as gases in the containment. These two highly radiotoxic elements (Section 5.5.1) have a complex chemistry in both their gas and liquid phases and can react with painted surfaces and metal surfaces in the containment. Their interactions with the water and air radiolysis products, formed under the radiation emitted by the FPs in the atmosphere and sumps of the containment, also play an important role.

\subsubsection{Physical phenomena}

\section{- Chemistry of gaseous FPs in the RCS}

The chemical speciation of FPs in the RCS during a core melt accident can be estimated by assuming, as a first approximation, that the chemical reactions have reached thermodynamic equilibrium, with understanding of the concentrations of the various chemical elements and of the thermodynamic properties of the various chemical species likely to be formed. However, given the complexity of the chemical systems involved, particularly due to the large number of elements involved in the chemical reactions (FPs, elements released by degradation of the control rods and core structures, hydrogen and oxygen in the carrier gas molecules), the existing thermodynamic databases are not comprehensive enough. Furthermore, some of these databases contain significant uncertainties. It is for these reasons that the chemical species of FPs in the RCS cannot be determined with certainty by thermodynamic calculations.

Furthermore, the thermodynamic equilibrium is not always reached. This is particularly true when chemical reactions occur at a rate too slow for equilibrium concentrations of the species formed to be obtained. While thermodynamic equilibrium is most probably reached at high temperature in the vessel near the core (chemical reactions occur very quickly at high temperature), this is most likely not to be the case in the cold legs, 
where the temperatures are lower, and for some species in the parts of the RCS where the temperature of the carrier fluid drops quickly (the steam generators in particular). Thus, in the parts where the temperature drops quickly, the reaction rates become sufficiently slow to have an effect on the final speciation of the FPs. As a result, the species found are not always those that would have been formed at thermodynamic equilibrium.

Studies conducted to determine the species formed initially looked at the volatile elements (particularly iodine) and the simple reaction system limited to the elements $\mathrm{Cs}, \mathrm{I}, \mathrm{O}, \mathrm{H}$ [34], while taking into consideration the influence of boric acid. These studies led to the conclusion that, in the absence of boron, iodine is transported as caesium iodide $(\mathrm{Csl})$ with the remaining caesium in hydroxide form $(\mathrm{CsOH})$. The presence of boron may lead to the formation of caesium borate, which is less volatile than $\mathrm{CsOH}$, and where part of the iodine converts to hydroiodic acid (HI), which is more volatile than Csl [36]. These studies are based on the results of experiments conducted with simulated FPs, such as the British FALCON programme [35].

The results of these preliminary studies led developers of computer codes such as MELCOR (an American code; see Chapter 8) to set the chemical forms of the transported elements without taking the chemical reactions into account. The computer codes, such as SOPHAEROS (a module of the ASTEC integral code; see Chapter 8), for which modelling of the transport of FPs in the RCS was developed more recently, calculate the chemical speciation of FPs. These are not thermodynamic calculations of the complete reaction systems. Rather, they are simplified calculations limited to reaction systems most important for the chemical speciation of FPs and which were carried out using a thermodynamic database that was as comprehensive and validated as possible.

The chemical forms selected based on the aforementioned preliminary studies were challenged primarily by the results of the Phebus FP programme (Section 7.3). One strong point of this programme is that the source of the FPs and structural materials is the most realistically achievable both in terms of its composition and the release kinetics. This is because the source comes from an irradiated fuel rod cluster undergoing degradation.

In the Phebus FP tests, the chemical forms are not determined directly, owing to the detection limits of the various techniques for low amounts of radioactive materials. However, indirect indications are provided by the volatility of the elements (their condensation temperatures) and their solubility in water or acid.

Regarding caesium, the results of the Phebus FP programme (Section 7.3) showed that in the presence of a carrier gas rich in water vapour, caesium was primarily in the condensed phase at $700^{\circ} \mathrm{C}$. This is incompatible with caesium hydroxide, which is in the vapour phase at this same temperature. These tests also showed that with a steam-rich carrier gas, two things occur: (1) molybdenum releases are higher than initially expected and (2) molybdenum is present in the RCS at a much higher concentration than caesium, thus promoting the formation of caesium molybdate, a less-volatile species than caesium hydroxide. The concentration of this species is correctly calculated by the ASTEC code, which uses thermodynamic data for the species involving molybdenum. After 
reviewing the results of the Phebus FP tests, the developers of the MELCOR (US NRC) code modified it to take into account the formation of caesium molybdate.

In the case of iodine, calculations made with the ASTEC code predict the formation of caesium or rubidium iodide (equivalent properties). The Phebus tests, particularly FPT2, showed that this is not always the case. Depending on the oxidising-reducing conditions and the concentration of elements from the control rods in the RCS (Ag, In and Cd or B), caesium iodide and at least one more-volatile species may be present or absent. This chemical speciation is not currently predicted by the models. The aim of the CHIP experimental programme, conducted at Cadarache by IRSN and devoted to iodine chemistry in the RCS in event of a core melt accident, is to provide indications on the chemical reactions involved and the species formed. This programme is discussed more in detail in Section 5.5.6.2.

\section{Interactions of FPs with the walls of the RCS}

Fission product vapours can react with the walls of the RCS. Elements such as tellurium can also be chemisorbed, increasing deposition. However, this does not seem to occur if sufficient amounts of tin (a component of Zircaloy) are transported with tellurium to form tin telluride. If degradation of Zircaloy cladding leads to a significant release of tin, higher amounts of tellurium may be transported by the aerosols in the containment.

The FP vapours condense on the metal walls and react with them. This is particularly the case with caesium in the hot leg of the RCS. This interaction has been demonstrated by many experimental programmes, including the DEVAP programme [37] conducted for IRSN at CEA's centre in Grenoble, and the Phebus FP programme. Deposit revaporisation tests conducted on hot-leg samples from the FPT1 test of the Phebus FP programme showed that interactions between caesium and steel may lead to the formation of several different volatile species [38]. Revolatilisation of deposited FPs may occur after their main release from the core during a core melt accident. This can lead to long-term releases, particularly in the case of delayed containment failure (failure occurring at least 24 hours after the onset of the accident via mode $\delta$ or mode $\varepsilon$, for example; see Section 4.3.3.3). Such releases are determined by the volatility of the species in the deposits.

\section{lodine chemistry in the RCS}

In the RCS, iodine is likely to combine with many other elements (FPs or structural materials), particularly caesium, rubidium, silver, indium and cadmium. Iodine may also be present in the RCS as atoms $(\mathrm{I})$, molecules $\left(\mathrm{I}_{2}\right)$ or hydroiodic acid $(\mathrm{HI})$. These species have the particularity of being in the gas phase in the conditions that prevail in the RCS during a core melt accident.

Following the studies conducted after the TMI-2 accident, it was generally accepted in the 1980s and 1990s that iodine was transported primarily as caesium iodide (Csl). In 1995, the US NRC conducted a new set of studies aimed at better estimating releases 
to the containment during a core melt accident. These studies were summarised in benchmark report NUREG-1465 [40], which indicated that a significant fraction (5\%) of volatile iodine ( $\mathrm{I}$ and $\mathrm{HI}$ ) may be released into the containment. This percentage was not determined based on experimental results but rather on calculations, for several accident sequences, of the thermodynamics of the $\mathrm{Cs}, \mathrm{I}, \mathrm{O}, \mathrm{H}$ simple system supplemented by assessments of the speeds of the chemical reactions for the iodine speciation. As mentioned above, when the reaction rates are sufficiently low, iodine does not have time to fully react with the caesium in the RCS. As a result, non-negligible fractions of volatile iodine (I and $\mathrm{HI}$ ) remain.

The results of the Phebus FP tests show that the behaviour of iodine in the RCS is in reality more complex. lodine is not always present primarily in the form of caesium iodide, but rather forms species with other elements released during degradation of fuel and structural materials. In particular, thermodynamic assessments have shown that the silver and cadmium in SIC control rods can affect the iodine chemistry in the RCS depending on the oxidising-reducing conditions and temperature levels. Thermodynamic data of the species that may be present in the RCS were compiled and verified. This considerable task has made it possible to implement extensive databases in computer codes such as ASTEC. Despite this work, however, the thermodynamic calculations still do not make it possible to reproduce the iodine behaviour observed during the tests of the Phebus FP tests.

Another notable result of the Phebus FP tests is that the presence of gaseous iodine in the containment at the onset of fuel degradation cannot be explained by chemical reactions in the containment. This presence is attributed to an influx of gaseous iodine from the RCS. The fractions of gaseous iodine transported in the RCS at a given moment in relation to the total iodine (gaseous iodine and iodine aerosols) reached $30 \%$ during the FPT- 0 test and $4 \%$ during the FPT1 test $[39,41]$. It should be noted that:

- during these tests, the maximum fractions of gaseous iodine were measured when the hydrogen content in the RCS was at its highest (approx. 50\%);

- these are estimates for a cold-leg break; the results of the FPT1 test seem to show that the fraction of gaseous iodine is higher for a hot-leg break;

- the difference in iodine concentrations between the two tests (30 times less iodine during test FPTO, which was conducted with only very slightly irradiated fuel) suggests that the reaction rates for the formation of iodine compounds have an influence on the fraction of gaseous iodine;

- the relationship between the fraction of gaseous iodine and the hydrogen concentration is less clear for the FPT2 test;

- the FPTO test is a special case in that the test fuel was very slightly irradiated and, as a result, the iodine concentrations were not representative of an actual accident sequence.

Phebus tests FPT0, FPT1 and FPT2 were conducted using a SIC control rod like those used in French 900 MWe PWRs (also in most PWRs of Western design) for example. On 
the other hand, Phebus test FPT3 was conducted using a boron carbide $\left(\mathrm{B}_{4} \mathrm{C}\right)$ control rod, like the ones used in $1300 \mathrm{MWe}$ and $1450 \mathrm{MWe}$ PWRs. The iodine fraction in the gaseous phase measured in the containment during this test was significantly higher (more than $80 \%$ [43]) than during the other tests in the programme. This result can be explained by a number of assumptions, including the absence of silver, indium and cadmium (which reduces the number of elements with which iodine can chemically combine) and the presence of high concentrations of boric acid from oxidation of the control rod (boric acid can combine with caesium, preventing the formation of caesium iodide). The combination reactions of iodine with other elements may be lower and more iodine may remain in gaseous form. The CHIP experimental programme conducted at Cadarache by IRSN aims to test these assumptions.

Nevertheless, caution should be exercised in extrapolating these experimental results to real accident sequences in a power reactor. Although studies conducted around the year 2000 on possible releases during core melt accidents took into account the results of the FPT0 and FPT1 tests (by taking a 5\% fraction of gaseous iodine in the fluid leaking from an RCS break), supplementary studies are necessary to take into account the implications of the results of the FPT3 test for power reactors.

\section{lodine chemistry in the containment sump}

lodine released in aerosol form in the containment behaves like the other aerosols (Section 5.5.5) that are primarily entrained into the sump water. With the notable exception of silver iodide (Agl), most of the metal iodides (Csl, Rbl, $\mathrm{CdI}_{2}, \mathrm{InI}$ ) are soluble. The soluble iodides dissolve in water, forming $\mathrm{I}^{-}$and $\mathrm{IO}_{3}^{-}$ions.

The large amount of FPs in the containment sump create significant dose rates in the sump water, leading to the formation of water radiolysis products including reactive molecules and radicals such as $\mathrm{OH}, \mathrm{O}_{2}^{-}, \mathrm{H}_{2} \mathrm{O}_{2}$, etc. Many chemical reactions take place, the net result of which is radiolytic oxidation of the iodide ions $\left(\mathrm{I}^{-}\right)$into volatile molecular iodine $\left(\mathrm{I}_{2}\right)$. The formation of $\mathrm{I}_{2}$ depends on many parameters, the most important being water $\mathrm{pH}$. If the $\mathrm{pH}$ is kept basic, the $\mathrm{I}_{2}$ production rate is very low.

The sump water also contains organic compounds primarily from submerged paintwork. The iodine reactions with the organic radicals formed through decomposition of these organic compounds due to the dose rates produce volatile organic iodides such as methyl iodide $\left(\mathrm{CH}_{3} \mathrm{I}\right)$ or low-volatile organic iodides such as compounds of higher molecular weight.

These reactions in the liquid phase (see Figure 5.59) have been studied in depth both experimentally and theoretically, and the associated phenomena are reasonably well understood $[45,46]$. However, there remain uncertainties about the effect of some impurities, such as the $\mathrm{NO}_{3}{ }^{-} / \mathrm{NO}_{2}{ }_{2}^{-}$ions produced by radiolysis of the gases in the containment atmosphere (a product of radiolysis is nitric acid $\left[\mathrm{HNO}_{3}\right]$, which is drawn into the sump by the condensing water vapour), the $\mathrm{Fe}^{2+} / \mathrm{Fe}^{3+}$ ions from the steel surfaces in contact with the liquid phase in the sump (these ions are formed by corrosion reactions), or the $\mathrm{Cl}^{-}$ions that may come from cable pyrolysis during an accident involving fire in 
the containment. The effect of these impurities is still being investigated by experimental programmes conducted in Canada and Switzerland, primarily as part of the OECD's international Behaviour of lodine Project (BIP).

During the first Phebus FP tests, it was noticed that the silver released from the SIC control rods reacted with the iodine in the sump to form insoluble silver iodide. If there is sufficiently more silver than iodine (since this is a reaction between silver particles and iodine solubilised in the form of iodide $\left(\mathrm{I}^{-}\right)$or iodine $\left(\mathrm{I}_{2}\right)$, the number of active sites on the surface of the silver particles must be high enough to react with most of the iodine) the concentration of iodide ions $\left(\mathrm{I}^{-}\right)$drops sharply in the sump, leading to very little production by radiolysis of gaseous iodine $\left(\mathrm{I}_{2}\right)$. These phenomena have been quantified and models have been developed from the results of dedicated experiments, particularly the Phebus RTF tests conducted by AECL to study the reactions of iodine with silver in the sump [47] and the tests conducted by PSI, under the Phebus FP programme, to study the stability of silver iodide (AgI) [48].

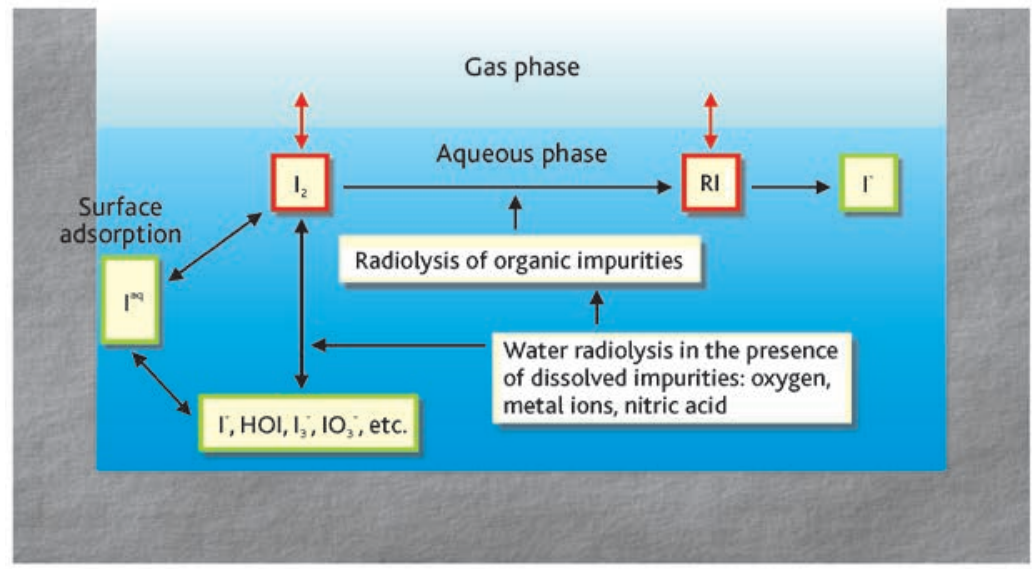

Figure 5.59. Main reactions involving iodine in the liquid phase in the containment sump (taken from [3], reproduced by courtesy of the OECD).

\section{lodine chemistry in the containment atmosphere}

Gaseous iodine in the containment atmosphere has two origins:

- gaseous iodine exiting the break in the RCS;

- gaseous iodine produced by radiolytic reactions in the sump water.

Transfers of gaseous iodine from the sump obey classic laws of mass transfer. Masstransfer models exist that can be applied to a sump with and without evaporation of water vapour to the containment atmosphere.

lodine in the gas phase of the containment reacts with the surfaces in the containment, mainly those made of metal or covered by paint, in physical and chemical adsorption and desorption reactions. These reactions are a function of the temperature and dose rate. 
Existing data on iodine adsorption and desorption are derived from laboratory-scale experiments or more integral tests such as those conducted in the RTF [49] in Canada and the CAIMAN facility [50] in France. The experimental parameters investigated were primarily the type of paint, its ageing, temperature and dose rate. The derived correlations correspond to first-order kinetics.

In safety terms, the iodine-paint interactions are highly significant because they lead to the formation of gaseous organic iodides that are not retained by the filters, especially when the containment filtered venting system is opened (U5 procedure in France, see Section 4.3.3.3). Organic iodide production rates were established from the results of a large number of small-scale tests that involved taking painted surfaces on which iodine had been deposited and irradiating them in an atmosphere representative of the containment atmosphere. These tests show that radiation has a greater effect than temperature and their results have been used to develop semi-empirical models. However, given the dispersion of the results and the difficulty in distinguishing the influence of the various parameters, the models are only capable of reproducing the experimental results to within about one order of magnitude.

When exposed to radiation, molecular iodine $\left(\mathrm{I}_{2}\right)$ is oxidised by the radiolysis products of the gases in the containment atmosphere (ozone and nitrogen oxides) to form iodine oxides and nitroxides. These compounds are less volatile than molecular iodine particularly because they react with the water vapour to form compounds that are entrained down to the sump. Several reactions occur simultaneously (Figure 5.60):

- the oxidising species (ozone and nitrogen oxides) are formed and destroyed by irradiation;

- the oxidising species interact with the metal surfaces and painted surfaces;

- the oxidising species react with the iodine;

- the iodine reacts with the metal surfaces and painted surfaces.

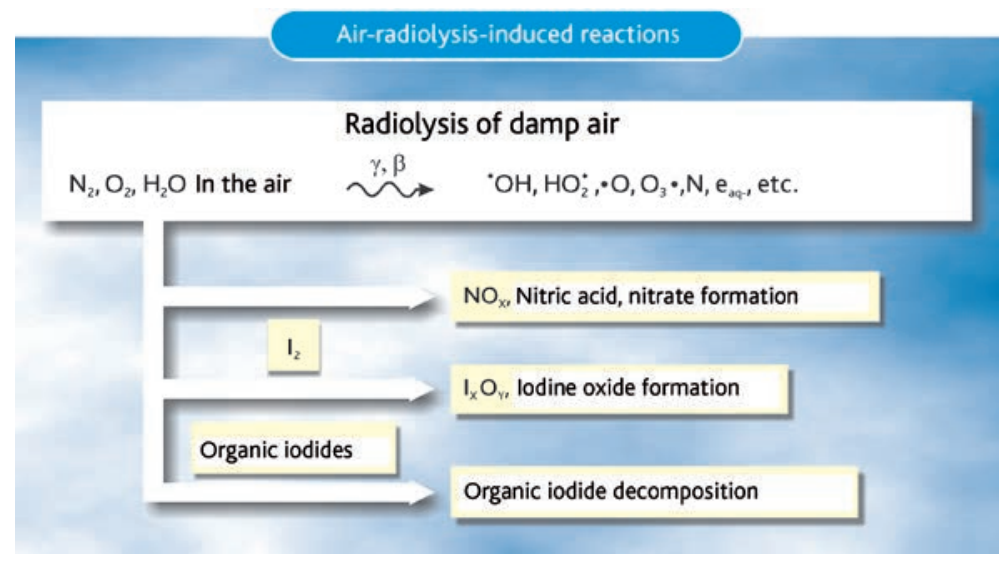

Figure 5.60. Main reactions involving iodine and radiolysis products in the containment atmosphere sump (taken from [3], reproduced by courtesy of the OECD). 
The tests conducted during the preliminary studies on the effect of air radiolysis products, particularly ozone, found high iodine concentrations. The models derived from these tests could not be easily extrapolated to the conditions of a core melt accident in a power reactor. More recent tests (PARIS project [51]) have made it possible to gain a better understanding of the phenomena and identify the most influential parameters.

Organic iodine $\left(\mathrm{CH}_{3} \mathrm{I}\right)$ is also destroyed by reactions with air radiolysis products. The tests carried out show that the destruction rate of organic iodine is proportional to the dose and that temperature has little effect on the rate of the destruction reaction.

An important mechanism that lowers the concentration of gaseous iodine in the containment is its capture by the spray droplets [32]. This mechanism involves the following process:

- transfer of the iodine from the gas phase to the droplets;

- transfers at the gas-droplet interface and within the droplets;

- in-sump liquid-phase chemical reactions.

Capture of gaseous molecular iodine depends on the $\mathrm{pH}$ of the droplets. It is more efficient when the $\mathrm{pH}$ is basic, which is the case when the containment spray system (CSS) is used in direct mode. Unlike molecular iodine $\left(\mathrm{I}_{2}\right)$, organic iodine $\left(\mathrm{CH}_{3} \mathrm{I}\right)$ is not efficiently scavenged by the droplets.

The RECI tests [52] conducted by IRSN in the early 2000s studied the possible interactions of iodine in the recombiners. The following phenomena are involved in these interactions:

- heating of the metal halide aerosols ( $\mathrm{Csl}, \mathrm{Agl}, \mathrm{CdI}_{2}$, etc.) as they pass between the plates of the recombiners;

- vaporisation and dissociation of the iodides, leading to the formation of dissociated gaseous iodine in the hottest sections;

- quenching at the outlets of the recombiners, with the formation of gaseous molecular iodine and fine aerosols by nucleation.

The small-scale RECI tests have more recently been supplemented by larger-scale tests using real recombiners and conducted as part of OECD/NEA THAI project [53]. The production of gaseous iodine by iodide dissociation in the recombiners has been quantified and its impact on iodine releases during a core melt accident has been assessed. Although this impact is not zero, it is lower than that of other phenomena, such as gaseous iodine injected into the containment from the RCS.

\section{- Ruthenium chemistry}

As mentioned in Section 5.5.2, large amounts of ruthenium may be released from fuel during an accident with fuel degradation in the presence of air. Such an accident may be a core melt accident caused by vessel melt-through, a spent fuel handling accident, or a spent fuel pool uncovery accident [54]. If released to the environment, the dosimetric impact of ruthenium may be high and similar to that of iodine in the short term and caesium in the medium term [6]. Furthermore, ruthenium has a very complex chemistry. 
Ruthenium is in metal form in the fuel. However, in the presence of air, it is released primarily as ruthenium(IV) oxide $\left(\mathrm{RuO}_{2}\right)$. When it reaches the colder sections of the RCS, $\mathrm{RuO}_{2}$ can either condense on the walls or oxidise to form gaseous ruthenium tetroxide $\left(\mathrm{RuO}_{4}\right)$. This gaseous $\mathrm{RuO}_{4}$ can then react with the walls and deposit on them in the form of $\mathrm{RuO}_{2}$. Due to its kinetics, this last reaction may not be complete in the colder sections of the RCS, allowing ruthenium to persist in the form of gaseous $\mathrm{RuO}_{4}$. The behaviour of ruthenium in the RCS was investigated during the RUSET tests [55-57] conducted by AEKI (Hungary) and tests conducted by VTT [58] in Finland. Conducted under various oxidising-reducing conditions, these ruthenium vaporisation tests revealed, despite significant deposits on the walls of the loops, the existence of gaseous ruthenium in the coolest sections of the loops. During the RUSET tests, partial pressures of gaseous ruthenium corresponding to the equilibrium between the gaseous $\mathrm{RuO}_{4}$ and the deposited dioxide were measured at temperatures of around $600-700^{\circ} \mathrm{C}$.

As mentioned above, the gaseous $\mathrm{RuO}_{4}$ can react with the walls of the pipes and remain trapped there. These effects were studied experimentally by VTT [58] in Finland. The ruthenium deposition (in the form of $\mathrm{RuO}_{2}$, as the $\mathrm{RuO}_{4}$ had been reduced during the reactions with walls) was measured on aluminium oxide and steel pipes. This deposition was light on the aluminium oxide pipes but heavy on the steel pipes except in the presence of water vapour. No explanation was given for this result. The conclusion drawn from these tests is that a significant fraction of ruthenium can be released in gaseous form in the containment.

The behaviour of gaseous ruthenium in the containment was the subject of experiments conducted at IRSN [59-63] as part of the "containment ruthenium" section of the ISTP. These experiments investigated three areas: (1) adsorption and desorption phenomena of gaseous ruthenium on steel walls and painted surfaces; (2) radiation effects that lead to the formation of air radiolysis products such as ozone; and (3) reactions of ruthenium deposited on the containment walls or dissolved in the sump water with these products, which can lead to revolatilisation of gaseous ruthenium.

The results of these tests suggest that, if gaseous $\mathrm{RuO}_{4}$ is present in the containment, a significant portion of this gaseous ruthenium can remain suspended in the containment atmosphere despite being deposited on its walls. These results also suggest that the ruthenium deposited on the walls or dissolved in the sump water can be revolatilised by radiation. Having been established, the kinetics of these reactions are used to build viable models for determining the quantities of gaseous ruthenium present in the containment of a power reactor during a core melt accident.

\subsubsection{Experimental programmes, physical models and simulation codes}

\section{- Fission product chemistry in the RCS}

Regarding the behaviour of FPs in the RCS, the calculation and experimental results are compared primarily for deposition of FPs on the walls of the RCS and for quantities of FPs released to the containment. Work in interpreting these results, especially for 
the Phebus FP and VERCORS HT tests with the ASTEC code, made it possible to supplement the thermodynamic databases used for relative calculations of the chemistry of the FPs in the RCS. The results obtained using the supplemented thermodynamic databases, now integrated into the ASTEC software, are satisfactory, except for simulating the behaviour of the iodine measured during the Phebus FP tests.

In particular, the ASTEC calculations do not correctly predict the fractions of gaseous iodine present in the RCS. As a result, the CHIP experimental programme was launched in 2005 to obtain additional data on the iodine chemistry in the RCS, both in terms of its thermodynamics and its chemical kinetics. This programme consists of two types of tests conducted at Cadarache by IRSN:

- analytical tests that study chemical systems consisting of, in addition to hydrogen and oxygen (elements that make up the carrier gas), iodine and only one other element in order to obtain data on the kinetics and thermodynamics of the chemical reactions involving iodine;

- larger-scale studies for studying more complex chemical systems having a higher number of elements (representative of the FPs, control-rod components and core structures) in order to obtain data on the amounts of volatile iodine in the RCS as a function of the elements present and the boundary conditions (oxidising-reducing conditions, element concentrations, temperatures, carrier gas flow rates).

These tests are supplemented by literature reviews to establish kinetic and thermodynamic databases for developing kinetic models. When this data are missing or too uncertain, they are obtained using methods of theoretical chemistry ( $a b$ initio calculations). The models are then validated by comparison with results of the CHIP tests and progressively integrated in the ASTEC code.

The behaviour of ruthenium is studied in the experimental programmes led by AEKI and VTT described in the previous section (5.5.6.1). The results obtained confirm that a significant portion of ruthenium is transported as metastable gaseous $\mathrm{RuO}_{4}$ to the free volume of the containment even if the gaseous ruthenium deposits onto the steel pipes.

\section{- Fission product chemistry in the containment}

Research on this topic primarily covers iodine and ruthenium chemistry in both experimental and modelling terms.

lodine chemistry in the containment during a core melt accident has been the subject of many research programmes in several countries since the 1980s. There are detailed reviews that present the main advances made in this area (see [3] in particular).

Until the mid-1990s, before the first results of the Phebus FP tests had been analysed, the research programmes conducted on iodine chemistry in the containment during a core melt accident primarily focussed on studying volatilisation of molecular iodine from the sump and its adsorption on the metal and painted surfaces in the containment. 
This was because it was assumed that iodine was released in the containment exclusively in the form of Csl aerosols, that these aerosols were drawn down to the sump and that they led to the formation of iodides $\left(\mathrm{I}^{-}\right)$through solubilisation of the Csl.

The research programmes conducted at the time made it possible to satisfactorily understand and model the kinetics of the chemical reactions involving, with or without radiation, the inorganic iodine species in the sump (primarily iodides $[\mathrm{I}]$, iodates $\left[\mathrm{IO}_{3}{ }^{-}\right]$ and molecular iodine $\left.\left[\mathrm{I}_{2}\right]\right)[45,46]$. The main parameters that influence the kinetics of the reactions and the volatilisation of molecular iodine from the sump are the $\mathrm{pH}$, the dose rate, the temperature and the oxidising-reducing conditions in the liquid phase. The effect of each of these parameters on iodine volatility has been studied in detail (up to an in-sump temperature of $80-90^{\circ} \mathrm{C}$ ). It turns out that $\mathrm{pH}$ is the parameter that has the greatest influence: a basic $\mathrm{pH}$ (in the sump or spray droplets) sharply reduces volatility of iodine in the containment.

Based on the results of these programmes, the conclusion was made that the effect of high temperatures (beyond $90^{\circ} \mathrm{C}$ ) and of the presence of impurities in the sump on iodine volatility had to be quantified. The aim of the EPICUR programme (conducted by IRSN as part of the ISTP and described in detail below), and the OECD BIP (conducted by $\mathrm{CNL}$, formerly $\mathrm{AECL}$ ) is to obtain sufficient data to be able to model these effects. It should be noted that PSI has conducted a programme complementary to the OECD BIP to study the effect of the presence of impurities in the sump on iodine volatility.

Research programmes have also made it possible to obtain a database for assessing the adsorption rates of molecular iodine on the metal walls and painted walls of the containment in order to obtain preliminary results for assessing the production of organic iodides from painted surfaces (see, for example, [49, 50], which present the results obtained during the RTF integral tests conducted by AECL and the CAIMAN tests conducted by the CEA for IRSN).

However, the results obtained from the Phebus FP tests showed that iodine volatility in the containment could be affected by other processes, particularly:

- releases of gaseous iodine from the RCS. This gaseous iodine, which is not produced by the chemical reactions occurring in the sump, can react directly with the painted walls of the containment and ultimately lead to releases of organic iodides. Furthermore, gaseous iodine can also react with gas radiolysis products in the containment atmosphere. Until the mid-1990s, all these chemical reactions in the containment atmosphere had been studied very little;

- releases of silver through degradation of the SIC control rods. The silver that ends up in the sump forms silver iodide, which sharply reduces the volatilisation of gaseous iodine from the sump. Like the reactions in the containment atmosphere, the influence of silver on the iodine chemistry in the sump had not been studied as part of specific research programmes.

Since then, research programmes studying the influence of silver on iodine volatility in the containment have been conducted by $A E C L$, as part of the international Phebus FP 
programme, and by PSI $[48,49]$. These programmes have made it possible to model the reactions involving silver. This model is integrated in most integral codes for core melt accidents, particularly ASTEC. These models allow a satisfactory understanding of the influence of silver on iodine volatility.

A research programme studying the reactions between gas radiolysis products in the containment atmosphere and gaseous iodine was recently conducted by AREVA-NP in collaboration with IRSN [51]. The results of these tests have increased understanding and modelling of chemical reactions that affect iodine volatility. However, they do not make it possible to precisely quantify this effect. It should be noted that iodine volatility is reduced by the reactions between air radiolysis products and gaseous iodine in the containment atmosphere. The reason is that the products thus formed react with the water vapour and form compounds that are entrained down to the sump.

In 2005, IRSN launched the EPICUR programme as part of the ISTP. The programme aims to study more particularly the processes whose effects on iodine volatility in the containment were insufficiently quantified:

- the formation of organic iodides in the containment atmosphere from painted surfaces;

- in-sump iodine radiolysis, particularly at high temperatures (beyond $90^{\circ} \mathrm{C}$ );

- iodine radiolysis in the containment atmosphere.

The EPICUR facility (see diagram in Figure 5.61) consists of a vessel that can hold a liquid phase in its bottom section. This vessel can be exposed to irradiation by ${ }^{60} \mathrm{Co}$ source. Small painted specimens can be placed in either the liquid phase or the gas

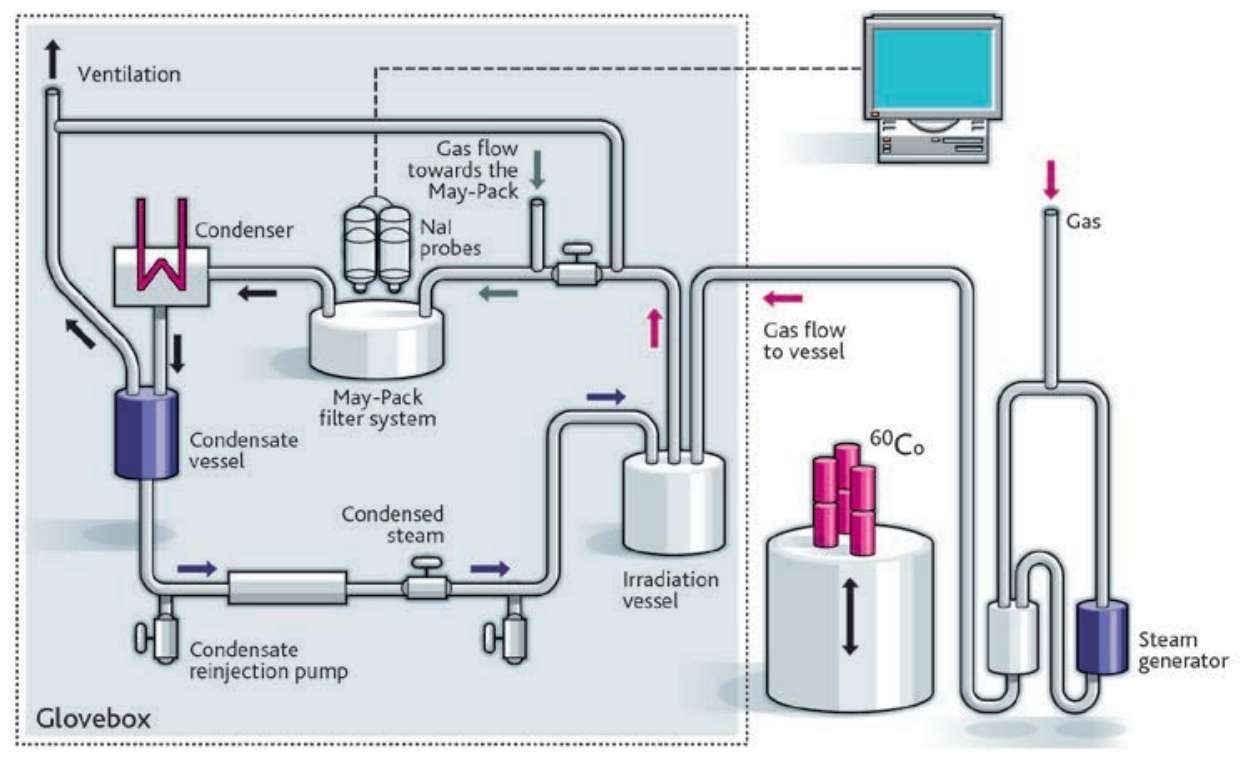

Figure 5.61. Schematic view of the EPICUR facility. 
phase of the vessel. The liquid phase can hold iodide ions or molecular iodine solubilised according to its $\mathrm{pH}$. Likewise, iodine can be deposited on the painted specimens before they were placed in the vessel.

Volatile iodine (molecular and organic) produced by radiation from either the liquid phase or the painted specimens, as well as the iodine oxide aerosols produced by radiation in the vessel atmosphere, are continuously entrained by a gas flow and collected in selective filters that separate the iodine, molecular iodine and organic iodine aerosols. The use of iodine containing iodine-131 $\left({ }^{131} I\right)$ makes it possible during a test to perform gamma spectrometry measurements at each filtration stage and determine the kinetics of the processes of volatile iodine production.

The ASTEC code is used at IRSN to interpret these tests. The first part of the programme, which looked at iodine radiolysis in the liquid phase, was fully implemented and made it possible to improve the in-sump iodine radiolysis models. The results obtained also showed that releases of organic iodine from the liquid phase are low but that releases of organic iodine from the painted specimens placed in the vessel atmosphere are high. It remains to be examined whether this mechanism of organic iodine production on the painted surfaces in the containment atmosphere can have an effect on the possible releases during a core melt accident.

It should be noted that, in addition to the tests of the influence of the presence of insump impurities on iodine volatility, some of the OECD BIP tests, complementary to the EPICUR tests, investigate the formation of organic iodides from painted surfaces in the containment for the purposes of validating the reaction models involving organic iodides and developed using the results of the EPICUR programme.

At the same time, work on interpreting the Phebus FP tests is continuing, with the participation of a number of partners from outside the programme. The results of the Phebus FPT3 test are drawing special attention. Analyses of these results show that the concentration of gaseous iodine in the containment, very high at the start of the test, decreased quickly and that much iodine is trapped on the painted surfaces of the containment.

In 2010, IRSN published a summary detailing the model of the iodine chemistry in the containment during a core melt accident implemented in the ASTEC code and its use for interpreting the Phebus FPT2 test [65].

An experimental programme on the behaviour of ruthenium in the containment was conducted at IRSN between 2004 and 2008 [59, 63]. This programme investigated a number of areas, including:

- adsorption of gaseous ruthenium by the metal surfaces and the painted surfaces in containment and its desorption from these surfaces;

- revolatilisation of the ruthenium deposited on the surfaces of the containment under the action of ozone and radiation;

- revolatilisation of the ruthenium from the liquid phase of the sump under the action of ozone and radiation. 
The results of this programme made it possible to develop models of ruthenium chemistry in the containment during a core melt accident.

\subsubsection{Summary and Outlook}

\section{- Fission product chemistry in the RCS}

The Phebus FP integral tests have prompted a review of a number of assumptions on the chemistry of FPs - particularly caesium and iodine - in the RCS. Recent studies of degradation in air of fuel have also shown that a review of ruthenium chemistry was necessary.

Contrary to assumptions prior to the Phebus tests, caesium is not necessarily in the form of $\mathrm{CsOH}$ but can be in the form of caesium molybdate, which is less volatile. The models now take this into account. Phenomena of revolatilisation from deposition in the RCS have also been observed and may lead to delayed releases, after the main release phases associated with fuel degradation, in the containment.

lodine chemistry is more complex. lodine is not always in the form of caesium iodide in the RCS. The Phebus FP tests show that, apart from the gaseous forms, at least two other species could be present depending on the conditions prevailing in the RCS (other elements present, oxidising-reducing conditions, temperature in the RCS). Part of the iodine is also in gaseous form in the RCS until its release in the containment. Exploitation of the results of the Phebus FP tests as well as of the results of the specific studies using the entire set of available experimental data resulted in using a gaseous iodine quantity of $5 \%$ in relation to the total iodine released in the containment for studies on releases during core melt accidents. However, the percentage observed during the last test in the Phebus FP programme (Phebus FPT3) exceeded $80 \%$. This percentage was probably due to highly different chemical conditions in the RCS during the test resulting from the absence of species from degradation of a SIC control rod and the presence of species from degradation of a boron carbide control rod (for this test, the SIC control rod had been replaced by a boron carbide rod). That said, there are two reasons why caution should be exercised in relation to the consequences of this result in terms of the possible releases during a core melt accident:

- the control rods in $1300 \mathrm{MWe}$ and $1450 \mathrm{MWe}$ power reactors are not made solely of boron carbide but are composed in part of a silver-indium-cadmium alloy;

- during the Phebus FPT3 test, the concentration of gaseous iodine in the containment decreased rapidly and much of this iodine was trapped on the painted surfaces.

As regards more specifically iodine chemistry in the RCS, critical reviews of the thermodynamic data for the various possible chemical species have been conducted and have enabled chemical speciation calculations to be made. However, these calculations do not make it possible to fully reproduce the iodine behaviour observed in the RCS during the Phebus FP tests, particularly the existence of several non-gaseous species of metal iodide. A possible hypothesis is that the thermodynamic calculations are 
insufficient for modelling iodine chemistry in the RCS, particularly in the sections where the temperature falls sharply (at the core outlet and the inlets of the steam generators), and that they must be supplemented by calculations of the kinetics of the chemical reactions. Indeed, if they are sufficiently slow, the kinetics of some reactions can lead to incomplete reactions of iodine with metallic elements (such as caesium, silver or cadmium) and gaseous iodine. The CHIP experimental programme is continuing to identify the important chemical reactions of iodine with silver, indium and cadmium and determine the kinetic data needed to conduct chemical kinetics calculations.

Experiments conducted in Hungary and Finland have shown that, during a core melt accident with vessel melt-through and air ingress, the ruthenium released from the fuel can be transported as metastable gaseous $\mathrm{RuO}_{4}$ to the free volume of the containment although a significant amount of the ruthenium remains on the pipes. Additional data on the behaviour of ruthenium in the RCS were collected during a test conducted at the CEA's VERDON facility as part of the ISTP (Section 5.5.2.2) to study in-air degradation of the irradiated fuel, FP releases and associated transfers to the RCS and are collected as part of the OECD STEM project.

Lastly, the experimental data on revolatilisation of FPs deposited in the RCS are insufficient for quantifying the possible effect of this process on releases during a core melt accident. Additional experiments aimed at allowing this quantification are being conducted as part of the OECD STEM project conducted by IRSN and which began in 2011.

\section{Fission product chemistry in the containment}

During a core melt accident, the two FPs whose chemistry in the containment can strongly influence radioactive releases and their consequences are iodine and ruthenium $^{12}$. This is due to the fact that both FPs can exist in gaseous form under the conditions prevailing in the containment. These gaseous species may be released to the environment by either direct or indirect leaks from the containment or during implementation of the containment filtered venting procedure.

\section{lodine}

Many experimental and theoretical studies have been conducted on iodine chemistry in the containment during a core melt accident. These studies have looked at iodine chemistry in the sump and the containment atmosphere, its interactions with the surfaces of the containment and the influence of radiation on these various processes [3]. The available models describing this chemistry are either mechanistic, spanning several hundred reactions, or simplified to cover a smaller range of reactions. The latter type of model is generally used in the integral codes such as ASTEC [65].

12. Other FPs, such as caesium, may significantly contribute to the radiological consequences of a core melt accident with containment failure. However, their chemistry in the containment has not a strong influence on their behaviour during releases. 
Despite these research efforts, substantial uncertainties remain about the estimation of radioactive iodine releases during a core melt accident. This was brought to the fore during the OECD International Standard Problem (ISP) exercises, which compare the results of calculations and experiments. ISP 41 dealt with iodine chemistry in the containment for an RTF experiment conducted by AECL. ISP 46 dealt with iodine chemistry in the RCS and the containment for the Phebus FPT1 experiment. This is particularly true for the formation of organic iodides in the containment atmosphere. The EPICUR, OECD STEM, and OECD BIP experimental programmes aim to provide new data on this matter as well as certain aspects related to liquid-phase and gas-phase iodine radiolysis.

The effect of spraying, which enables partial capture of iodine in droplets, has been quantified and validated models are available.

Analytical experiments have revealed that the interactions between iodine aerosols and the plates of hydrogen recombiners could lead to the formation of gaseous iodine in the containment. A larger-scale experiment was conducted as part of the OECD/ NEA THAI project led by Becker Technology in Germany [53]. The transposition of these results to the recombiners in the containment shows that the production of gaseous iodine by the recombiners in the containment is not zero but lower than that due to other sources such as gaseous iodine from the RCS.

Another source of gaseous iodine in the containment is related to radiation-induced decomposition of the metal halides (e.g., caesium iodide) and iodine oxides deposited on the walls of the containment. This is one of the themes of the experimental studies of the OECD STEM project conducted by IRSN which began in 2011.

\section{Ruthenium}

Regarding ruthenium chemistry in the containment during a core melt accident, the experiments conducted show that part of the ruthenium can be in gaseous form in the containment. Experiments have made it possible to study adsorption of gaseous ruthenium on the surfaces of the containment and its desorption from the surfaces as well as revolatilisation of ruthenium deposited or trapped in the liquid phase of the sump under the action of radiation $[59,63]$. The kinetics of the various processes have been established so that it is possible to assess gaseous ruthenium concentrations in the containment during a core melt accident. Ruthenium transport in the RCS is being studied as part of the OECD STEM project.

\subsubsection{Conclusion}

Releases and transfers of FPs in the RCS during a core melt accident has been the subject of many research programmes. Releases of FPs from fuel inside the reactor core are in overall terms well understood. Nevertheless, improvements in physical modelling are expected between now and late 2015 on the basis of the results of a few additional tests (VERDON programme conducted by the CEA as part of the ISTP). The current state of knowledge of releases from corium outside the vessel seems satisfactory. 
Transfers and behaviour of FPs in the RCS and the containment are governed by physical processes that depend primarily on aerosol physics and chemical processes. Aerosol physics is well established and the corresponding models seem satisfactory. Nevertheless, it would be desirable to have additional data in order to better analyse some complex situations, such as aerosols in the secondary sides of steam generators during an accident with steam generator tube rupture. The situation is different for the chemical processes. Although the analysis of the results of the programmes conducted between 1990 and 2010, particularly those of the Phebus FP programme, have made it possible to improve understanding and modelling of the most important processes, additional programmes remain necessary to reduce the uncertainties, particularly regarding iodine chemistry. Improvements in modelling are expected to be made by late 2015 on the basis of the experimental results of the ISTP programmes (CHIP, EPICUR) and OCDE BIP-2, THAI-2 and STEM. The research conducted on this topic bring aspects of chemical kinetics into play in complex reaction systems.

The models developed are implemented in computer codes, such as ASTEC. These codes play a role in the capitalisation of knowledge and are used to conduct safety studies for power reactors.

\section{Reference documents}

[1] A.L. Wright, Primary System Fission Product Release and Transport, A state-ofthe-art report to the Committee on the Safety of Nuclear Installations, NUREG/ CR-6193, NEA/CSNI/R(94)2, ORNL/TM-12681 (1994).

[2] Insights into the Control of the Release of lodine, Caesium, Strontium and other Fission Products in the Containment by Severe Accident Management, Report NEA/CSNI/R(2000)9, 2000.

[3] B. Clément (coordinator) et al., State of the Art Report on lodine Chemistry, Report NEA/CSNI/R(2007)1, 2007.

[4] H. J. Allelein (coordinator) et al., State of the Art Report on Nuclear Aerosols, Report NEA/CSNI/R(2009)5, 2009.

[5] H. Kleykamp, The chemical state of the fission products in oxide fuels, Journal of Nuclear Materials, 131, 221-246, 1985.

[6] D.J. Alpert, D.I. Chanin, and L.T. Ritchie, Relative Importance of Individual Elements to Reactor Accident Consequences Assuming Equal Release Fractions, NUREG/ CR-4467, SAND85-2575, Sandia National Laboratories, Albuquerque, NM, March 1988.

[7] Y. Pontillon et al., Lessons learnt from VERCORS tests. Study of the active role played by UO2-ZrO2-FP interactions on irradiated fuel collapse temperature, Journal of Nuclear Materials 344, 265-273, 2005.

[8] M. Barrachin, P.Y. Chevalier, B. Cheynet, E. Fischer, New modelling of the U-Zr-O phase diagram in the hyper-stoichiometric region and consequences for the fuel 
rod liquefaction in oxidising conditions, Journal of Nuclear Materials 375, 397-409, 2008.

[9] S. Valin, Étude des mécanismes microstructuraux liés au relâchement des gaz de fission du dioxyde d'uranium irradié, Thèse à l'Institut National Polytechnique de Grenoble, 1999.

[10] Y. Pontillon et al., Behaviour of fission products under severe accident conditions: The VERCORS experimental programme - part 1: General description of the programme - part 2: Release and transport of fission gases and volatile fission products - part 3: Release of low-volatile fission products and actinides, Nuclear Engineering and Design 240 (7), 1843-1852, 2010.

[11] $\mathrm{H}$. Albrecht et al., Release of Fission and Activation Products during Light Water Reactor Core Meltdown, Nuclear Technology 46, 559-565, 1979.

[12] R.A. Lorenz, M.F. Osborne, A summary of ORNL Fission Product release tests with recommended release rates and diffusion coefficients, ORNL/TM-12801 NUREG/CR-6261, 1995.

[13] D.S Cox et al., Fission Product releases from $\mathrm{UO}_{2}$ in air and inert conditions at 1700-2350 K: analysis of the MCE-1 experiment, ANS-ITM on the safety of thermal reactors, Portland, USA, 1991.

[14] T. Kudo et al., VEGA; an experimental study of radionuclides release from fuel under severe accident conditions, ANS Water reactor fuel performance meeting, Kyoto, October 2005.

[15] G. Ducros et al., Fission Product release under severe accidental conditions; general presentation of the program and synthesis of VERCORS 1 to 6 results, Nuclear Engineering and Design 208 (2), 191-203, 2001.

[16] B. Clément and R. Zeyen, The Phebus Fission Product and Source Term International Programme, Int. Conf. Nuclear Energy for New Europe, Bled, Slovenia, 2005.

[17] W. Plumecocq et al., Fission product release modelling in the ASTEC integral code: the status of the ELSA module, 8th Int. Conf. On CANDU fuel, Honey Harbour, Ontario, 2003.

[18] G. Nicaise et al., Analysis of accidental sequence tests and interpretation of fission product release: interdependence of $\mathrm{Cs}$, Mo and Ba release, 8th Int. Conf. On CANDU fuel, Honey Harbour, Ontario, 2003.

[19] R.D. Barrand, R.S. Dickson, Z. Liu, D.D. Semeniuk, Release of fission products from CANDU fuel in air, steam and argon atmosphere at $1500-1900^{\circ} \mathrm{C}$ : the HCE3 experiment, Canadian Nuclear Society, 6th Int. Conf. CANDU fuel, Niagara Falls, 26-30 Sept., 1999.

[20] M. P. Kissane, I. Drosik, Interpretation of fission-product transport behaviour in the PHEBUS FPT-0 and FPT-1 tests, Nuclear Engineering and Design 236 (11), 12101223, 2006. 
[21] L. Talbot et al., Thermophoresis of particles in a heated boundary layer, Journal of Fluid Mechanics, 101, 737-758, 1980.

[22] A. Zoulalian, T. Albiol, Analysis of fluid-wall interactions in an open material system where the residence time distribution of a fluid is known. Application of aerosol deposition by diffusiophoresis, Canadian Journal of Chemical Engineering 73 (6), 800-897, 1995.

[23] M. Missirlian, Modélisation des dépôts d'aérosols par diffusiophorèse dans un écoulement. Application aux réacteurs à eau sous pression en situation accidentelle, thèse de l'université de Provence/ Aix-Marseille I, 1999.

[24] C. Housiadas, K. Müller, J. Carlsson, Y. Drossinos, Two-dimensional effects in thermophoretic particle deposition: the PHEBUS FP steam generator, Journal of Aerosol Science 32 (Suppl.1), 1029-1040, 2001.

[25] A. Zoulalian, T. Albiol, Evaluation of aerosol deposition by thermo- and diffusiophoresis during flow in a circular duct - application to the experimental programme 'Tuba diffusiophoresis', Canadian Journal of Chemical Engineering 76 (4), 799-805, 1998.

[26] A. De los Reyes et al., International Standard Problem 40 - Aerosol Deposition and Resuspension, Final Comparison, Report NEA/CSNI/R(99)4, 1999.

[27] S. Güntay, D. Suckow, A. Dehbi, R. Kapulla, ARTIST: introduction and first results, Nuclear Engineering and Design 231 (11), 109-120, 2004.

[28] A. Bujan, L. Ammirabile, A. Bieliauskas, B. Toth, ASTEC V1.3 code SOPHAEROS module validation using the STORM experiments, Progress in Nuclear Energy 52 (8), 777-788, 2010.

[29] T. Lind, A. Dehbi, S. Güntay, Aerosol retention in the flooded steam generator bundle during SGTR, Nuclear Engineering and Design 241, 357-365, 2011.

[30] W. Shoek, M. Wagner-Ambs, Resuspension of fission product aerosols from the boiling sump, Proceedings of the International Centre for Heat and Mass Transfer, pp. 539-546, 1990.

[31] V. Saldo, E. Verloo, A. Zoulalian, Study on aerosol deposition in the PITEAS vessel by settling, thermophoresis and diffusiophoresis phenomena, J. Aerosol Science 29 (Suppl.2), S1173-S1174, 1998.

[32] V. Fournier-Bidoz, V. Layly, D. Roblot, J. Vendel, Efficiency of the PWR spray system - information derived from the CARAIDAS tests, Rapport scientifique et technique IRSN, 2000.

[33] R.K. Hilliard, A.K. Postma, Large-scale fission product containment tests, Nuclear technology 53 (2), 163-175, 1981.

[34] E.C. Beahm, C.F. Weber, T.S. Kress, lodine chemical forms in LWR Severe Accidents, NUREG/CR-5942 (ORNL/TM-11861), April 1992. 
[35] A.M. Beard, L. Codron, A. Mason, Boric acid experiments: vaporisation, deposition on Inconel and interaction with caesium hydroxide, EUR 15766/1 EN, Commission of the European Communities.

[36] E. Hontanon, M. Lazaridis, Y. Drossinos, The effect of chemical interactions on the transport of caesium in the presence of boron, J. Aerosol Sci. 27 (1), 19-38, 1996.

[37] G. Le Marois, M. Megnin, Assessment of fission product deposits in the reactor coolant system: the DEVAP program, Nuclear Safety 35 (2), 213-222, 1994.

[38] A.B. Anderson, A. Auvinen, P.D.W. Bottomley, C.J. Bryan, N.E. Freemantle, J.P. Hiernaut, J.K. Jokiniemi, A.F. Kingsbury, A.T. Tuson, Revaporisation tests on samples from Phebus FP: final report, European Commission 4th framework programme, Report ST: RVP(00)-P029, 2000.

[39] B. Clément, N. Hanniet-Girault, G. Repetto,D. Jacquemain, A.V. Jones, P. von der Hardt: LWR Severe Accident Simulation: Synthesis of the results and interpretation of the Phebus FP experiment FPT0, Nuclear Engineering and Design 226 (1), $5-82,2003$.

[40] L. Suffer, S.B. Burson, C.M. Ferrell, Accident Source Terms for Light-Water Nuclear Power Plants, NUREG-1465, 1995.

[41] N. Hanniet, D. Jacquemain, An overview of the iodine behaviour in the first two PHEBUS tests FPTO and FPT1, Proceedings of OECD Workshop on lodine Aspects in Severe Accident Management, Vantaa (Finland), NEA/CSNI/R(99)7.

[42] N. Hanniet, S. Dickinson, F. Funke, A. Auvinen, L. Herranz, E. Kraussmann, lodine behaviour under LWR accident conditions: lessons learnt from analyses of the first two Phebus FP tests, Nuclear Engineering and Design 236 (12), 1293-1308, 2006.

[43] Ph. March et al., First Results of the Phebus FPT3 test, Proceedings of ICONE 14, 14th International Conference on Nuclear Engineering, Miami, Florida, USA, July 17-20, 2006.

[44] B. Xerri, S. Canneaux, F. Louis, J. Trincal, F. Cousin, M. Badawi, L. Cantrel, Ab initio calculations and iodine kinetic modeling in the reactor coolant system of a pressurized water reactor in case of severe nuclear accident, Computational and Theoretical Chemistry 990, 194-208, 2012.

[45] J.C. Wren, J.M. Ball, G.A. Glowa, The Chemistry of lodine in Containment, Nuclear Technology 129, 297, 2000.

[46] E. Krausmann, A state-of-the art report on iodine chemistry and related mitigation mechanisms in the containment, Report EUR 19752 EN, 2001.

[47] J.M. Ball, G.A. Glowa, J.C. Wren, Summary of the Phebus Radioiodine Test Facility, Proceeding of the $4^{\text {th }}$ TechnicalSeminar of the Phebus FP Programme, Marseille, France, March 2000. 
[48] S. Güntay, R.C. Cripps, B. Jäckel, H. Bruchertseifer, On the radiolytic decomposition of colloidal silver iodide in aqueous solution, Nuclear Technology 150, 303314, 2005.

[49] G.J. Evans, W.C.H. Kupferschmidt, R. Portman, A.S. Palson, G.G. Sanipelli, Radiochemical analysis of iodine behaviour in the Radioiodine Test Facility, Journal of Radioanalytical and Nuclear Chemistry 180 (2), 225-235, 1994.

[50] L. Cantrel, Radiochemistry of iodine: Outcomes of the CAIMAN programme, Nuclear Technology 156, (1), 11-28, 2006.

[51] L. Bosland, F. Funke, N. Girault. G. Langrock, PARIS project: Radiolytic oxidation of molecular iodine in containment during a nuclear reactor severe accident -- Part 1. Formation and destruction of air radiolysis products - Experimental results and modelling, Nuclear Engineering and design 238 (12), 3542-3550, 2008.

[52] F. Deschamps, J.C. Sabroux, Étude de la production d'iode gazeux par un aérosol d'iodure de césium soumis à des températures élevées dans l'air humide, ASFERA, Actes $d u 18^{e}$ congrès français sur les aérosols, Paris, 11-12 décembre, 2002.

[53] CSNI report, OECD/NEA THAI Project Hydrogen and Fission Product Issues Relevant for Containment Safety Assessment under Severe Accident Conditions, Final Report, JT03285992, NEA/CSNI/R(2010)3, 2010.

[54] D.A. Powers, L.N. Kmetyk, R.C. Schmidt, A review of the technical issues of air ingression during severe accidents, US NRC NUREG/CR-6218, 1994.

[55] L. Matus, O. Prokopiev, B. Alföldy, A. Pintér, Z. Hózer, Oxidation and release of ruthenium in high temperature air, IRSN-AEKI Phebus FP Programme Agreement, Report on in-kind contribution of AEKI part 1, November 2002.

[56] L. Matus et al., Oxidation and release of ruthenium from short fuel rods in high temperature air, IRSN-AEKI Phebus FP Programme Agreement, Report on in-kind contribution of AEKI part 2 and part 3, December 2004.

[57] I. Nagy et al., Oxidation and release of ruthenium from short fuel rods above $1500^{\circ} \mathrm{C}$, EUR 21752 EN, April 2005.

[58] U. Backman, M. Lipponen, A. Auvinen, J. Jokiniemi, R. Zilliacus, Ruthenium behaviour in severe nuclear accident conditions - final report, VTT report PR03/P27/04, June 2004.

[59] C. Mun, L. Cantrel, C. Madic, A literature review on ruthenium behaviour in nuclear power plant severe accidents, Nuclear Technology 156 (3), 332-346, 2006.

[60] C. Mun, J.-J. Ehrhardt, J. Lambert, C. Madic, XPS investigation of ruthenium deposited onto representative inner surfaces of nuclear reactor containment buildings, Applied Surface Science 253 (18), 7613-7621, 2007.

[61] C. Mun, L. Cantrel, C. Madic, Study of $\mathrm{RuO}_{4}$ decomposition in dry and moist air, Radiochimica Acta 95 (11), 643-656, 2007. 
[62] C. Mun, L. Cantrel, C. Madic, Oxidation of ruthenium oxide deposits by ozone, Radiochimica Acta 96 (6), 375-384, 2008.

[63] C. Mun, L. Cantrel, C. Madic, Radiolytic oxidation of ruthenium oxide deposits, Nuclear Technology 164 (2), 245-254, 2008.

[64] L. Cantrel, E. Krausmann, Reaction kinetics of a fission product mixture in a steamhydrogen carrier gas in the Phebus primary circuit, Nuclear Technology 144 (1), 1-15, 2003.

[65] L. Bosland, L. Cantrel, N. Girault, B. Clément, Modelling of iodine radiochemistry in the ASTEC severe accident code: description and application to FPT2 Phebus test, Nuclear Technology 171 (1), 88-107, 2010. 
